\title{
Buoyancy-Driven Circulation in the Red Sea
}

\author{
By \\ Ping Zhai
}

Submitted in partial fulfillment of the requirements for the degree of

Doctor of Philosophy in Physical Oceanography

at the
MASSACHUSETTS INSTITUTE OF TECHNOLOGY
and the

WOODS HOLE OCEANOGRAPHIC INSTITUTION

September 2014

(c) Ping Zhai 2014. All rights reserved.

The author hereby grants to MIT and WHOI permission to reproduce and to distribute publicly paper and electronic copies of this thesis document

in whole or in part in any medium now known or hereafter created.

Signature of Author .

Joint Program in Oceanography - Massachusetts Institute of Technology /

Woods Hole Oceanographic Institution June 16, 2014

Certified by

Amy S. Bower

Senior Scientist, Woods Hole Oceanographic Institution

Thesis Supervisor

Certified by

Lawrence J. Pratt

Senior Scientist, Woods Hole Oceanographic Institution

Thesis Supervisor

Accepted by

Glenn Flierl

Professor, Massachusetts Institute of Technology Chair, Joint Committee for Physical Oceanography 


\title{
Buoyancy-Driven Circulation in the Red Sea
}

\author{
by \\ Ping Zhai
}

\begin{abstract}
This thesis explores the buoyancy-driven circulation in the Red Sea, using a combination of observations, as well as numerical modeling and analytical method.

The first part of the thesis investigates the formation mechanism and spreading of Red Sea Overflow Water (RSOW) in the Red Sea. The preconditions required for open-ocean convection, which is suggested to be the formation mechanism of RSOW, are examined. The RSOW is identified and tracked as a layer with minimum potential vorticity and maximum chlorofluorocarbon-12. The pathway of the RSOW is also explored using numerical simulation. If diffusivity is not considered, the production rate of the RSOW is estimated to be $0.63 \mathrm{~Sv}$ using Walin's method. By comparing this $0.63 \mathrm{~Sv}$ to the actual RSOW transport at the Strait of Bab el Mandeb, it is implied that the vertical diffusivity is about $3.4 \times 10^{-5} \mathrm{~m}^{2} \mathrm{~s}^{-1}$.

The second part of the thesis studies buoyancy-forced circulation in an idealized Red Sea. Buoyancy-loss driven circulation in marginal seas is usually dominated by cyclonic boundary currents on $f$-plane, as suggested by previous observations and numerical modeling. This thesis suggests that by including $\beta$-effect and buoyancy loss that increases linearly with latitude, the resultant mean Red Sea circulation consists of an anticyclonic gyre in the south and a cyclonic gyre in the north. In mid-basin, the northward surface flow crosses from the western boundary to the eastern boundary. The observational support is also reviewed. The mechanism that controls the crossover of boundary currents is further explored using an ad hoc analytical model based on PV dynamics. This ad hoc analytical model successfully predicts the crossover latitude of boundary currents. It suggests that the competition between advection of planetary vorticity and buoyancy-loss related term determines the crossover latitude.
\end{abstract}

The third part of the thesis investigates three mechanisms that might account for eddy generation in the Red Sea, by conducting a series of numerical experiments. The three mechanisms are: i) baroclinic instability; ii) meridional structure of surface buoyancy losses; iii) cross-basin wind fields.

Thesis Supervisor: Amy S. Bower

Title: Senior Scientist, Woods Hole Oceanographic Institution

Thesis Supervisor: Lawrence J. Pratt

Title: Senior Scientist, Woods Hole Oceanographic Institution 
In memory of my father 


\section{Acknowledgement}

I am deeply grateful to my advisors, Amy Bower and Larry Pratt, for supporting me during my PhD studies. They always patiently supervised me and guided me in the right direction. They not only gave me helpful suggestions when I had problems about the science, but also gave me moral support to help me get through some hard times. Their creativity, broadness, and enthusiasm to science will always be an inspiration for me.

I thank my thesis committee: Paola Rizzoli, Jiayan Yang, and Tom Farrar, for their valuable guidance, brilliant comments, and consistent encouragement I received throughout the research work. I also would like to thank my thesis defense chair Claudia Cenedese. Claudia provided many useful feedbacks.

I would also like to express my sincere gratitude to Ruixin Huang and his wife Luping Zou. Xin gave me many advices on how to be a independent researcher. Luping, a good friend, taught me wisdom of life. I would also like to thank Dexing Wu and Xiaopei Lin in Ocean University of China for their guidance and help during my study in Ocean University of China.

I have had many wonderful friends and classmates in the Joint Program. I would like to thank all of you.

Finally, special thanks to my parents and my brother for supporting me through all these tough years. I would not be able to finish the $\mathrm{PhD}$ study without their encouragement.

This work is supported by Award Nos. USA 00002, KSA 00011 and KSA 00011/02 made by King Abdullah University of Science and Technology (KAUST), National Science Foundation OCE0927017, and WHOI Academic Program Office. 


\section{Contents}

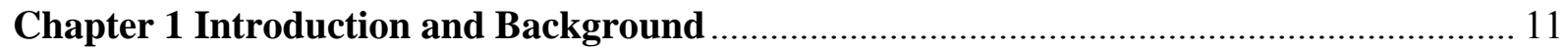

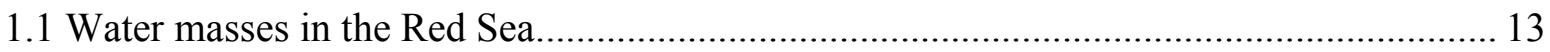

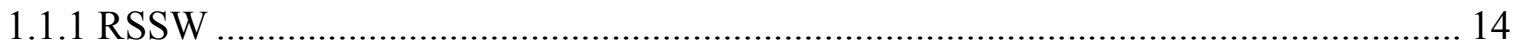

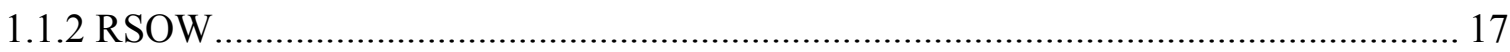

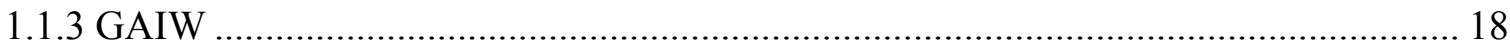

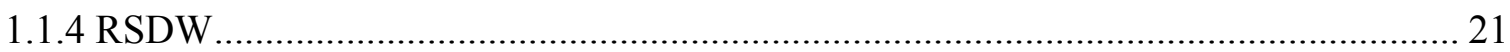

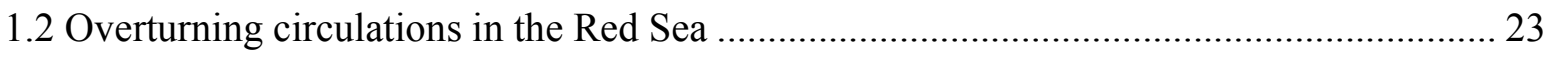

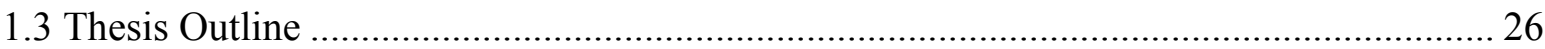

Chapter 2 Red Sea Overflow Water Formation and its Spreading Pathways .......................29

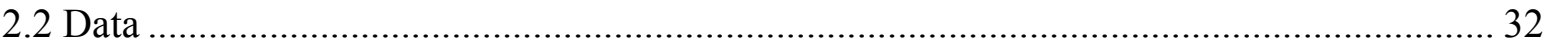

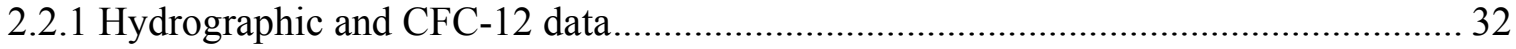

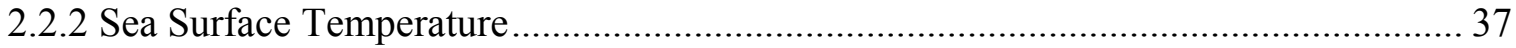

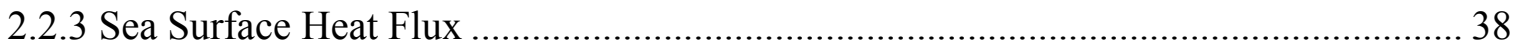

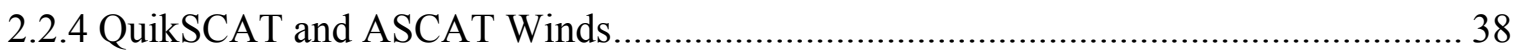

2.3 Preconditioning of Open- Ocean Convection in the Northern Red Sea.............................. 39

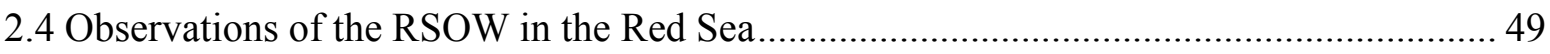

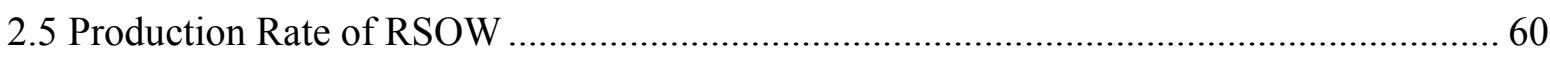

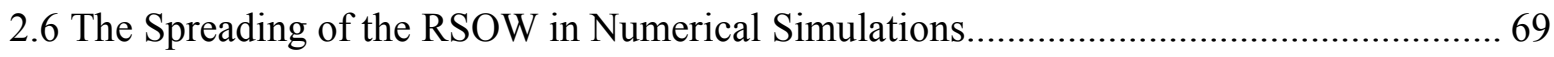

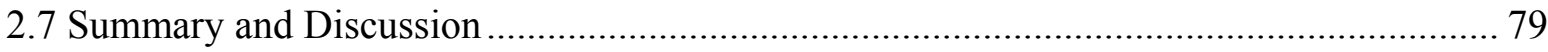

Chapter 3 On the Crossover of Boundary Currents in an Idealized Model of the Red Sea 85

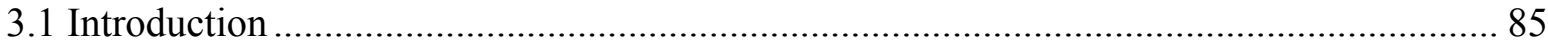

3.2 Numerical Model Simulation of the Buoyancy-Driven Circulation in an Idealized Red Sea

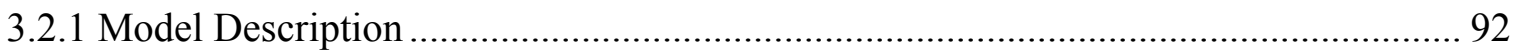

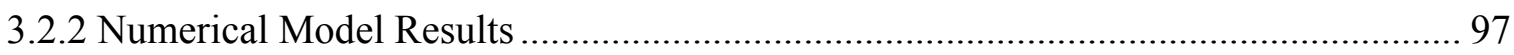

3.3 An ad hoc Analytical Model of the Crossover Latitude ............................................... 104

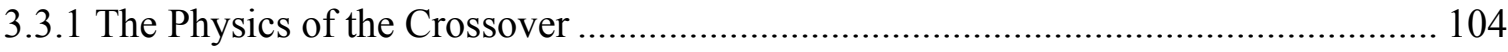


3.3.2 An ad hoc analytical model of Crossover Latitude.

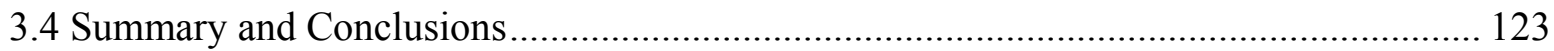

Chapter 4 Eddy Generation Mechanisms in the Red Sea .................................................... 131

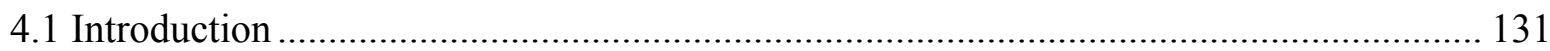

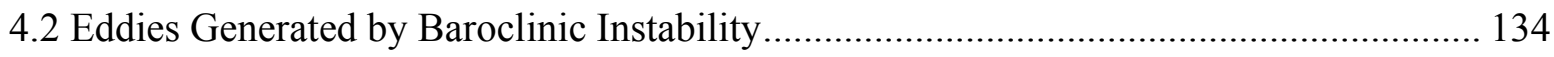

4.3 Quasi-stationary Eddies Generated by Meridional Structure of Surface Buoyancy Forcing 147

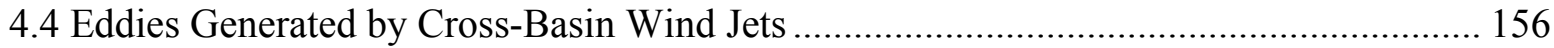

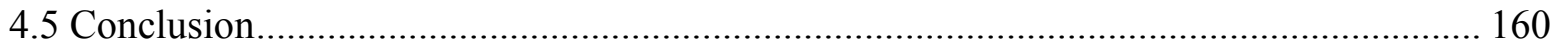

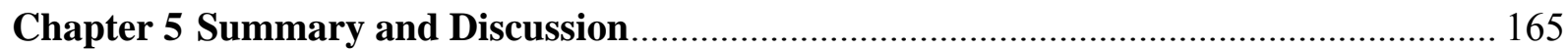

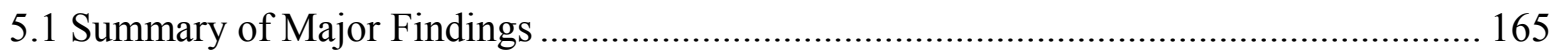

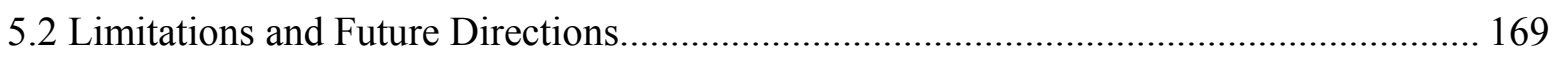

Appendix A Relation between Boundary Current and Interior Densities ........................... 171 


\section{Chapter 1}

\section{Introduction and Background}

The Red Sea is a semi-enclosed marginal sea, connected to the Indian Ocean via the narrow, shallow Strait of Bab el Mandeb. It presents many of the same features as other marginal seas, such as the Mediterranean Sea and the Labrador Sea. There is often net buoyancy loss to the atmosphere in marginal seas, due to heat flux, fresh water flux or both. Buoyancy loss over marginal seas can produce dense intermediate and deep water masses, which feed the deep branch of the global thermohaline circulation. These water masses usually hold distinct water properties. The Red Sea Overflow Water (RSOW), which is formed in the northern Red Sea due to surface buoyancy loss, can be tracked in the Indian Ocean as a salinity maximum. On the other hand, the Red Sea has its own unique characteristics compared to other marginal seas. The large meridional extent of the Red Sea suggests that $\beta$-effect could be more important than in other marginal seas. As a result, the Red Sea circulation could be very different from other marginal seas. Although RSOW is one of the most saline water masses in the world ocean, it cannot sink to the bottom of the Indian Ocean because it entrains very light ambient water (Price and Baringer, 1994; Bower et al., 2000). The Red Sea is a major route for commercial ships between Europe and East Asia. The Red Sea also has one of the most diverse coral reefs in the world. In addition, the Red Sea is a geologically young widening basin and it might become an ocean in the future. These unique features make the Red Sea a very interesting basin to study. However, the Red Sea circulation remains largely unexplored. In this chapter, I will review previous studies on Red Sea water masses and circulation. 
The Red Sea is a long and narrow basin that is located between Africa and Asia (Figure 1.1). It extends from $12.5^{\circ} \mathrm{N}$ to $30^{\circ} \mathrm{N}$, a distance of about $2250 \mathrm{~km}$, and has an average width of about $280 \mathrm{~km}$. The average depth is about $490 \mathrm{~m}$, but the maximum depth along the middle axis can exceed $2000 \mathrm{~m}$. The Red Sea is connected to the Indian Ocean through the Strait of Bab el Mandeb, and to the Mediterranean Sea through the Suez Canal. At about $28^{\circ} \mathrm{N}$, the Red Sea splits into the Gulf of Suez and Gulf of Aqaba. At the southern end (about $\left.12^{\circ} \mathrm{N}\right)$, the Red Sea has a minimum width of about $18 \mathrm{~km}$ (Murray and Johns, 1997) at the Perim Narrows in the Strait of Bab el Mandeb. The Hanish Sill, a shallow sill with a maximum depth of $137 \mathrm{~m}$ (Werner and Lange, 1975), is present at $13.7^{\circ} \mathrm{N}$, slightly north of the Strait of Bab el Mandeb.

Both wind and buoyancy forcing have been suggested as important drivers of Red Sea circulation. The surface winds over the Red Sea blow mainly along the axis of the basin due to the high mountains on both sides. North of $18-19^{\circ} \mathrm{N}$, winds blow southeastward throughout the year. In contrast, winds in the southern Red Sea are strongly influenced by the Indian monsoon system. South of $18-19^{\circ} \mathrm{N}$, the wind direction changes seasonally from southeasterly during the winter monsoon season to northwesterly during the summer monsoon season (Pedgley, 1972).

Due to high evaporation, negligible precipitation, and no river runoff, the Red Sea is one of the most saline basins in the world. Heat and freshwater fluxes over the Red Sea must be balanced by heat and freshwater transports through the Strait of Bab el Mandeb. Using this constraint, combined with current and water property data measured at the Strait of Bab el Mandeb, Sofianos et al. (2002) estimate that the annual mean heat and freshwater losses to the atmosphere are $11 \pm 5 \mathrm{~W} \mathrm{~m}^{-2}$ and $2.06 \pm 0.22 \mathrm{~m} \mathrm{yr}^{-1}$, respectively. Based on results from numerical experiments with different forcing fields, Sofianos and Johns (2003) suggest that the mean circulation of the 
Red Sea is primarily driven by surface buoyancy losses due to surface heat loss and evaporation. This thesis will focus on buoyancy-driven circulation.

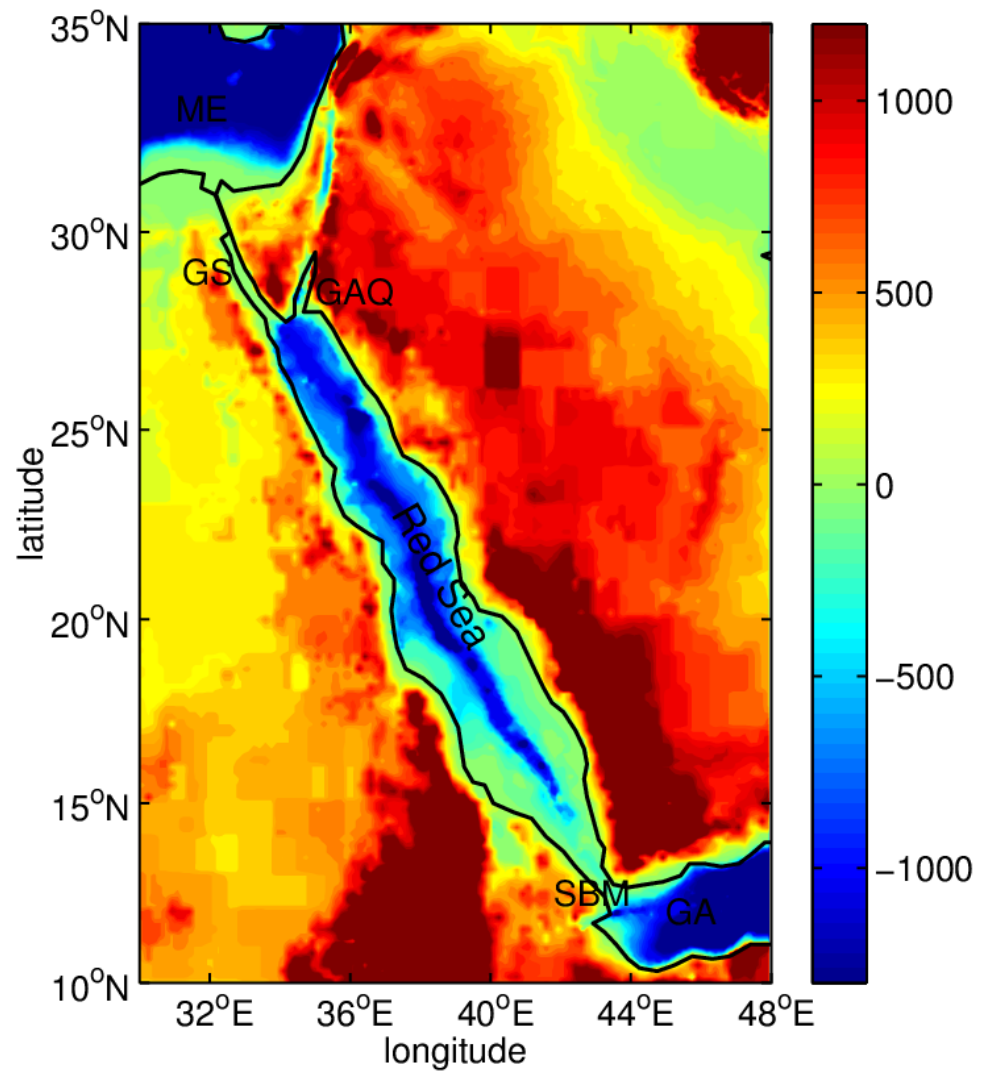

Figure 1.1: Topographic map of the Red Sea. The colors represent elevation and bathymetric values (m). The locations of Gulf of Aqaba (GAQ), Gulf of Suez (GS), Gulf of Aden (GA), Mediterranean Sea (ME), and Strait of Bab el Mandeb (SBM) are shown.

\subsection{Water masses in the Red Sea}

The main water masses in the Red Sea are Red Sea Surface Water (RSSW), Gulf of Aden Intermediate Water (GAIW), Red Sea Overflow Water (RSOW), and Red Sea Deep Water (RSDW). 


\subsubsection{RSSW}

The surface salinity in the Red Sea increases from $\sim 36.5$ in the south to $\sim 41$ in the north (Cember, 1988; Sofianos and Johns, 2007). Figure 1.2 and Figure 1.3 show the distribution of water properties measured in March 2010 and September-October 2011. These figures indicate that the surface water properties display strong seasonal variations. The fresher warm water in the south and the saltier cold water in the north form a meridional density gradient at the surface. 

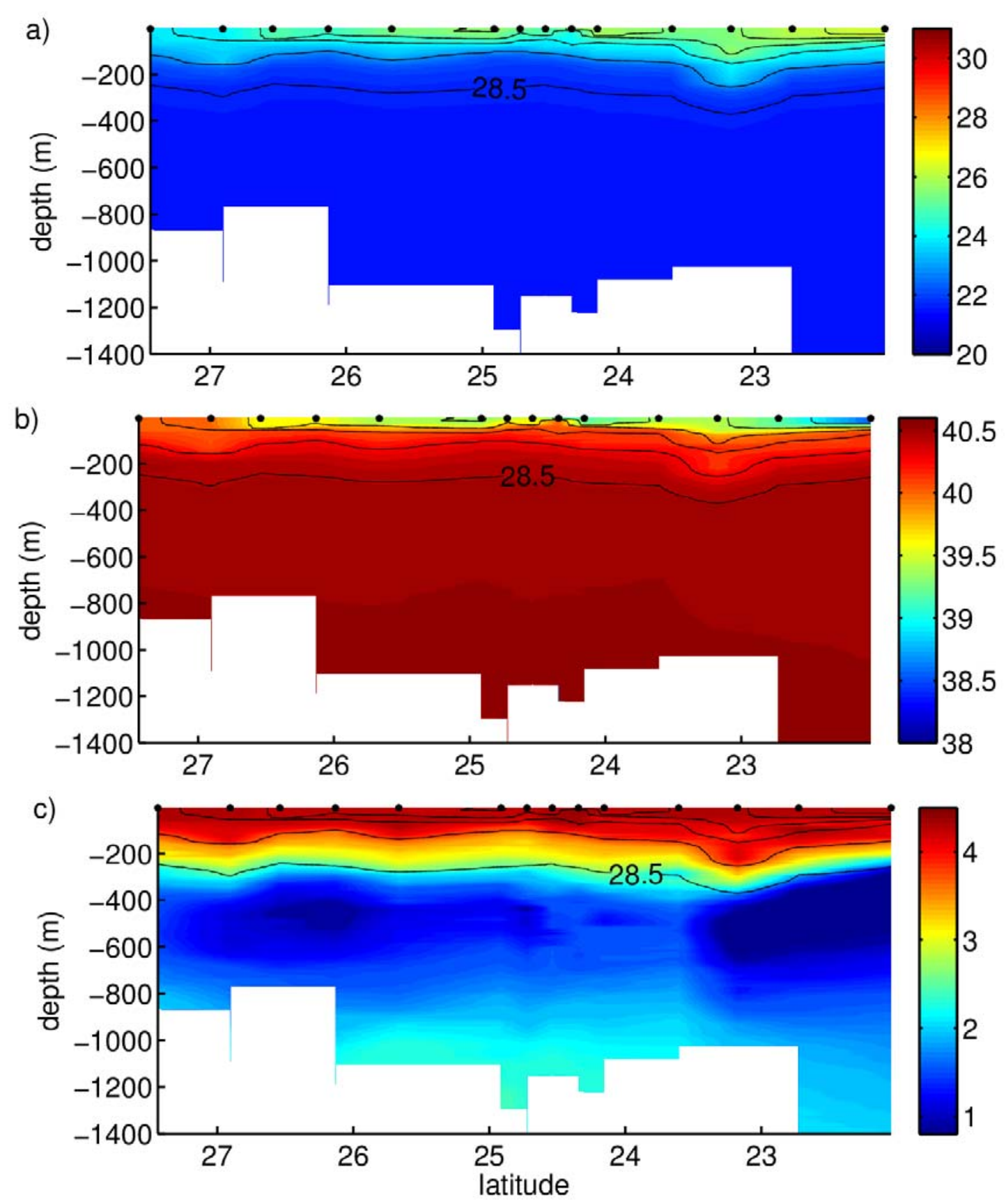

Figure 1.2: Water properties along the central axis of the Red Sea in March 2010: (a) potential temperature $\left({ }^{\circ} \mathrm{C}\right)$, (b) salinity, and (c) dissolved oxygen concentration $\left(\mathrm{ml}^{-1}\right)$. Black dots indicate station locations. Black lines represent isopycnals (contour interval is $0.5 \mathrm{~kg} \mathrm{~m}^{-3}$ ) 

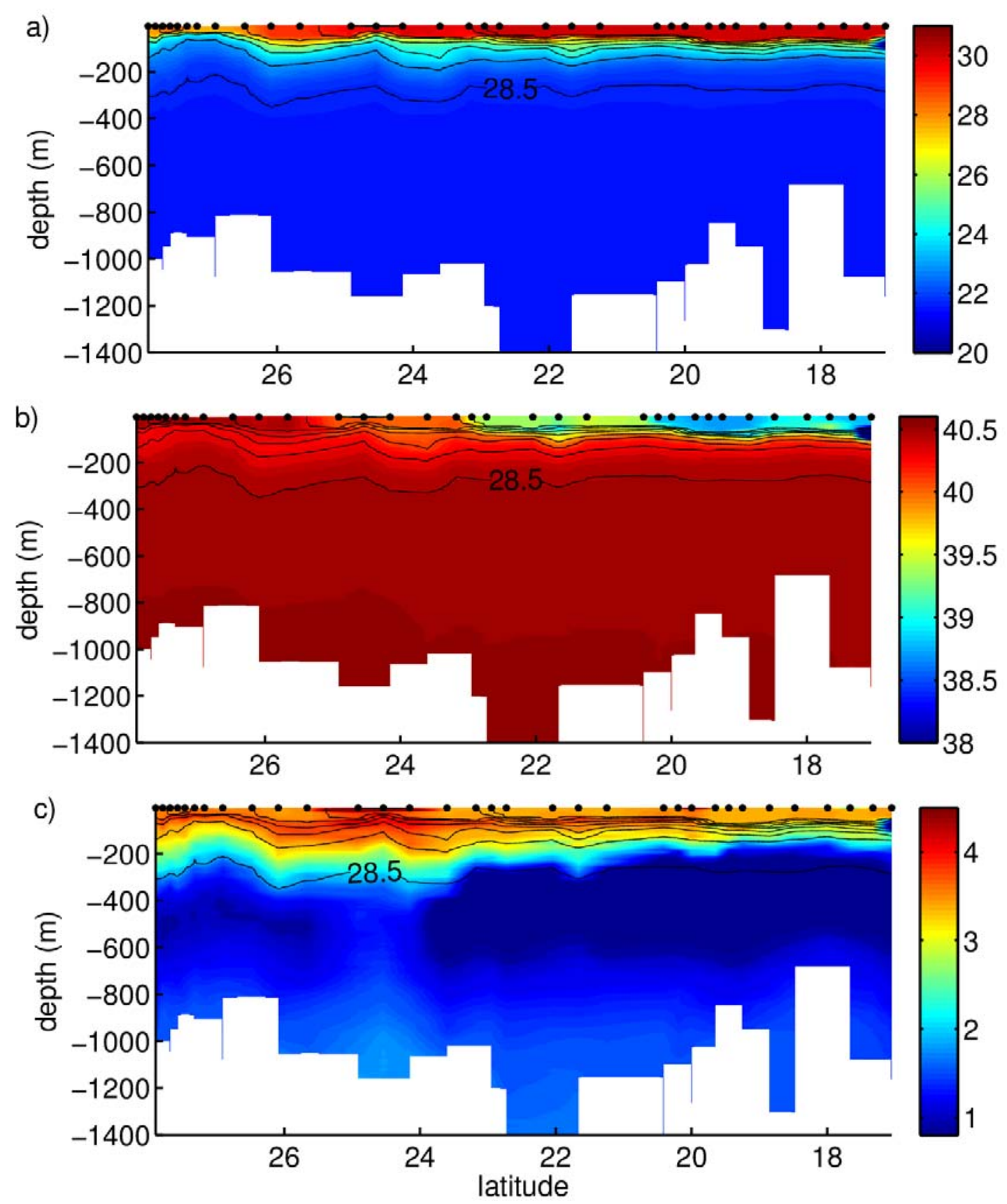

Figure 1.3: Water properties along the central axis of the Red Sea in September-October 2011: (a) potential temperature $\left({ }^{\circ} \mathrm{C}\right)$, (b) salinity, and (c) dissolved oxygen concentration $\left(\mathrm{mll}^{-1}\right)$. Black dots indicate station locations. Black lines represent isopycnals (contour interval is $0.5 \mathrm{~kg} \mathrm{~m}^{-3}$ ). 


\subsubsection{RSOW}

RSOW is one of the most saline water masses in the world ocean. It outflows into the Gulf of Aden from the Red Sea and moves southward along the African coast. Although the annual transport of RSOW through the Strait of Bab el Mandeb is only 0.36 Sv (Murray and Johns, 1997), its signal is observed in the Indian Ocean up to $6000 \mathrm{~km}$ away from its source as a salinity maximum at intermediate depth (Gordon et al., 1987; Valentine et al., 1993; Beal et al., 2000).

In this section, unless otherwise specified, winter is defined as November through March, and summer is defined as June through September. Previous studies in the Strait of Bab el Mandeb (e.g., Morcos, 1970; Maillard and Soliman, 1986; Patzert, 1974; Neuman and McGill, 1962; Murray and Johns, 1997) indicate a 2-layer exchange flow pattern in winter and a 3-layer exchange flow pattern in summer season, as shown in Figure 1.4. In winter season, RSOW that has salinity of 40 flows out of the Red Sea beneath an incoming surface layer from the Gulf of Aden that has salinity of $36.5 \mathrm{psu}$. In summer, the exchange flow has a 3-layer structure: a surface flow from the Red Sea, the incoming Gulf of Aden Intermediate Water and, the outgoing RSOW. An 18-month time series of moored ADCP and hydrographic observations of the exchange flow at the Strait of Bab el Mandeb was collected in 1995-1996 (Murray and Johns, 1997; Sofianos et al., 2002). Velocity data indicate that in winter the average transport of RSOW is $0.6 \mathrm{~Sv}$, with a speed of $0.8-1 \mathrm{~m} \mathrm{~s}^{-1}$. In summer, the mean RSOW transport is reduced to $0.05 \mathrm{~Sv}$, with a speed of 0.2-0.3 $\mathrm{m} \mathrm{s}^{-1}$. Sofianos and Johns (2002) used the Miami Isopycnic Coordinate Ocean Model (MICOM) to study the causes of the seasonal variation of flow through the Strait of Bab el Mandeb. They argue that a combination of seasonal variations in wind stress and thermohaline forcing produces the seasonal exchange flow pattern. 
Sofianos and Johns (2003) also used MICOM to suggest that RSOW is formed in the northern Red Sea through open-ocean convection. In their model, there is a cyclonic gyre in the northern Red Sea, which is an important precondition for open-ocean convection (Marshall and Scott., 1999). The cyclonic gyre brings water from the deeper ocean to the surface, with weak stratification. In winter, convection starts when the weakly stratified water is exposed to surface cooling. The cyclonic gyre in the northern Red Sea has been observed by Morcos and Soliman (1972), Clifford et al. (1997), and Manasrah et al. (2004). Trajectories of five surface drifters during 1993-1994 showed a cyclonic gyre north of $26^{\circ} \mathrm{N}$ ( Clifford et al., 1997).
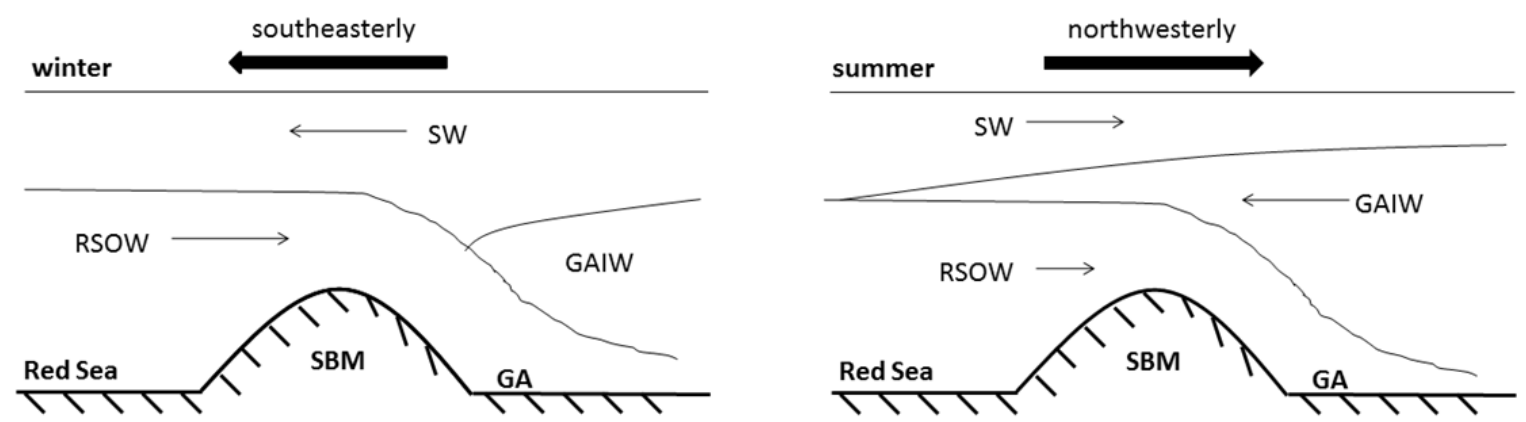

Figure 1.4: Sketch of the two circulation patterns in the Strait of Bab el Mandeb. Left: winter, Right: summer. SW = surface water, GAIW = Gulf of Aden Intermediate Water, RSOW $=$ Red Sea Overflow Water, SBM = Strait of Bab el Mandeb, and GA = Gulf of Aden (reproduced from Smeed, 2004, his Fig. 1).

\subsubsection{GAIW}

Figure 1.4 shows that GAIW flows into the Red Sea in summer. GAIW is fresher and colder than ambient surface water and RSOW. Observations made in April -December 1996 in the Strait of Bab el Mandeb show that the salinity of GAIW is as low as 36.2 and the temperature is about $18^{\circ} \mathrm{C}$ (Murray and Johns, 1997). Hydrographic data collected in August 2001 in the Strait of Bab 
el Mandeb near the Hanish Sill confirm the GAIW characteristics of relatively low salinity, low temperature, and low oxygen concentration (Sofianos and Johns, 2007).

Analysis of ADCP data near the Hanish Sill and Perim Narrows from June 1995 through November 1996 reveals that GAIW transport reaches its maximum value of $0.3 \mathrm{~Sv}$ in summer (Sofianos et al., 2002). Sofianos and Johns (2007) analyzed hydrographic data collected in the Red Sea in August 2001. They found that GAIW can be traced northward in the Red Sea to $22^{\circ}$ N. GAIW was also observed in September-October 2011 in the Red Sea (Churchill et al., submitted). Figure 1.3 and Figure 1.5 clearly show that GAIW is characterized by low temperature, salinity and oxygen values at the southern end of the section along the central axis of the Red Sea. This survey showed that GAIW was flowing near the eastern boundary after it enters the Red Sea. 

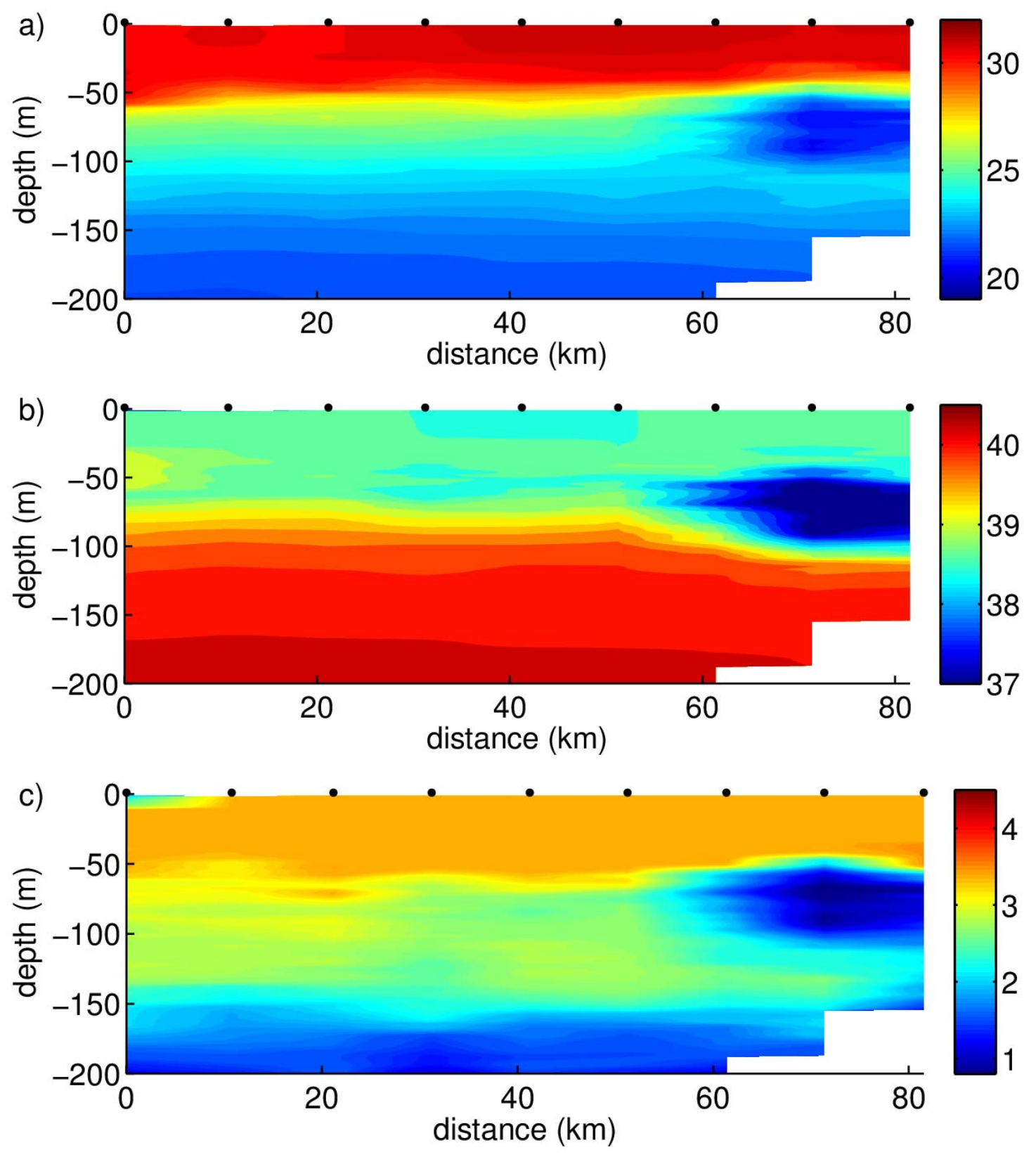

Figure 1.5: Red Sea water properties measured in September-October 2011 along transect 2 (transect location is shown in Figure 1.6): (a) potential temperature $\left({ }^{\circ} \mathrm{C}\right)$, (b) salinity, and (c) dissolved oxygen concentration $\left(\mathrm{ml}^{-1}\right)$. Black dots indicate station locations. Distance $(\mathrm{km})$ is from the west side of the section. 


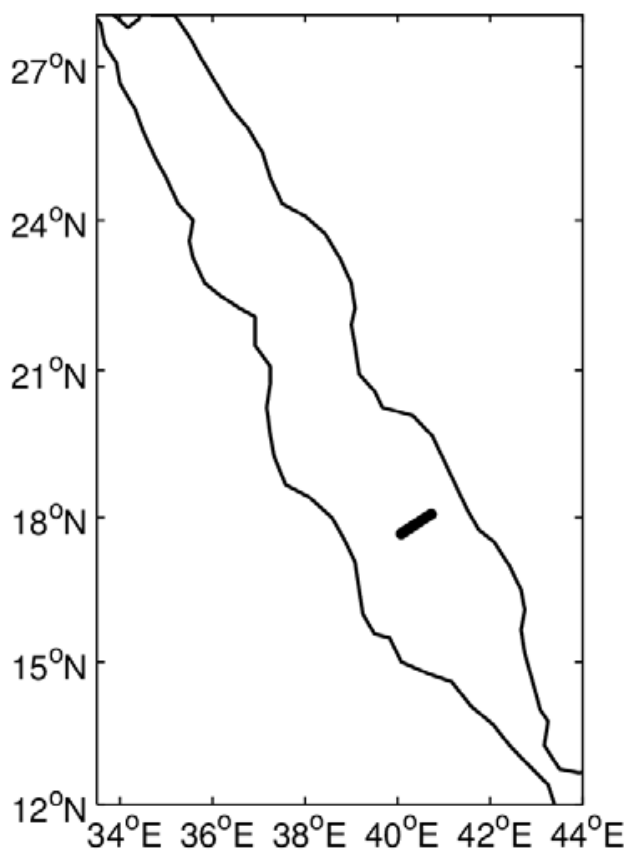

Figure 1.6: Location of transect 2, September-October 2011.

\subsubsection{RSDW}

RSDW, which underlies RSOW, is a nearly homogeneous water mass that fills the Red Sea basin from a depth of about $200 \mathrm{~m}$ to the bottom. Figure 1.2 and Figure 1.3 shows that RSDW is nearly homogeneous in salinity (40.6-40.8) and potential temperature $\left(21-21.5^{\circ} \mathrm{C}\right)$. The typical potential density of RSDW is $1028.55-1028.63 \mathrm{~kg} \mathrm{~m}^{-3}$. The Hanish Sill depth is $137 \mathrm{~m}$, which is shallower than RSDW. Therefore, RSDW might not be able to flow over the sill into the Gulf of Aden.

Historic hydrographic data suggest that the Gulf of Suez outflow water is likely to be the main source of RSDW, while the overflow water from Gulf of Aqaba might be a secondary source of RSDW (Cember, 1988). By analyzing current measurements at the mouth of the Gulf of Suez during late winter 1971-1972, Maillard (1974) found that the wintertime outflow transport from the Gulf of Suez is $0.082 \mathrm{~Sv}$. Data from 12 moored current meters in the Tiran Strait, which 
connects the Gulf of Aqaba and the Red Sea, indicated that the overflow transport from the Gulf of Aqaba to the Red Sea was about 0.029 Sv in February 1982 (Murray et al., 1984). However, these data were collected over a short time period and therefore may not be representative of the annual mean. Biton and Gildor (2011) used the MIT general circulation model (MITgcm) to simulate the circulation in Gulf of Aqaba and the exchange flow between the Gulf of Aqaba and the northern Red Sea. They estimated that the annual mean outflow from the Gulf of Aqaba to the northern Red Sea is $0.0185 \mathrm{~Sv}$, with a flow of $0.04 \mathrm{~Sv}$ during early winter and $0.005 \mathrm{~Sv}$ during early spring.

Natural and anthropogenic tracers, such as ${ }^{3} \mathrm{He},{ }^{14} \mathrm{C}$, and chlorofluorocarbons (CFCs), are frequently used in ocean circulation studies to define the pathways, timescales, and transport of deep water masses. CFCs are trace gases of industrial origin that cause stratospheric ozone depletion. Release of CFCs into the atmosphere began in the 1940s, and their concentration in the atmosphere increased with time until the 1990s, when their use was curtailed by the Montreal Protocol. A small fraction of atmospheric CFCs enters the ocean through air-sea gas exchange at the ocean surface. They are chemically inert in seawater, and are carried from the surface to the interior by currents and turbulent mixing. CFCs can be used as an indicator of ocean ventilation and to determine the source of deep water formation. CFCs have been used extensively as a tracer to study the spreading of North Atlantic Deep Water and Antarctic Bottom Water (Smethie, 1993, 2000; Schlosser et al., 1991; Willey et al., 2004).

A few CFC profiles were collected in the far northern Red Sea and the Gulf of Aqaba in February and March 1999 (Plähn et al., 2002). These profiles revealed that RSDW could be divided into deep and bottom water masses. Overflow of very dense water from Gulf of Aqaba (through the Tiran Strait) is the main source of the bottom water. Although Cember (1988) 
suggested that outflow water from the Gulf of Suez is the main source of RSDW, outflow water from the Gulf of Suez is not dense enough to sink to the bottom and it reaches gravitational equilibrium above the water from the Gulf of Aqaba.

\subsection{Overturning circulations in the Red Sea}

Previous studies suggest that there are two overturning circulation cells in the Red Sea, driven by open-ocean convection in the northern Red Sea and dense outflows from Gulf of Suez and Gulf of Aqaba. Figure 1.7 shows a schematic diagram of the overturning circulation in the Red Sea according to Cember (1988). The upper overturning circulation cell consists of a northward flow at the surface and a subsurface southward flow of "isopycnal mode" water. Low-salinity surface water enters the Red Sea from the Gulf of Aden. Cember (1988) suggests that the isopycnal mode water is formed mainly by open-ocean convection and then injected below the thermocline. According to Sofianos and Johns (2003), the isopycnal mode water is identified as RSOW.

The upper overturning circulation cell was also predicted by a two-dimendional similarity model developed by Phillips (1966). In his model, the Red Sea is a semi-enclosed basin with a sill on a meridional-vertical plane, and rotation is not considered. In his model, the upper overturning circulation is driven by a uniform buoyancy flux, and the sill depth marks the lower limit of the circulation, with the deeper ocean being almost motionless. Phillips' model agrees qualitatively with the observed winter flow pattern at the Strait of Bab el Mandeb. However, later work by Tragou and Garrett (1997) and Yao et al. (2014b) found that Phillips' similarity solution doesn't agree well with observations and numerical simulation. Tragou and Garret (1997) modified Phillips' model and suggested that a large eddy viscosity is required in the southward return flow in order to match the observed stratification. 
Due to its elongated shape, the Red Sea is usually treated as a two-dimensional basin in early studies. However, modeling studies by Eshel and Naik (1997), Sofianos and Johns (2003), Biton et al. (2008), and Yao et al. (2014a, b) suggest that the Red Sea circulation is a more complex three-dimensional system. Sofianos and Johns (2003), and Yao et al. (2014b) studied the buoyancy driven circulation in the Red Sea and found that inflow from the Gulf of Aden moves along the western boundary and then crosses the basin to the eastern boundary. Chapter 3 of this thesis will further explore the mechanism that is responsible for the crossover of the boundary currents.

Figure 1.7 also shows a deep overturning circulation cell in the Red Sea. Dense water from the Gulf of Suez and Gulf of Aqaba sinks to the bottom of the Red Sea and moves southward. Near the sill in the southern Red Sea, it is thought that the water upwells and returns northward at a depth of about $300-500 \mathrm{~m}$. As the intermediate water moves northward, it mixes with the pycnocline water. Evidence for this deep cell is found in the vertical profiles of helium-3 $\left({ }^{3} \mathrm{He}\right)$. Figure 1.8 shows the distribution of ${ }^{3} \mathrm{He}$ from 3 GEOSECS stations in the Red Sea (Cember, 1988). The three stations were located along the central axis of the Red Sea at $14.7^{\circ} \mathrm{N}, 19.9^{\circ} \mathrm{N}$, and $27.3^{\circ} \mathrm{N}$, and each had a maximum ${ }^{3} \mathrm{He}$ concentration at about $500 \mathrm{~m}$. The ${ }^{3} \mathrm{He}$ concentration increases southward near the bottom.

In seawater, ${ }^{3} \mathrm{He}$ in has two sources: air-sea exchange and Earth's interior. Cember pointed out that most of the ${ }^{3} \mathrm{He}$ is released from Earth's interior by tectonic activity. The ${ }^{3} \mathrm{He}$ distribution shown in Figure 1.8 suggests that the deep water moves southward and gathers ${ }^{3} \mathrm{He}$, which is released from the sea floor. At the southernmost Red Sea (near the Hanish Sill), the deep water is supposedly uplifted along the topography and reaches its maximum concentration of ${ }^{3} \mathrm{He}$ at about $500 \mathrm{~m}$. As the deep water moves back northward, the ${ }^{3} \mathrm{He}$ concentration decreases as a result of 
distance from the source and vertical mixing with ambient water, which has a low ${ }^{3} \mathrm{He}$ concentration.

Cember's hypothesis of the deep overturning circulation is based on data from only three stations in the Red Sea. Dissolved oxygen and CFC-12 can also be used as indicators of the deep overturning circulation. At the bottom in the northern Red Sea, high dissolved-oxygen concentrations were observed, indicating newly formed deep water. When RSDW moves southward, the dissolved oxygen is depleted, and its concentration decreases (Sofianos and Johns, 2007). The dissolved-oxygen minimum occurs at about $400 \mathrm{~m}$, which could be an indication of relatively old recirculating deep water flowing northward. Although there is no direct measurement of the intermediate northward return flow, the distribution of carbon- $14,{ }^{3} \mathrm{He}$, and oxygen is consistent with its existence (Cember, 1988; Sofianos and Johns, 2007).

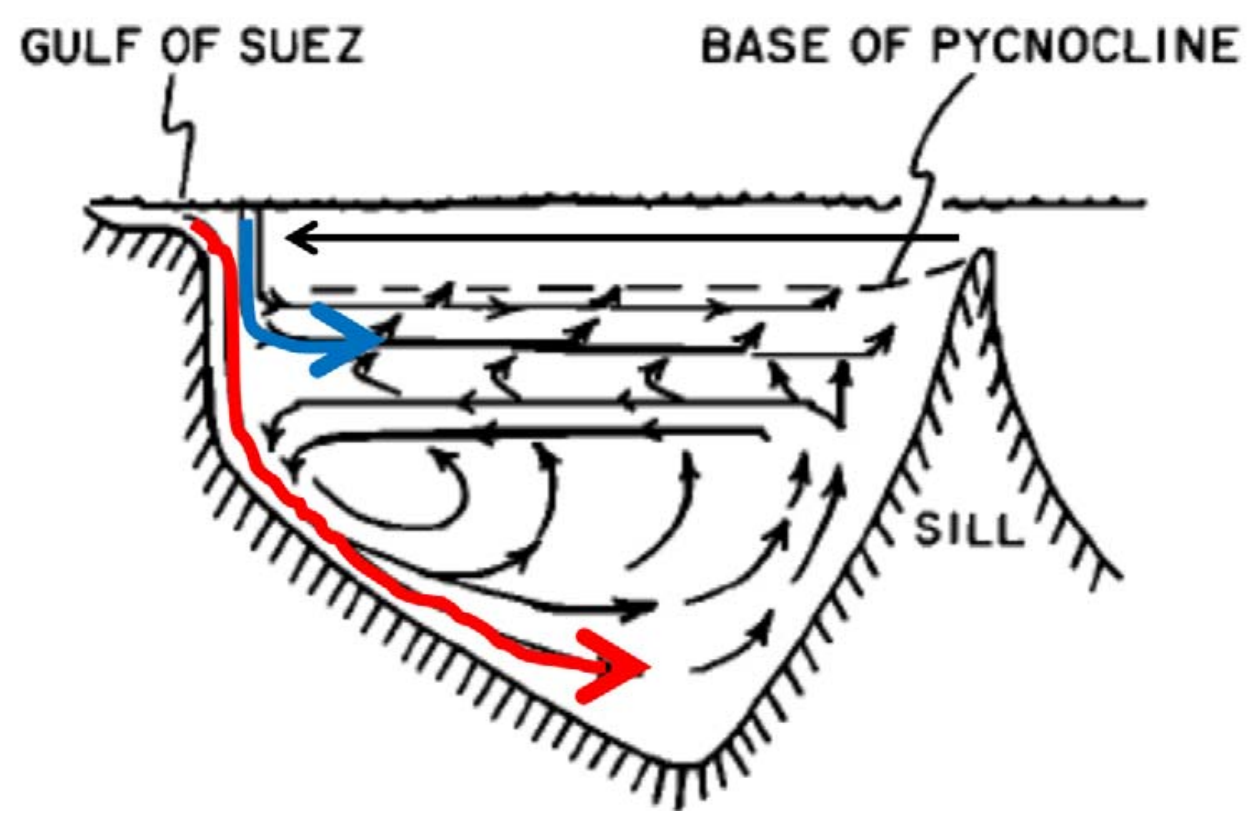

Figure 1.7: Schematic of general circulation in the Red Sea, according to Cember (1988, his Fig. 1). The red and blue arrows indicate convective and isopycnal modes, respectively. 


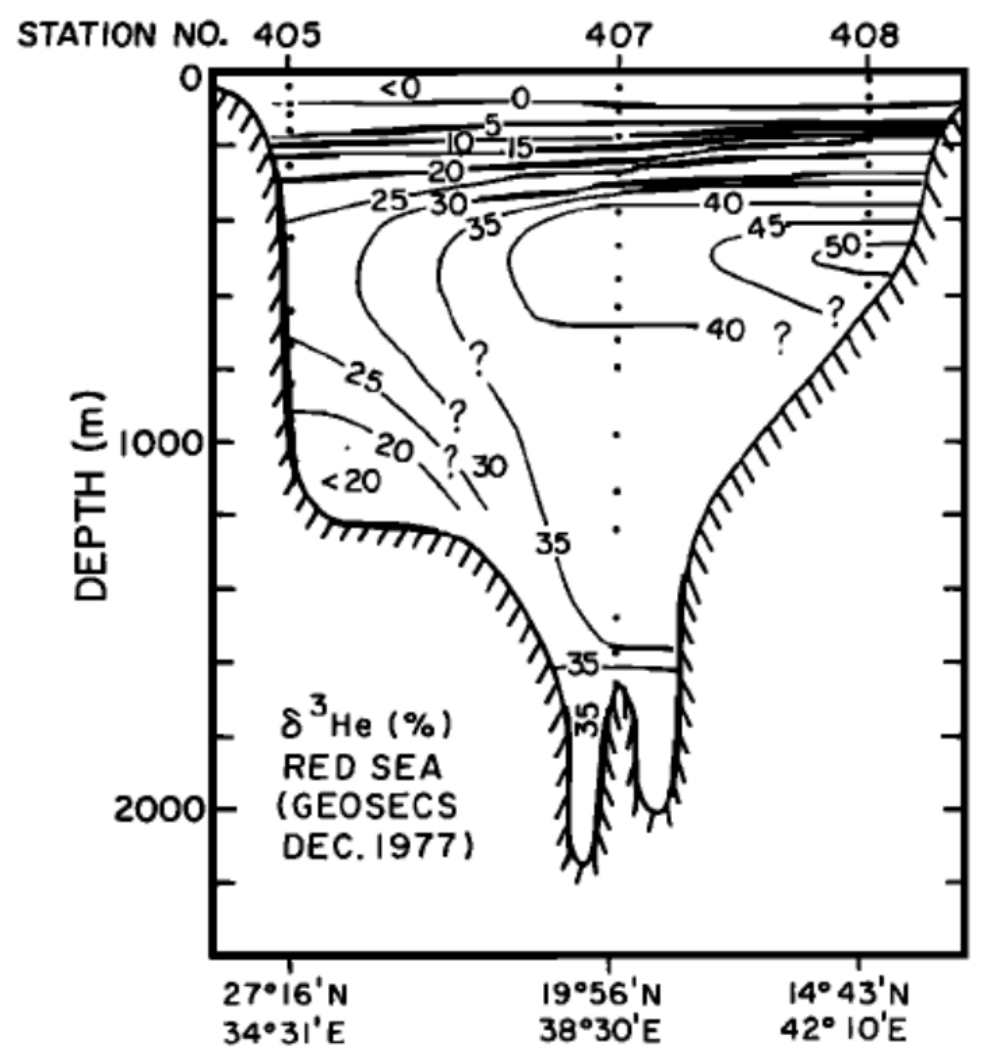

Figure 1.8: Distribution of ${ }^{3} \mathrm{He}$ in the Red Sea (Cember, 1988; his Fig. 7).

\subsection{Thesis Outline}

This study focuses on the upper overturning circulation cell, which is primarily driven by surface buoyancy loss. The upper overturning circulation cell connects the Red Sea with the open ocean and governs exchange processes between the Red Sea and the Indian Ocean. Fresher water coming from the Indian Ocean undergoes heat loss and evaporation in the Red Sea and is transformed into saltier RSOW. Based on results from a numerical study, Sofianos and Johns (2003) suggest that RSOW is formed by open-ocean convection in the northern Red Sea. In Chapter 2 of this work, new observations are analyzed to support the hypothesis that RSOW is 
formed by open-ocean convection and to identify RSOW. Numerical modeling is used to study the pathways and transit time of RSOW from its origin to the Strait of Bab el Mandeb.

Buoyancy-loss forced circulation in marginal seas is usually dominated by cyclonic boundary currents (Spall, 2004). However, a numerical studies by Sofianos and Johns (2003) and Yao et al. (2014b) indicate that the Red Sea circulation is more complex, with a cyclonic gyre in the northern Red Sea and an anticyclonic gyre in the southern Red Sea. They found from their numerical simulations that the northward boundary current crosses the basin from the western boundary to the eastern boundary at a certain latitude (crossover latitude). Sofianos and Johns (2003) suggested that the crossover latitude is the latitude beyond which Rossby waves are no longer possible. Numerical experiments in Chapter 3 show that their explanation cannot be correct. A new mechanism for the crossover of boundary currents is studied in Chapter 3, using numerical modeling and an ad hoc analytical model.

Some observational and modeling studies have shown that the surface-layer circulation in the Red Sea is characterized by a series of basin-scale eddies (Morcos, 1970; Morcos and Soliman, 1972; Quadfasel and Baudner, 1993). The cyclonic and anticyclonic gyres are not permanent, but tend to reappear at preferential locations, such as the anticyclonic eddy centered at $23^{\circ} \mathrm{N}$ and the cyclonic eddy near $26^{\circ} \mathrm{N}$. These eddies are strong and are usually confined to the upper 100-200 m. Using shipboard ADCP, Sofianos and Johns (2007) observed a strong dipole near $19^{\circ} \mathrm{N}$ in August 2001, with a cyclone to the north and an anticyclone to the south, both with a maximum speed of about $1 \mathrm{~m} \mathrm{~s}^{-1}$. These eddies can influence the distribution of water properties, such as chlorophyll concentrations. On the other hand, water properties can be used as an indicator of eddies. For example, the distribution of chlorophyll-a from SeaWiFS indicates an anticyclone 
centered at $23^{\circ} \mathrm{N}$ in August 1998 and an anticyclone centered at $18.7^{\circ} \mathrm{N}$ in October 2002 (Acker et al., 2007).

Eddies play an important role in transporting heat, freshwater, and mass in the Red Sea. However, the mechanisms that generate these eddies are not well-understood. Clifford et al. (1997) suggested that cross-basin wind fields can generate eddies in the Red Sea. Zhai and Bower (2013) studied the Red Sea response to the Tokar Wind Jet which blows eastward from Sudan onto the Red Sea. They found that the Tokar Wind Jet generates a dipole, i.e. two counter-rotating eddies. In Chapter 4, the eddy generation mechanism that is related to cross-basin winds is reviewed. Chapter 4 also studies two additional mechanisms for eddy generation in the Red Sea: baroclinic instability, and meridional structure of surface buoyancy forcing.

Finally, chapter 5 summarizes the conclusions of the thesis as a whole. 


\section{Chapter 2}

\section{Red Sea Overflow Water Formation and its Spreading Pathways}

\subsection{Introduction and background}

RSOW is one of the most saline water masses in the world ocean. After flowing over the Hanish Sill, the RSOW entrains less dense overlying water in the Gulf of Aden and its properties changes dramatically. With a combination of observational data and numerical simulations, Bower et al. $(2000,2005)$ found that the RSOW reached neutral buoyancy at about $400-800 \mathrm{~m}$ in the Gulf of Aden with salinity of 37.5. Outside the Gulf of Aden, the RSOW has been observed up to $6000 \mathrm{~km}$ away from its source in the Agulhas retroflection region as a water mass with high salinity and low oxygen at intermediate depth (Gordon et al., 1987; Valentine et al., 1993; Beal et al., 2000). It has been observed that the primary spreading pathway of RSOW is along the African continental coast through the Mozambique Channel (Wyrtki, 1973; Beal et al., 2000). By using a simple mixing model, Beal et al. (2000) suggested that RSOW dominated the Indian Ocean salt budget in the intermediate depth layer. The RSOW can also be used as a tracer to investigate the Indian Ocean circulation. The RSOW is suggested to be formed in the northern Red Sea through open-ocean convection. Atmospheric conditions there directly influences production rate of RSOW. Therefore, understanding the formation mechanism of RSOW and how RSOW production rate changes under difference conditions in the Red Sea is important in studying the RSOW's impact on Indian Ocean circulation and properties.

Sofianos and Johns (2003) suggest that the Red Sea Overflow Water (RSOW) is formed through open-ocean convection in the northern Red Sea. Open-ocean convection is one of the most 
important processes by which the intermediate and deep water masses in the global oceans are formed. The Labrador, Greenland, Mediterranean and Weddell Seas are major open-ocean convection locations. Intermediate or deep water masses formed in these convective regions usually hold distinct water properties which allow them to be tracked far from their origins.

The evolution of open-ocean convection can be divided into the three phases shown in Figure 2.1: preconditioning, deep convection, lateral exchange and spreading. Open-ocean convection can occur when three conditions are satisfied: i) the water column is weakly stratified; ii) the cyclonic gyre with doming isopycnals brings the denser deep water close to the sea surface; iii) there is intense sea surface buoyancy loss to the atmosphere due to cooling and evaporation (Marshall and Schott, 1999). When these conditions are satisfied, vigorous vertical mixing occurs within the preconditioned area (Figure 2.1b). At the same time, eddy flux spreads the homogeneous water column horizontally. When the surface buoyancy loss decreases or ceases, the surface water becomes restratified. A well-mixed layer remains as intermediate or deep water (right panel of Figure 2.1c) below the surface (Marshall and Schott, 1999) and spreads out at its neutrally buoyant level. 


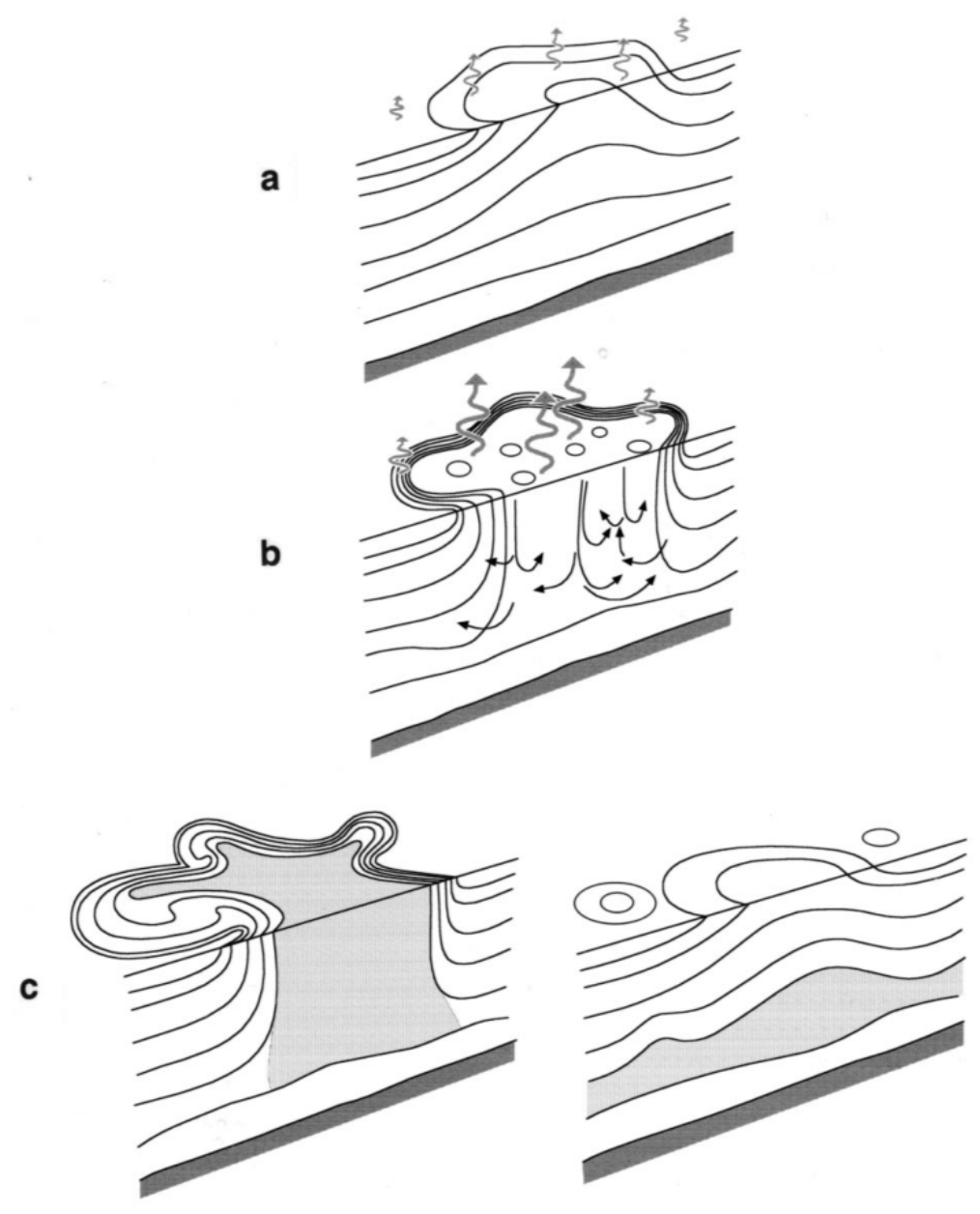

Figure 2.1: A schematic diagram of the three phases of open-ocean convection: (a) precondition, (b) deep convection, (c) lateral exchange and spreading. The curly arrows represent surface buoyancy loss and the shaded is the water mixed by convection. (Marshall and Schott, 1999, their Figure 3).

Hence, preconditioning is an essential prerequisite for open-ocean convection. Marshall and Schott (1999) summarized the preconditions of open-ocean convection in the North Atlantic and West Mediterranean. Cyclonic boundary circulations are observed in the Labrador, Greenland and West Mediterranean Seas where deep convection also occurs. For example, in the Labrador Sea, the cyclonic circulation is composed of the West Greenland Current and the Labrador Current. Strong winds coming from land bring cold and dry air to the convective region and 
remove heat and fresh water from the sea surface. In the Greenland Sea, brine rejection from ice also plays an important role in surface density increase. The typical values of net heat fluxes from ocean to atmosphere in winter in the Labrador, Greenland and Mediterranean Seas are -490 , -530 and $-500 \mathrm{~W} \mathrm{~m}^{-2}$, respectively (Marshall and Schott, 1999). Based on CFC-11 inventories, Smethie and Fine (2001) estimated the deep water formation rates: 7.4 Sv for Labrador Sea Water, 2.4 Sv for Denmark Strait Overflow Water, and 5.2 Sv for Iceland-Scotland Overflow Water. The transport of the Mediterranean Overflow Water is about $1 \mathrm{~Sv}$ at the Strait of Gibraltar according to observations (Send et al., 1999).

The primary aim of this chapter is to understand the formation process of the RSOW and the three-dimensional spreading pathways in the Red Sea. Section 2.2 introduces the data sets used in this study. The preconditioning of open-ocean convection in the northern Red Sea is described in Section 2.3. In Section 2.4, potential vorticity and chlorofluorocarbon-12 (CFC-12) distributions are used to identify the RSOW. In Section 2.5 the production rate of the RSOW is estimated using a method developed by Walin (1982). The spreading pathways and transit time of the RSOW calculated from a numerical model will be described in Section 2.6. Section 2.7 contains conclusions and a discussion of this chapter.

\subsection{Data}

\subsubsection{Hydrographic and CFC-12 data}

Two hydrographic survey cruises were conducted in the Red Sea during March 16-29, 2010 and September 15-October 10, 2011 by the Woods Hole Oceanographic Institution and King Abdullah University of Science and Technology. The primary purpose of these cruises was to carry out a large-scale survey of the eastern Red Sea, including observations of top-to-bottom 
ocean currents and water properties, including temperature, salinity, dissolved oxygen, turbidity and fluorescence. The cruise that was conducted in March 2010 consisted of 111 CTD (Conductivity, Temperature, and Depth) and LADCP (Lowered Acoustic Doppler Current Profiler) stations. The cruise in September and October 2011 consisted of 206 CTD and LADCP stations. Figure 2.2 shows the locations of CTD and LADCP stations for these two cruises. The station spacing along each transect was about $10 \mathrm{~km}$. At each station, profiles of temperature, salinity, dissolved oxygen and velocity data were collected using a modified SeaBird 911plus rosette/CTD system and LADCP. Seawater samples were collected at nearly all stations to calibrate CTD measurements of salinity and oxygen. Velocity in the upper 600 meters was measured by Shipboard ADCP. 


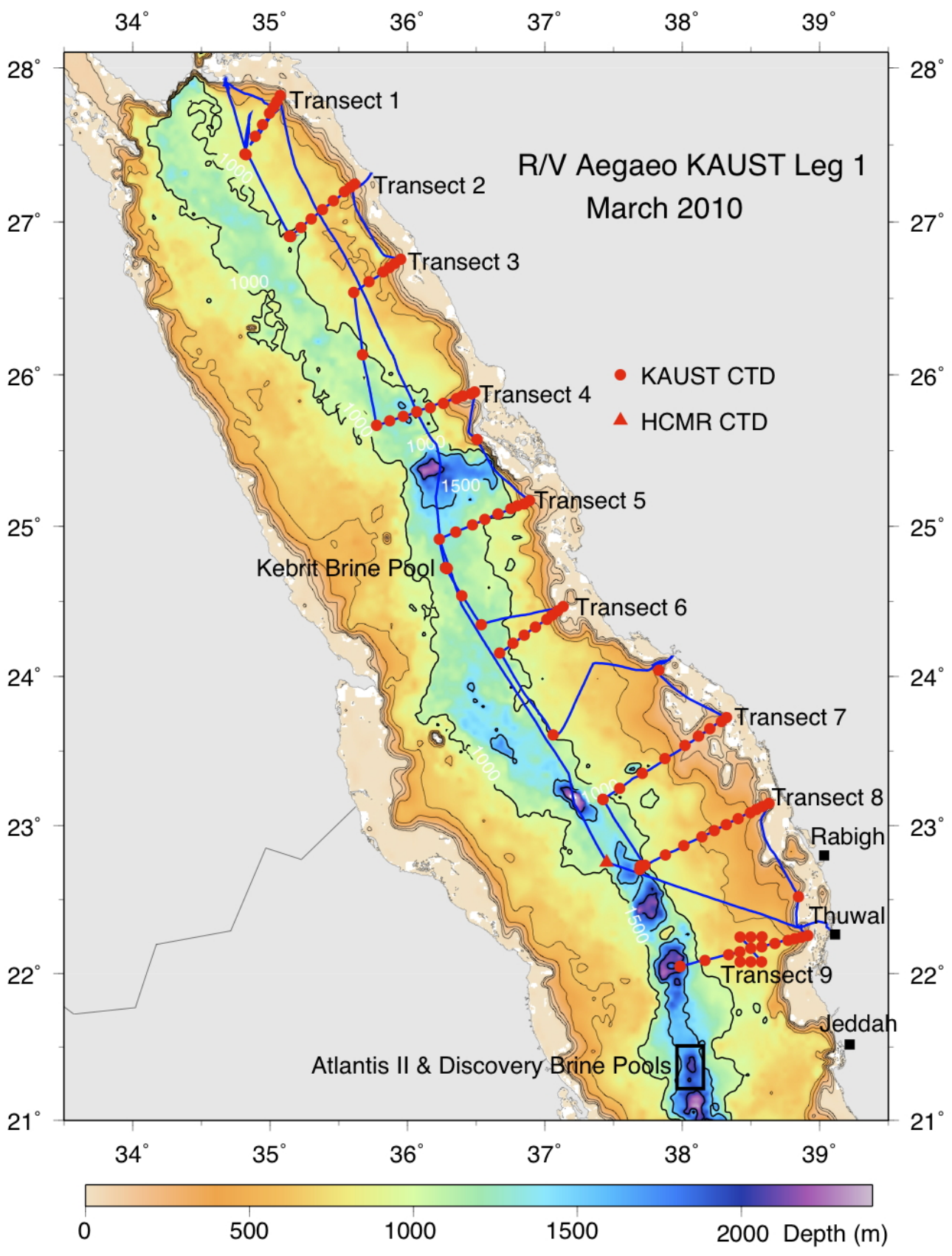




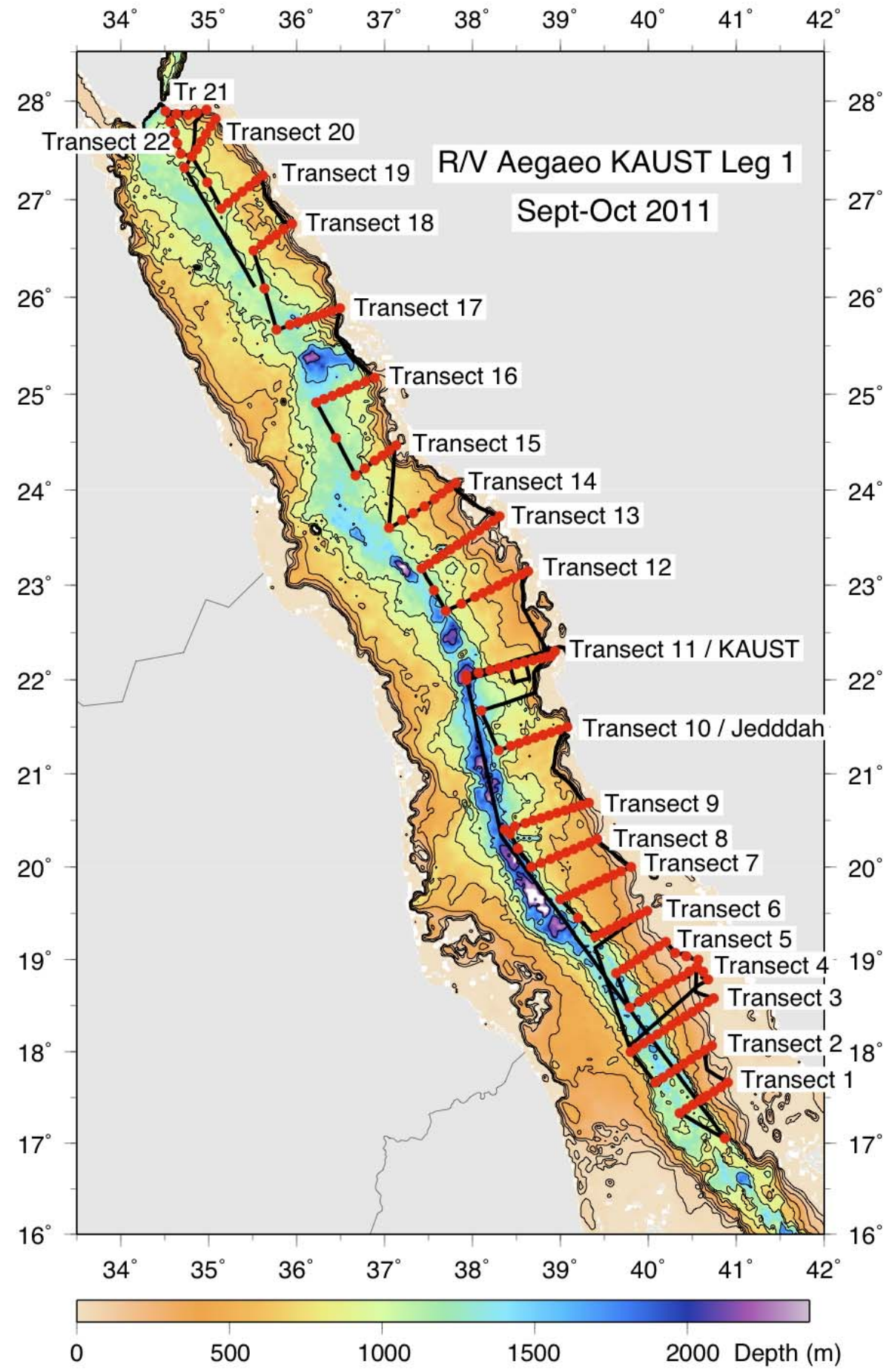

Figure 2.2: Locations of CTD stations of Red Sea cruise in March 2010 and September-October 2011 (Bower, 2010; Bower and Abualnaja, 2011). 
During the September-October 2011 Red Sea cruise, water samples for CFC-12 analysis were collected at selected stations. The locations where CFC-12 samples were collected are shown in Figure 2.3. Water samples were collected by using two methods. $250 \mathrm{ml}$ stoppered bottles were used to collect samples for CFC-12 at 5 stations. $50 \mathrm{ml}$ ampoules were used to collect $\mathrm{CFC}-12$ samples at 14 stations. Nitrogen was used to flow through the top of the ampoules to keep the water samples from being contaminated by air. The flame-sealing of the glass ampoule samples was done by propane and oxygen. Both stoppered bottles and ampoules samples were collected at stations 194, 157 and 205 in order to compare the two sampling methods and increase the measurement accuracy. The CFC-12 data obtained during the 2011 cruise were the first data for the Red Sea that covers from $17^{\circ} \mathrm{N}$ to $28^{\circ} \mathrm{N}$. 


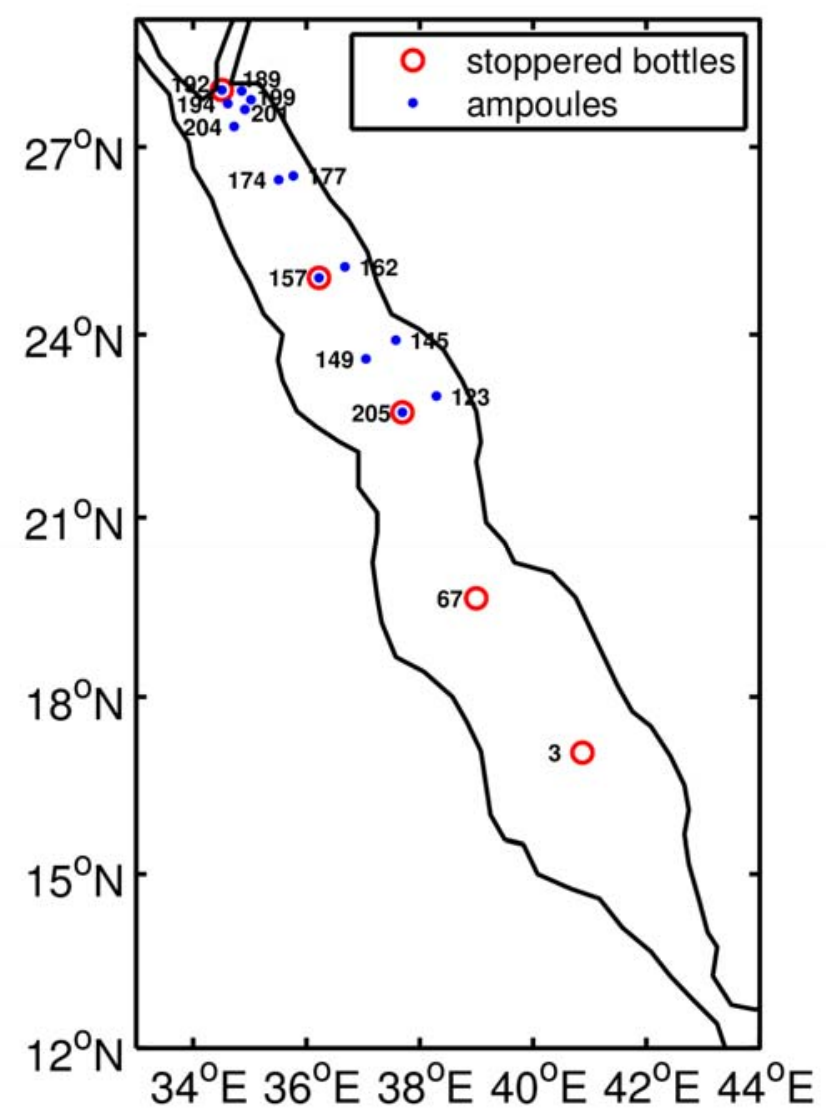

Figure 2.3: Station numbers and locations for CFC-12 water sample collection during September 15-October 10, 2011 Red Sea cruise.

\subsubsection{Sea Surface Temperature}

SSTs can be determined from satellite remote sensing using microwave (MW) and infrared (IR) radiometers. IR SSTs have higher spatial resolution $(1-4 \mathrm{~km})$ than MW SSTs $(25 \mathrm{~km})$ does. However, the accuracy of IR SSTs is affected by cloud, aerosols and water vapors. The advantage of MW radiometry is that it is not affected by cloud cover. In this study we use MWIR SSTs which is processed and distributed by Remote Sensing System (RSS). This product combines the satellite observations from MW and IR sensors. The MW SSTs are derived from the Advanced Microwave Scanning Radiometer (AMSR-E), the Tropical Rainfall Measuring 
Mission's Microwave Image (TMI) and the WindSAT Polarimetric Radiometer (WindSAT). The IR SSTs are derived from MODerate-resolution Imaging Spectroradiometer (MODIS). The merged MW-IR SST product has greater coverage and higher resolution. This product is distributed on a $0.09^{\circ}$ grid and covers data from January 2006.

\subsubsection{Sea Surface Heat Flux}

The sea surface heat flux used in estimating the production rate of RSOW is obtained from the global Objectively Analyzed air-sea Flux (OAflux). The OAflux is constructed from an objective analysis of in situ observations, satellite data and atmospheric reanalysis (Yu et al., 2008). The fluxes are computed using the Coupled Ocean-Atmosphere Response Experiment (COARE) bulk flux algorithm 3.0 and are mapped on a regular $1^{\circ}$ grid. The data product used in this study includes the monthly mean net heat flux and evaporation for the period from 1984 to 2009 .

\subsubsection{QuikSCAT and ASCAT Winds}

The QuikSCAT was launched in 1999 and its mission ended in November 2009. The QuikSCAT (Quik SCATterometer) winds analyzed here are produced by Remote Sensing Systems and sponsored by the NASA Ocean Vector Winds Science Team. QuikSCAT data product includes daily and time averaged wind data (3-day average, weekly and monthly) at $10 \mathrm{~m}$ above the sea surface. The data product used here is 0.25 -degree gridded data. An air-sea interaction buoy was deployed on October 11,2008 at $22.16^{\circ} \mathrm{N}, 38.50^{\circ} \mathrm{E}$ in the Red Sea $60 \mathrm{~km}$ offshore of the Saudi Arabian coast. The QuikSCAT wind speeds compare well with the buoy wind measurements (Zhai and Bower, 2013). Their results show that the mean differences for wind speed and 
direction are $-0.02 \mathrm{~m} \mathrm{~s}^{-1}$ and $10.7^{\circ}$, root mean squared differences are $0.68 \mathrm{~m} \mathrm{~s}^{-1}$ and $29.9^{\circ}$ and correlation coefficients of 0.95 and 0.76 .

The Advanced Scatterometer (ASCAT) on board Metop-A was launched in 2006 and provides sea surface wind at $10 \mathrm{~m}$ height since March 2007. The data product is mapped on a 0.25 degree grid. ASCAT wind has similar accuracies to QuikSCAT based on previous studies (Bentamy et al., 2008). Wind data before November 2009 used in this study are from QuikSCAT and data after November 2009 are from ASCAT.

\subsection{Preconditioning of Open- Ocean Convection in the Northern Red Sea}

Open-ocean convection can reach thousands of meters in the North Atlantic region. However, the situation in the northern Red Sea is different. In order to escape to the Gulf of Aden, RSOW formed in the northern Red Sea has to flow over the Hanish Sill with a depth of $137 \mathrm{~m}$. Therefore, convection down to this depth is sufficient for the formation of the RSOW.

Observations in the Labrador, Greenland and Mediterranean Seas suggest that open-ocean convection occurs in open-ocean regions that are close to boundaries because wind blowing from land usually brings cold and dry air which can remove sensible heat, latent heat and fresh water from the sea surface. Although the Red Sea region is not as cold as high latitudes, the air here is exceptionally dry, leading to strong evaporation and latent heat loss. In addition to the intense atmospheric forcing, two more features are usually observed in open-ocean convection region: weak stratification and cyclonic gyre (Marshall and Schott, 1999). Cyclonic circulation can cause doming of isopycnal surfaces and raise the weakly-stratified water to the surface. In this section, in situ observations and satellite measurements are used to describe the conditions that lead to convection in the northern Red Sea. 
Some previous observations in the Red Sea suggest that there is a cyclonic gyre in the northern Red Sea (Morcos and Soliman, 1974; Clifford et al., 1997; and Manasrah, 2004; Chen et al., 2014). The cyclonic gyre is also suggested in satellite SST images. Figure 2.4 shows the monthly mean SST anomaly in March, June, October and December. Monthly mean SST is obtained by averaging MW-IR SST from January 2006 to December 2012. The SST anomaly is obtained by subtracting the spatial average of monthly mean SST of each month in the area north of $22^{\circ} \mathrm{N}$ from monthly mean SST. It is obvious that there is a cold pool in the northern Red Sea in October and December. Cold pool is usually associated with lower sea level, which suggests the emergence of a cyclonic gyre. The center of the cold pool is closer to the western part of the basin. The SST images also suggest that the closed contours disappear on the western boundary in March and June, which eliminates evidence of a closed cyclonic gyre. 

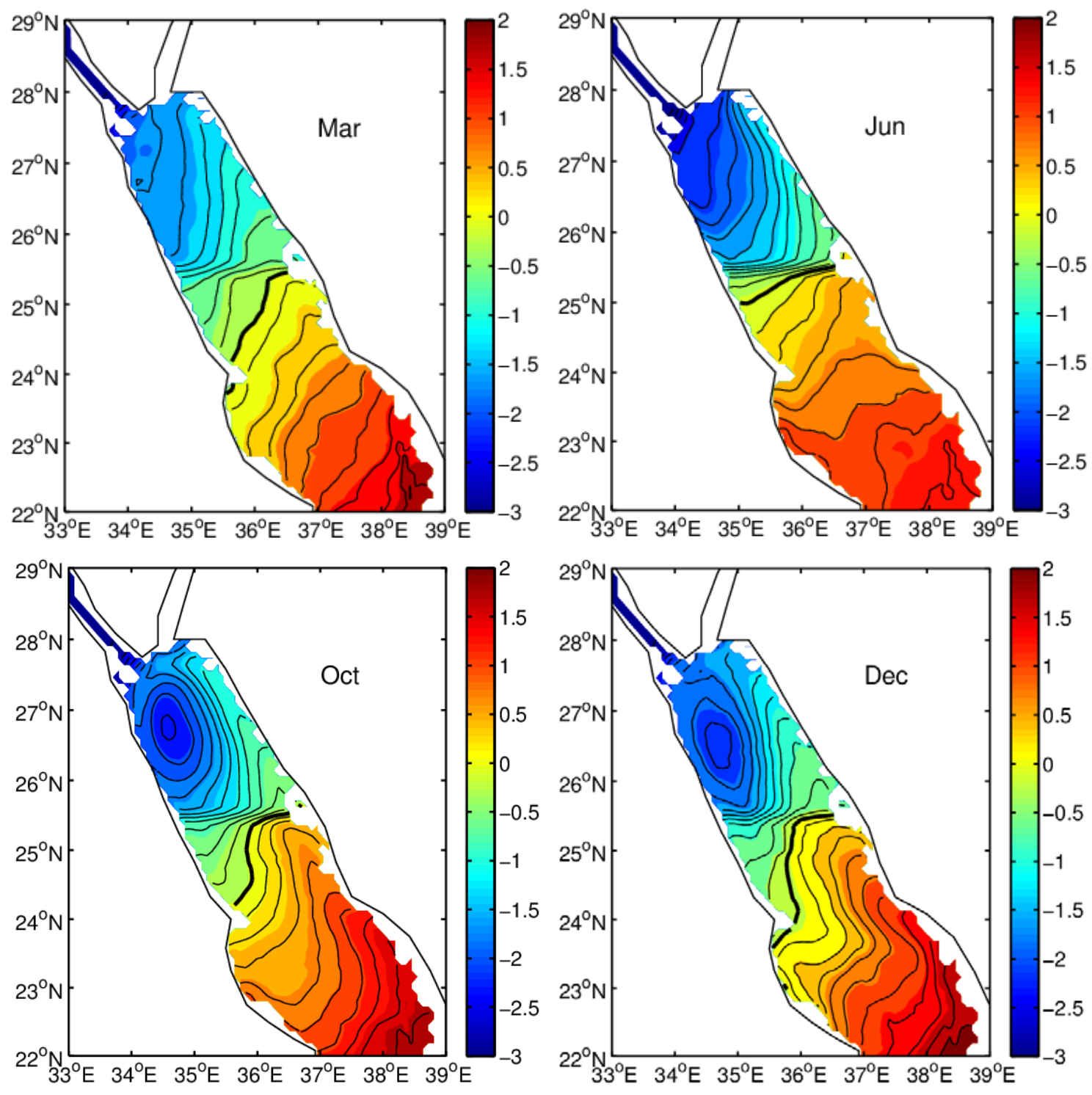

Figure 2.4: Monthly mean SST anomaly for March, June, October and December. Here anomaly means that spatial average of SST is subtracted for each month. The contour interval is $0.2{ }^{\circ} \mathrm{C}$, and thick black line is zero-contour.

Although in situ observations are sparse, several investigators have found evidence of cyclonic circulation in the northern Red Sea (Morcos and Soliman, 1972; Clifford et al., 1997; Manasrah et al., 2004). Potential density at Transects 18,19 and 20 in the northern Red Sea in October 
2011 cruise are plotted in Figure 2.5. It indicates a shoaling of isopycnals toward the interior of the basin, consistent with a cyclonic gyre there. However, we were not able to capture the structure of the western part of the cyclonic gyre due to political reasons. Sofianos and Johns (2007) described zonal sections of temperature, salinity, oxygen and velocity on the western half of the Red Sea at about $26.5^{\circ} \mathrm{N}$ in August 2001. The western half of the cyclonic gyre was captured by their observations, with a southward flow along the western boundary and eastward rising isopycnals.
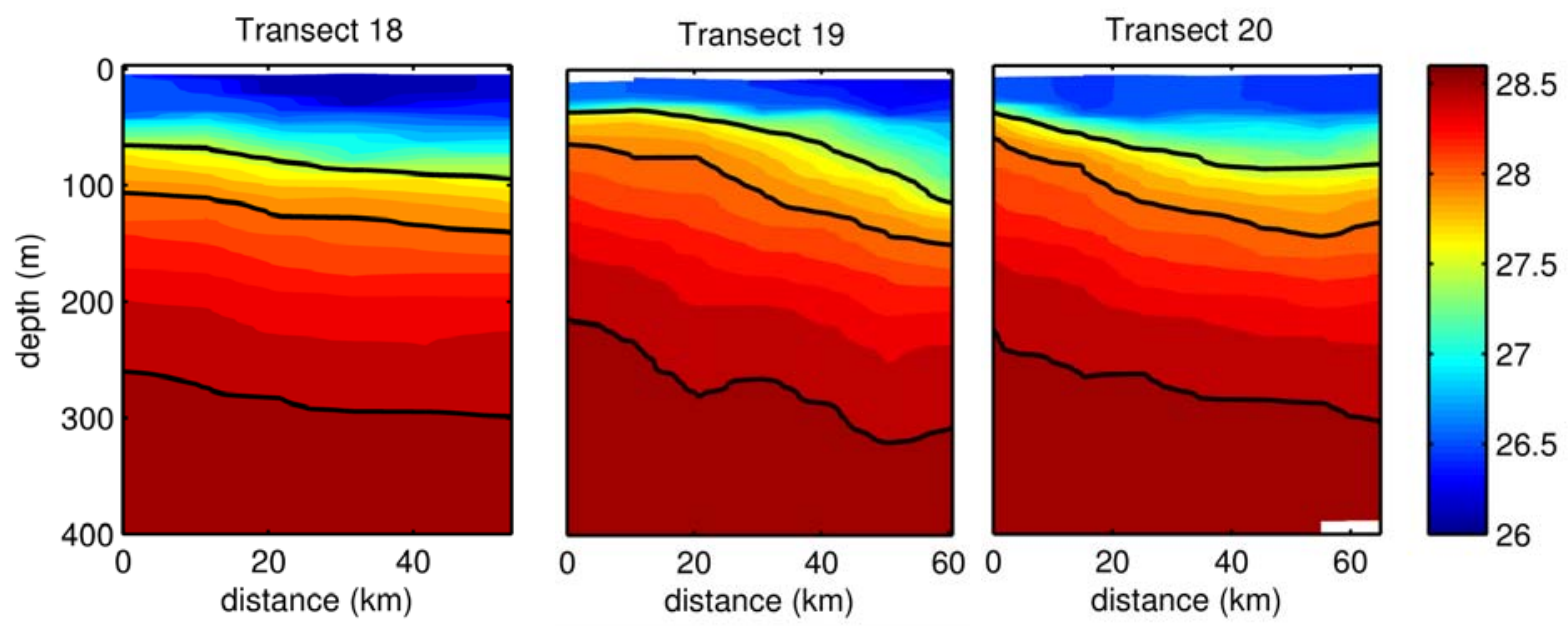

Figure 2.5: Potential density at Transects 18, 19 and 20 in September-October 2011 cruise (See Figure 2.2 for location). $\mathrm{x}$-axis is distance from the most west station. Isopycnals of 27.5, 28 and $28.5 \mathrm{~kg} \mathrm{~m}^{-3}$ are plotted with black lines.

The SST images exhibit that the coldest water in winter (December to February) is located closer to the western part of the basin than the eastern part. Since satellite sea surface salinity (SSS) is not available in the Red Sea, surface density can't be calculated directly from remotely measured surface temperature and salinity. The scatter plot of surface temperature and density measured during March 2010 cruise reveals that the surface density was linearly related to the SST (Figure 2.6). The least square fit of the linear relation between SST and density is 
$\rho=42.2302-0.61571 \times \mathrm{SST}$ (Figure 2.6). Here 0.67414 is not a thermal expansion coefficient since the salinity part of the equation of state is included implicitly. Density can be approximated by a linear equation of state, such that density is linearly related to salinity and temperature. Figure 2.7 shows that salinity is also linearly related to SST in the north Red Sea. Therefore, there is a very close agreement between the density calculated from in situ salinity and temperature (in situ density) and the density estimated from in situ temperature. The statistical analysis reveals that the linear correlation coefficient is 0.99 with a mean difference and root mean squared difference of $2 \times 10^{-12} \mathrm{~kg} \mathrm{~m}^{-3}$ and $0.06 \mathrm{~kg} \mathrm{~m}^{-3}$, respectively (Figure 2.6). By employing the linear relation between density and SST, we can estimate density and explore its horizontal structure. I am assuming that the linear relationship observed in March 2010 holds throughout the winter months. Figure 2.9 shows sea surface density in December, January and February calculated from satellite SST. It implies that there is a cyclonic gyre in December and January. The cyclonic gyre disappears in February because convection might stop in February and water column gets restratified. The densest water is located closer to the western part of the basin. In situ observations at the strait of Bab el Mandeb recorded that the density of the RSOW at the strait was about 27.5 28 $\mathrm{kg} \mathrm{m}^{-3}$ (Sofianos et al., 2002). As shown in Figure 2.9, the 27.5 $\mathrm{kg} / \mathrm{m}^{3}$ isopycnal outcrops in January and February in the northern Red Sea, which makes it possible for the RSOW formation. It should be pointed out that the linear relation between SST and density is based on the in situ observation during March 2010 cruise. The least square fit of the linear relation between SST and density for September-October 2011 cruise was $\rho=45.4378-0.67414 \times \mathrm{SST}$ (Figure 2.8), which was very close to the linear relation in March 2010. The root mean squared difference of the in situ density and density calculated from temperature is $0.22 \mathrm{~kg} \mathrm{~m}^{-3}$. Since we are interested in convection, which occurs only in winter, 
the linear relation between SST and $\rho$ from March 2010 cruise is chosen to estimate density from satellite SST.
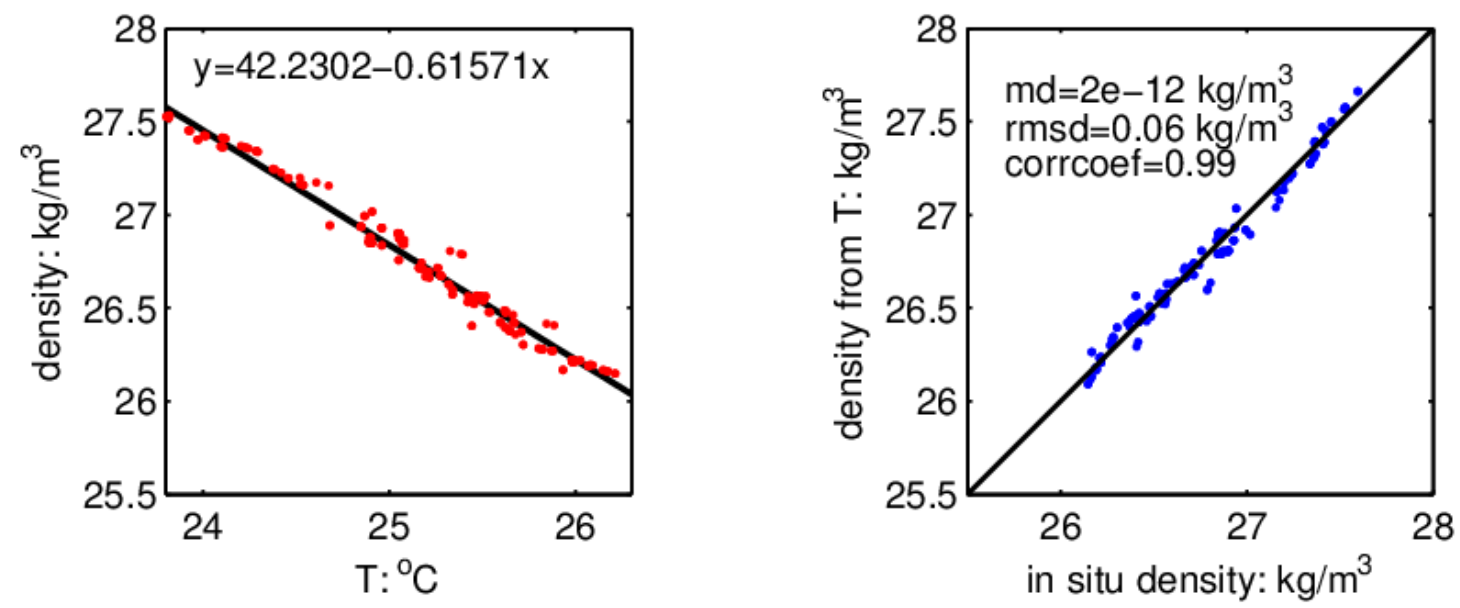

Figure 2.6: Left: Relationship between surface temperature and density in the northern Red Sea (north of $22^{\circ} \mathrm{N}$ ). Red dots represent temperature and density observed during March 2010 cruise in the upper 5 meters. Black line is least square fit of the linear relation between temperature and density. Right: Comparison between the density calculated from in situ temperature and salinity (x-axis) and density calculated using the linear relation between temperature and density shown in the left panel (y-axis).

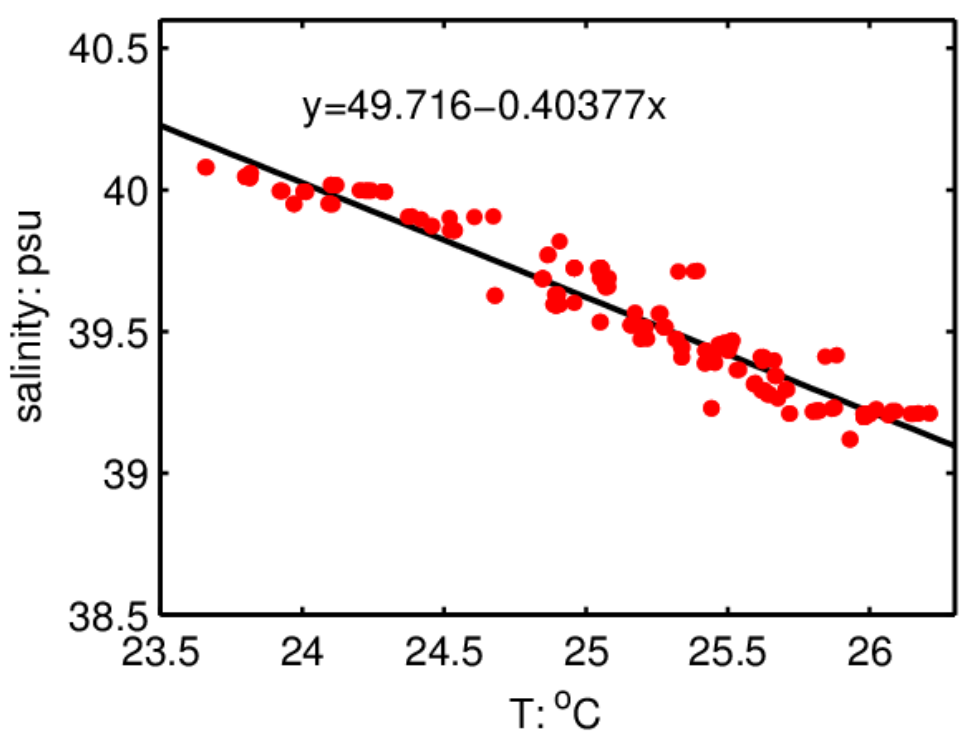

Figure 2.7: Relationship between surface temperature and salinity in the northern Red Sea (north of $22^{\circ} \mathrm{N}$ ). Red dots are temperature and salinity observed during March 2010 cruise in the upper 5 meters. Black line is least square fit of the linear relation between temperature and salinity. 

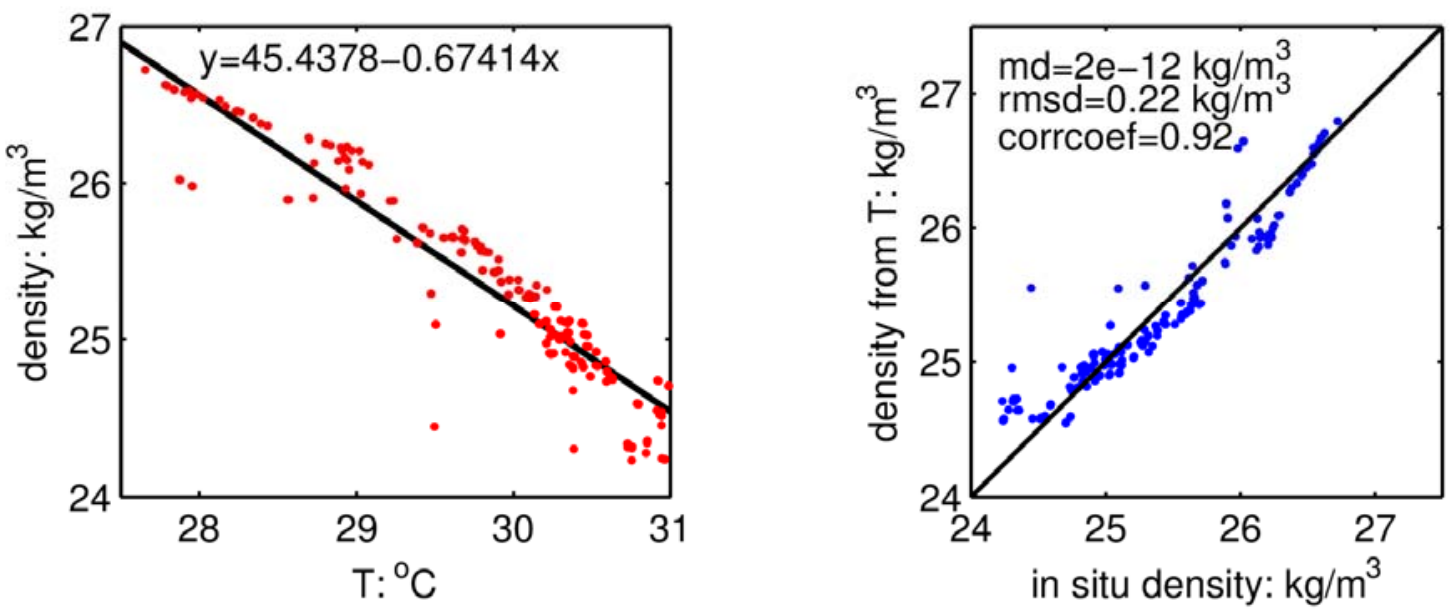

Figure 2.8: The same as Figure 2.6, but data are from September-October 2011 cruise.
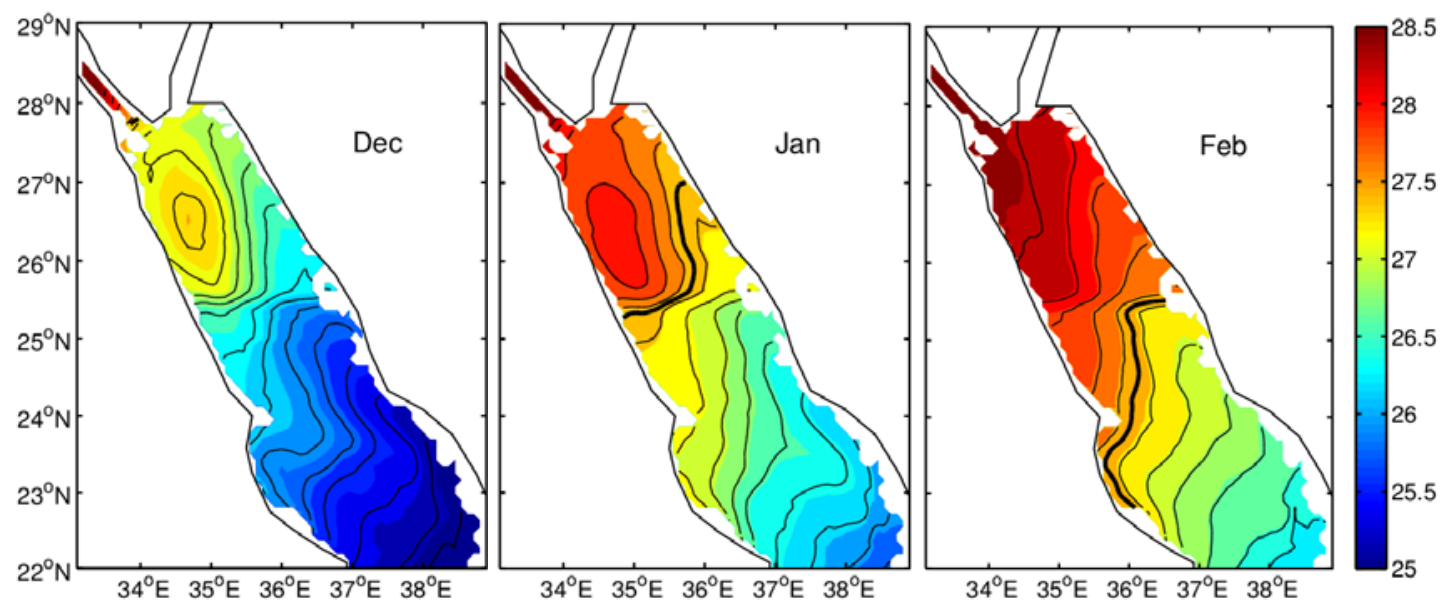

Figure 2.9: Sea surface density in December, January and February calculated from satellite SST through the linear relation based on observation during March 2010 cruise. The contour interval is $0.2 \mathrm{~kg} / \mathrm{m}^{3}$. The thick black line represents the $27.5 \mathrm{~kg} \mathrm{~m}^{-3}$ isopycnal.

The seasonal cycle of net heat flux and evaporation rate averaged north of $25^{\circ} \mathrm{N}$ are plotted in Figure 2.10. In summer, the net heat flux is positive, which means that the sea surface gains heat from the atmosphere. Starting from September, the net heat flux changes its sign and the sea surface begins to lose heat into the atmosphere. In December and January, the heat loss 
approaches $-200 \mathrm{~W} \mathrm{~m}^{-2}$, which is much smaller than the heat loss in Labrador $\left(-490 \mathrm{~W} \mathrm{~m}^{-2}\right)$, Greenland $\left(-530 \mathrm{~W} \mathrm{~m}^{-2}\right)$ and Mediterranean $\left(-500 \mathrm{~W} \mathrm{~m}^{-2}\right)$ Seas. However, as we have mentioned earlier, the convection doesn't have to be deeper than $200 \mathrm{~m}$ in the northern Red Sea because the RSOW flows over a sill with a depth of $137 \mathrm{~m}$. Papadopoulos et al. (2013) found that the net heat loss in winter in the northern Red Sea varied from $-50 \mathrm{~W} \mathrm{~m}^{-2}$ to $-400 \mathrm{~W} \mathrm{~m}^{-2}$ from year to year. They pointed out that the extreme heat loss events in certain years were caused by positive sea level pressure (SLP) anomaly over the eastern Mediterranean and Middle East. In these years, the strong southeastward wind carried cold and dry air into the northern Red Sea and led to extreme heat loss and evaporation.
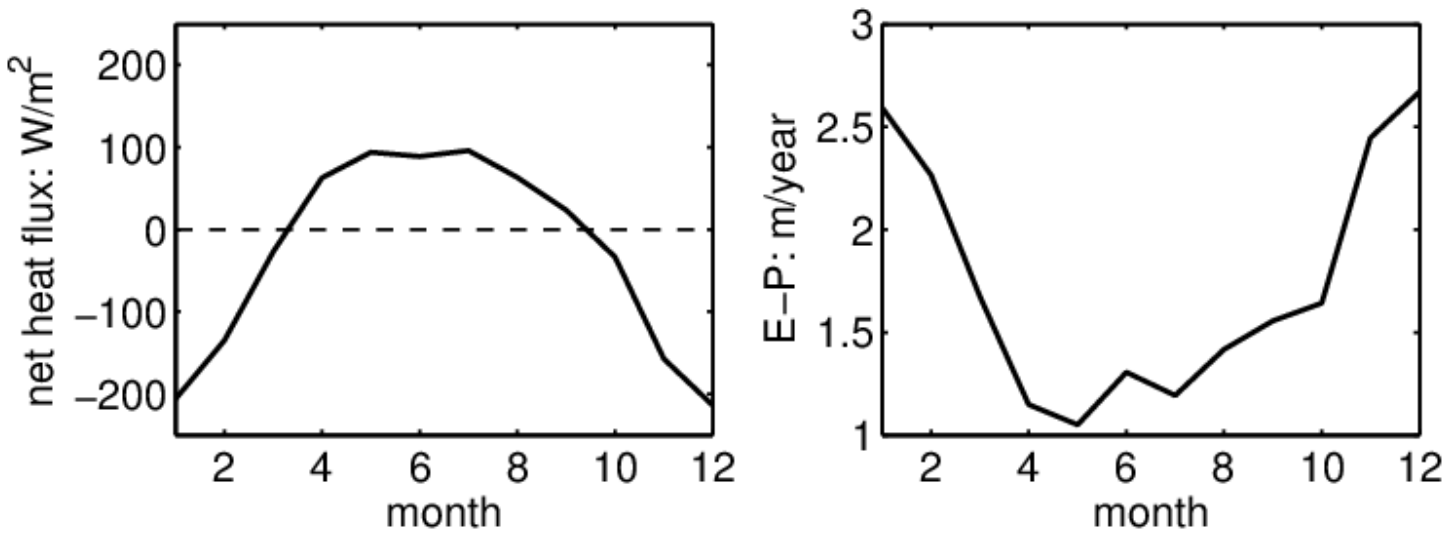

Figure 2.10: Annual mean net heat flux and evaporation rate averaged north of $25^{\circ} \mathrm{N}$.

Figure 2.4 and Figure 2.9 reveals that the coldest and densest water is located closer to the western part of the basin instead of being in the middle of the northern Red Sea. The horizontal structure of surface $10-\mathrm{m}$ winds shows that the winds are stronger near the western boundary than that near the eastern boundary (Figure 2.11). Gulfs of Suez and Gulf of Aqaba connect with the northern Red Sea and are surrounded by mountains. The surface winds in the two gulfs are mainly along the longitudinal axis of the basins due to the mountains' constraint. Winds from the 
Gulf of Suez and Gulf of Aqaba converge near the western boundary of the northern Red Sea and cause stronger wind there. This idea is supported by a high resolution numerical simulation using the Weather Research and Forecasting (WRF) model (Jiang et al., 2009). Their simulation captured the wind pattern in the Gulf of Suez and Gulf of Aqaba, which was not observed by QuikSCAT. The turbulent heat flux (including latent and sensible heat fluxes) and evaporation increase with wind speed. Therefore, wind can influence the surface temperature and salinity. The presence of stronger winds close to the western boundary might explain the asymmetry in the cold pool. 

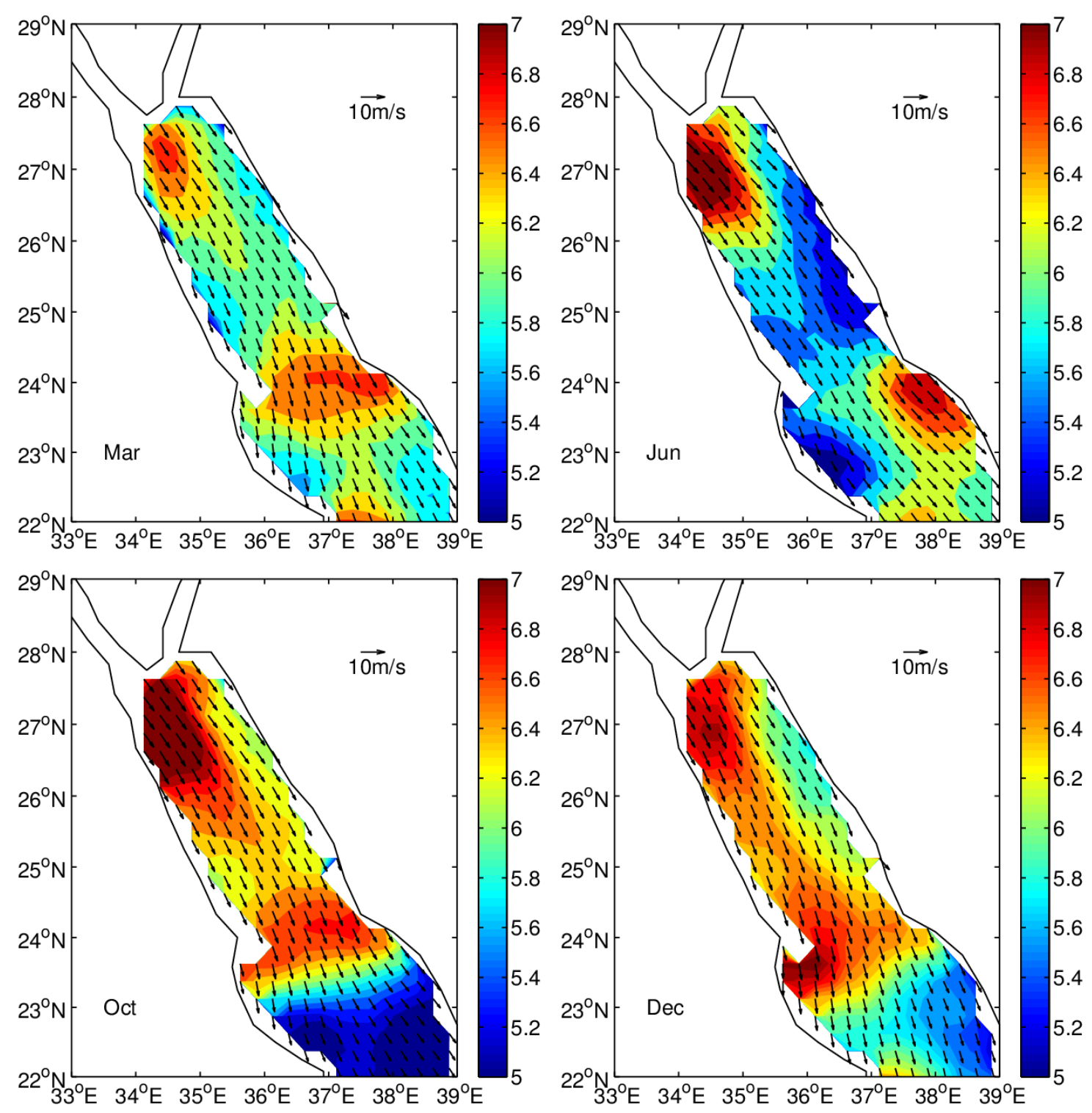

Figure 2.11: Monthly mean of 10-m wind vector field overlapped with its magnitude (color contours) from QuikSCAT.

In summary, there is evidence to support a cyclonic gyre with doming isopycnals in the center of the northern Red Sea from satellite SST and hydrographic data. This study also indicates that the cyclonic gyre is closer to the western boundary. In winter, strong buoyancy loss causes vertical mixing in the weakly stratified layer and convection occurs. The preconditions of open-ocean 
convection are satisfied in the northern Red Sea. Figure 2.1c shows that there is a nearly homogeneous water layer that remains below the sea surface after convection ceases. This water mass is usually marked with distinct properties, such as low potential vorticity (PV) and high oxygen. Only a few studies have addressed the southward spreading of RSOW after its formation (Phillips, 1966; Cember 1988; Sofianos and Johns, 2003). Phillips (1966) developed a 2dimention similarity model to study buoyancy-driven circulation in the Red Sea. He pointed out that buoyancy loss over the Red Sea surface drives a shallow overturning circulation which included a northward surface current and a southward subsurface current. The southward flow returns to the Gulf of Aden and is known as RSOW. Based on Carbon-14 and ${ }^{3} \mathrm{He}$ profiles at three stations along the middle axis of the Red Sea, Cember (1988) identified a southwardflowing current in about 100-200 $\mathrm{m}$ depth range. Sofianos and Johns (2003) simulated the formation and spreading of RSOW using the Miami Isopycnic Coordinate Ocean Model (MICOM). They found that RSOW was carried out of the Red Sea by a southward undercurrent after RSOW was formed in the northern Red Sea. These studies of southward spreading of RSOW are based on limited observations or numerical simulations. This study will provide new evidence to explore the southward spreading of the RSOW by analyzing hydrographic data, CFC-12 data and numerical output in the following sections.

\subsection{Observations of the RSOW in the Red Sea}

In the last section, it was shown that the northern Red Sea is preconditioned for open-ocean convection. When convection stops and the surface water starts to restratify, the recently formed RSOW with nearly homogeneous water properties remains trapped below surface and flows southward in a specific density range. The homogeneous layer signifies weak stratification and 
thus relatively low potential vorticity $\left(-\frac{f}{\rho_{0}} \frac{\partial \rho}{\partial z}\right)$. Figure 2.12 shows potential vorticity calculated from density profiles measured in March 2010 cruise. The RSOW is identifiable by a minimum of potential vorticity which is bounded by isopycnals of 27.5 and $27.8 \mathrm{~kg} \mathrm{~m}^{-3}$. Isopycnal of 27.5 $\mathrm{kg} \mathrm{m}^{-3}$ outcrops at transect 1 and 2 where open-ocean convection could have occurred. The distribution of the minimum of potential vorticity layer compares well with the two bounded isopycnals. For example, at transect 7, the two isopycnals rise eastward in the same direction as the minimum of potential vorticity layer. The deeper low PV layer is associated with RSDW. 

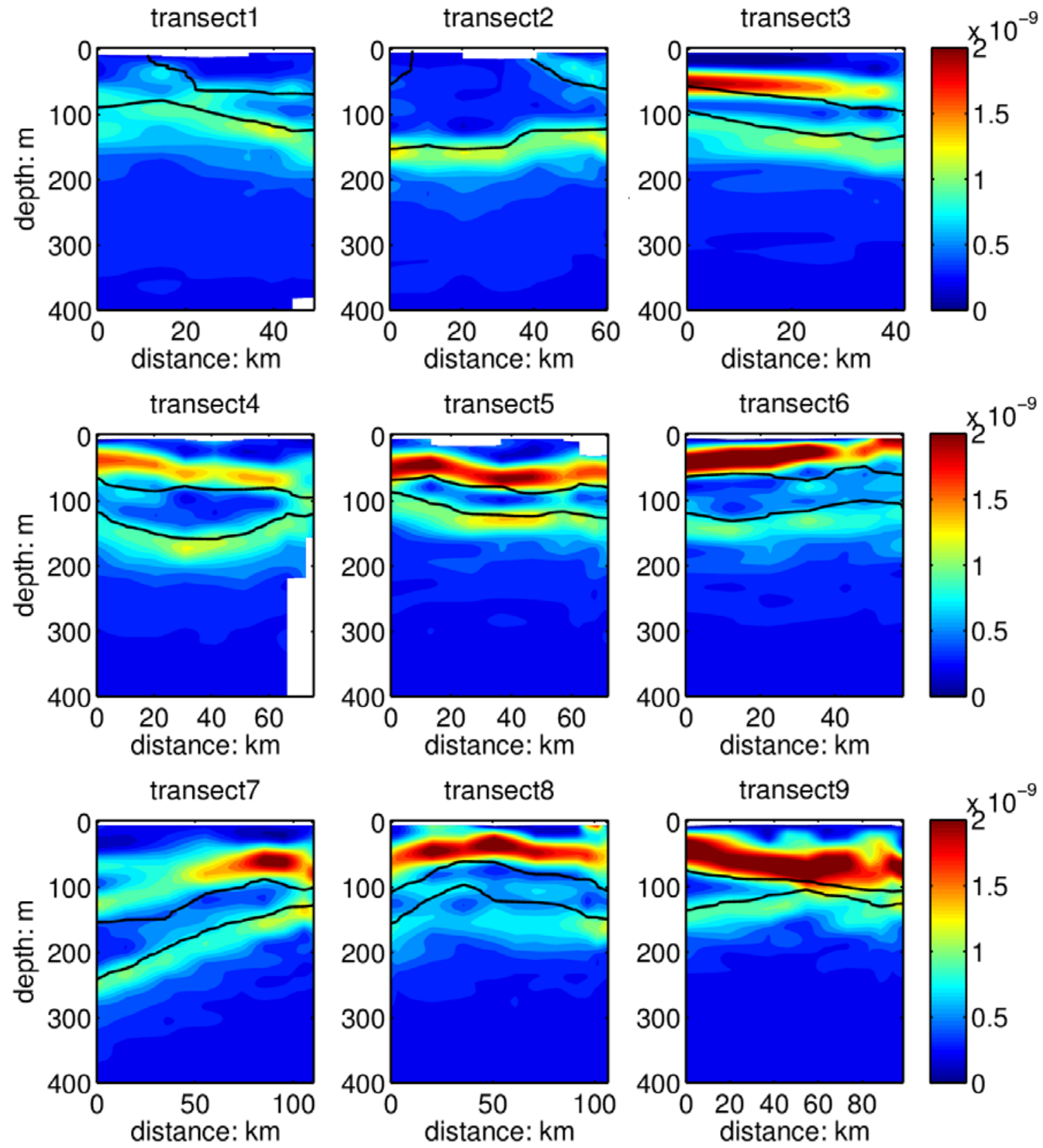

Figure 2.12: Potential vorticity $\left(\mathrm{m}^{-1} \mathrm{~s}^{-1}\right)$ at nine transects during March 2010 cruise (See Figure 2.2 for location). $\mathrm{x}$-axis is distance from the most west station. Isopycnals of 27.5 and 27.8 $\mathrm{kg} \mathrm{m}^{-3}$ are plotted. Distance $(\mathrm{km})$ is from the west side of the transec.

The minimum of potential vorticity layer is also observed in September-October 2011 cruise (Figure 2.13). In addition to potential vorticity, chemically inert tracers, such as CFC-12 can also 
be used to trace and identify water masses. Water samples of CFC-12 were collected at 16 stations during September-October 2011 cruise by using either stoppered bottles or ampoules and then measured by Smethie's lab at Lamont-Doherty Earth Observatory. At three stations, both methods were used to collect CFC-12 water samples. Figure 2.14 plots the vertical profile of CFC-12 at these three stations. Measurements by the two methods generally agree well with each other, with mean difference of $0.004 \mathrm{pmol} \mathrm{kg}^{-1}$. The coefficient of variation of the root mean squared deviation between the two methods is 0.0297 . In Figure 2.14, there is a maximum of CFC-12 layer centered at about $150 \mathrm{~m}$ depth and a minimum of CFC layer centered at about 400 $\mathrm{m}$ depth. This structure is further supported by CFC-12 measurements at other stations (Figure 2.16 and Figure 2.17). The vertical profiles of $\Delta^{14} \mathrm{C}$ plotted by Cember (1988) exhibits the same vertical structure (Figure 2.15) with a maximum of $\Delta^{14} \mathrm{C}$ layer at $100-200 \mathrm{~m}$ depth and a minimum of $\Delta{ }^{14} \mathrm{C}$ layer at $400-600 \mathrm{~m}$. The maximum of CFC-12 layer centered at $150 \mathrm{~m}$ depth is RSOW which is formed in the northern Red Sea by open-ocean convection. CFC-12 concentration continuously decreases from $200 \mathrm{~m}$ to $400 \mathrm{~m}$ depth and then increases till bottom. CFC-12 enters into seawater from atmosphere through the sea surface. According to our observations in March 2010 and September-October 2011 cruises, the convection in the northern Red Sea is not deep enough to replenish CFC-12 at the bottom layer. Therefore, there must be other sources that account for the relatively high CFC-12 concentration near bottom. By analyzing hydrographic and CFC-12 data measured in the Gulf of Aqaba and the northern Red Sea, Plähn et al. (2002) discussed that the sources of the Red Sea Deep Water (RSDW) include outflow water from the Gulf of Aqaba and Gulf of Suez. They suggested that the outflow from the Gulf of Aqaba is dense enough to sink to the bottom of the Red Sea, while the outflow from 
the Gulf of Suez is lighter than that from the Gulf of Aqaba and overlies on top of Gulf of Aqaba water.
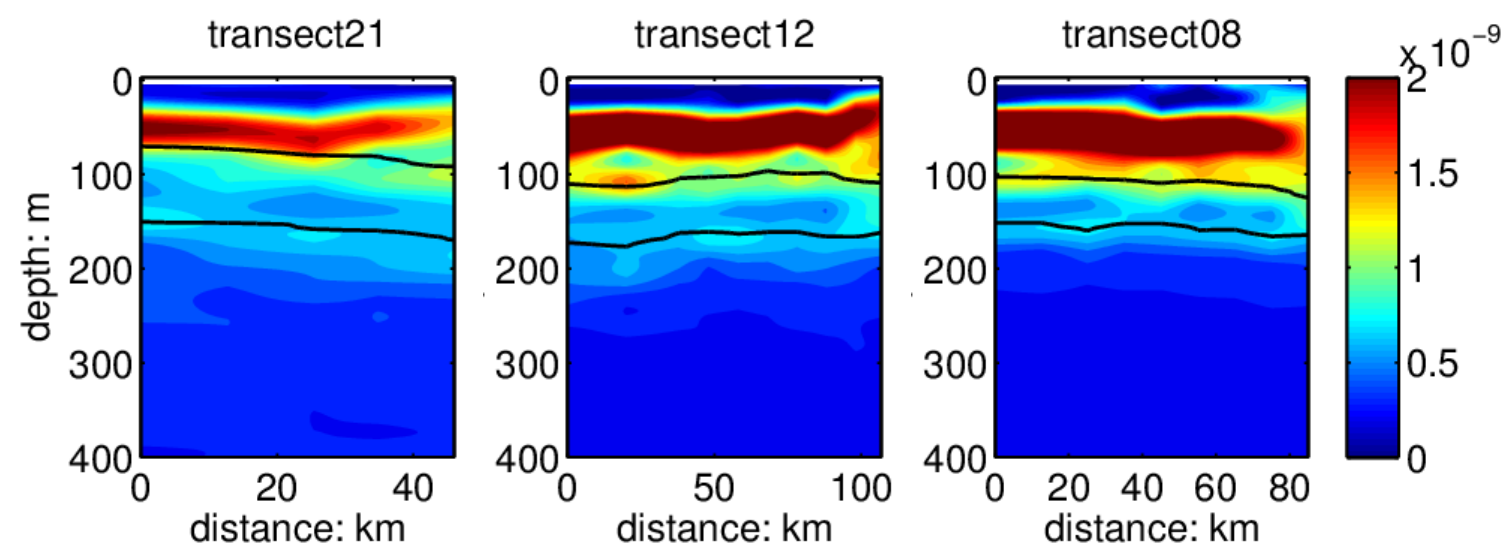

Figure 2.13: Potential vorticity $\left(\mathrm{m}^{-1} \mathrm{~s}^{-1}\right)$ at three selected transects during September-October 2011 cruise (See Figure 2.2 for location). $\mathrm{x}$-axis is distance from the most west station. Isopycnals of 27.5 and $28.1 \mathrm{~kg} \mathrm{~m}^{-3}$ are plotted. 


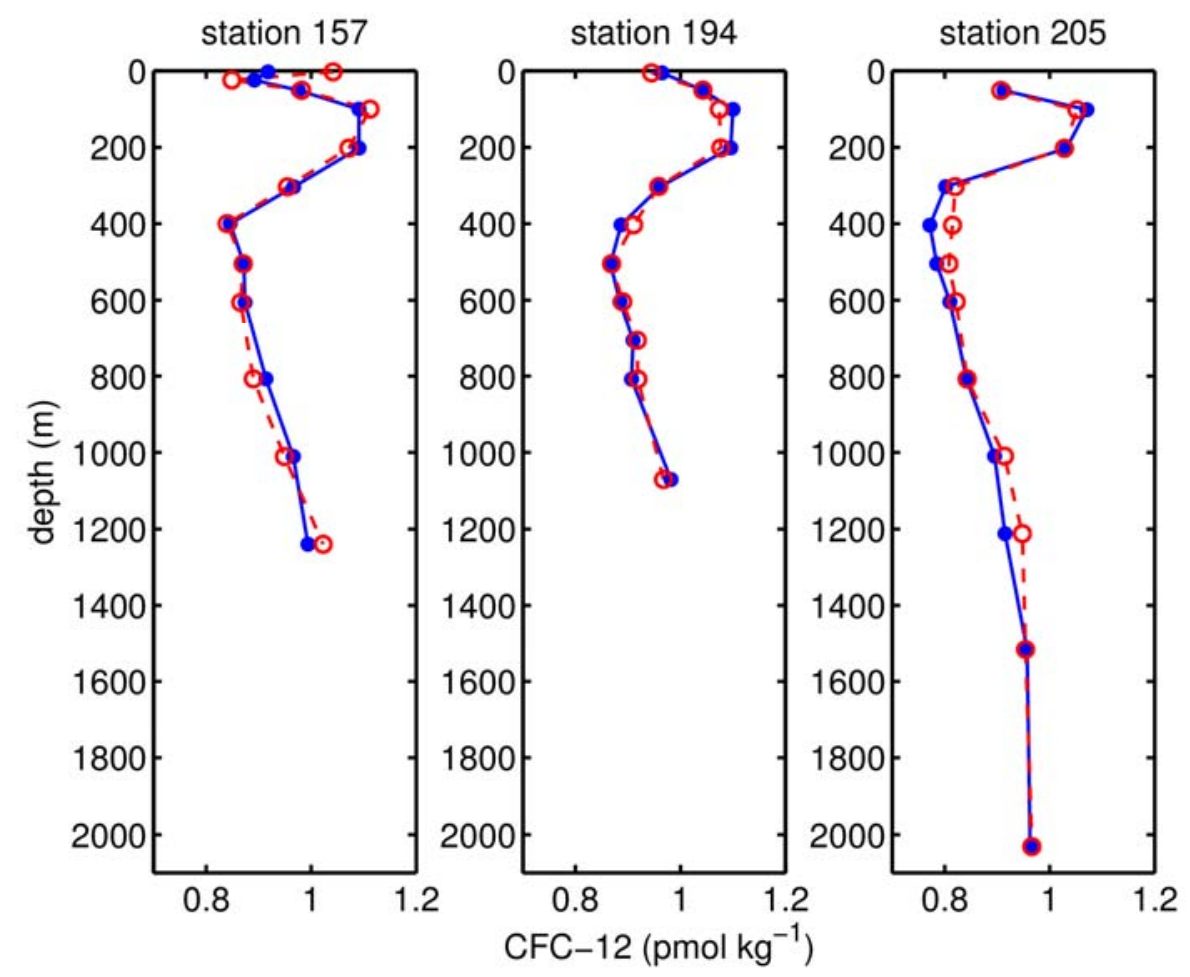

Figure 2.14: Vertical profiles of CFC-12 at three stations. Samples collected using stoppered bottles are plotted with blue-dotted lines, while samples collected using ampoules are plotted with red-circle lines. 


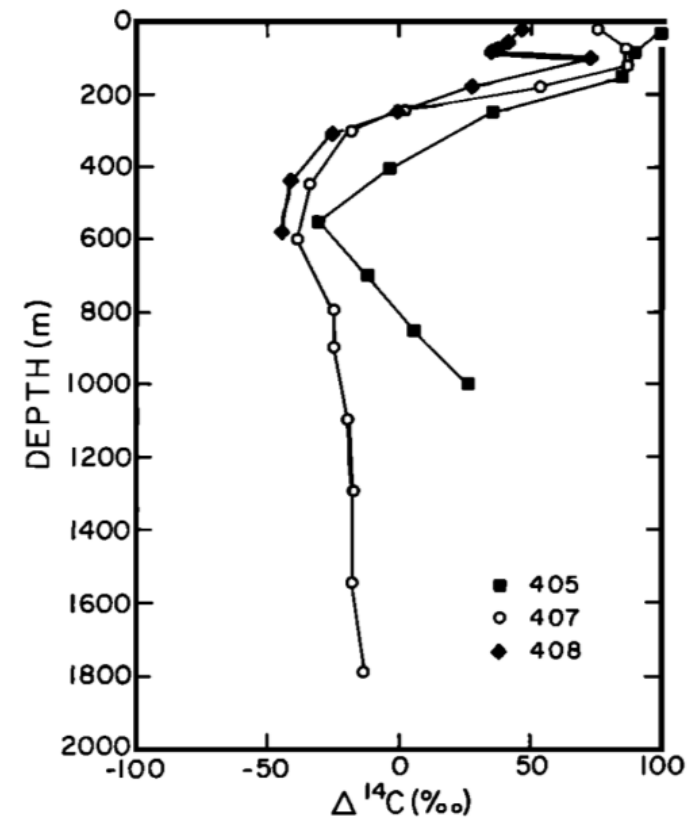

Figure 2.15: Vertical profiles of $\Delta^{14} \mathrm{C}$ from three stations in the Red Sea (Cember 1988, his Fig. $8)$. The station locations of 405,407 and 408 are $\left(34^{\circ} 31^{\prime} \mathrm{E}, 27^{\circ} 16^{\prime} \mathrm{N}\right),\left(38^{\circ} 30^{\prime} \mathrm{E}, 19^{\circ} 56^{\prime} \mathrm{N}\right)$, $\left(42^{\circ} 10^{\prime} \mathrm{E}, 14^{\circ} 43^{\prime} \mathrm{N}\right)$, respectively. 


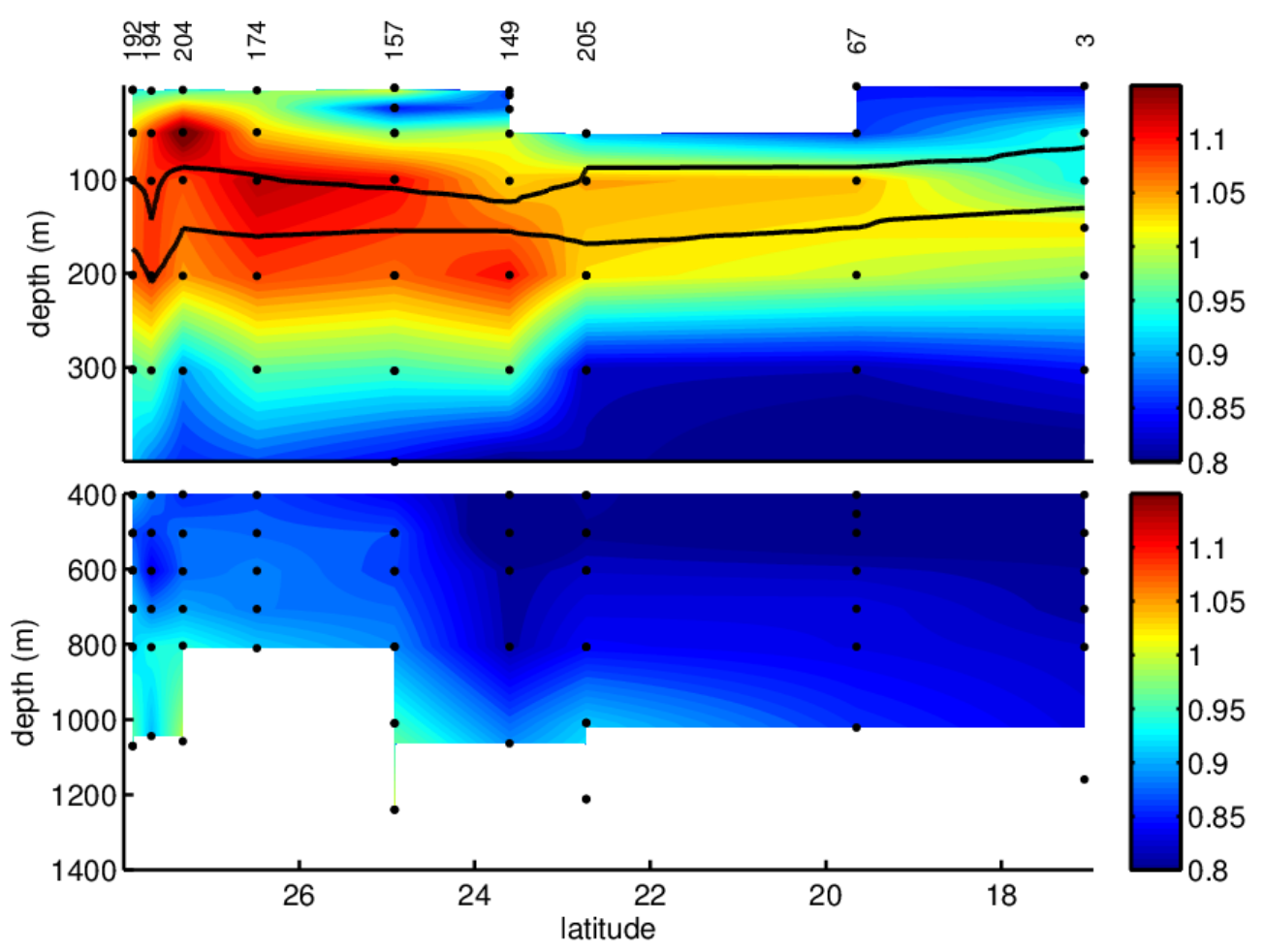

Figure 2.16: CFC-12 concentration ( $\mathrm{pmol} \mathrm{kg}^{-1}$ ) along the middle axis of the Red Sea (See Figure 2.3 for location). Station numbers and depth at which measurements were taken are marked with black dots. Isopycnals of 27.5 and $28.1 \mathrm{~kg} \mathrm{~m}^{-3}$ are plotted. 


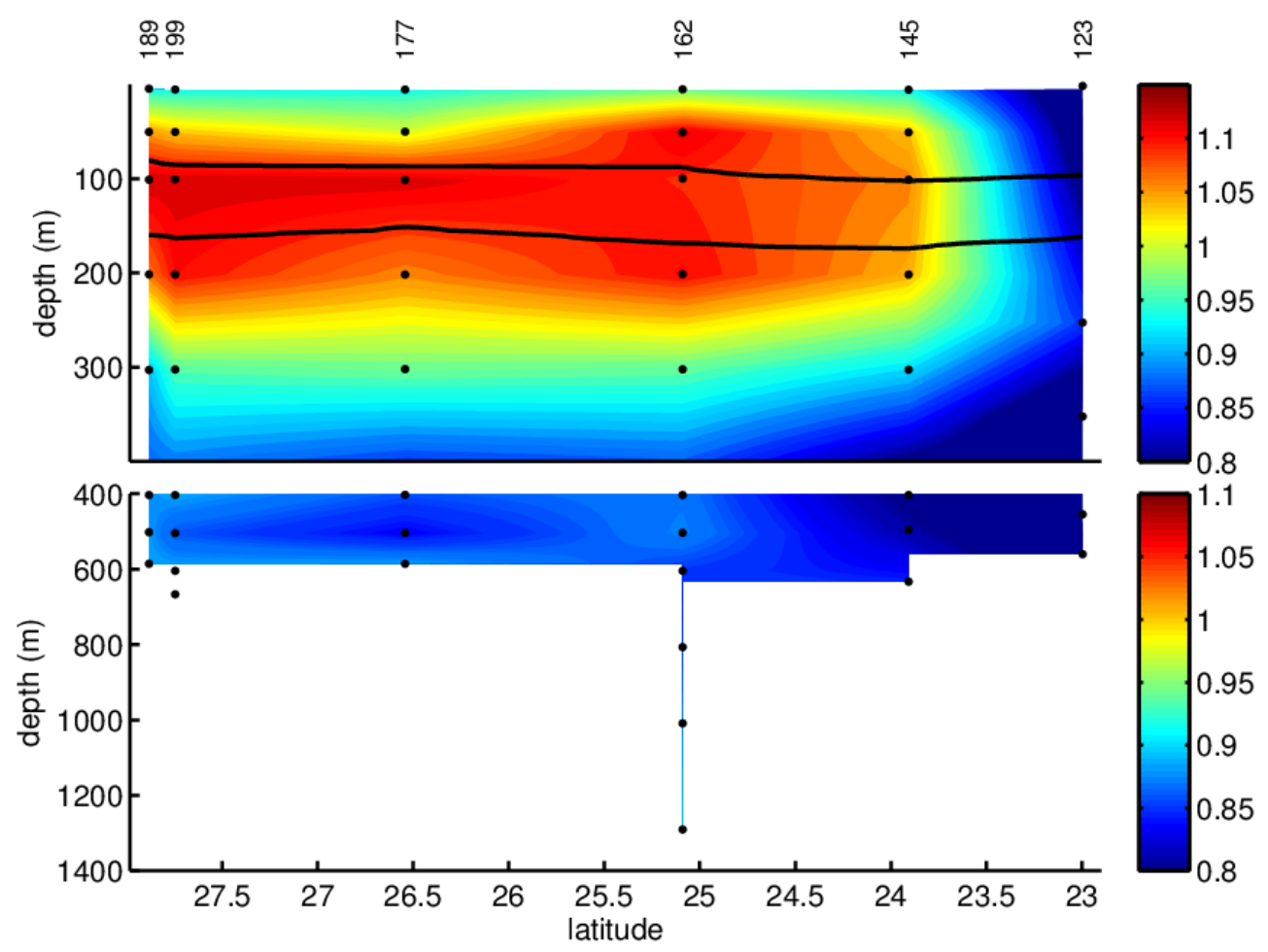

Figure 2.17: The same as Figure 2.16, except that stations are closer to the eastern coast instead of along the middle axis of the Red Sea (See Figure 2.3 for location). Isopycnals of 27.5 and 28.1 $\mathrm{kg} \mathrm{m}^{-3}$ are plotted.

In Figure 2.16 and Figure 2.17, isopycnals of 27.5 and $28.1 \mathrm{~kg} \mathrm{~m}^{-3}$ are plotted. The layer with maximum of $\mathrm{CFC}-12$ resides in this density range, which is the same as the density range of low potential vorticity layer shown in Figure 2.13. The tongue of high CFC-12 centered at $150 \mathrm{~m}$ extends southward from the northern Red Sea. The concentration of CFC-12 decreases in the southward direction. This might be caused by that $\mathrm{CFC}-12$ in the southern part experiences longer time mixing with ambient water, which dilutes the concentration of CFC-12. As will be suggested in Chapter 3, the path of the southward movement of RSOW may be more complex than a simple, along-axis flow. Variation of CFC-12 concentration along the section shown in Figure 2.16 and Figure 2.17 would be influenced by the circulation. Even if the path were primarily along the section shown, the CFC-12concentration could be diminished by lateral 
diffusion. It seems that the layer with high CFC-12 terminates at station 123 (Figure 2.17). This might not represent the real situation, since there is no measurement between surface and $250 \mathrm{~m}$ at station 123. As a result, the maximum of CFC-12 concentration might not be captured in Figure 2.17 at station 123 . The distributions of potential vorticity and CFC-12 provide evidences that the RSOW is formed through open-ocean convection in the northern Red Sea and then spreads southward.

Density ranges of the RSOW chosen from 2010 cruise and 2011 cruise are different (Figure 2.12 and Figure 2.13). The densities of the minimum potential vorticity layer observed in the 2011 cruise are about $0.3 \mathrm{~kg} \mathrm{~m}^{-3}$ higher than that in the 2010 cruise. It implies that the RSOW formed in 2011 is denser than in 2010. The mean winter surface temperature in the northern Red Sea in 2011 is about $0.6^{\circ} \mathrm{C}$ colder than that in 2010 (Figure 2.18). If the relation between density and surface temperature shown in Figure 2.6 holds for winter, then sea surface density in winter 2011 is about $0.37 \mathrm{~kg} \mathrm{~m}^{-3}$ higher than that in winter 2010 . Northwesterly wind in the northern Red Sea brings cold and dry air from land to the Red Sea. Higher wind speed also removes more heat and freshwater from the sea surface. Figure 2.18 shows that the $10-\mathrm{m}$ wind speed in winter (January, February and March) 2011 is $1.5 \mathrm{~m} \mathrm{~s}^{-1}$ higher than in winter 2010. Therefore, stronger winds in winter 2011 could cause more buoyancy loss and thus form denser RSOW. 

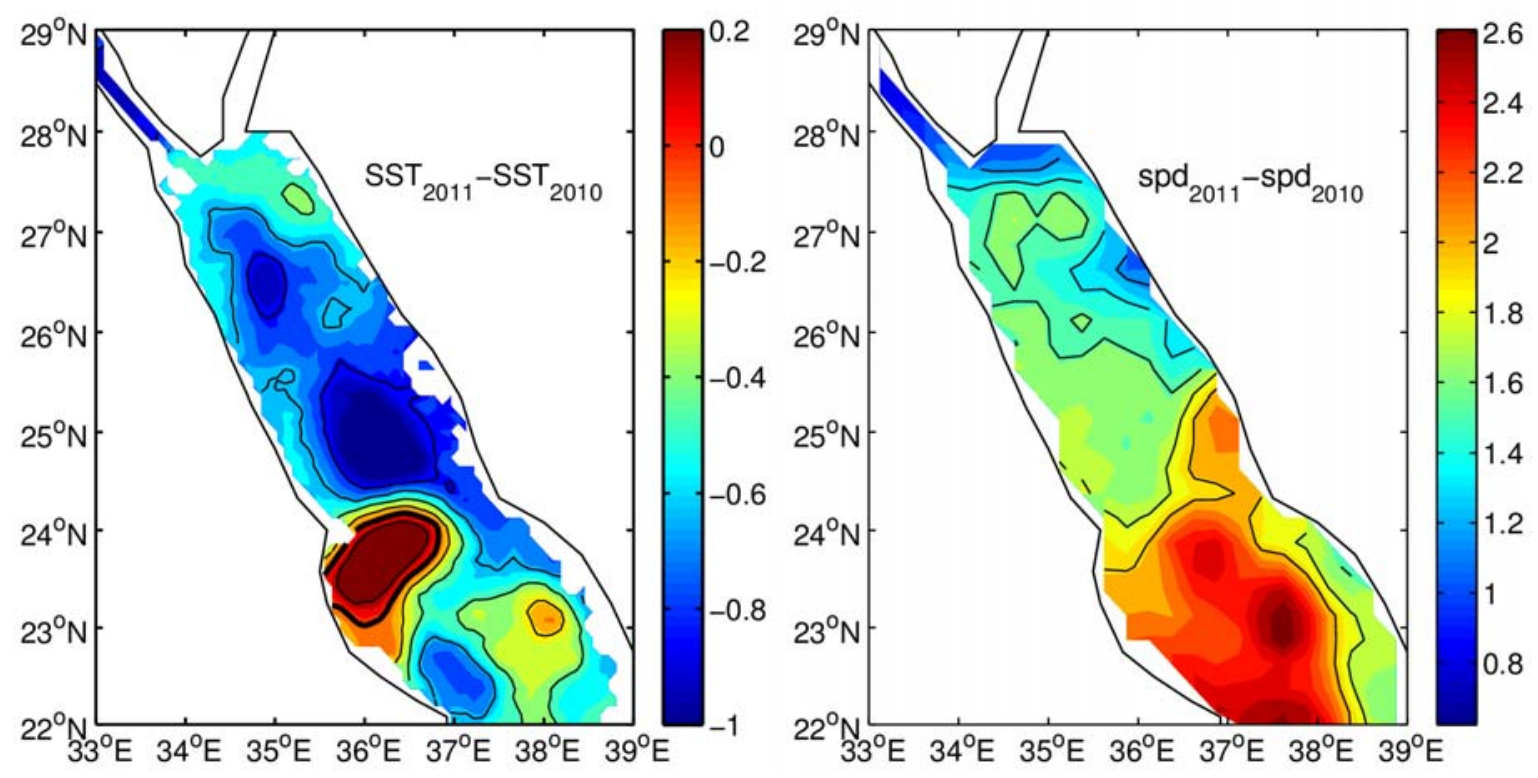

Figure 2.18: SST (left panel, ${ }^{\circ} \mathrm{C}$ ) and wind speed (right panel, $\mathrm{m} / \mathrm{s}$ ) difference between 2011 and 2010 winter (averaged in January, February and March).

Oxygen enters seawater through air-sea interaction as CFC-12. Different from CFC-12, the concentration of oxygen can be influenced by chemical processes and biological activities. Figure 2.19 shows dissolved oxygen concentration at three transects in the March 2010 cruise. However, the relatively higher concentration is not clearly shown at transects 3,5 and 7 . Oxygen is not a conservative tracer. Therefore, dissolved oxygen might not be used as an appropriate tracer to track water masses. Comparison between oxygen and CFC-12 distributions reveals the advantage of CFC-12 as a passive tracer in identifying RSOW. 

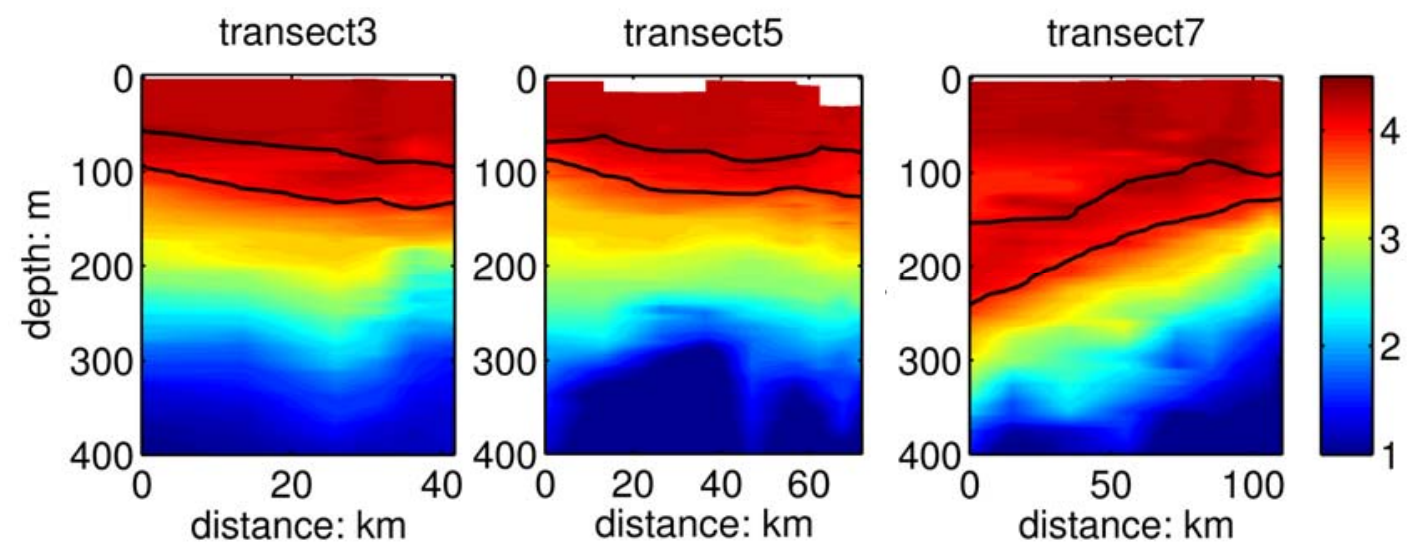

Figure 2.19: Dissolved oxygen $\left(\mathrm{ml} \mathrm{l}^{-1}\right)$ at selected three transects during the 2010 cruise (See Figure 2.2 for location). $\mathrm{x}$-axis is distance from the most west station. Isopycnals of 27.5 and $27.8 \mathrm{~kg} \mathrm{~m}^{-3}$ are plotted.

In summary, the RSOW is identified as a layer with relatively low potential vorticity and higher concentration of CFC-12. In addition, the density range of the RSOW is about $27.5-27.8 \mathrm{~kg} \mathrm{~m}^{-3}$ in 2010 and $27.5-28.1 \mathrm{~kg} \mathrm{~m}^{-3}$ in 2011 . The interannual variability of atmospheric forcing might have caused the density difference of the RSOW formed in 2010 and 2011.

\subsection{Production Rate of RSOW}

By looking at the vertical profiles of $\Delta^{14} \mathrm{C}$, Cember (1988) identified two different modes of water in the Red Sea: the convective mode and the isopycnal mode. The convective mode water with its origin from the Gulf of Suez and Gulf of Aqaba was a source for the Red Sea Deep and Bottom Water. The isopycnal mode water was the RSOW which flowed southward at a depth centered at $100 \mathrm{~m}$. The formation rate of the isopycnal mode water was estimated to be about $0.11 \mathrm{~Sv}$ (Cember, 1988). In Sofianos and Johns's model (2003), production rate of the RSOW formed by open-ocean convection in the northern Red Sea was about 0.25 Sv. Walin (1982) derived a theory for how water masses were transformed from one temperature class to another 
by air-sea heat flux and mixing. In this section, the production rate of the RSOW will be estimated through Walin's method.

Figure 2.20 is a schematic diagram illustrating the basic idea of Walin (1982). The control volume $(R)$ is bounded by the sea surface, bottom, one outcropping isotherm $\left(T_{0}\right)$, and a fixed control surface $(B)$. Here the control surface is essentially vertical and lies at the entrance of the strait that connects the Red Sea and the Gulf of Aden. We will initially allow the position of isotherm $T_{0}$ to vary with time, so that the volume of $R$ can change. Water masses are transformed from one temperature class to another due to sea surface heat losses and interior mixing (eddy diffusivity). The transformation rate $(G)$ of water masses at a particular temperature can be determined from heat and volume conservation for the control volume. In Walin (1982), he started his arguments with the equations of heat and volume conservation over the control volume without a detailed derivation. Hence, it was not clear whether his arguments were valid when the isotherm $T_{0}$ varied with time. In this section, we will derive Walin's method in more detail than what was originally presented in Walin (1982).

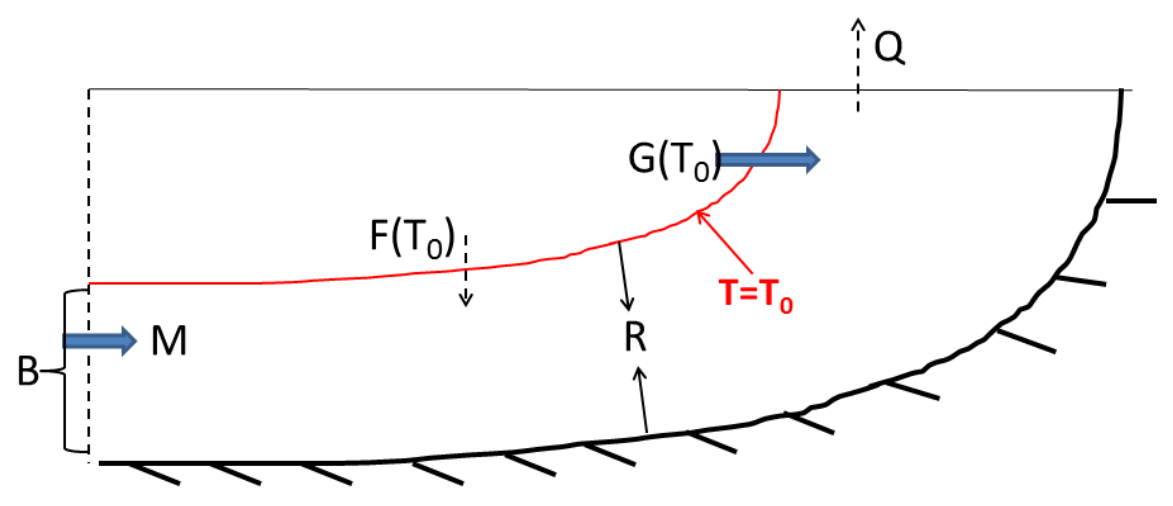

Figure 2.20: A schematic diagram showing the transformation of water across a isotherm by airsea heat fluxes and interior mixing. 
Integrating the continuity equation $\nabla \cdot \boldsymbol{v}=0$ over the control volume and using the divergence theorem, the volume conservation equation can be written as $\iint_{A} \boldsymbol{v} \cdot \boldsymbol{n} d A=0$, where $A$ is the surface of the control volume, $\boldsymbol{v}$ is velocity vector, $\boldsymbol{n}$ is the unit vector normal to the control surface. The surface consists of four parts, sea surface, bottom, isotherm $T=T_{0}$ and a fixed control surface $B$. Assuming that there is a rigid-lid sea surface and no volume flux across the sea surface and bottom, the velocity at isotherm $T=T_{0}$ can be decomposed into the net velocity through the isotherm $\boldsymbol{v}_{\boldsymbol{G}}$ and the velocity of the isotherm $\boldsymbol{v}_{\boldsymbol{A}}$. Therefore, $\iint_{T=T_{0}} \boldsymbol{v} \cdot \boldsymbol{n} d A=\iint_{T=T_{0}} \boldsymbol{v}_{\boldsymbol{G}} \cdot \boldsymbol{n} d A+\iint_{T=T_{0}} \boldsymbol{v}_{\boldsymbol{A}} \cdot \boldsymbol{n} d A$. The change of the volume of $R$ is caused by the moving of isotherm $T=T_{0}$. Therefore,

$$
\frac{\partial V}{\partial t}=\iint_{T=T_{\theta}} \boldsymbol{v}_{A} \cdot \boldsymbol{n} d A
$$

The net diathermal volume flux is defined as $G=-\iint_{T=T_{0}} \boldsymbol{v}_{\boldsymbol{G}} \cdot \boldsymbol{n} d A$, and the volume flux through $B$ is $M=-\int_{-H}^{z\left(\mathrm{~T}_{0}\right)} v d z$. Here $G$ and $M$ are defined positive when directed into the control volume. Therefore, the volume budget of $R$ is given by:

$$
\frac{\partial V}{\partial t}=G+M
$$

where $V$ is the volume of $R, G$ is the net volume flux across isotherm surface and $M$ is the volume flux across control surface $B$. 
The temperature equation is $\frac{\partial T}{\partial t}+\nabla \cdot(v T)=\kappa \frac{\partial^{2} T}{\partial z^{2}}$, in which horizontal diffusivity is neglected. By integrating the temperature equation over the control volume and using the divergence theorem, the advection part can be written as

$$
\iiint_{R} \nabla \cdot(\boldsymbol{v} T) d V=\iint_{B} \boldsymbol{v} T \cdot \boldsymbol{n} d A+\iint_{T=T_{0}}\left(\boldsymbol{v}_{\boldsymbol{G}}+\boldsymbol{v}_{A}\right) T \cdot \boldsymbol{n} d A
$$

Using definition in Eq. (2.1), temperature flux across the isotherm $T=T_{0}$ can be modified as

$$
\iint_{T=T_{0}}\left(\boldsymbol{v}_{\boldsymbol{G}}+\boldsymbol{v}_{A}\right) T \cdot \boldsymbol{n} d A=T_{0} \frac{\partial V}{\partial t}-T_{0} G,
$$

and temperature flux across the fixed control surface $B$ is

$$
\iint_{B} T v \cdot n d A=-\int_{B} T d M
$$

where $d M=-v d z$.

The volume integral of the temporal change of temperature can be written as

$$
\iiint_{R} \frac{\partial}{\partial t} T d V=\frac{\partial}{\partial t} \iiint_{R} T d V-\iiint_{R} T \frac{\partial}{\partial t} d V
$$

The temporal change of volume is due to the moving of the isotherm $T=T_{0}$, therefore,

$$
\iiint_{R} T \frac{\partial}{\partial t} d V=T_{0} \int_{T=T_{0}} \frac{\partial}{\partial t} d V=T_{0} \frac{\partial V}{\partial t}
$$


The integral of the vertical diffusion term is

$$
\iiint_{R} \kappa \frac{\partial^{2} T}{\partial z^{2}}=\left.\int_{A_{S}} \kappa \frac{\partial T}{\partial z}\right|_{z=0} d A+\int_{T=T_{0}} \kappa \frac{\partial T}{\partial z} d A
$$

where $\left.\quad c \int_{A_{S}} \kappa \frac{\partial T}{\partial z}\right|_{z=0} d A=Q$ is the surface heat flux and $c=4.2 \times 10^{6} \mathrm{~W} \mathrm{~s}^{\circ} \mathrm{C}^{-1} \mathrm{~m}^{-3}$ is heat capacity per unit volume.

Combining Eq. (2.5)-Eq. (2.8), the integral of the temperature equation (heat budget) can be written as

$$
c \frac{\partial}{\partial t} \iiint_{R} T d V=Q+c G T_{0}+F+c \int_{B} T d M
$$

where $F=c \int_{T=T_{0}} \kappa \frac{\partial T}{\partial z} d A$ is diffusive heat flux through the isotherm $T=T_{0}$.

$T_{0}$ is not specifically chosen in the derivations above, so Eq. (2.9) is valid for any T. The heat budget equation of $R$ can also be written in temperature space as:

$$
c \frac{\partial}{\partial t} \int_{R} v T d T=Q+c G T+F+c \int_{B} T m d T
$$

where $v=\frac{\partial V}{\partial T}$ and $m=\frac{\partial M}{\partial T}$.

Taking partial derivative with respect to $T$ of Eqs (2.2) and (2.10), we obtain:

$$
\frac{\partial v}{\partial t}=m+\frac{\partial G}{\partial T}
$$




$$
c T \frac{\partial v}{\partial t}=c m T+c T \frac{\partial G}{\partial T}+c G+\frac{\partial F}{\partial T}+\frac{\partial Q}{\partial T} .
$$

Multiplying Eq. (2.11) with $c T$ and subtracting from Eq. (2.12), the transformation rate can be obtained by

$$
c G=-\frac{\partial Q}{\partial T}-\frac{\partial F}{\partial T}
$$

Eq. (2.13) shows that the transformation rate can be determined by two processes: the one due to surface heat loss $-\frac{\partial Q}{\partial T}$ and the other one due to diffusion $-\frac{\partial F}{\partial T}$. By neglecting the diffusive part, Walin (1982) estimated the surface North Atlantic poleward transport to be about $10 \mathrm{~Sv}$. In this calculation, the diffusive part $-\frac{\partial F}{\partial T}$ in Eq. (2.13) is also neglected. If we choose two isotherm surfaces $T=T_{1}$ and $T=T_{2}$ as two boundaries of $R$, transformation rate $G\left(T_{1}\right)$ and $G\left(T_{2}\right)$ induced by surface heat flux can be estimated through the first term on the right-hand side of Eq. (2.13). If the upper and lower temperature limits of the RSOW are chosen as two isotherm surfaces, in a steady state, the production rate of RSOW $(M)$ can be estimated through the transformation rate difference between $G\left(T_{1}\right)$ and $G\left(T_{2}\right)$ according to Eq. (2.2). The transformation rate due to surface heat loss obtained through Eq. (2.13) is plotted in Figure 2.21. Here, the surface heat loss used in Eq. (2.13) is from OAflux (Yu et al., 2008) and is averaged in four months from December to March. SST is from MW-IR and is averaged in the same months. Sea surface density can be estimated through the linear relation between SST and density based on observations during March 2010 cruise. The $27.5 \mathrm{~kg} \mathrm{~m}^{-3}$ isopycal outcrops from December to March. Therefore, it is assumed that open-ocean convection occurs from December to March, 
during which the RSOW is formed. The resolution of OAflux product is 1 degree which is very coarse for the Red Sea. Therefore, only limited results of transformation rates are obtained. Figure 2.21 shows that transformation rates are 2.7 and $0.8 \mathrm{~Sv}$ for $\mathrm{T}=23.2^{\circ} \mathrm{C} \mathrm{T}=23.4^{\circ} \mathrm{C}$, respectively. If we choose 23.4 and $23.2^{\circ} \mathrm{C}$ as $T_{1}$ and $T_{2}$, the annual mean production rate of the RSOW due to surface heat loss is $(2.7-0.8) \times 4 / 12=0.63 \mathrm{~Sv}$. This value is larger than the 0.36 Sv annual mean transport measured at the Strait of Bab el Mandeb during the time period of June 1995 and November 1996 (Murray and Johns, 1997; Sofianos et al., 2002). The discrepancy implies that the diffusive part in Eq. (2.13) might play an important role in regulating the transformation rate. In addition, other sources of uncertainty, such as accuracy of OAflux product and lack of information of sea surface salinity and evaporation, could also contribute to the discrepancy.

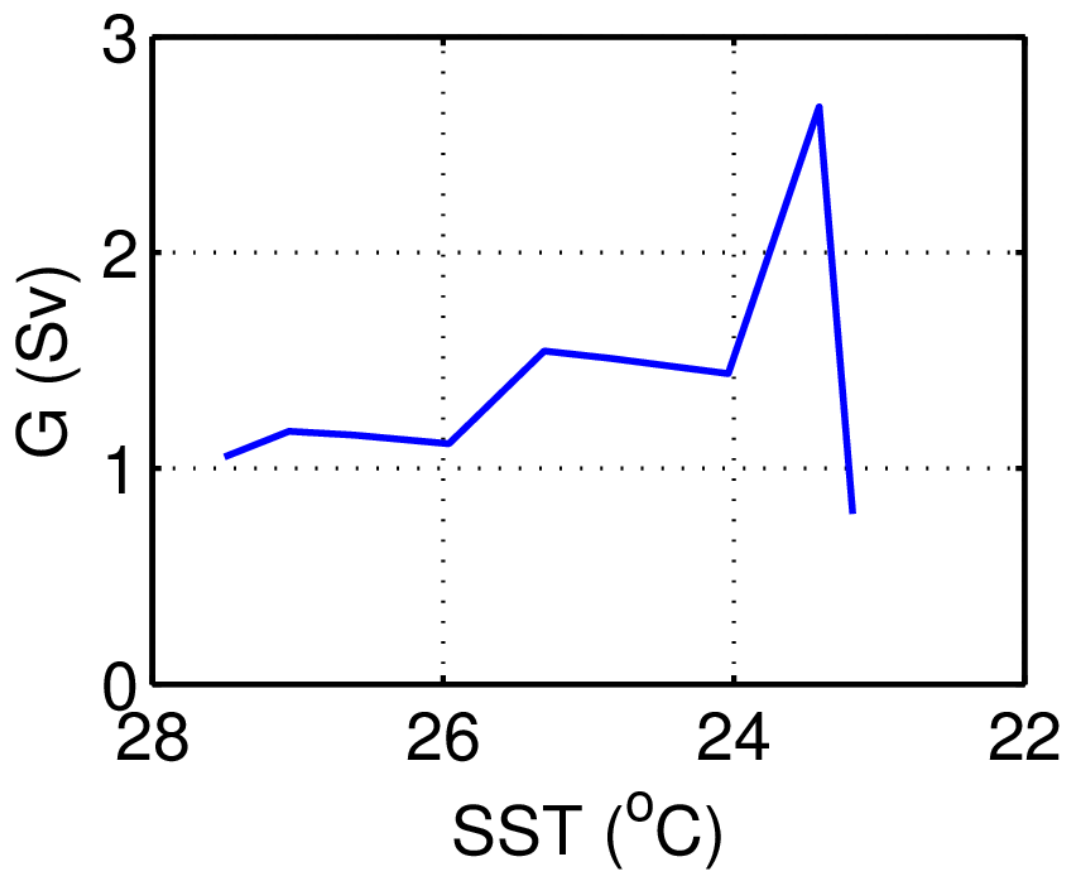

Figure 2.21: Transformation rate due to surface heat losses. 
The diffusive flux can be approximated as:

$$
F=c \kappa \frac{\partial T}{\partial z} S
$$

where $S$ is the area of isotherm surface, and the outcropping area is excluded since the vertical stratification is very weak in that region. According to Eq. (2.13), the production rate of water in the temperature range of $T_{1}$ and $T_{2}$ are:

$$
G\left(T_{1}\right)-G\left(T_{2}\right)=\left(-\frac{\partial Q\left(T_{1}\right)}{\partial T}-\left[-\frac{\partial Q\left(T_{2}\right)}{\partial T}\right]-\frac{\partial F\left(T_{1}\right)}{\partial T}-\left[-\frac{\partial F\left(T_{2}\right)}{\partial T}\right]\right) / c .
$$

Combining Eqs (2.14) and (2.15), the vertical diffusivity can be estimated by

$$
\kappa=\left[-\frac{1}{c} \frac{\partial Q\left(T_{1}\right)}{\partial T}-\frac{1}{c}\left(-\frac{\partial Q\left(T_{2}\right)}{\partial T}\right)-\left(G_{1}-G_{2}\right)\right] /\left[S\left(\left.\frac{\partial}{\partial T} \frac{\partial T}{\partial z}\right|_{T_{1}}-\left.\frac{\partial}{\partial T} \frac{\partial T}{\partial z}\right|_{T_{2}}\right)\right]
$$

Isotherms outcrop in winter in the northern Red Sea, and thus stratification there is weak. Therefore, the temperature profiles south of $26^{\circ} \mathrm{N}$ from March 2010 cruise are averaged to calculate $\frac{\partial}{\partial T} \frac{\partial T}{z}$ in Eq. (2.16). The mean vertical profiles of temperature, stratification and $\frac{\partial}{\partial T} \frac{\partial T}{z}$ are plotted in Figure 2.22. The average width of the Red Sea is about $280 \mathrm{~km}$. The length of the Red Sea south of $26^{\circ} \mathrm{N}$ is about $1500 \mathrm{~km}$. According to $\mathrm{Eq}(2.16)$, the vertical diffusivity is estimated to be $\kappa=\left(0.63 \times 10^{6}-0.36 \times 10^{6}\right) /(280000 \times 1500000) /[0.0064-(-0.0127)]=3.4 \times 10^{-5}$ $\mathrm{m}^{2} \mathrm{~s}^{-1}$. The value is comparable to estimations in other studies. The tracer release experiment in the Antarctic Circumpolar Current indicated that the diapycnal diffusivity was about 
$(1.3 \pm 0.2) \times 10^{-5} \mathrm{~m}^{2} \mathrm{~s}^{-1}$ near $1500-\mathrm{m}$ depth (Ledwell et al., 2011). Based on fine-scale parameterization methods, Kunze et al., (2006) found that the vertical diffusivity ranged from $0.3 \times 10^{-5} \mathrm{~m}^{2} \mathrm{~s}^{-1}$ to $7 \times 10^{-5} \mathrm{~m}^{2} \mathrm{~s}^{-1}$, as functions of latitude and depth. Vertical eddy diffusivity might be much larger than $3.4 \times 10^{-5} \mathrm{~m}^{2} \mathrm{~s}^{-1}$ in convective region in the Northern Red Sea due to vigorous vertical mixing. However, the vertical eddy diffusivity estimated using Walin's method is the average value in the RSOW layer in the entire Red Sea, which reflects the diffusivity in most part of the RSOW layer.

In Walin's paper, the transformation rate is calculated using the surface heat flux and SST. Tziperman (1986) extended this method by including sea surface freshwater flux and salinity as well as sea surface heat flux and temperature in the calculation. If sea surface salinity was available in the Red Sea, vertical eddy diffusivity of salinity could be estimated.
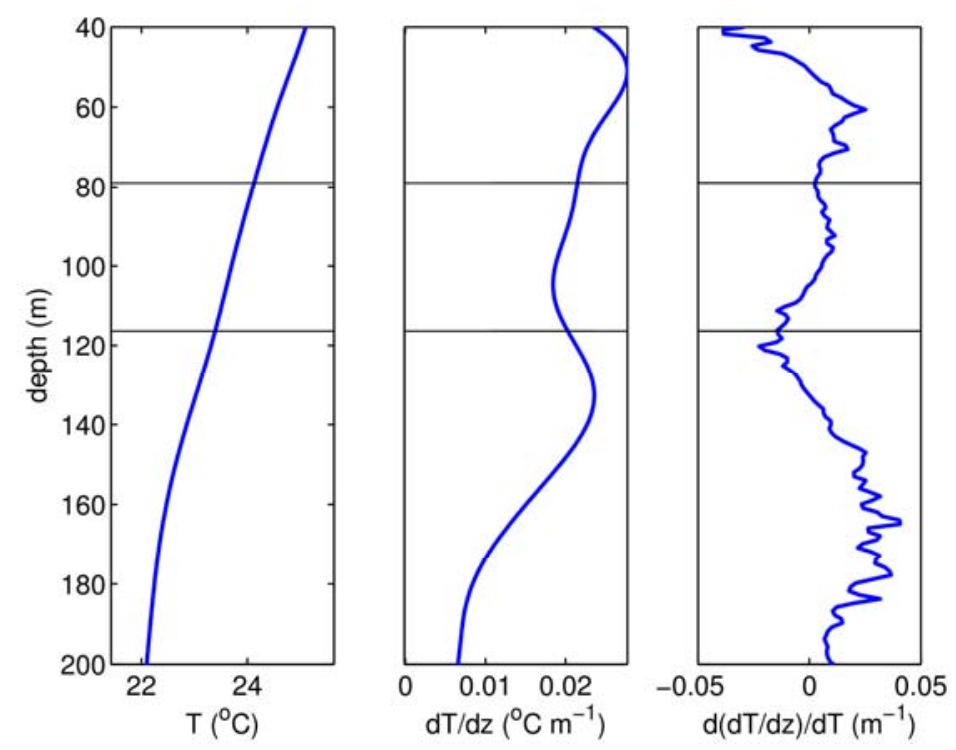

Figure 2.22: Vertical profiles of temperature, stratification and $\frac{\partial}{\partial T} \frac{\partial T}{z}$ in Eq. (2.16). 


\subsection{The Spreading of the RSOW in Numerical Simulations}

Since observations are limited in the Red Sea, numerical modeling is introduced to study the pathway and transit time of the RSOW from its formation region to the strait.

The Massachusetts Institute of Technology General Circulation Model (MITgcm) (Marshall et al., 1997) is used to simulate the buoyancy-driven circulation in the idealized Red Sea and the trajectories of numerical particles. The model solves the nonhydrostatic momentum and density equations on a Cartesian, staggered Arakawa $\mathrm{C}$ grid. The model domain includes the idealized Red Sea, Strait of Bab el Mandeb and Gulf of Aden (Figure 2.23). The bottom topography is illustrated in Figure 2.23. The idealized Red Sea is a rectangular basin with width of $300 \mathrm{~km}$ and length of $1600 \mathrm{~km}$. The Gulf of Aden is $600 \mathrm{~km}$ wide and $250 \mathrm{~km}$ long. In the Red Sea and the Gulf of Aden, bottom depth increases from $0 \mathrm{~m}$ on boundary to $1000 \mathrm{~m}$ at a horizontal distance of $80 \mathrm{~km}$. The Strait of Bab el Mandeb is $100 \mathrm{~km}$ wide and $150 \mathrm{~km}$ long, with a sill depth of 200 $\mathrm{m}$. The horizontal grid spacing is $5 \mathrm{~km}$ and there are 29 vertical levels, with thickness varying from $10 \mathrm{~m}$ at surface to $100 \mathrm{~m}$ at the bottom. The variation of Coriolis parameter with latitude is

approximated by $f=f_{0}+\beta y$ with $f_{0}=3.5 \times 10^{-5} \mathrm{~s}^{-1}$ and $\beta=2.1 \times 10^{-11} \mathrm{~m}^{-1} \mathrm{~s}^{-1}$, which is typical of the Red Sea. 


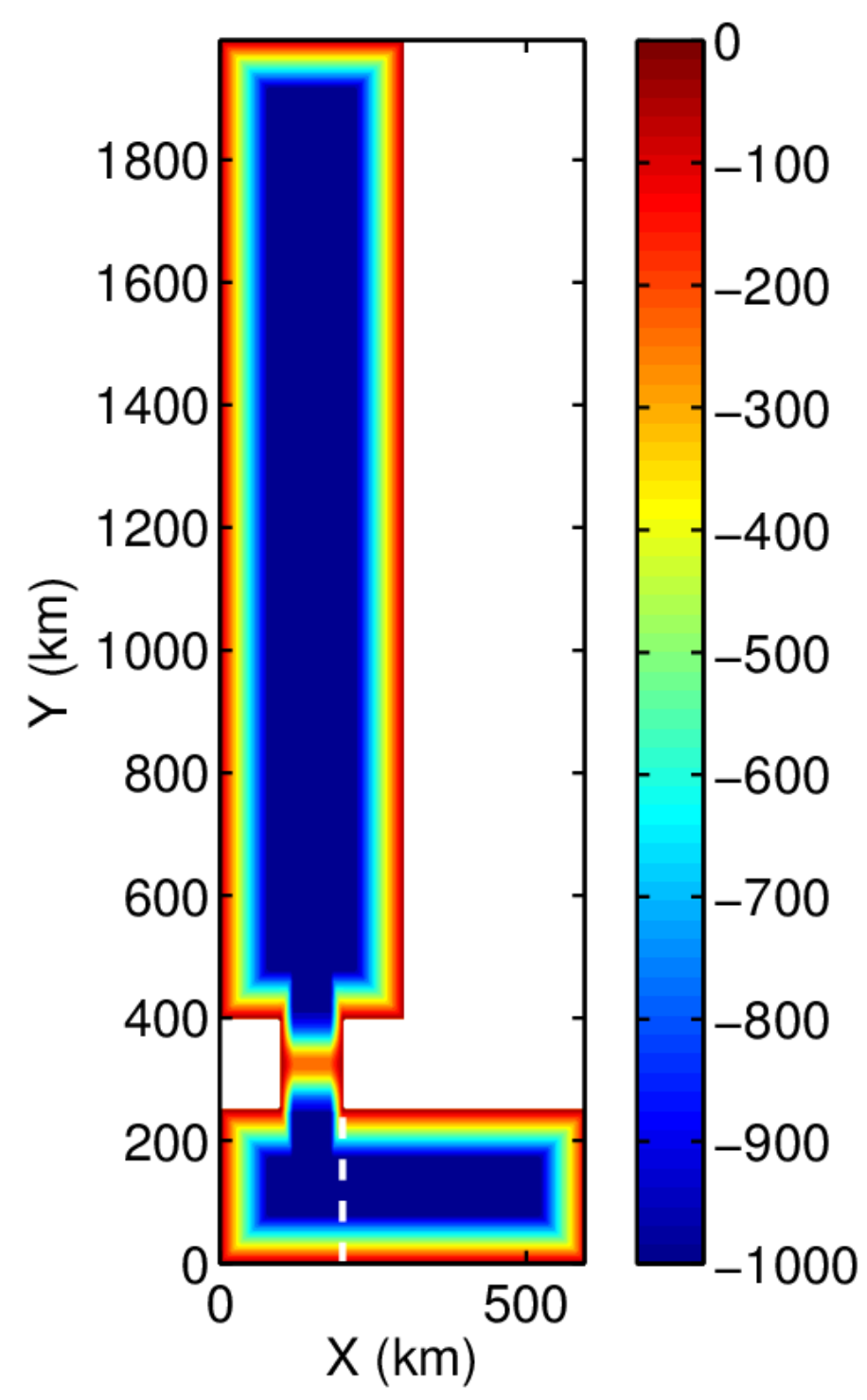

Figure 2.23: Model domain with bottom topography (colors, unit in $\mathrm{m}$ ). Temperature and salinity are restored to the initial profiles in the region east of the dashed white line.

The model is forced by climatological monthly mean surface heat $(Q)$ and freshwater $(E)$ fluxes in the Red Sea (Figure 2.24). Monthly mean OAflux data from 1984 to 2009 is used to generate the climatological monthly mean sea surface fluxes. The data is adjusted so that the annual mean heat flux and evaporation rate are $-10 \mathrm{~W} \mathrm{~m}^{-2}$ and $2 \mathrm{~m} \mathrm{yr}^{-2}$, in order to be consistent with previous estimates (Sofianos et al., 2002). The zonally averaged 1-degree OAflux product 
in the Red Sea is linearly interpolated into the meridional grids in the model. The sea surface fluxes are zonally uniform in the model. The fluxes of heat and freshwater used to force the idealized model are plotted in Figure 2.24. The sea surface loses heat into the atmosphere in winter and absorbs heat from the atmosphere in summer. The freshwater flux is positive all year round. It is indicated that in winter evaporation and heat loss in the northern Red Sea are stronger than in the southern Red Sea. The strongest evaporation and heat loss is located at about 1800 $\mathrm{km}$. We use a linear equation of state, such that $\rho=\rho_{0}\left[1+\alpha_{T}\left(T-T_{0}\right)+\beta_{S}\left(S-S_{0}\right)\right]$, where $\rho_{0}$, $T_{0}$ and $S_{0}$ are reference density, temperature and salinity respectively, and $\alpha_{T}=2 \times 10^{-4}{ }^{\circ} \mathrm{C}^{-1}$ and $\beta_{S}=8 \times 10^{-4}$ are thermal expansion and haline contraction coefficients. The surface buoyancy flux calculated from $Q$ and $E$ is $B_{0}=-\alpha_{T} Q / c_{w}+\rho_{0} \beta_{S} S_{0} E$, where $c_{w}=3900 \mathrm{~J} \mathrm{~kg}^{-1}{ }^{\circ} \mathrm{C}^{-1}$ is the heat capacity of water. In this model, surface freshwater flux acts to change the salinity of sea water, but not the volume of water. 

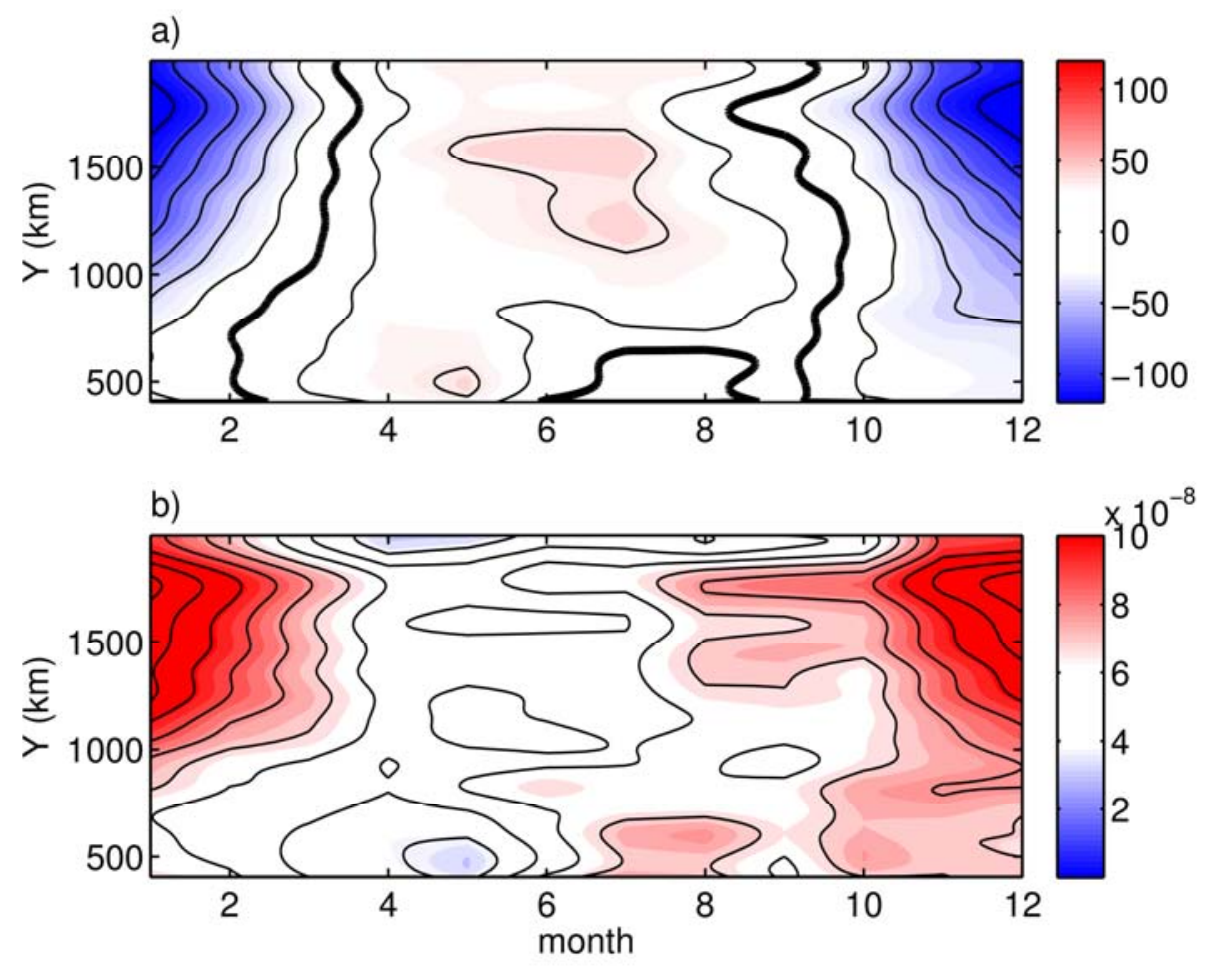

Figure 2.24: Climatological monthly mean sea surface fluxes used to drive the circulation in the idealized Red Sea: (a) heat flux (contour interval is $20 \mathrm{~W} \mathrm{~m}^{-2}$ ), zero contour is marked with thick black lines; and (b) evaporation rate (contour interval is $1 \times 10^{-8} \mathrm{~m} \mathrm{~s}^{-1}$ ). The sea surface fluxes are zonally uniform in the model.

The initial conditions for temperature and salinity are based on the average profiles of temperature and salinity measured from the March 2010 and September-October 2011 Red Sea cruises. The temperature and salinity in the eastern part of the Gulf of Aden (Figure 2.23) is relaxed to the initial profiles with a relaxation time scale of 60 days. The relaxation of temperature and salinity in the Gulf of Aden can provide buoyancy to balance the surface buoyancy losses in the Red Sea.

Second order viscosity and diffusivity are used to parameterize subgrid-scale processes. The vertical viscosity and diffusivity for temperature and salinity are $10^{-5} \mathrm{~m}^{2} \mathrm{~s}^{-1}$. The vertical diffusivity is increased to $1000 \mathrm{~m}^{2} \mathrm{~s}^{-1}$ to parameterize convection when the water column is 
statically unstable. There is no explicit horizontal diffusivity of temperature and salinity in the model. The Smagorinsky viscosity is used to determine the horizontal viscosity $A_{h}=\left(v_{S} / \pi\right)^{2} L^{2} \sqrt{\left(u_{x}-v_{y}\right)^{2}+\left(u_{y}+v_{x}\right)^{2}}$, where $L$ is the spacing grid scale, $u$ and $v$ are horizontal velocities and subscripts represent partial derivatives. The coefficient $v_{S}$ is suggested to be from 2.2 to 4 for oceanic problems (Griffies and Hallberg, 2000). $v_{S}=2.5$ is chosen in our model. No-slip boundary conditions are applied at bottom and lateral boundaries. The model was run for 25 years with climatological monthly mean surface heat flux and evaporation and reached a quasi-steady state. The horizontal velocity fields averaged over the final 5 years at three levels are plotted in Figure 2.25. It is clearly shown in Figure 2.25 that the dominant flow is northward at $15 \mathrm{~m}$ depth and southward at $188 \mathrm{~m}$ depth. 

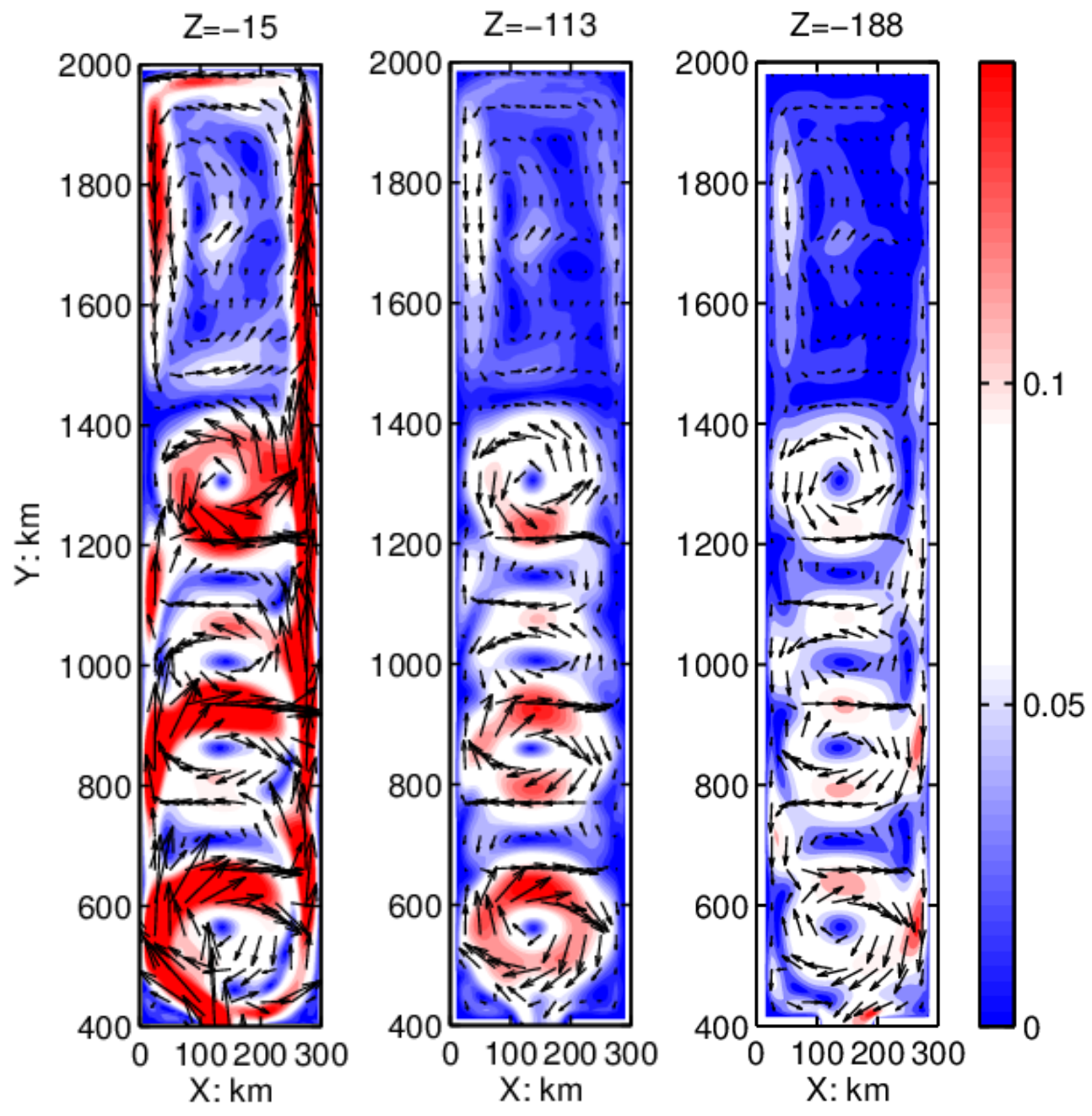

Figure 2.25: Five year mean horizontal velocity fields at depth of 15,113 and $188 \mathrm{~m}$ below the surface.

In order to investigate the pathway of RSOW, backward trajectories of particles that enter into the strait from the Red Sea are calculated, using 2 years of 3-dimensional velocity fields from the numerical model as input. The time interval of velocity fields is 5 days. The time step in the trajectory calculation is 3 hour. The 5-day velocity fields are linearly interpolated into 3-hour time scale in the calculation. The particles are released every 5 days for two years at the strait and the trajectories are integrated over 6 years. $20 \times 15 \times 144=43200$ particles are released, 
where 20 represents number of zonal grids at the strait, 15 represents number of vertical levels at the strait and 144 represents the total number of particles at each grid point that are released in two years. Since the backward trajectories are integrated over 6 years, the two-year velocity fields are recycled three times. This approach is similar to van Sebille et al. (2013) in which the pathways of the Antarctic Bottom Water were diagnosed.

Using the backward trajectories of particles, the probability map of RSOW particles is produced (Figure 2.26). The probability can be interpreted as the chance that a particle will visit that grid point within 6 years. Thus the probability map is a different expression of pathways. The probability shown in Figure 2.26 is the sum of probability in the upper $200 \mathrm{~m}$. From the probability map, it is indicated that in the southern Red Sea, instead of moving along the boundary current, the RSOW particles recirculate in the southern Red Sea before they enter the strait. In the northern Red Sea, the probability is higher along the western boundary than along the eastern boundary. Therefore, most of the particles flow southward along the western boundary in the northern Red Sea on their way to the strait. The different horizontal structures of the probability map in the southern and northern Red Sea can be explained by the horizontal velocity fields plotted in Figure 2.25. The velocity fields in the northern Red Sea are much simpler than that in the southern Red Sea. North of $1400 \mathrm{~km}$, there is a strong western boundary current penetrating to $188 \mathrm{~m}$ depth. Circulation in the southern Red Sea consists of a series of basin-scale eddies. Therefore, the probability in the southern Red Sea is nearly homogeneous due to eddies. The reason why the circulation in the southern Red Sea is more complex will be investigated in chapter 4. 


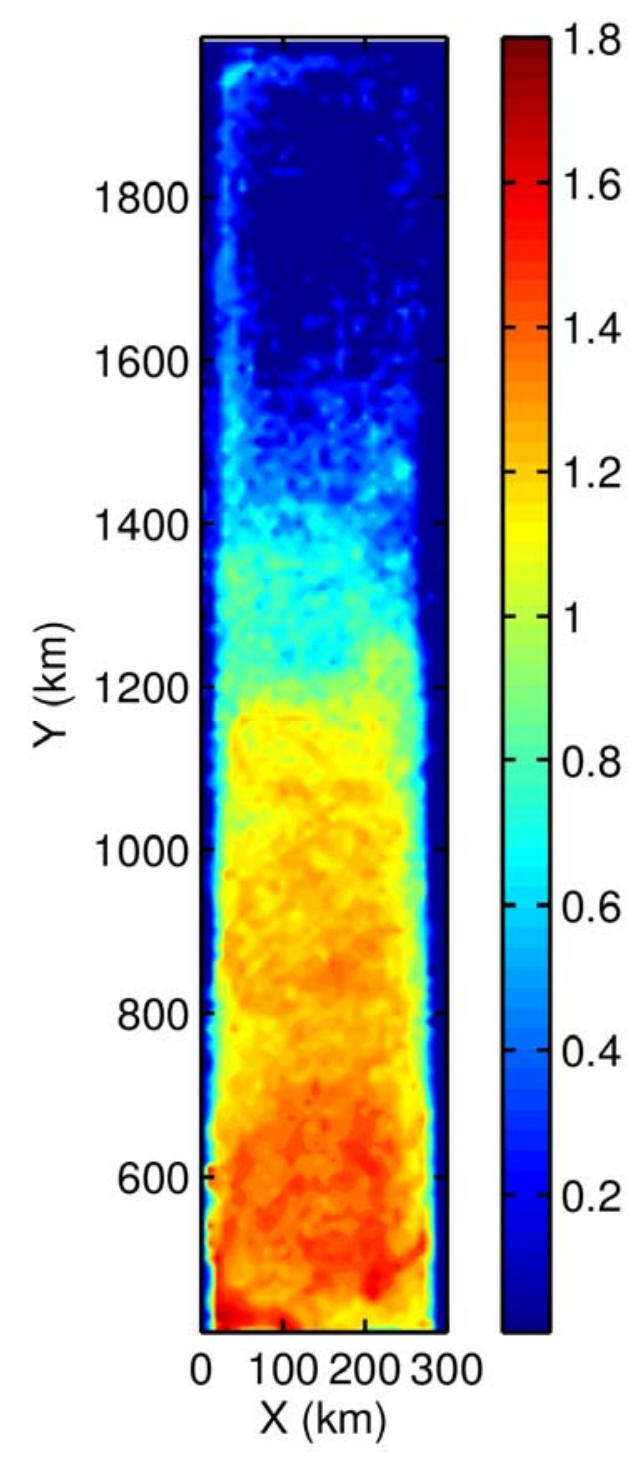

Figure 2.26: The pathway of RSOW before entering the strait. The particles are released at the strait and tracked backward in time. The map shows the percentage $\left[\log _{10}\right.$ (percentage)] of particles that cross through each $10 \mathrm{~km} \times 10 \mathrm{~km}$ cell at some time in the 6 -year integration.

The probability map illustrates the pathways of RSOW. However, it doesn't tell us how long it takes for the particles to transit from the formation region to the strait. In order to estimate the transit time, particles are released every 5 days for two years at each grid point. Therefore, at each grid point, 144 particles are released in two years. The time of particles when they cross the 
strait is recorded as transit time. There are 144 transit time at each grid point and the mean transit time for the upper $200 \mathrm{~m}$ is plotted in Figure 2.27. Generally speaking, the transit time increases northward since particles in the northern Red Sea travel a longer distance before they enters the strait. In the northern Red Sea, the mean transit time in the interior region is more than 3.5 years. The mean transit time near the boundaries is about 2.5-3 years. This is in accordance with the transit time distribution (TTD) plotted in Figure 2.28. The dominant transit time in the interior region is about 3.2 years. And the dominant transit time in the western boundary is about 2.4 years. That is because the current in the interior of the northern Red Sea is much weaker than boundary currents (Figure 2.25). Therefore, the particles in the interior generally take 10 months longer to arrive at the strait than the particles in the western boundaries. 


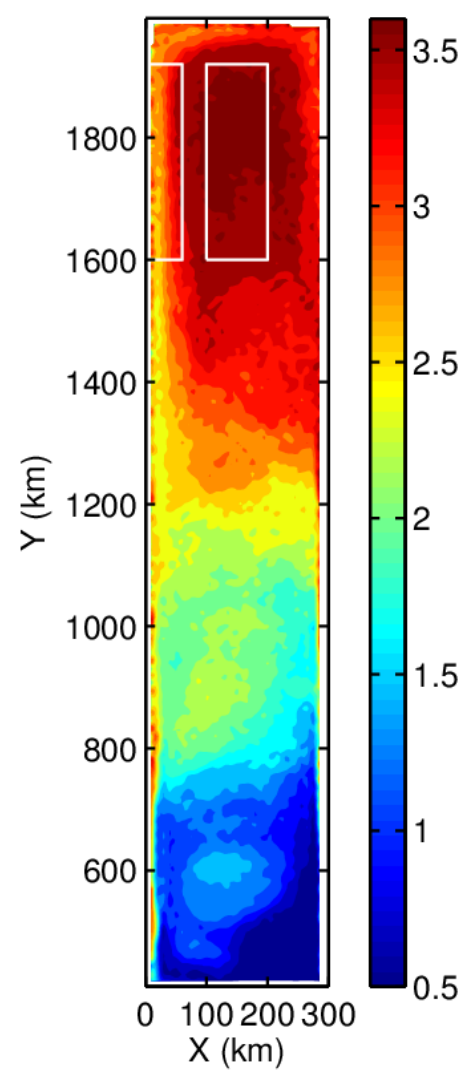

Figure 2.27: Map of mean transit time (year) for particles in the upper $200 \mathrm{~m}$. Particles are released every 5 days for two years at each grid point. 


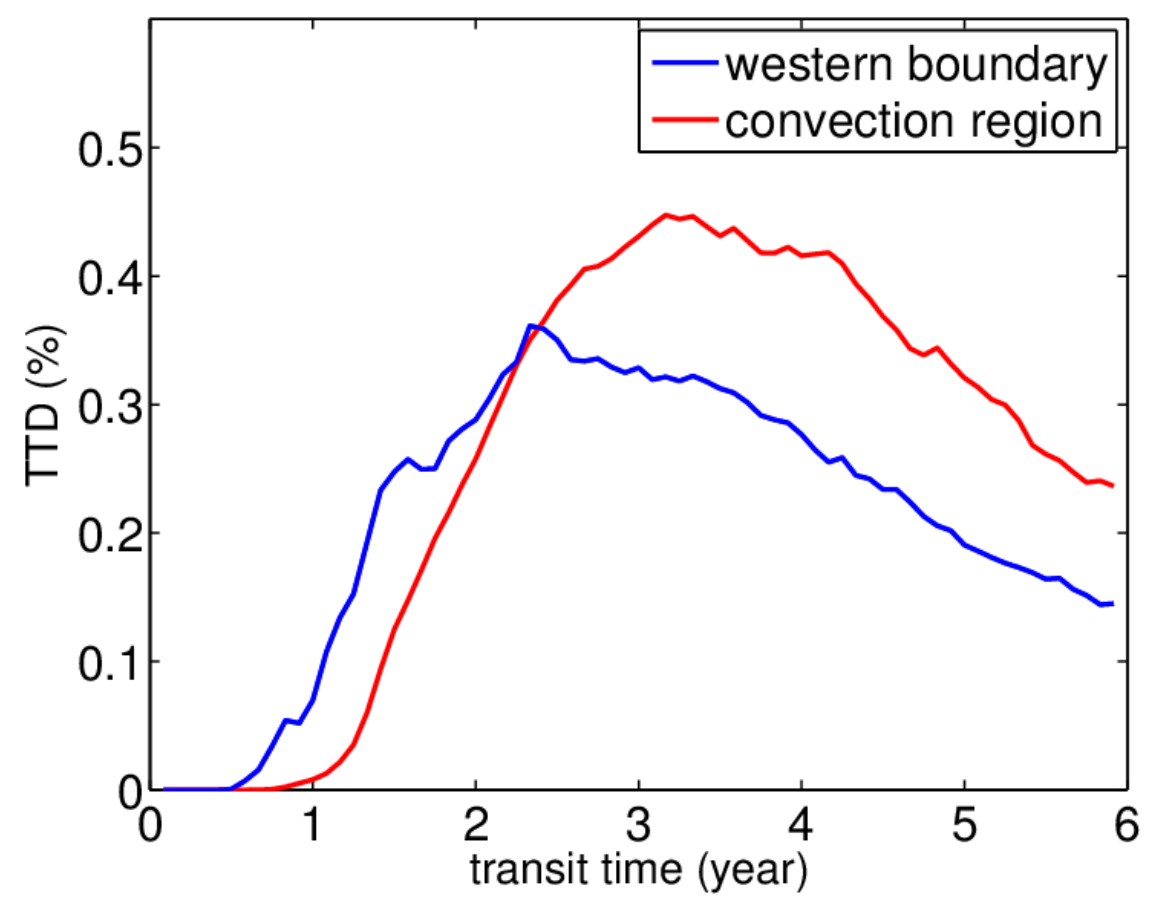

Figure 2.28: Transit time distribution (TTD) for particles in the upper $200 \mathrm{~m}$ in the western boundary and interior convection region. The location of the western boundary and interior convection region used in the calculation is highlighted with white boxes in Figure 2.27.

\subsection{Summary and Discussion}

Open-ocean convection is suggested to be the formation mechanism of the RSOW. This study analyzes hydrographic data, Shipboard ADCP velocity and satellite SST images and find that the preconditions required for open-ocean convection are satisfied in the northern Red Sea. From the satellite SST images and hydrographic data, the cyclonic gyre with cold water in the center is observed. In winter, the surface heat loss can be as large as $-200 \mathrm{~W} \mathrm{~m}^{-2}$. Different from the deep open-ocean convection in marginal seas in the North Atlantic, the convection in the northern Red Sea doesn't have to exceed $200 \mathrm{~m}$ for the RSOW formation. 
Potential vorticity and CFC-12 measured in 2010 and 2011 cruises are used to identify the RSOW, which can be identified as a minimum in PV due to weak stratification and as a maximum in CFC due to ventilation of the RSOW layer during formation. The vertical profiles of the potential vorticity and CFC-12 imply that the RSOW formed in 2010-2011 winter is denser than the RSOW formed in 2009-2010 winter. Papadopoulos et al. (2013) pointed out that the surface heat flux in the Red Sea had a close relation with the SLP over the eastern Mediterranean and Middle East. They found that when there was positive SLP anomaly, the prevailing northwesterly in the Red Sea was stronger and carries more cold and dry air to the Red Sea. The interannual variability of buoyancy forcing in the northern Red Sea might have caused the density variation of the RSOW in different years.

Hydrograhic data measured in March 2010 and September-October 2011 suggest that convection in the northern Red Sea is confined to the upper layer with potential density smaller than 28 $\mathrm{kg} \mathrm{m}^{-3}$. This implies that buoyancy loss in the northern Red Sea might be not strong enough to generate a deep convection for the surface water to sink to the bottom. The density equation can be written as $H \frac{d \rho}{d t}=B_{0}$, where $H$ is the vertica scale of convection, $B_{0}$ is surface buoyancy loss. Figure 2.29 shows mean density profile measured in October 2011. Assuming that it takes three months (November, December, and January) for density in the upper layer to increase to 28 $\mathrm{kg} \mathrm{m}^{-3}$ during a shallow convection, then the average buoyancy loss required for convection is about $1.1 \times 10^{-5} \mathrm{~kg} \mathrm{~m}^{-2} \mathrm{~s}^{-1}$ according to the density equation. However, if convection occurs through the whole water column, then the average buoyancy loss required for convection is $2.8 \times 10^{-5} \mathrm{~kg} \mathrm{~m}^{-2} \mathrm{~s}^{-1}$, which is more than two times larger than that required for the shallow 
convection. Figure 2.30 indicates that buoyancy loss in the northern Red Sea might not be strong enough to support a deep convection under current conditions.

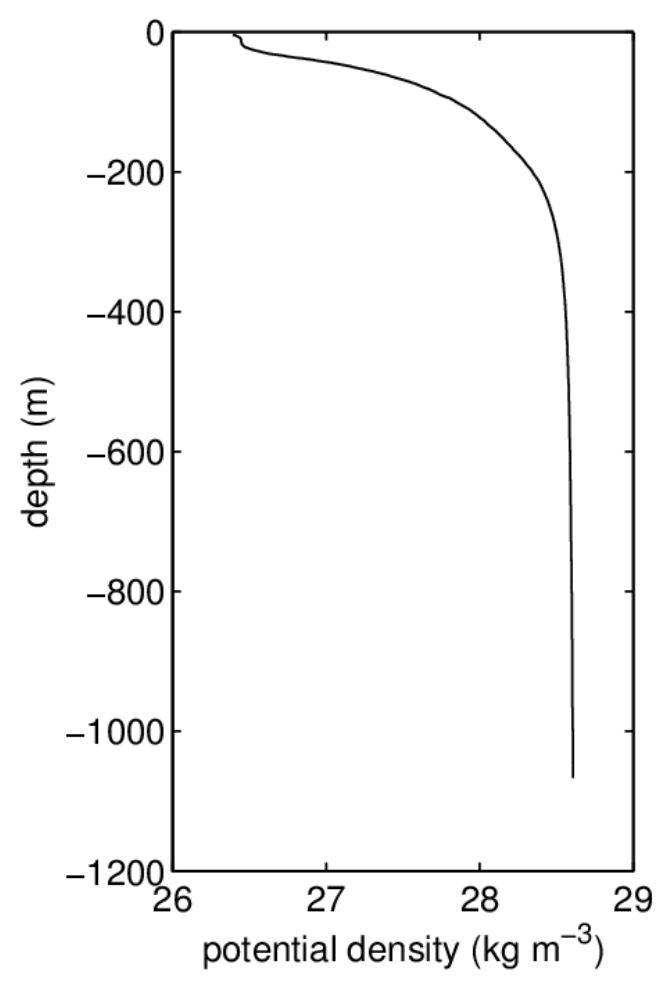

Figure 2.29: Mean potential density profile $\left(\mathrm{kg} \mathrm{m}^{-3}\right)$ averaged in the north of $26^{\circ} \mathrm{N}$ measured in October 2011. 


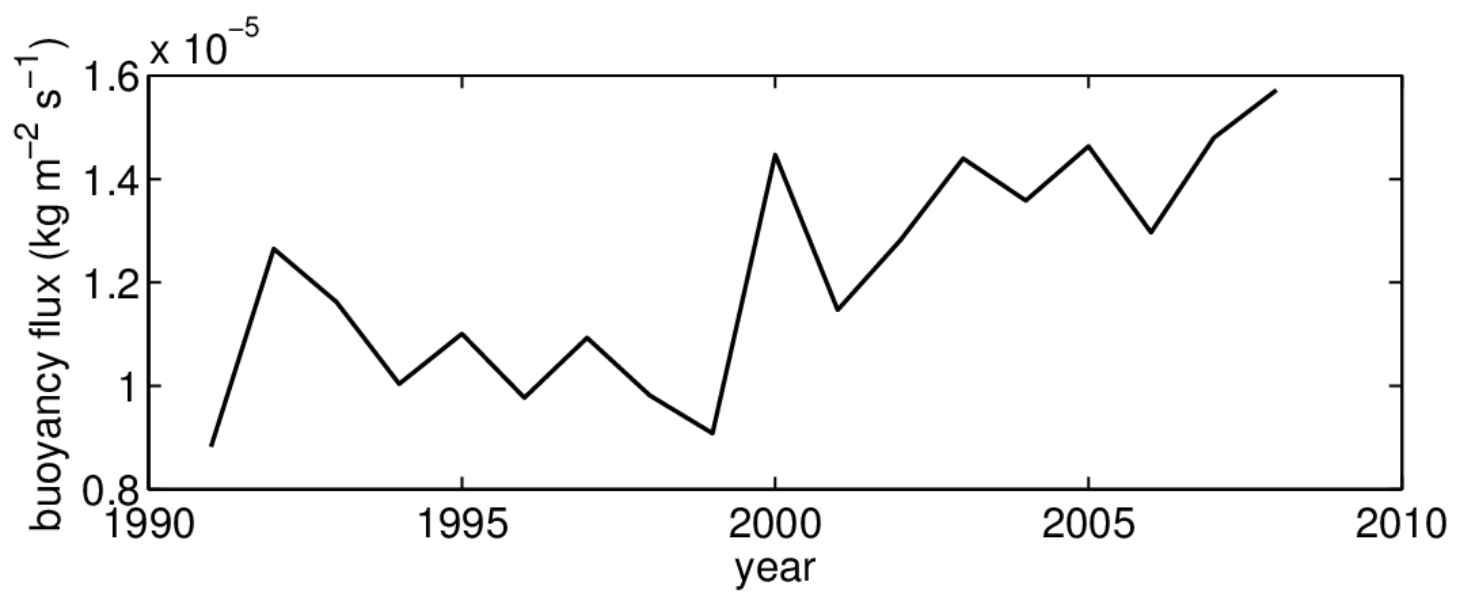

Figure 2.30: Buoyancy flux $\left(\mathrm{kg} \mathrm{m}^{-2} \mathrm{~s}^{-1}\right)$ averaged in November to January in the north of $26^{\circ} \mathrm{N}$ calculated from OAflux data.

In this study, Walin's method is used to estimate the production rate of the RSOW. The production rate of the RSOW is calculated using sea surface heat flux and SST. In the calculation, surface heat flux is a function of SST, instead of spatial location. The annual mean production rate of the RSOW due to surface heat loss is estimated to be $0.63 \mathrm{~Sv}$. However, the $0.36 \mathrm{~Sv}$ annual mean transport of the RSOW observed at the Strait of Bab el Mandeb is smaller than 0.63 Sv. A vertical diffusivity of $3.4 \times 10^{-5} \mathrm{~m}^{2} \mathrm{~s}^{-1}$ is required to match the production rate to previous observations of transport of the RSOW through the strait. Therefore, interior mixing might play an important role in regulating the water mass transformation rate. The vertical diffusivity calculated in this study is comparable to estimations in other studies. The tracer release experiment in the Antarctic Circumpolar Current indicated that the diapycnal diffusivity is about $(1.3 \pm 0.2) \times 10^{-5} \mathrm{~m}^{2} \mathrm{~s}^{-1}$ near $1500-\mathrm{m}$ depth (Ledwell et al., 2011). Based on fine-scale parameterization methods, Kunze et al., (2006) found that the vertical diffusivity ranged from $0.3 \times 10^{-5} \mathrm{~m}^{2} \mathrm{~s}^{-1}$ to $7 \times 10^{-5} \mathrm{~m}^{2} \mathrm{~s}^{-1}$, as functions of latitude and depth. Another reason for why the production rate due to surface heat loss is larger than the observed RSOW transport might be 
that part of the produced water forms a closed internal overturning circulation in the Red Sea and never escapes from the Red Sea, as is sketched in Figure 2.31. Numerical evidence of the closed internal overturning circulation can be found in Sofianos and Johns (2003) and the supplementary information of Biton et al. (2008).

Numerical model results indicate that the RSOW flows southward along the western boundary in the northern Red Sea due to a strong western boundary current there. However, there are many basin-scale eddies in the southern Red Sea. As a result, RSOW moves all over the southern basin instead of being confined in a boundary current in the southern Red Sea. In the northern Red Sea, the mean transit time of the RSOW from boundaries to the strait is about 2.5-3 years. The current in the interior region of the northern Red Sea is much weaker than boundary currents. Therefore, the mean transit time of the RSOW from the interior region (convective region) to the strait is more than 3.5 years. The particles in the interior region generally take 10 months longer to arrive at the strait than the particles in boundaries.

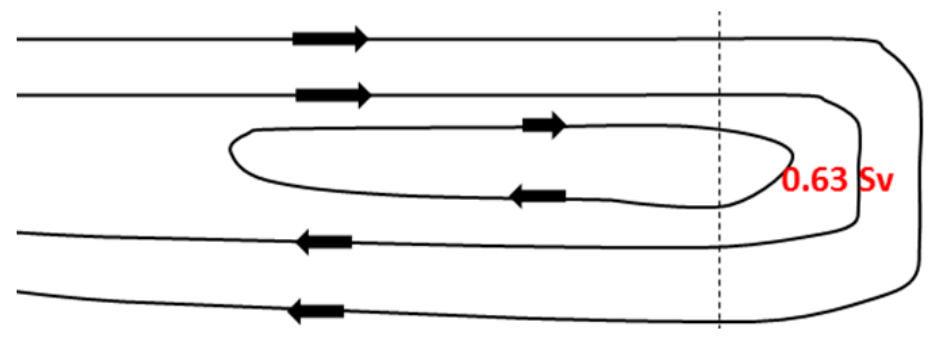

Figure 2.31: A schematic diagram showing the relation between the overturning circulation and the outflow transport. 


\section{Chapter 3}

\section{On the Crossover of Boundary Currents in an Idealized Model of}

\section{the Red Sea}

\subsection{Introduction}

The Red Sea experiences extensive evaporation and forms one of the most saline water masses in the world ocean. Through analyzing the freshwater and heat budgets of the Red Sea using observational temperature, salinity and velocity at the Strait of Bab el Mandeb, Sofianos et al. (2002) estimated that the annual mean surface fluxes of freshwater and heat over the Red Sea are $2.06 \pm 0.22 \mathrm{~m} \mathrm{yr}^{-1}$ and $11 \pm 5 \mathrm{~W} \mathrm{~m}^{-2}$, respectively. The evaporation and heat losses in the Red Sea drive a surface fresher and warmer inflow and a saltier and colder subsurface outflow with an annual mean transport of about 0.36Sv at the Strait of Bab el Mandeb (Murray and Johns, 1997).

Buoyancy losses due to cooling and evaporation in marginal seas, such as the Red Sea, the Mediterranean Sea and the Labrador Sea, can produce dense intermediate and deep water, which feed the deep branch of the oceanic meridional overturning circulation. These water masses usually hold distinct water properties and can influence the thermohaline circulation by transports of heat and freshwater. The buoyancy losses in marginal seas are balanced by lateral advection of heat and freshwater through the straits that connect the marginal seas and the open oceans. Previous observations and numerical simulations indicate that boundary currents in the marginal seas usually flow cyclonically around the basin when the circulation is driven by buoyancy losses over the marginal sea (Spall, 2004). For example, in the Labrador Sea, the 
cyclonic boundary circulation is composed of the West Greenland Current and the Labrador Current (Marshall and Schott, 1999; Pickart et al., 2002). In most cases the basin in question is sufficiently small that the beta effect is negligible. Yet the Coriolis parameter in the Red Sea doubles from $3.5 \times 10^{-5} \mathrm{~s}^{-1}$ in the south to $6.8 \times 10^{-5} \mathrm{~s}^{-1}$ in the north, which indicates that the meridional variation of the Coriolis parameter is not negligible in the Red Sea. In addition, Spall (2004) used horizontally uniform buoyancy forcing to drive a circulation in a marginal sea and result in a cyclonic boundary current. However, the surface buoyancy loss in the Red Sea has a notable meridional gradient. Therefore, the circulation in the Red Sea might present different features from the circulation in Spall (2004) due to the meridional variations of Coriolis parameter and buoyancy forcing in the Red Sea.

Using the Miami Isopycnic Coordinate Ocean Model (MICOM), which was forced by surface buoyancy fluxes and wind forcing with seasonal cycle, Sofianos and Johns (2003) simulated the Red Sea circulation. They found that the buoyancy forced circulation dominated the wind forced circulation in the Red Sea. Unlike the buoyancy-driven cyclonic boundary currents in marginal seas that are simulated by Spall (2004), Sofianos and Johns (2003) found that in the 9-year mean winter circulation the inflow from the Gulf of Aden moves along the western boundary after it enters the Red Sea and crosses the basin to the eastern boundary at certain latitude (crossover latitude, Figure 3.1). Using a high-resolution MIT general circulation model (MITgcm) with constant February atmospheric forcing for 10 years, Yao et al. (2014b) also simulated the crossover from western boundary current in the south to eastern boundary current in the north. Numerical model studies in the Red Sea, with realistic topography and atmospheric forcing, suggest that boundary currents in marginal seas might be more complex than just a cyclonically flowing current. 


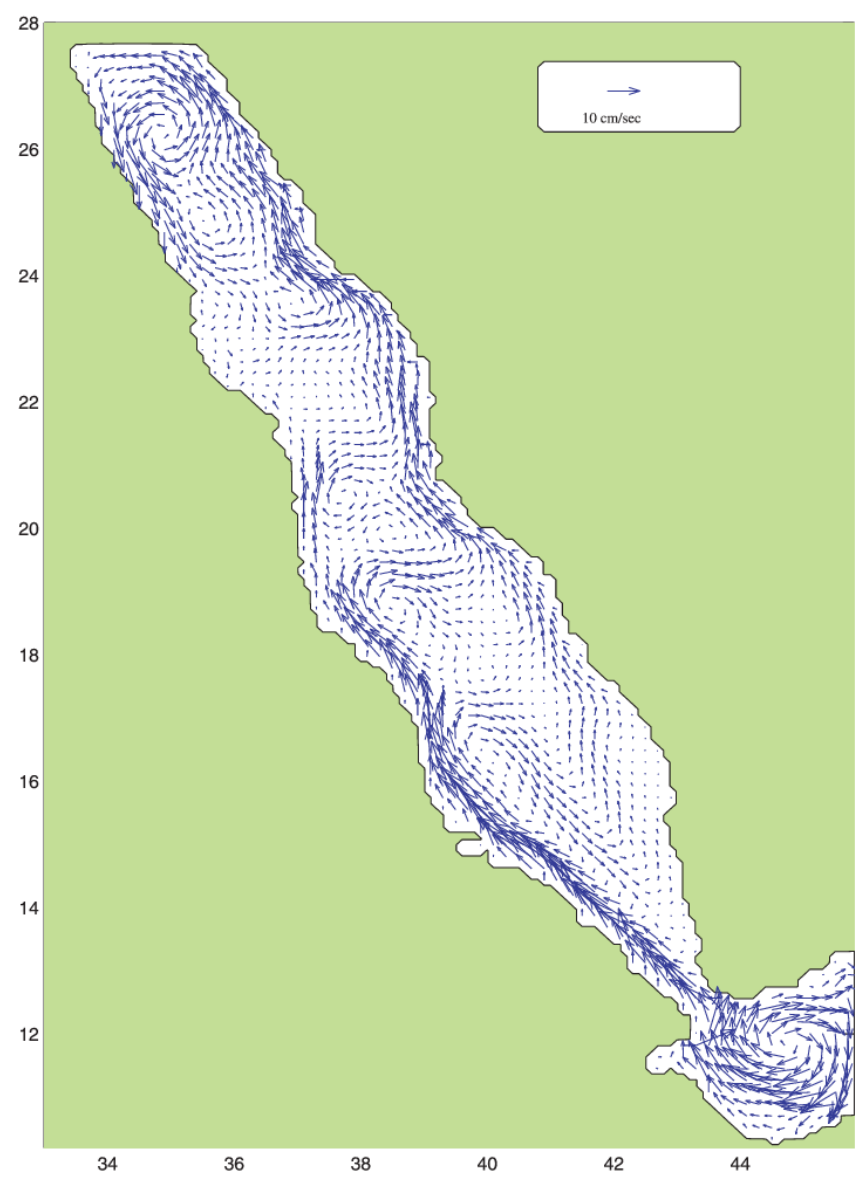

Figure 3.1: Nine-year average surface current driven by surface buoyancy-forcing using MICOM (Sofianos and Johns, 2003, their Figure 15).

Observations in the Red Sea are very sparse. There are very few time series of velocity at fixed locations, so the calculation of a mean circulation from in situ observations is out of the question. We can, however, examine evidence inferred from satellite sea surface temperature (SST) and sea level anomaly (SLA). SST can be determined from satellite remote sensing using microwave (MW) and infrared (IR) radiometers. The merged MW-IR SST product has greater coverage and higher resolution. This product is distributed on a $0.09^{\circ}$ grid and covers data from January 2006 . Figure 3.2 shows monthly mean SST in December 2008 and 2010. There is a warm tongue along the eastern boundary in the northern part, which could be indicative of a northwards boundary 
current along the eastern coast. This warm tongue continues along the western boundary in the northern Red Sea, which implies that there is a southward boundary current along the western coast in the north. There is also cool tongue along the western boundary in the south, suggesting a northward flow from the Strait of Bab el Mandeb along the western coast. Although these SST features do not necessarily indicate a flow direction, the horizontal structure of SST is suggestive of cyclonic boundary currents in the northern Red Sea and a northwestward western boundary current in the southern Red Sea.

Figure 3.3 shows monthly mean satellite sea level anomaly (SLA) and geostrophic current anomaly (GCA) calculated from SLA. The SLA used in this study is merged from all available satellite altimetry data by AVISO (Archiving, Validation and Interpretation of Satellite Oceanographic Data). The merged SLA is mapped on a regular $0.25^{\circ}$ grid every 7 days. Since dynamic height data is not available in the Red Sea, only anomaly can be analyzed. Images of SLA and GCA indicate that there are several eddies in the Red Sea. Another striking feature is that there might be a northward flow moving along the western boundary in the southern Red Sea. This flow turns eastward and crosses the basin at about $20^{\circ} \mathrm{N}$. SLA and GCA shown in Figure 3.3 indicate that crossover of boundary currents might exist in the real Red Sea in winter. 

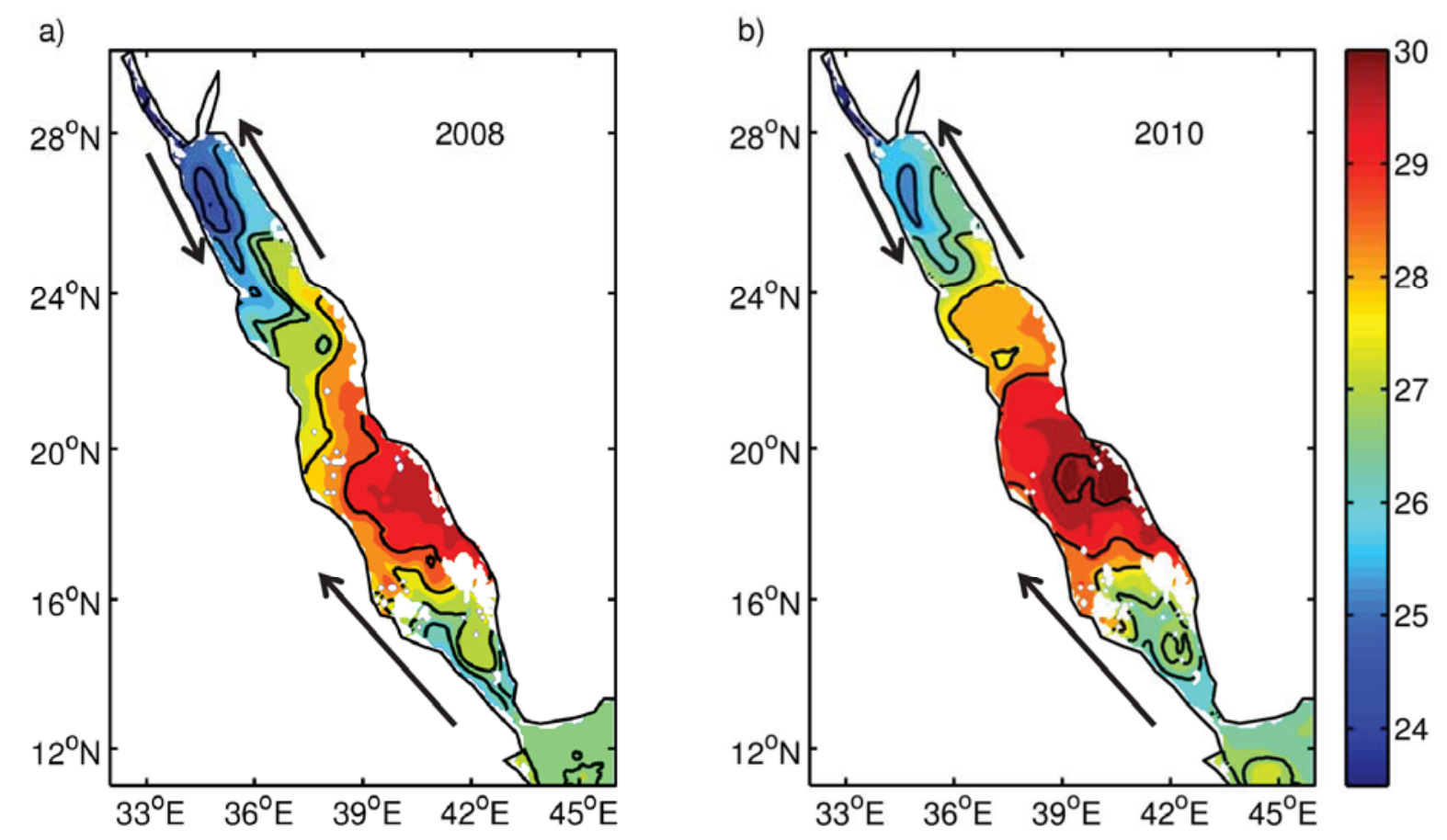

Figure 3.2: Monthly mean MW-IR SST $\left({ }^{\circ} \mathrm{C}\right.$ ) in (a) December 2008 and (b) 2010. 


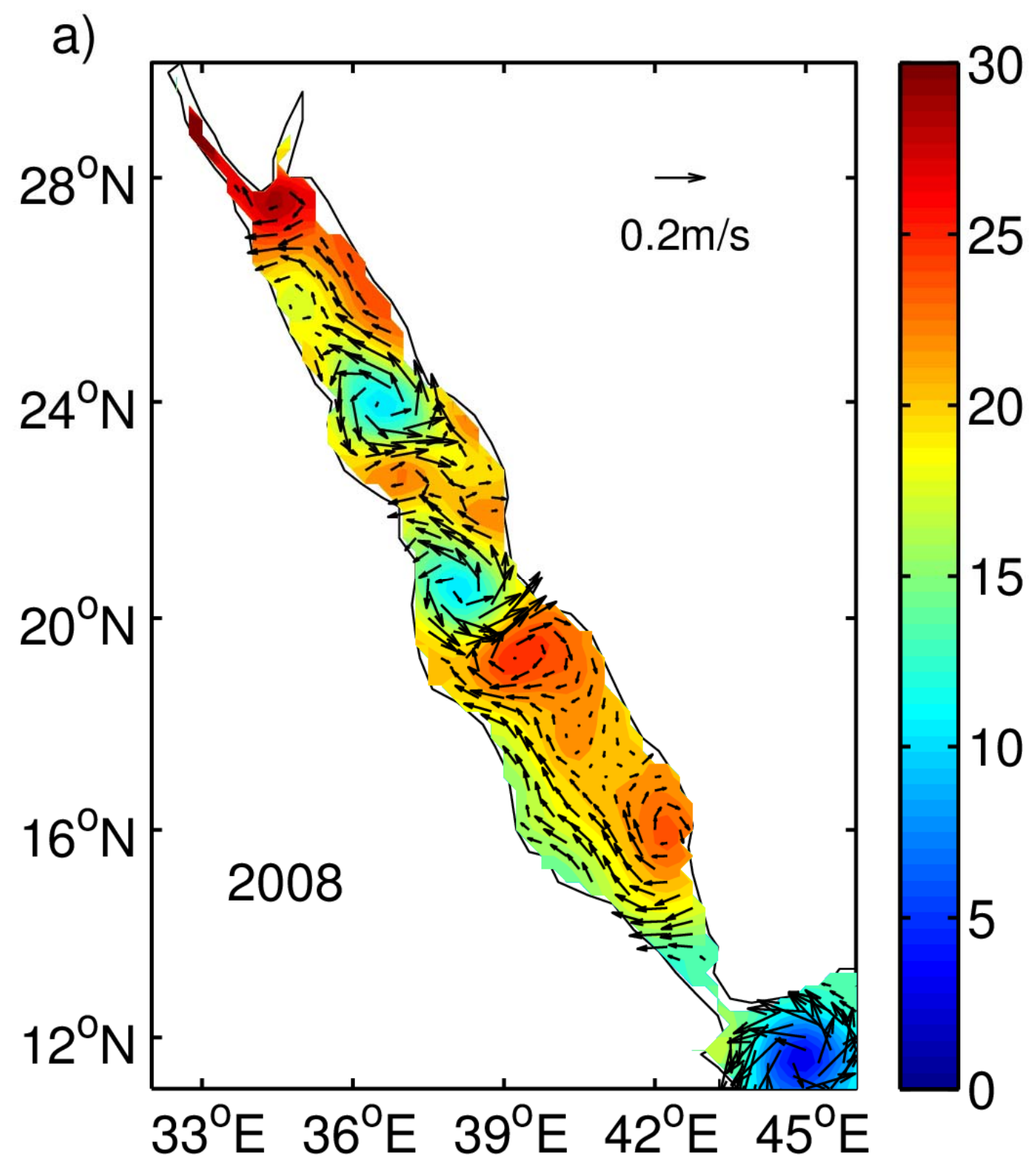




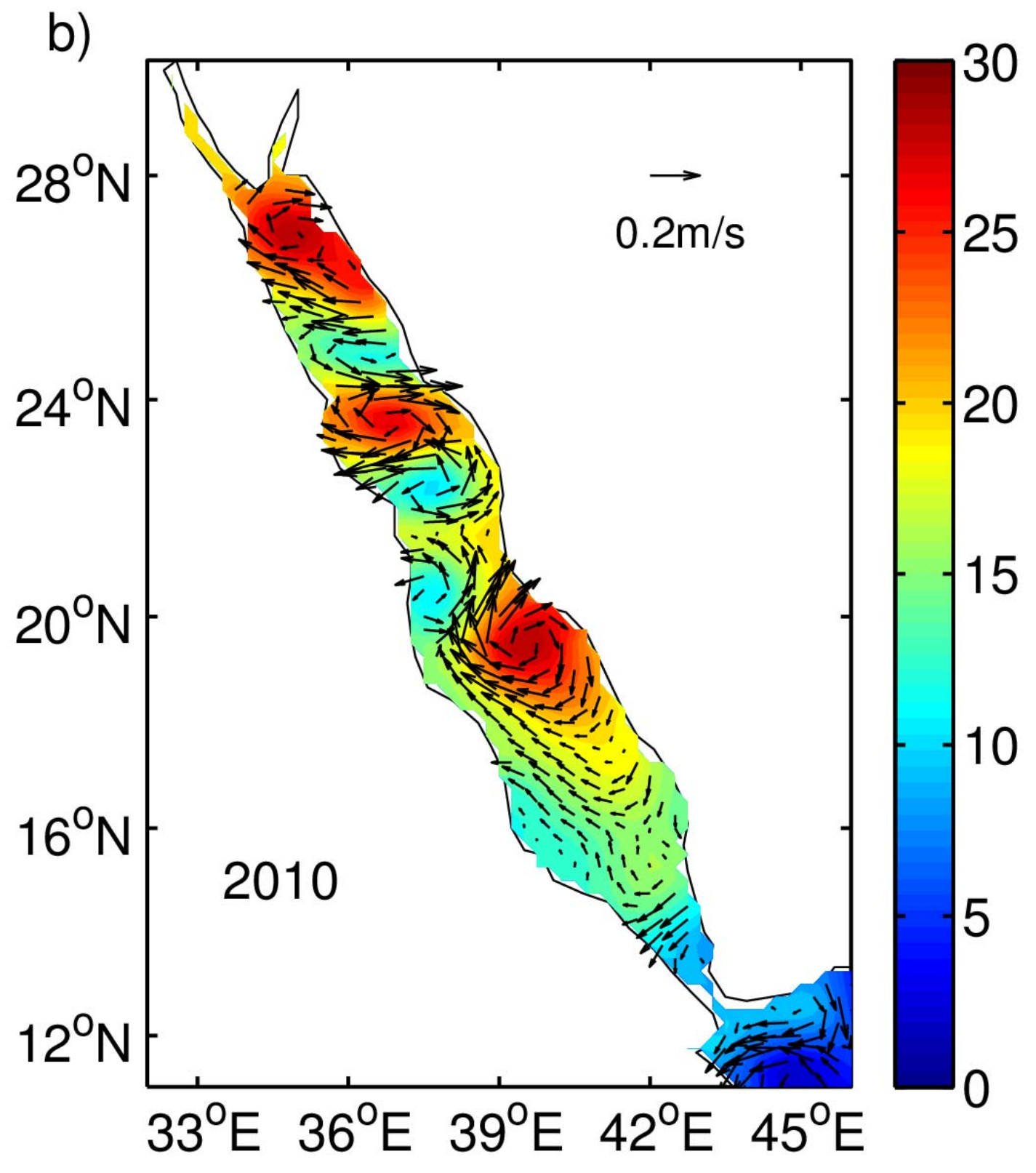

Figure 3.3: Monthly mean SLA (cm) and geostrophic current anomaly in (a) December 2008 and (b) 2010 .

Buoyancy loss in marginal seas usually drives cyclonic boundary circulation as suggested by previous observational and numerical studies. However, numerical modeling and limited observations from satellite imply that the circulation in the Red Sea might be more complex than 
just a cyclonic circulation. Therefore, it is interesting to investigate dynamically what particular features of the Red Sea make the Red Sea circulation so different from circulations in other marginal seas. In addition, studying what mechanisms control the crossover of the surface northward inflow and how the crossover might change under different conditions will help us understand the ecology and biological activity in the Red Sea.

We have mentioned that the meridional variations of the Coriolis parameter and buoyancy forcing might be responsible for the crossover of the northward inflow. This study will investigate the sensitivity of the crossover to these parameters. Different from previous model studies with realistic topography and atmospheric forcing, we will conduct a series of numerical experiments on a $\beta$-plane (the Coriolis parameter is approximated by $f=f_{0}+\beta y$ ) in an idealized Red Sea, in which $f_{0}, \beta$, and the meridional gradient of buoyancy forcing will be varied. The objective of this study is to understand what controls the crossover latitude of the northward western boundary current in the idealized Red Sea. The question will be addressed with both a numerical model and an ad hoc analytical model. This chapter is organized as follows: section 3.2 describes the numerical simulation of the buoyancy-driven circulation in the idealized Red Sea using an eddy-resolving general circulation model; section 3.3 introduces an ad hoc analytical model, based on potential vorticity dynamics, to investigate the parameter dependencies of the crossover latitude, and section 3.4 offers some conclusions.

\subsection{Numerical Model Simulation of the Buoyancy-Driven Circulation in an Idealized Red}

\section{Sea}

\subsubsection{Model Description}


The Massachusetts Institute of Technology General Circulation Model (MITgcm) (Marshall et al., 1997) is used to simulate the buoyancy-driven circulation in an idealized Red Sea. The model is nonhydrostatic and solves the momentum and density equations on a Cartesian, staggered Arakawa $\mathrm{C}$ grid. The parameters that are used in the control experiment (EXP0) are described in this section, whereas parameter settings for other experiments are listed in Table 3.1. The model domain includes the idealized Red Sea, the Strait of Bab el Mandeb and the Gulf of Aden (Figure 3.4). The idealized Red Sea is a rectangular basin with a width of $300 \mathrm{~km}$ and a length of 1600 $\mathrm{km}$. The Gulf of Aden is $600 \mathrm{~km}$ wide and $250 \mathrm{~km}$ long. In the Red Sea and the Gulf of Aden, the bottom depth increases from $0 \mathrm{~m}$ at coast to $1000 \mathrm{~m}$ over and offshore distance of $80 \mathrm{~km}$. The Strait of Bab el Mandeb is $100 \mathrm{~km}$ wide and $150 \mathrm{~km}$ long, with a sill depth of $200 \mathrm{~m}$. The horizontal grid spacing is $5 \mathrm{~km}$ and there are 29 vertical levels, with thickness varying from $10 \mathrm{~m}$ at surface to $100 \mathrm{~m}$ at the bottom. The Coriolis parameter in EXP0 is approximated by $f=f_{0}+\beta y$ with $f_{0}=3.5 \times 10^{-5} \mathrm{~s}^{-1}$ and $\beta=2.1 \times 10^{-11} \mathrm{~m}^{-1} \mathrm{~s}^{-1}$, which are typical of the Red Sea. 
Table 3.1: Model run parameters and symbols used in Figure 3.16. $B_{0}=a y+b$ represents the surface buoyancy flux, and cross $\mathrm{Y}$ is the crossover latitude. Unit: $B_{0}\left(\mathrm{~kg} \mathrm{~m}^{-2} \mathrm{~s}^{-1}\right) ; f_{0}\left(\mathrm{~s}^{-1}\right)$; $\beta\left(\mathrm{m}^{-1} \mathrm{~s}^{-1}\right) ; a\left(\mathrm{~kg} \mathrm{~m}^{-3} \mathrm{~s}^{-1}\right) ; b\left(\mathrm{~kg} \mathrm{~m}^{-2} \mathrm{~s}^{-1}\right) ; \operatorname{crossY}(\mathrm{km})$.

\begin{tabular}{lllllll}
\hline EXP \# & $f_{0}$ & $\beta$ & $a$ & $b$ & crossY & symbol \\
\hline EXP0 & $3.5 \times 10^{-5}$ & $2.1 \times 10^{-11}$ & $3.5 \times 10^{-12}$ & $-1.4 \times 10^{-6}$ & 1028 & $\Delta$ \\
EXP1 & $1.5 \times 10^{-5}$ & $2.1 \times 10^{-11}$ & $3.5 \times 10^{-12}$ & $-1.4 \times 10^{-6}$ & 1351 & $\bullet$ \\
EXP2 & $2.5 \times 10^{-5}$ & $2.1 \times 10^{-11}$ & $3.5 \times 10^{-12}$ & $-1.4 \times 10^{-6}$ & 1139 & $\bullet$ \\
EXP3 & $7 \times 10^{-5}$ & $2.1 \times 10^{-11}$ & $3.5 \times 10^{-12}$ & $-1.4 \times 10^{-6}$ & 798 & $\bullet$ \\
EXP4 & $10.5 \times 10^{-5}$ & $2.1 \times 10^{-11}$ & $3.5 \times 10^{-12}$ & $-1.4 \times 10^{-6}$ & 674 & $\bullet$ \\
EXP5 & $3.5 \times 10^{-5}$ & $0.5 \times 10^{-11}$ & $3.5 \times 10^{-12}$ & $-1.4 \times 10^{-6}$ & 852 & $\Delta$ \\
EXP6 & $3.5 \times 10^{-5}$ & $1.5 \times 10^{-11}$ & $3.5 \times 10^{-12}$ & $-1.4 \times 10^{-6}$ & 995 & $\Delta$ \\
EXP7 & $3.5 \times 10^{-5}$ & $4 \times 10^{-11}$ & $3.5 \times 10^{-12}$ & $-1.4 \times 10^{-6}$ & 1152 & $\Delta$ \\
EXP8 & $3.5 \times 10^{-5}$ & $6 \times 10^{-11}$ & $3.5 \times 10^{-12}$ & $-1.4 \times 10^{-6}$ & 1218 & $\Delta$ \\
EXP9 & $3.5 \times 10^{-5}$ & $2.1 \times 10^{-11}$ & 0 & $2.8 \times 10^{-6}$ & 658 & $\mathrm{O}$ \\
EXP10 & $3.5 \times 10^{-5}$ & $2.1 \times 10^{-11}$ & $1.7 \times 10^{-12}$ & $0.7 \times 10^{-6}$ & 927 & $\mathrm{O}$ \\
EXP11 & $3.5 \times 10^{-5}$ & $2.1 \times 10^{-11}$ & $2.6 \times 10^{-12}$ & $-0.34 \times 10^{-6}$ & 989 & $\mathrm{O}$ \\
EXP12 & $3.5 \times 10^{-5}$ & $2.1 \times 10^{-11}$ & $4.3 \times 10^{-12}$ & $-2.4 \times 10^{-6}$ & 1074 & $\mathrm{O}$ \\
\hline
\end{tabular}




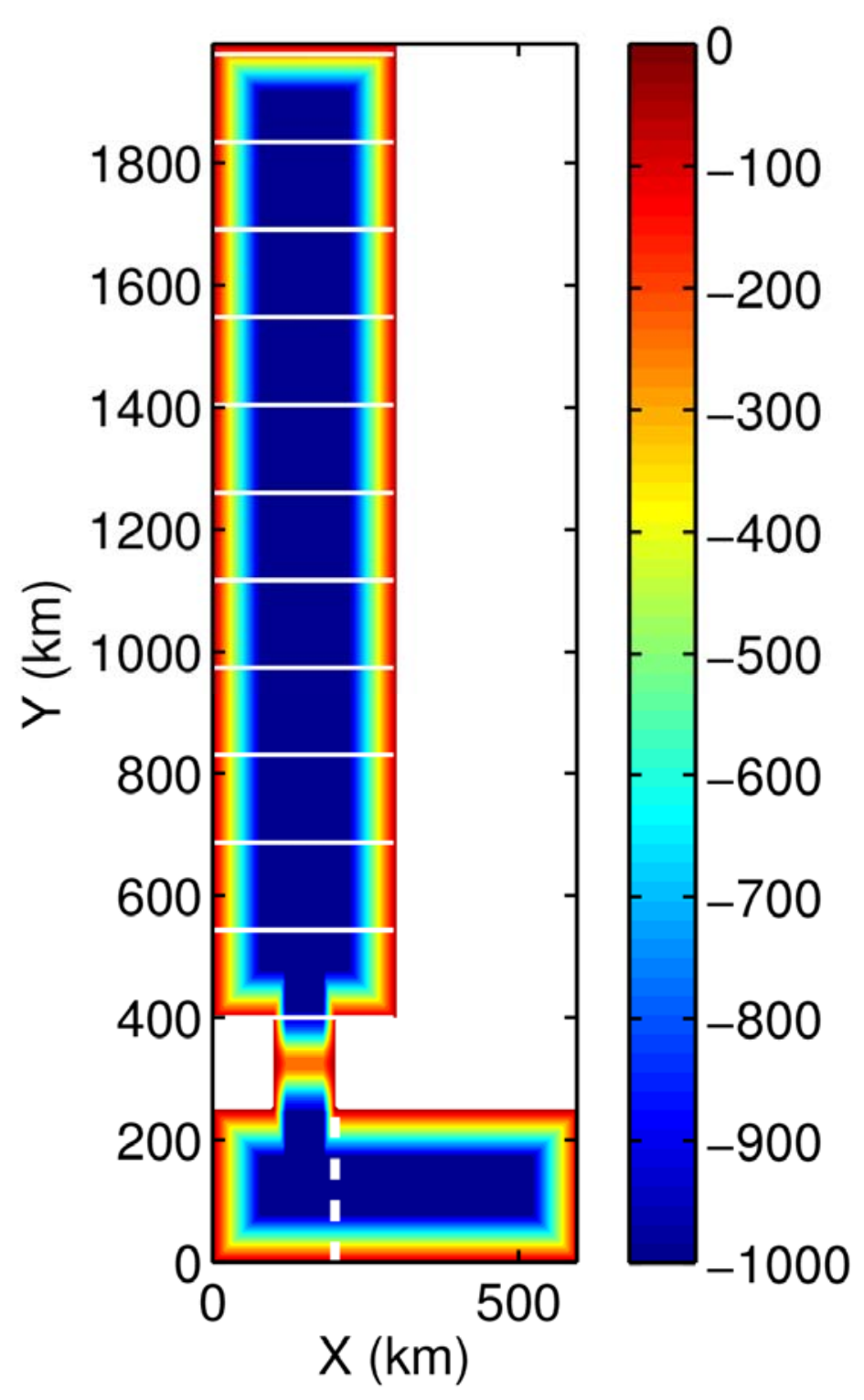

Figure 3.4: Model domain with bottom topography (colors, with depth in m) and EXP0 surface buoyancy loss (white contours with contour interval of $0.5 \times 10^{-6} \mathrm{~kg} \mathrm{~m}^{-2} \mathrm{~s}^{-1}$, and with zero contour at $\mathrm{Y}=400 \mathrm{~km}$ ). Temperature and salinity in the region east of the dashed white line are restored to the initial profiles.

The model is forced by surface fluxes of heat $(Q)$ and freshwater $(E)$ in the Red Sea. In EXP0, $Q$ changes linearly from 0 at the southern end of the Red Sea $(y=400 \mathrm{~km})$ to $-20 \mathrm{~W} \mathrm{~m}^{-2}$ at the 
northern end ( $y=2000 \mathrm{~km}$ ), and $E$ increases linearly from 0 at the southern end of the Red Sea to $4.3 \mathrm{~m} \mathrm{yr}^{-1}$ at the northern end. We use a linear equation of state, such that $\rho=\rho_{r}\left[1-\alpha_{T} T+\beta_{S} S\right]$, where $\rho_{r}=999.8 \mathrm{~kg} \mathrm{~m}^{-3}$ is a reference density, $\alpha_{T}=2 \times 10^{-4}{ }^{\circ} \mathrm{C}^{-1}$ and $\beta_{S}=8 \times 10^{-4}$ are thermal expansion and haline contraction coefficients. The surface buoyancy flux (Figure 3.4) calculated from $Q$ and $E$ is

$$
B_{0}=-\alpha_{T} Q / c_{w}+\rho_{0} \beta_{S} S_{0} E
$$

where $c_{w}=3900 \mathrm{~J} \mathrm{~kg}^{-1}{ }^{\circ} \mathrm{C}^{-1}$ is the heat capacity of water. In this model, surface freshwater flux changes the salinity of sea water, but cannot affect the total volume. The buoyancy flux in Eq. (3.1) has units of $\mathrm{kg} \mathrm{m}^{-2} \mathrm{~s}^{-1}$. We will be particularly interested in how the mean state is affected by variations in the distribution of the surface buoyancy flux and in $f_{0}$ and $\beta$. The initial conditions for temperature and salinity (Figure 3.5) are based on average profiles of temperature and salinity measured from the March 2010 and September-October 2011 Red Sea cruises (Bower, 2010; Bower and Abualnaja, 2011). The temperature and salinity in the eastern part of the Gulf of Aden (Figure 3.4) is relaxed to these initial profiles with a relaxation time scale of 60 days. We have tried different relaxation profiles in the eastern Gulf of Aden and different choices of relaxation profiles don't influence the circulation pattern. The relaxation of temperature and salinity in the Gulf of Aden acts as a source of buoyancy to balance the surface buoyancy losses in the Red Sea. Second order viscosity and diffusivity are used to parameterize subgrid-scale processes. The vertical viscosity and diffusivity for temperature and salinity are $10^{-5} \mathrm{~m}^{2} \mathrm{~s}^{-1}$. The vertical diffusivity is increased to $1000 \mathrm{~m}^{2} \mathrm{~s}^{-1}$ when the water column is hydrostatically unstable, in order to simulate convection. There is no explicit horizontal diffusivity of temperature and 
salinity in the model. The Smagorinsky viscosity is used to determine the horizontal viscosity, such that $A_{h}=\left(v_{S} / \pi\right)^{2} L^{2} \sqrt{\left(u_{x}-v_{y}\right)^{2}+\left(u_{y}+v_{x}\right)^{2}}$, where $L$ is the spacing scale, $u$ and $v$ are horizontal velocities and subscripts represent partial derivatives. Recommended values for $v_{S}$ lie in the range of 2.2 to 4 for large-scale oceanic simulations (Griffies and Hallberg, 2000); we have chosen $v_{S}=2.5$. No-slip boundary conditions are applied at bottom and lateral boundaries.

The model was run for 25 years with steady surface heat loss and evaporation and reached a quasi-steady state. Unless it is explicitly stated otherwise, the mean fields discussed in this study will be the average over the final 5 years of the 25 -year simulation.
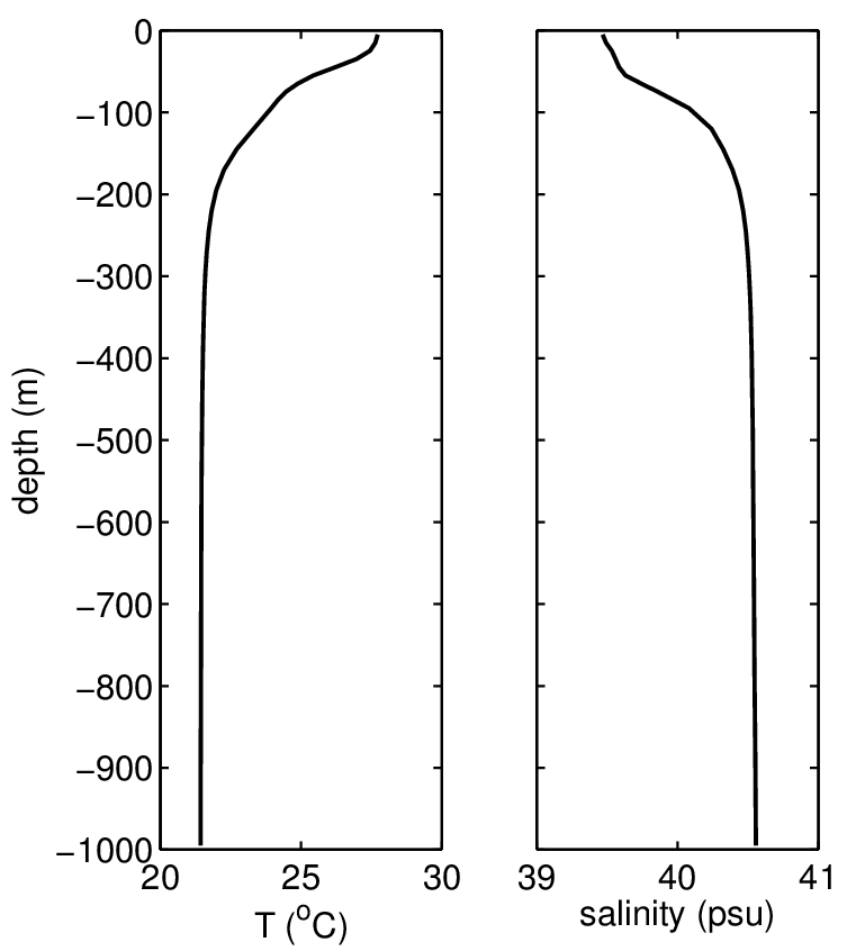

Figure 3.5: Initial profiles of temperature and salinity in the numerical model.

\subsubsection{Numerical Model Results}


The benchmark experiment EXP0 reveals a set of surface gyres and boundary currents (Figure 3.6a) that establish pathways for the northward movement of lighter water from the strait through the Red Sea basin. As indicated in Figure 3.6a, the surface inflow from the Gulf of Aden brings lighter water into the Red Sea through the Strait of Bab el Mandeb. When the inflow enters the Red Sea, it turns left and continues moving northward along the western boundary until it reaches about $1000 \mathrm{~km}$, where it turns east and crosses the basin. The northward velocities reach $35 \mathrm{~cm} \mathrm{~s}^{-1}$ in the western boundary layer. There is also a weaker northward boundary current along the eastern coast of the southern portion of the basin. Here the northward velocities are less than $10 \mathrm{~cm} \mathrm{~s}^{-1}$. Due to surface buoyancy losses, the density of each boundary current increases as the inflow moves northward. The 5-year mean circulation averaged in the upper $200 \mathrm{~m}$ shows that to the north of the crossover latitude, the boundary circulation is cyclonic. In the southern Red Sea, the boundary circulation is predominantly anticyclonic (Figure 3.6b). A snapshot of the surface temperature (Figure 3.7) from EXP0 suggests the same general configuration of boundary currents and crossover as in the 5-year mean fields (Figure 3.6a). Eddies are also present in the snapshot and the crossover occurs slightly to the south of its mean position near $1000 \mathrm{~km}$. The eddies may be instrumental in transporting warm and fresh water from the boundary currents to the interior, where heat and freshwater are lost due to surface cooling and evaporation, as described by Spall (2004). 
a)

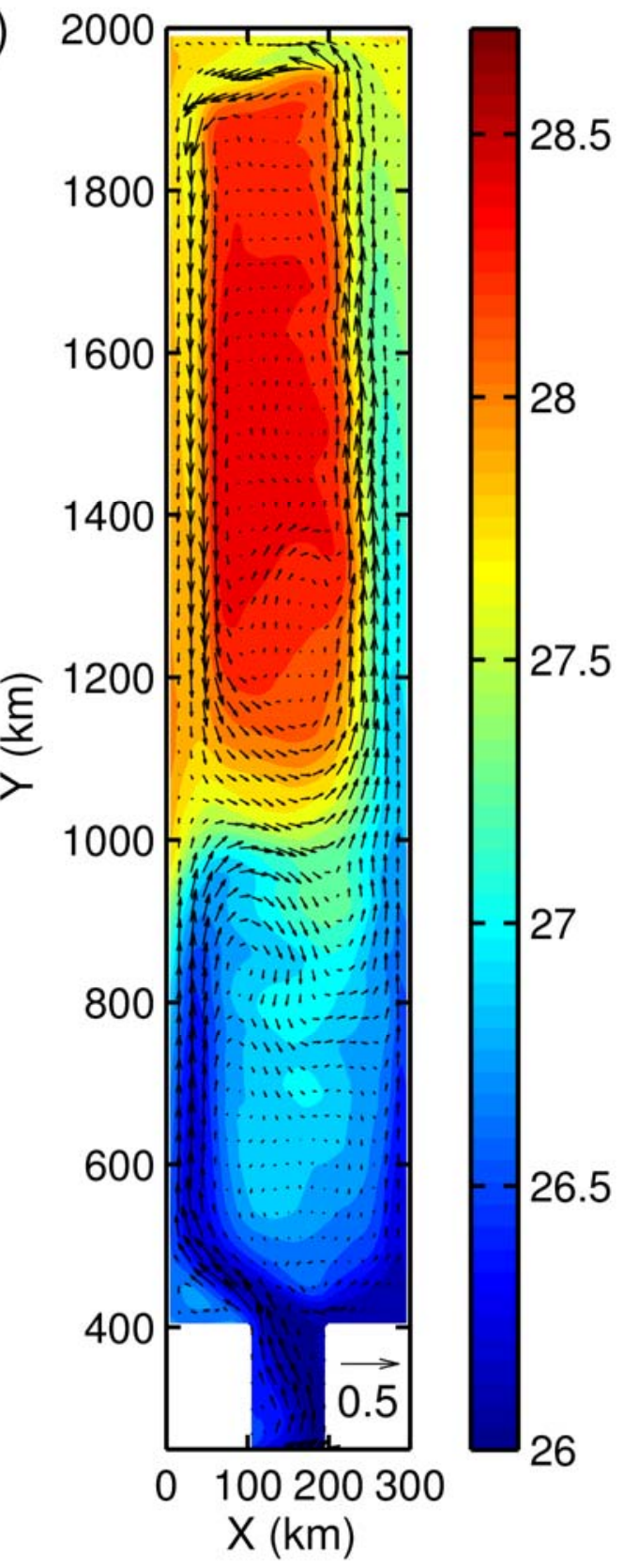

b)

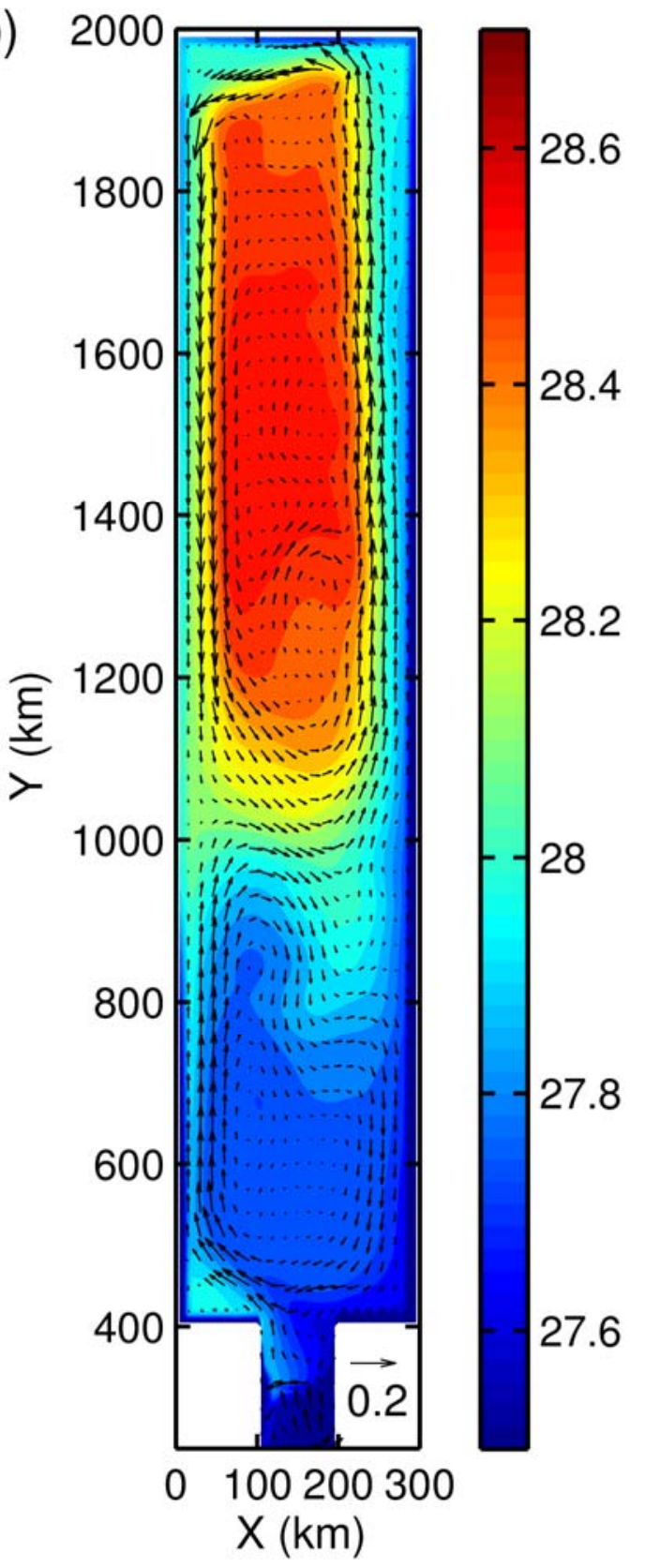

Figure 3.6: Mean density $\left(\mathrm{kg} \mathrm{m}^{-3}\right)$ and horizontal velocity $\left(\mathrm{m} \mathrm{s}^{-1}\right)$ for the control experiment EXP0 (a) at surface, and (b) averaged over the upper $200 \mathrm{~m}$. 


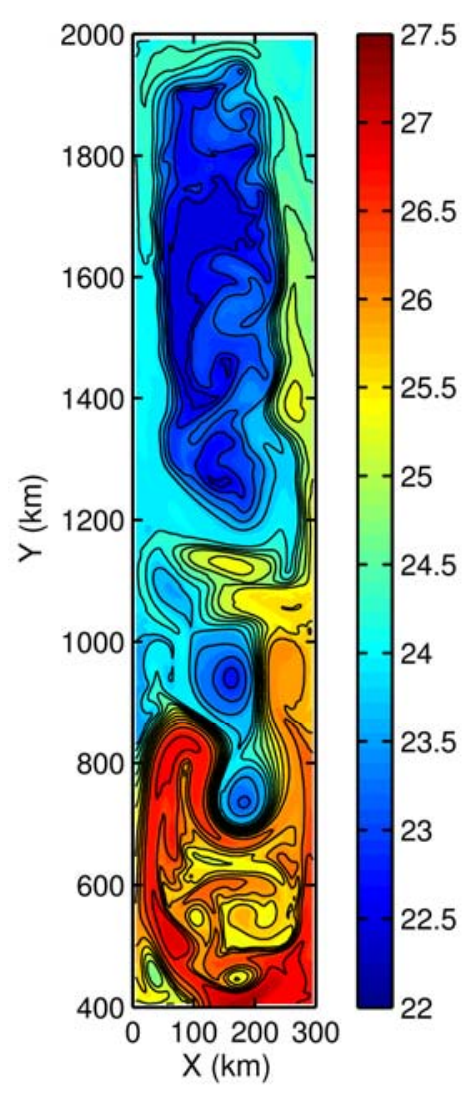

Figure 3.7: A snapshot of the surface temperature from EXP0 (contour interval is $0.3{ }^{\circ} \mathrm{C}$ ).

The zonal sections of meridional velocity at $\mathrm{y}=500 \mathrm{~km}$ and $\mathrm{y}=1770 \mathrm{~km}$ are plotted in Figure 3.8. The vertical structure of the meridional velocity at $y=1770 \mathrm{~km}$ indicates that the cyclonic boundary circulation in the northern Red Sea is intensified in the upper $200 \mathrm{~m}$ with maximum speed in excess of $30 \mathrm{~cm} \mathrm{~s}^{-1}$. Below $300 \mathrm{~m}$, there is a much weaker anticyclonic circulation with speed less than $5 \mathrm{~cm} \mathrm{~s}^{-1}$. The zonal section of meridional velocity at $y=500 \mathrm{~km}$ indicates that the circulation in the southern Red Sea is also intensified in the upper $200 \mathrm{~m}$. The western boundary current can extend to $800 \mathrm{~m}$. However, the speed below $200 \mathrm{~m}$ is very weak. The weaker, northward-flowing eastern boundary current only penetrates down to $100 \mathrm{~m}$ and overlies a countercurrent that extends from 100-300 $\mathrm{m}$ and is situated slightly offshore. The maximum 
velocity of the surface northward flow is about $5 \mathrm{~cm} \mathrm{~s}^{-1}$ and that of the subsurface southward countercurrent is about $10 \mathrm{~cm} \mathrm{~s}^{-1}$. The countercurrent returns water in the Red Sea back to the strait. Therefore, the vertical integrated boundary current on the eastern boundary is southward and the depth-integrated circulation in the southern Red Sea is predominantly anticyclonic. Overall, the surface circulation associated with waters entering the model domain through the strait is stronger than the intermediate circulation that carries the return flow. The primary reason for this mismatch is the presence of a strong recirculation component in the surface flow, especially in the northern basin.
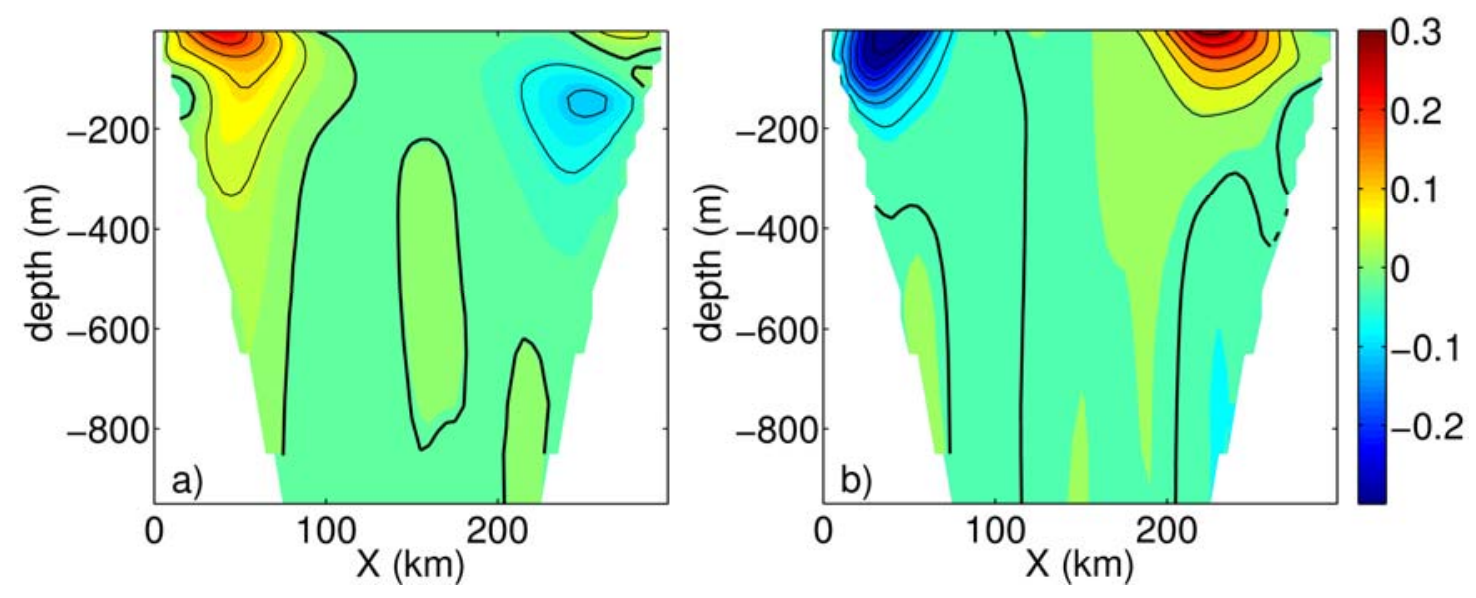

Figure 3.8: Zonal sections of mean meridional velocity (contour interval is $5 \mathrm{~cm} \mathrm{~s}^{-1}$ ) from EXP0 at $\mathrm{y}=500 \mathrm{~km}$ (a) and $\mathrm{y}=1770 \mathrm{~km}$ (b). Zero-velocity contour is plotted in thick black lines.

The determination of crossover latitude of the northward western boundary current in the numerical model is illustrated in Figure 3.9. The crossover latitude is defined as the zerocrossing point of the mean meridional velocity on the western boundary, taken as the average meridional velocity within $80 \mathrm{~km}$ of the western coast and in the upper $200 \mathrm{~m}$. (In our model, 80 $\mathrm{km}$ is the offshore topographic width scale and also the approximate width of the boundary current.) In EXP0, the crossover latitude of the western boundary is $1028 \mathrm{~km}$. Subsequent 
numerical experiments with different parameters will indicate that the crossover latitude varies with $f_{0}, \beta$ and the meridional gradient of surface buoyancy fluxes. For example, the crossover latitude moves to $1351 \mathrm{~km}$ when $f_{0}=1.5 \times 10^{-5} \mathrm{~s}^{-1}$ (EXP1), or to $1218 \mathrm{~km}$ when $\beta$ is increased to $6 \times 10^{-11} \mathrm{~m}^{-1} \mathrm{~s}^{-1}$ (EXP8). In EXP10, the meridional gradient of surface buoyancy flux is reduced and the crossover latitude shifts to $927 \mathrm{~km}$ (Table 3.1).

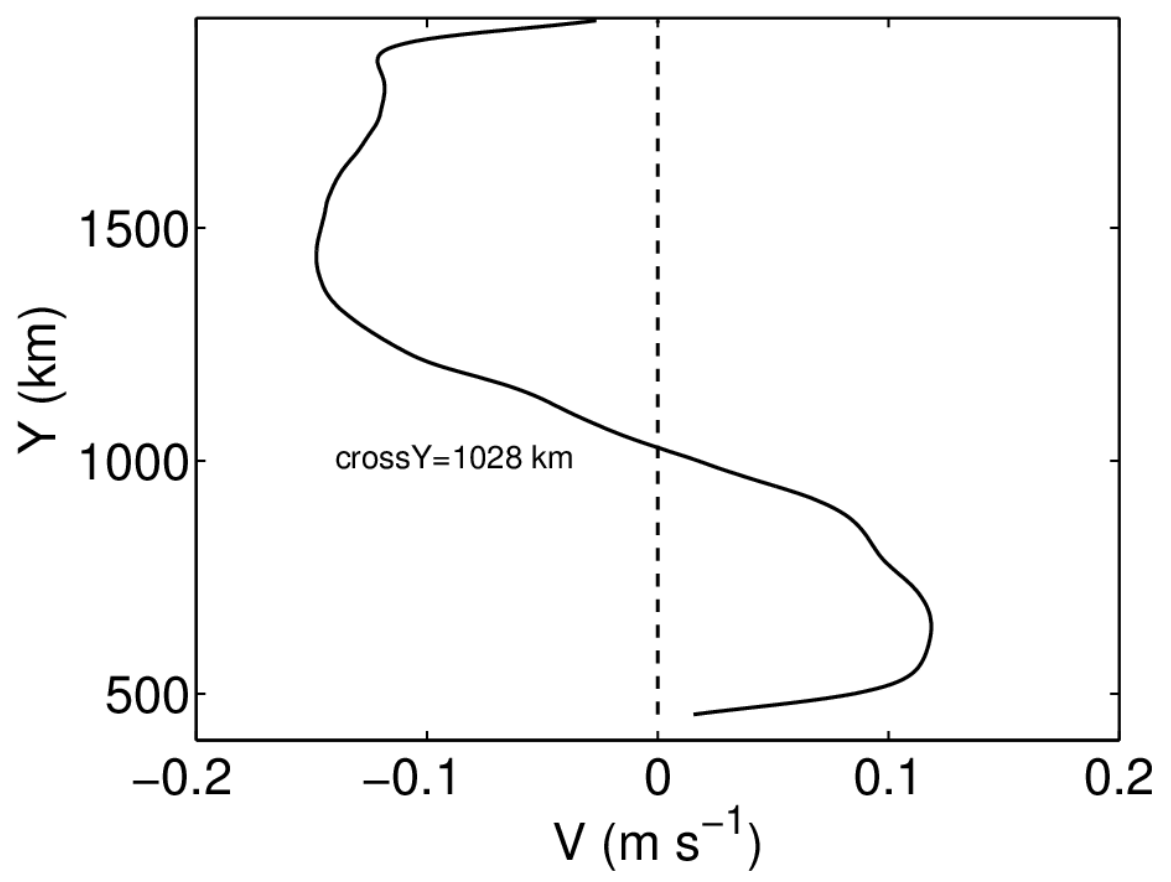

Figure 3.9: Mean western boundary current speed, which is calculated as the average meridional velocity in the western boundary (within $80 \mathrm{~km}$ of the western boundary) in the upper $200 \mathrm{~m}$. The crossover latitude (crossY) is defined as the zero-crossing point.

Sofianos and Johns (2003) suggested that the crossover of the boundary current is the latitude beyond which Rossby waves with the frequency of the forcing ( $2 \pi \mathrm{yr}^{-1}$ in their study) are no longer possible, and only Kelvin waves exist. One difficulty with this hypothesis is that the crossover exists in my model (and in that of Yao et al., 2014b) in the presence of steady forcing. For this case the forcing frequency is zero and Sofianos and Johns' prediction would put the 
crossover at $90^{\circ} \mathrm{N}$. In addition, the crossover latitude doesn't change if an annual cycle is added to the steady forcing in this study (Figure 3.10). Thus the frequency of the external buoyancy forcing doesn't have a notable impact on the crossover latitude. Therefore, Sofianos and John's explanation cannot be used to explain the crossover latitude in this study with steady forcing.

a)

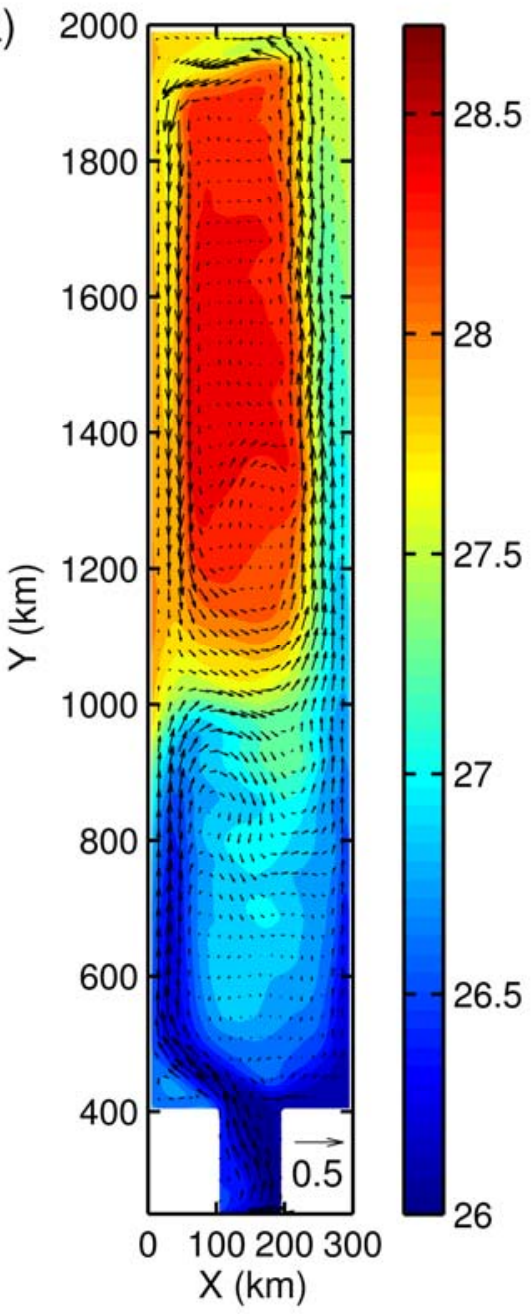

b)

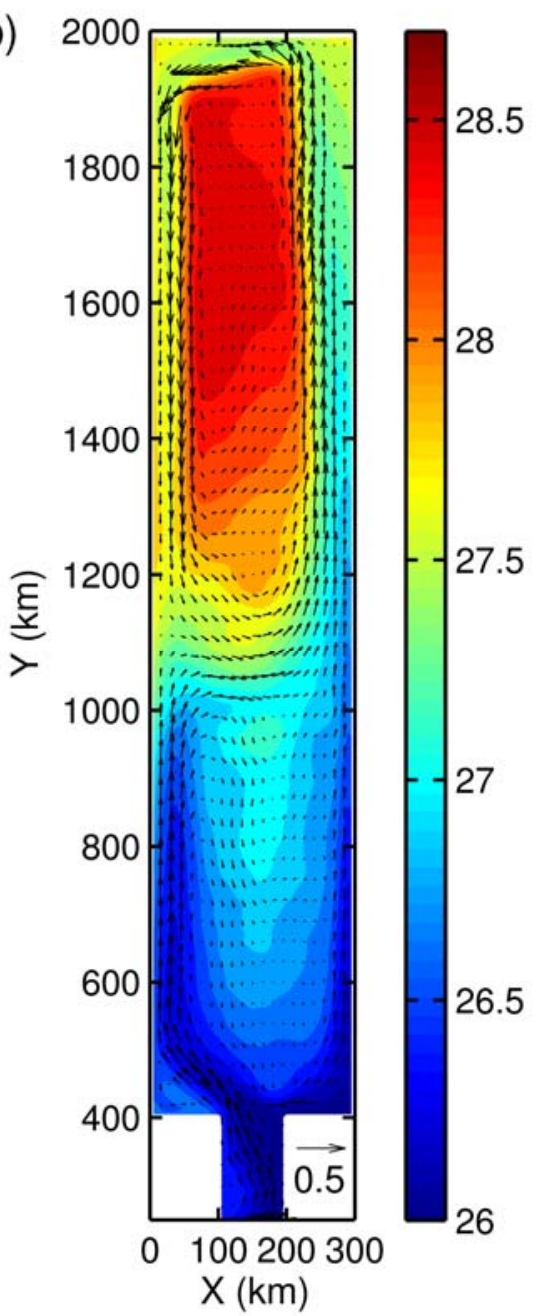

Figure 3.10: Mean surface density $\left(\mathrm{kg} \mathrm{m}^{-3}\right)$ and horizontal velocity $\left(\mathrm{m} \mathrm{s}^{-1}\right)$ in (a) EXP0 with steady forcing, and (b) a experiment using surface buoyancy foring with annual cycle (the annual mean buoyancy forcing is the same as EXP0). 
Buoyancy-driven models of circulation in $f$-plane marginal seas (e.g. Spall, 2004) often produce a cyclonic rim current at the surface, with no crossover. We therefore look to the $\beta$-effect and to other influences, such as the meridional variation of surface buoyancy forcing, to establish a crossover. Both are of potential significance over the large meridional extent of the Red Sea.

\subsection{An ad hoc Analytical Model of the Crossover Latitude}

The numerical model results in the previous section indicate that the crossover latitude of the northward western boundary current is related to the Coriolis parameter and meridional gradient of surface buoyancy forcing. In this section, an ad hoc analytical model based on potential vorticity (PV) dynamics is developed to study what controls the crossover latitude. The approach is very idealized and is not intended to resolve the details shown in the numerical modeling, but to understand the basic dynamics of the crossover latitude.

\subsubsection{The Physics of the Crossover}

The buoyancy loss over the Red Sea and resulting sinking implies a net northward surface flow, and most models concentrate this flow in boundary currents. In addition, the convection that occurs in the northern Red Sea implies weaker stratification there. We now consider how these factors influence the northward advection of potential vorticity, the sign of which determines which boundary is the 'dynamical western boundary'. We begin by partitioning the density field in the boundary current layer as $\rho(x, y, t)=\rho_{0}+\rho_{a}(x, y, t)$, where $\rho_{0}$ is mean density in the boundary current layer, and $\rho_{a}(x, y, t)$ is density anomaly referenced to $\rho_{0}$. The square of the buoyancy frequency in the boundary current is then given by $N^{2}=-\frac{g}{\rho_{0}} \frac{\rho_{0}-\rho_{d}}{H / 2}$, where $\rho_{d}$ is 
seawater density below the boundary current layer, $H$ is the vertical scale of boundary current layer. Consider the implications for the potential vorticity $q$ of a fluid parcel within the surface layer as it moves northward. If the quasigeostrophic approximation holds, then $q=\beta y-\frac{f_{0} g}{\rho_{0}} \frac{\rho_{a} / N^{2}}{H / 2}$ (Pedlosky, 1996). The surface flow is assumed sufficiently weak that the contribution from relative vorticity is negligible. The contribution from the planetary vorticity ( $\beta y$ ) decreases to the north, whereas the northward increase in density anomaly implies that the contribution from the stretching term $\left(-\frac{f_{0} g}{\rho_{0}} \frac{\rho_{a} / N^{2}}{H / 2}\right)$ increases to the north (as the surface density increases to the north, the vertical separation between isopycnals increases). In summary, the sign of northward potential vorticity gradient that a fluid parcel experiences depends on the relative size of the planetary and stretching terms.

If the northward flow is contained predominately in a boundary layer, either on the eastern or western side of the basin, then advection of potential vorticity will be dominated by the northward velocity, and a plausible form of the quasigeostrophic potential vorticity (PV) equation will be

$$
v \frac{\partial}{\partial y}\left(\beta y-\frac{f_{0} g}{\rho_{0}} \frac{\rho_{a} / N^{2}}{H / 2}\right)+\frac{\partial}{\partial x} \overline{u^{\prime} q^{\prime}}+\frac{\partial}{\partial y} \overline{v^{\prime} q^{\prime}}=\operatorname{curl} \boldsymbol{F}_{r},
$$

where $v(y)$ is temporal mean meridional velocity in the boundary layer, $\boldsymbol{F}_{r}$ is temporal mean friction, $\overline{u^{\prime} q^{\prime}}$ and $\overline{v^{\prime} q^{\prime}}$ represent eddy fluxes of PV and primes denote deviations from the time mean, $q^{\prime}=\frac{f_{0} g}{\rho_{0}} \frac{\rho_{a}{ }^{\prime} / N^{2}}{H / 2}$ is composed only of the stretching term. In traditional models of ocean 
circulation, the eddy flux terms are parameterized and aborbed into $\boldsymbol{F}_{\boldsymbol{r}}$. To offer an intuitive argument, let us temporarily assume that this is the case. Then the form of the friction vector $\boldsymbol{F}_{\boldsymbol{r}}$ varies from model to model. For simplicity, the effects of eddy flux are ignored here and will be added later in the detailed version of the model. However, if the northward boundary current is along the western boundary, one can reasonably expect the frictional torque to provide positive PV. The reverse is true for a northward boundary current on the east coast. If the potential vorticity gradient $\beta-\frac{\partial}{\partial y}\left(\frac{f_{0} g}{\rho_{0}} \frac{\rho_{a} / N^{2}}{H / 2}\right)$ is dominated by $\beta$, and therefore positive, the boundary current must lie on the western boundary, else it must lie on the east.

The above scenario is just an alternative way of explaining westward intensification, with the provision that the gradient of the stretching term may overwhelm $\beta$ and make the east coast the "dynamical western boundary". The crossover would then occur if the northward PV gradient changed sign. In the Red Sea, overturning and convection are felt mainly in the northern portion, so the northward gradient in the stretching term is largest there. It is therefore possible that the planetary term dominates in the south whereas the stretching term dominates in the north, and that the two cancel each other at intermediate latitude. In order to explore this possibility and estimate the crossover latitude, one needs to predict the northward change in stratification. This is done in the more detailed calculation presented below. In it, fluid enters at the surface of the Red Sea through the strait and is assumed to flow northwards along the western boundary. Buoyancy is lost to the boundary current through an eastward eddy flux into the basin interior and this is quantified using a parameterization of baroclinic instability. The northward current crosses to the eastern boundary at an unknown latitude and continues to lose buoyancy. For a given crossover latitude, the thermal wind relation and the density equation provide sufficient 
constraints to allow estimation of the meridional changes in stratification and thus the gradient of the stretching term. As it turns out, only one such latitude lies where the total PV advection is zero.

\subsubsection{An ad hoc analytical model of Crossover Latitude}

A diagram of boundary currents in the ad hoc analytical model is shown in Figure 3.11. The boundary currents are assumed to be in thermal wind balance. They lose buoyancy through eddy fluxes into interior regions where most of surface buoyancy loss to the atmosphere occurs. The eddy fluxes are estimated using a parameterization of baroclinic instability that is based on the meridional averages of the boundary layer velocity and density. This parameterization is described in Appendix A. The ad hoc analytical model estimates the characteristic velocity and density of each boundary current, both of which vary with y, and also the uniform density of the quiescent interior regions. The unknown variables can be calculated for any assumed value of the crossover latitude Yc. The correct Yc is obtained when it is consistent with the potential vorticity dynamics.

\subsubsection{Estimates of Densities and Velocities in the Boundary Currents}

Horizontal variations in the stretching PV term are associated with horizontal variations in density and velocity. We now attempt to estimate density and velocity in the boundary currents. Figure 3.11 shows a diagram of the boundary currents used in the ad hoc analytical model. It was suggested in Figure 3.8, and will be assumed here, that the motion in the numerical model occurs mainly above the $200 \mathrm{~m}$ sill depth. We therefore consider the depth averaged flow in the upper $200 \mathrm{~m}$ (as presented in Figure 3.6) and assume that the underlying fluid is quiescent. As described in Figure 3.11, it is assumed that the inflow from the Gulf of Aden moves northward 
near the western boundary until it reaches $Y_{C}$, the crossover latitude. The inflow then crosses the basin from the western boundary to the eastern boundary and continues its northward journey. The boundary currents are labeled as I, II, III depending on their locations. The crossover latitude of the boundary current divides the basin into southern and northern gyres. In the interior of the north and south gyres, the density is assumed to have the uniform values of $\rho_{\text {ins }}$ and $\rho_{\text {inN }}$. Motion in the interior region is weak and is neglected in the ad hoc analytical model. Previous studies have shown that buoyancy losses in the interior region are balanced by transports of heat and freshwater due to eddies originating from the boundary currents (Visbeck et al., 1996; Marshall and Schott, 1999; Spall, 2004, 2011 and 2013; Isachsen and Nost, 2012). According to their research, a parameterization of eddy density flux is derived in Appendix A. In the ad hoc analytical model, the densities and velocities of boundary currents can be estimated successively for currents I, II, III for a given $Y_{C}$. 


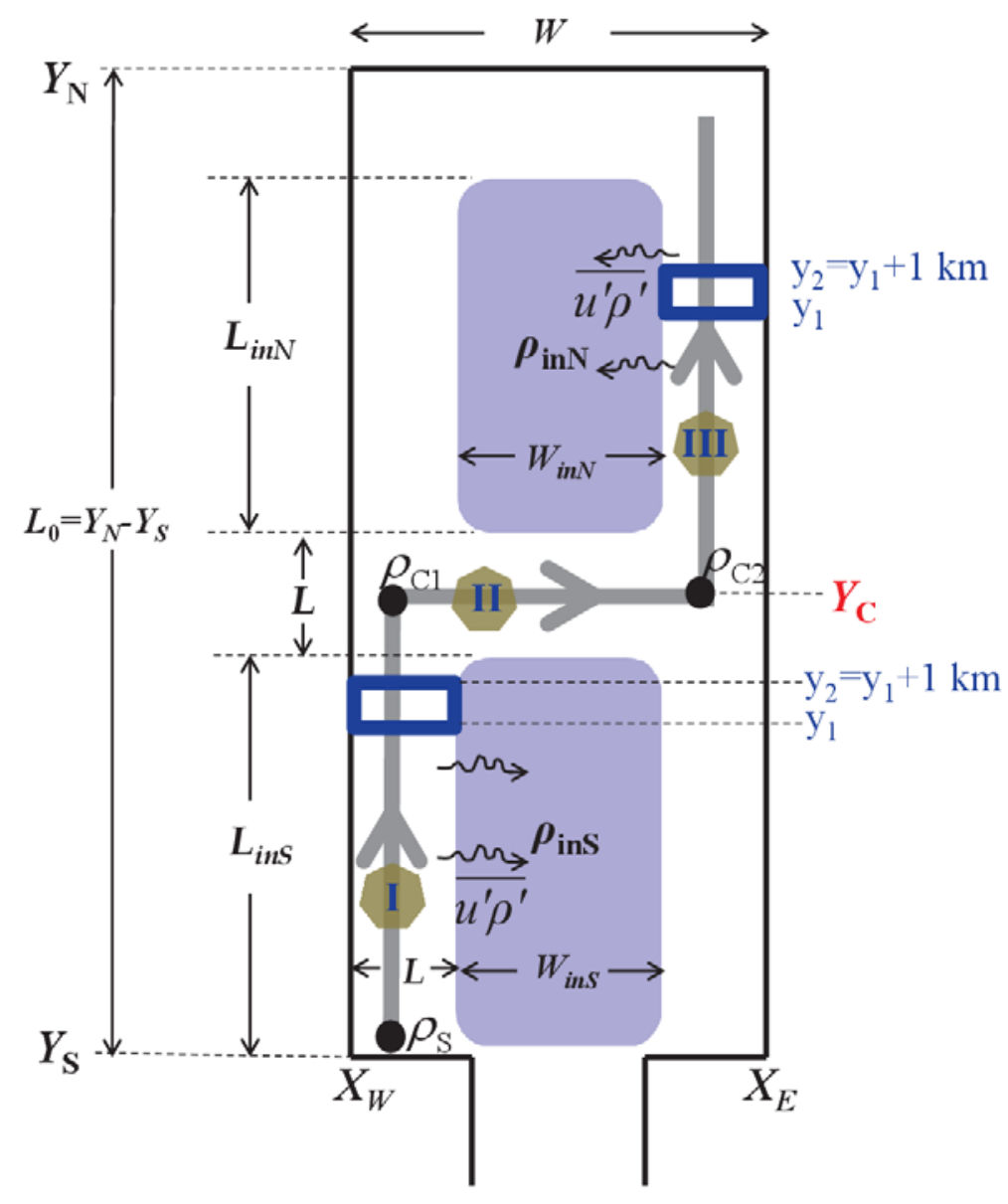

Figure 3.11: A schematic diagram illustrating the boundary currents in the ad hoc analytical model.

Firstly, we will estimate density and velocity for boundary current I. The density equation in boundary current I can be written as

$$
v_{1} \frac{\partial \rho_{1}}{\partial y}=\frac{B_{0}}{H}-\frac{\partial}{\partial x} \overline{u^{\prime} \rho^{\prime}},
$$

where $\rho_{1}(y)$ and $v_{1}(y)$ are the characteristic density and velocity of boundary current I at a given $\mathrm{y}, H(=200 \mathrm{~m})$ is the vertical scale of the boundary current, $B_{0}(y)$ is the sea surface buoyancy loss (with units of $\mathrm{kg} \mathrm{m}^{-2} \mathrm{~s}^{-1}$ ), and $\overline{u^{\prime} \rho^{\prime}}$ represents the zonal eddy buoyancy flux. We 
have assumed in Eq. (3.3) that the mean meridional advection of density is much larger than the meridional divergence of eddy flux. Integration of Eq. (3.3) across the boundary current I leads to

$$
v_{1} \frac{\partial \rho_{1}}{\partial y}=\frac{B_{0}}{H}-\frac{\left.\overline{u^{\prime} \rho^{\prime}}\right|_{x=L}}{L},
$$

Assuming that eddy flux along the offshore side of boundary current I is uniform and using Eq. (A1), the density equation in boundary current I is obtained:

$$
v_{1} \frac{\partial \rho_{1}}{\partial y}=\frac{1}{H}\left(B_{0}+\frac{W_{i n S} B_{T S}}{L L_{i n S}}\right)=\frac{B_{E}}{H},
$$

where $W_{i n S}$ and $L_{i n S}$ are width and length of interior region in the southern gyre, $L$ is the width of the boundary current, $B_{T S}=\int_{Y_{S}}^{Y_{C}} B_{0} d y, Y_{S}$ is the southern boundary of the southern gyre and $Y_{C}$ is the crossover latitude. Eq. (3.5) indicates that buoyancy losses in boundary current I is a combination of buoyancy losses into the atmosphere $\left(B_{0}\right)$ and buoyancy losses into the interior region $\left(\frac{W_{i n S} B_{T S}}{L L_{i n S}}\right)$

Through the thermal wind relation, the characteristic boundary velocity at a given $y$ can be estimated as

$$
v_{1}(y)=\frac{H g}{2 \rho_{0}\left(f_{0}+\beta y\right)} \frac{\rho_{1}(y)-\rho_{i n S}}{L},
$$


where $\rho_{\text {ins }}$ is the density of the interior region in the southern gyre. Substituting $v_{1}$ in Eq. (3.6) into (3.5) and integrating the result from the southern end of the boundary current $Y_{S}$ to an arbitrary latitude $y$ leads to

$$
\rho_{1}(y)^{2}-2 \rho_{i n S} \rho_{1}(y)-\left(\rho_{S}^{2}-2 \rho_{i n S} \rho_{S}\right)-2 F_{1}(y)=0,
$$

where $\rho_{S}$ is the density at the southern end of the boundary current and $F_{1}(y)=\int_{Y_{S}}^{y} \frac{2 B_{E}\left(f_{0}+\beta y\right) \rho_{0} L}{H^{2} g} d y$. For a northward flow, Eq. (3.6) suggests that $\rho_{1}$ is larger than $\rho_{\text {ins }}$. The appropriate root in the quadratic Eq. (3.7) is then

$$
\rho_{1}(y)=\rho_{i n S}+\sqrt{\left(\rho_{S}-\rho_{i n S}\right)^{2}+2 F_{1}(y)} .
$$

An estimate for the density difference between the boundary current and interior region can be formulated by balancing the surface buoyancy losses in the interior region with the eddy fluxes from the boundary current. The latter is assumed to be caused by baroclinic instability and can be parameterized in terms of the boundary layer velocity. The implementation of this constraint, which is detailed in the Appendix A, leads to

$$
\rho_{b S}-\rho_{i n S}=\sqrt{\frac{2 W_{i n S} B_{T S} \rho_{0} \overline{f_{S}} L}{c H^{2} g L_{i n S}}},
$$

where $\rho_{b S}$ is the mean density of the western boundary current I (i.e. the average of $\rho_{1}$ from $Y_{S}$ to $\left.Y_{C}\right), \overline{f_{S}}$ is the mean Coriolis parameter in the southern gyre, and $c$ is an empirical constant related to the efficiency of buoyancy transport by eddies. 
If we choose a value of $L_{\text {ins }}$, we are essentially guessing a value of the crossover latitude $Y_{C}=Y_{S}+L_{i n S}+L / 2$ (Figure 3.11). For a given $Y_{C}$ there are three unknown variables in Eqs. (3.6), (3.8) and (3.9): the density $\rho_{1}(y)$ and velocity $v_{1}(y)$ of boundary current $\mathrm{I}$, and the constant interior density $\rho_{\text {ins }}$. It is difficult to obtain solutions analytically, so we solve using an iterative procedure. Since $\rho_{i n S}$ is smaller than $\rho_{S}$, we run through a sequence of trial values of $\rho_{i n S}$ according to $\rho_{i n S}=\rho_{S}-n \times 0.01(n=1,2,3, \cdots)$. For each $\mathrm{n}$, we substitute the trial $\rho_{\text {inS }}$ into Eq. (3.8) and calculate the corresponding $\rho_{1}(y)$. The average of $\rho_{1}(y)$, i.e. $\rho_{b S}$, is then calculated and substituted into Eq. (3.9). We step through successive values of $n$ until Eq. (3.9) is satisfied and the numerical solutions of $\rho_{1}(y)$ and $\rho_{\text {ins }}$ are obtained. The boundary current speed $v_{1}(y)$ can then be calculated from Eq. (3.6). This gives us a table of values of the three variables for various trial crossover latitudes.

We next turn to the calculation of density and velocity along the crossover current at $y=Y_{C}$ (current II). According to the thermal wind relation, the characteristic velocity of current II is given by

$$
u_{2}(x)=\frac{H g}{2 \rho_{0}\left(f_{0}+\beta Y_{C}\right)} \frac{\rho_{i n N}-\rho_{i n S}}{L},
$$

where $\rho_{i n N}$ is the density of the interior region in the northern gyre. It is assumed that there is no eddy flux generated by crossover current II, thus the density equation for II can be simply written as

$$
u_{2} \frac{d \rho_{2}}{d x}=\frac{B_{0}}{H}
$$


Integrating Eq. (3.11) from the western boundary $x=X_{W}$ to an offshore location $x$, the density for current II can be calculated by

$$
\rho_{2}(x)=\rho_{\mathrm{C} 1}+\int_{X_{W}}^{x} \frac{2 L B_{0} \rho_{0}\left(f_{0}+\beta Y_{C}\right)}{H^{2} g\left(\rho_{i n N}-\rho_{i n S}\right)} d x,
$$

where $\rho_{\mathrm{C} 1}$ is the density at the western coast at $y=Y_{C}$ [and can be calculated from (3.8)]. Since $\rho_{i n N}$ is unknown, $\rho_{2}$ can't be estimated through (3.12) alone.

Densities and velocities for boundary currents III can be calculated through the same method used for estimating $\rho_{1}$ and $v_{1}$. The resulting relations (presented in Appendix A) can be used to calculate the difference between the mean density of northern boundary currents III $\rho_{b N}$ and the interior density $\rho_{i n N}$ in the northern gyre:

$$
\rho_{b N}-\rho_{i n N}=-\sqrt{\frac{2 W_{i n N} B_{T N} \rho_{0} \overline{f_{N}} L}{c H^{2} g L_{i n N}}} .
$$

There are five unknown variables in the northern gyre system: the densities $\rho_{2,3}$, the velocities $v_{2,3}$ and $\rho_{i n N}$. These variables can be obtained by solving five equations including two density equations and two thermal wind relations for currents II, III, and Eq. (3.13). $\rho_{b N}$ in Eq. (3.13) is average of $\rho_{3}$. The solution here is for an assumed value of the crossover latitude Yc. Each Yc has a different set of solutions.

\subsubsection{PV Constraints on the Boundary Currents and Crossover Latitude}


In the last subsection, densities and velocities of boundary currents I and III are estimated. In this subsection, these values will be substituted into the PV equation to calculate the advection of PV. The crossover of boundary currents occurs where the sign of PV advection changes from positive to negative.

In the ad hoc analytical model, eddies are assumed to be generated along the rim of boundary currents I and III. In boundary currents I and III the zonal velocity is zero and the meridional eddy flux is assumed to be negligible. Using density equation (3.3), the advection and eddy terms in Eq. (3.2) can be written as

$v_{1,3} \frac{\partial q_{1,3}}{\partial y}+\frac{\partial}{\partial x} \overline{u^{\prime} q^{\prime}}=v_{1,3} \beta-\frac{f_{0} g / N^{2}}{\rho_{0} H / 2}\left(v_{1,3} \frac{\partial\left(\rho_{\mathrm{a} 1,3}+\rho_{0}\right)}{\partial y}+\frac{\partial}{\partial x} \overline{u^{\prime} \rho^{\prime}}\right)=v_{1,3} \beta-\frac{2 f_{0} g B_{0}}{\rho_{0} H^{2} N^{2}}$.

We now use Eq. (3.14) to substitute for the eddy flux term into Eq. (3.2) and then integrate the result horizontally over the area surrounded by the blue rectangle (Figure 3.11), which may be situated either in boundary current I or boundary current III. The PV budget is then expressed by

$$
L \int_{y_{1}}^{y_{2}}\left(v_{1,3} \beta-\frac{2 f_{0} g B_{0}}{\rho_{0} H^{2} N^{2}}\right) d y=\iint_{A} \operatorname{curl} \boldsymbol{F}_{r} d x d y .
$$

The left-hand side of (3.15) is associated with PV advection due to both the mean flow and the eddy component. The eddy term is not shown explicitly in (3.15), yet it can affect $v_{1,3}$. The advection of PV on the left hand side of (3.15) is balanced by the frictional torque on the right hand side. If PV advection is positive, $\mathrm{PV}$ in the rectangle has a tendency to decrease. To balance PV advection, water must gain positive PV, which can be provided by friction along the western boundary. Therefore, when PV advection is positive, the northward flow moves along western 
boundary. The reverse is true that when PV advection is negative the northward flow should move along eastern boundary. The crossover of boundary current occurs at the latitude where the total PV advection decreases to 0 in boundary current I. The crossover latitude is not influenced by the PV advection in boundary current III in the ad hoc analytical model. However, PV advection in boundary current III is still calculated and shown in the following description in order to describe how the meridional gradient of surface buoyancy forcing influences the PV advection in boundary currents I and III.

Substituting velocities and surface buoyancy loss of boundary currents I or III into (3.15), the estimated PV advection is plotted in Figure 3.12, in which parameters from EXP0 are used, such that $\beta=2.1 \times 10^{-11} \mathrm{~s}^{-1} \mathrm{~m}^{-1}, f_{0}=3.5 \times 10^{-5} \mathrm{~s}^{-1}, g=9.8 \mathrm{~m} \mathrm{~s}^{-2}$. We have chosen $\rho_{S}$ in (3.7) as 1027.6 $\mathrm{kg} \mathrm{m}^{-3}$ and have verified that the resulting crossover latitude is not sensitive to reasonable variations in this choice. $N^{2}$ is chosen $2.4 \times 10^{-5} \mathrm{~s}^{-2}$ based on EXP0 results. The empirical constant $c$ ranges from 0.008 to 0.03 through estimations in numerical experiments by using (A4) and (A6). $c=0.015$ is used in the ad hoc analytical model, and the sensitivity of the crossover latitude in the ad hoc analytical model to $N^{2}$ and $c$ will be discussed below. The method of determining the crossover latitude in the ad hoc analytical model is illustrated in Figure 3.12. As shown in Figure 3.12, if we guess $Y_{C}=600 \mathrm{~km}$, PV advection calculated through (3.15) is positive south of $1100 \mathrm{~km}$, which implies that boundary current south of 1100 $\mathrm{km}$ should be on the western boundary. By guessing $Y_{C}=600 \mathrm{~km}$ in the ad hoc analytical model, it has already been assumed that north of $600 \mathrm{~km}$, the boundary current should be on the eastern boundary (Figure 3.11). However, the result calculated from (3.15) conflicts with the initial assumption. Therefore, $600 \mathrm{~km}$ is not the correct crossover latitude. If we choose $Y_{C}=1060 \mathrm{~km}$, 
PV advection is positive south of $1060 \mathrm{~km}$ and is negative north of $1060 \mathrm{~km}$. The sign of PV advection in the ad hoc analytical model agrees with the assumption of $Y_{C}=1060 \mathrm{~km}$. Therefore, $1060 \mathrm{~km}$ is the crossover latitude for EXP0 parameters. That is to say that the crossover occurs where PV advection vanishes. Using this criterion, crossover latitudes for different parameters can be estimated. It has been mentioned that the boundary circulation is cyclonic in the numerical model that is forced by a uniform buoyancy loss with constant Coriolis parameter (Spall, 2004). According to Eq. (3.15), when the Coriolis parameter is constant, the contribution from planetary PV is zero and the stretching PV dominates the PV advection, which leads to an overall cyclonic boundary current.

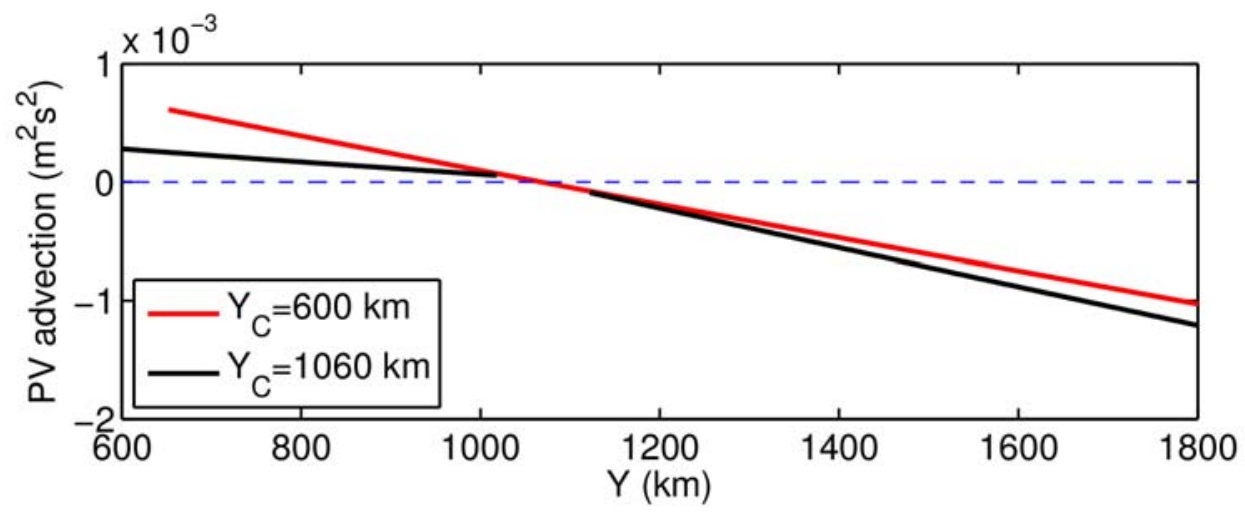

Figure 3.12: PV advection shown in (3.15). $f_{0}, \beta$ and surface buoyancy flux used in this example are the same as EXP0.

PV advection in (3.15) includes contributions from planetary PV and the term associated with surface buoyancy loss. As shown in Figure 3.13, contributions from planetary PV and buoyancyloss term to total PV advection have opposite signs. It is shown in Figure 3.13 that in the southern gyre, the contribution from planetary PV dominates in the total PV advection and the northward boundary current is on the western coast; and in the northern gyre, buoyancy-loss term becomes more important than planetary PV and the northward boundary current in on the 
eastern coast. Therefore, the competition between planetary PV and buoyancy-loss term determines the latitude where the circulation changes from anticyclonic to cyclonic, i.e. the crossover latitude of the northward western boundary current. Planetary PV is associated with $\beta$ and buoyancy-loss term increases with $f_{0}$ and with surface buoyancy loss. As a result, the crossover latitude is anticipated to increase with $\beta$ and decrease with $f_{0}$, which is supported by Figure 3.14. In Figure 3.14, the ad hoc analytical model indicates that the crossover latitude moves further north when $f_{0}$ is decreased or $\beta$ is increased. It is also indicated in Figure 3.14 that when the meridional gradient of the surface buoyancy flux decreases, the crossover latitude moves further south. That is because when the gradient decreases, the surface buoyancy losses become stronger in the southern Red Sea and the contribution of stretching PV increases. As a result, the crossover latitude moves southward. The crossover latitude increases when $\beta$ increases, $a$ increases, or $f_{0}$ decreases. Scaling analysis implies that crossover latitude is proportional to $\left(\frac{\beta}{f_{0}} \frac{a}{B_{m}}\right)^{1 / 2} L_{R S}{ }^{2}$, where a is meridional gradient of surface buoyancy forcing, $B_{m}$ is mean buoyancy forcing averaged over the entire basin, $L_{R S}$ is the length of the Red Sea, which is a constant in this study. The linear correlation coefficient between $\left(\frac{\beta}{f_{0}} \frac{a}{B_{m}}\right)^{1 / 2} L_{R S}{ }^{2}$ and crossover latitude is 0.91 (Figure 3.15). However, since the crossover latitude is not influenced by what happens in the northern part of the Red Sea in the analytical model, $L_{R S}$ might not be the correct length scale. Further study is needed to explore the right length scale of the crossover latitude. 

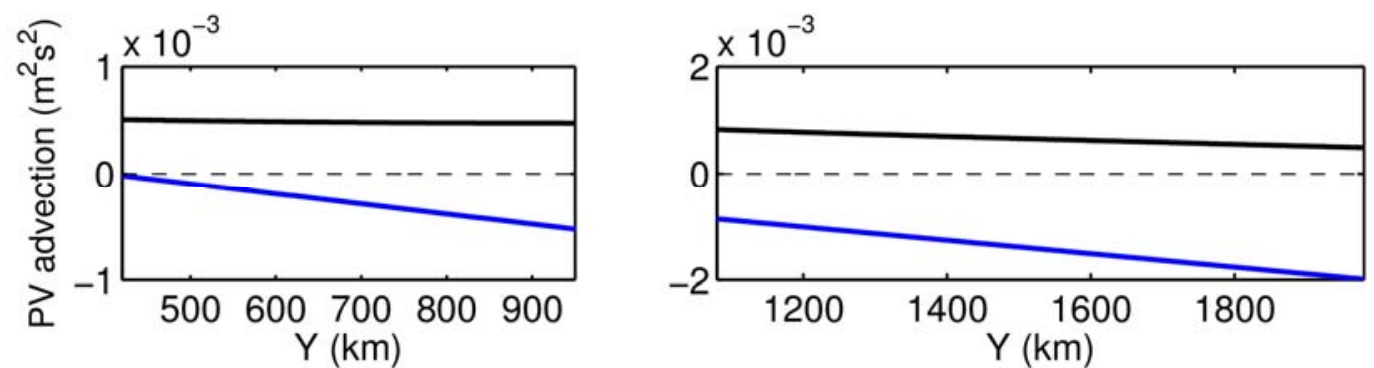

Figure 3.13: PV advection $\left(\mathrm{m}^{2} \mathrm{~s}^{2}\right)$ due to planetary PV (black) and stretching PV (blue).
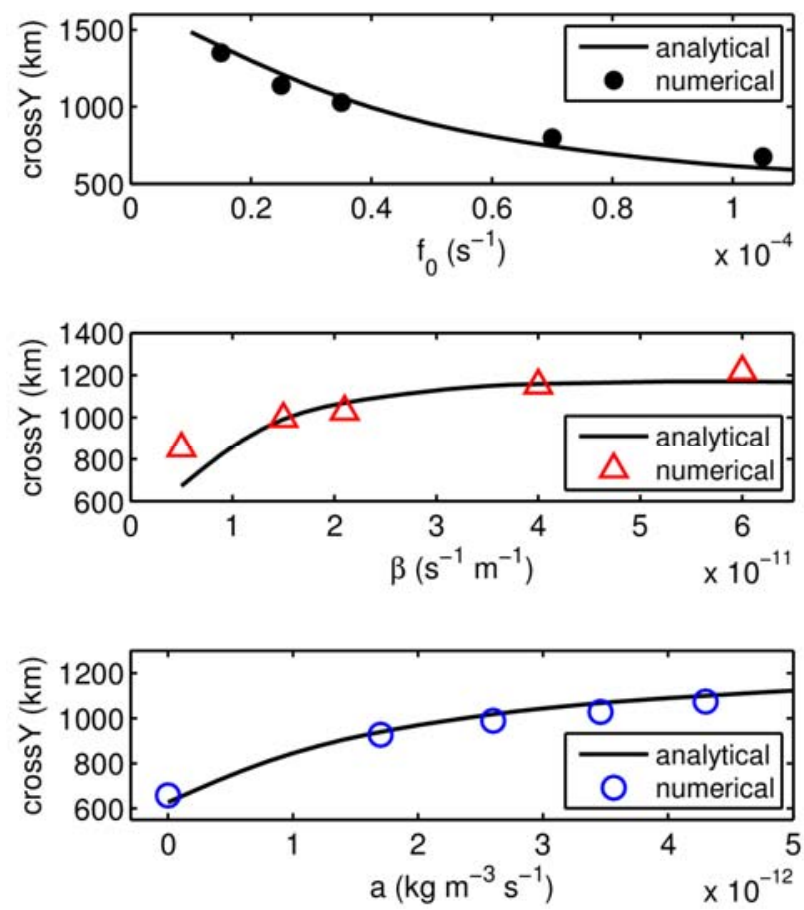

Figure 3.14: Variations of crossover latitude due to variations in (a) $f_{0}$, (b) $\beta$, and (c) meridional gradient of surface buoyancy loss $a$. The parameters for each experiment are given in Table 3.1. 


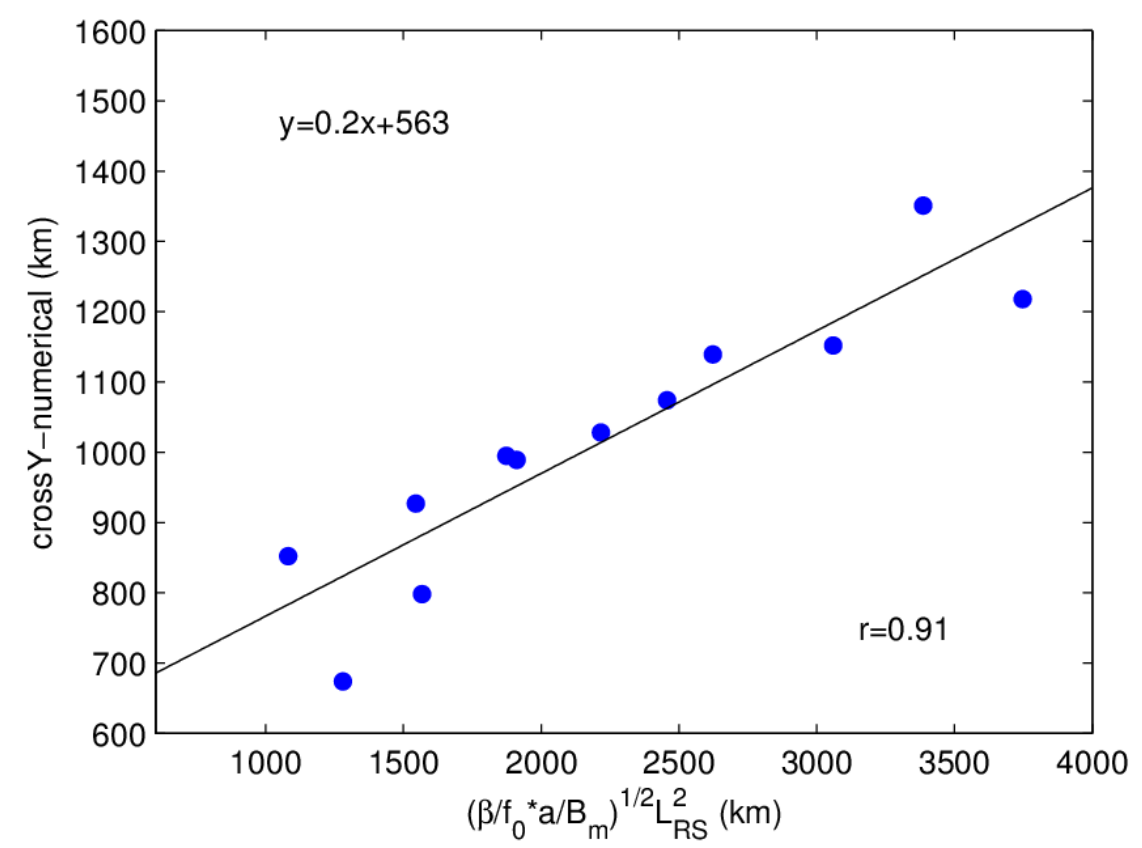

Figure 3.15: Comparison between crossover latitude calculated from the ad hoc analytical model and the scaling parameter $\left(\frac{\beta}{f_{0}} \frac{a}{B_{m}}\right)^{1 / 2} L_{R S}{ }^{2}$. The black line is the least squares fit line to the points plotted in this figure.

As shown in Figure 3.16, there is good agreement between the ad hoc analytical model and the numerical model in the value of the crossover latitude. They are related to each other with a least squares fit slope of 0.82 and a correlation coefficient of 0.98 . The slope of the least squares line is smaller than one. The ad hoc analytical model tends to overestimate crossover latitude when crossover latitude is larger than about $1050 \mathrm{~km}$, and underestimate crossover latitude when Yc is smaller than $1050 \mathrm{~km}$. The reason is that $N^{2}$ used in the ad hoc analytical model is a constant based on results in EXP0. However, $N^{2}$ is different in different numerical experiments. When the crossover latitude is larger, the mean stratification in the northern gyre will decrease because stratification weakens northward due to surface buoyancy loss. For example, $N^{2}$ reduces to $1.5 \times 10^{-5} \mathrm{~s}^{-2}$ in the northern gyre in EXP2, which has crossover latitude of $1351 \mathrm{~km}$. Therefore, 
if $N^{2}$ from EXP0 is used in the ad hoc analytical model to estimate the crossover latitude for EXP2, the contribution from stretching PV is underestimated and thus the crossover latitude tends to be larger than what is simulated in the numerical model.

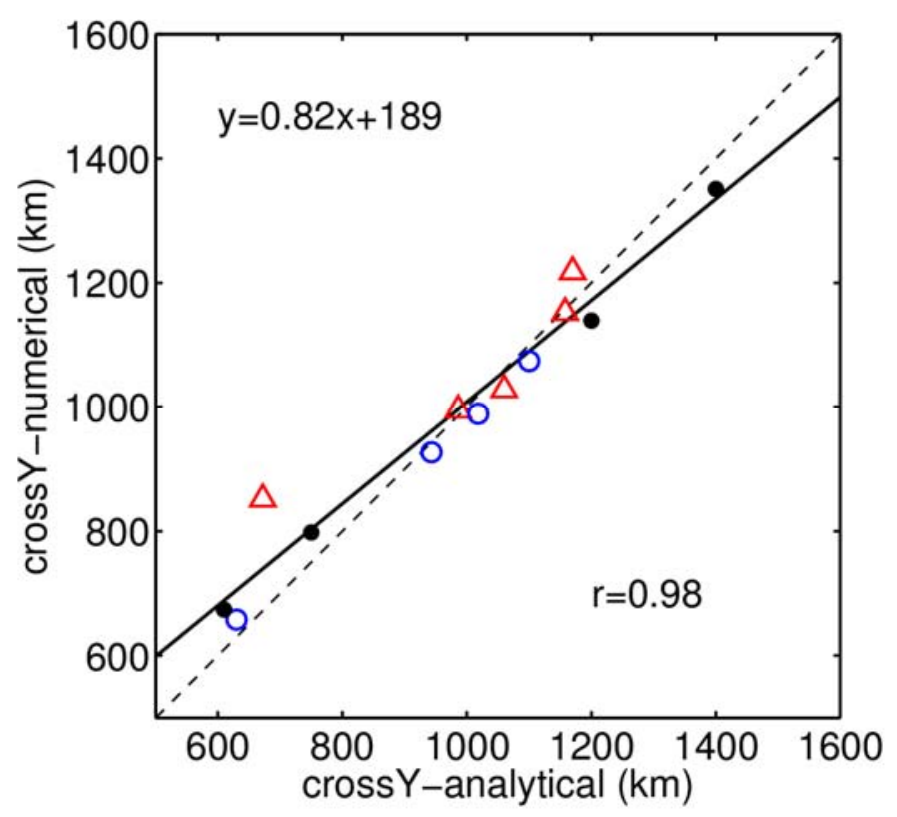

Figure 3.16: Comparison between the ad hoc analytical model and a series of numerical model. The meaning of different types of symbols is described in Table 3.1. Black dots-changing $f_{0}$; red triangle- changing $\beta$; blue circle-changing meridional gradient of surface buoyancy flux. The black line is the least squares fit line to the points plotted in this figure. The dashed line represents $\mathrm{y}=\mathrm{x}$.

The crossover latitude calculated from the ad hoc analytical model is sensitive to $N^{2}$. For example, when $N^{2}$ is chosen to be $3 \times 10^{-5} \mathrm{~s}^{-2}$ instead of $2.4 \times 10^{-5} \mathrm{~s}^{-2}$ in the ad hoc analytical model, the linear relation between the crossover latitude in the numerical model and that in the ad hoc analytical model is $\mathrm{y}=0.75 \mathrm{x}+168$ with a correlation coefficient of 0.92 (Figure 3.17). The crossover latitude estimated by the ad hoc analytical model is also sensitive to the efficiency coefficient $c$ that arises in the parameterization of baroclinic instability. When $c$ is changed 
from 0.015 to 0.03 in the ad hoc analytical model, the linear relation between the crossover latitude in the numerical model and that in the ad hoc analytical model changes to $\mathrm{y}=0.87 \mathrm{x}+232$ with a correlation coefficient of 0.98 (Figure 3.17 ). We have kept $N^{2}$ and $c$ fixed in the ad hoc analytical model.

Eq. (3.15) includes the effects of eddy fluxes implicitly. If the eddy effect is not considered, the crossover latitude should lie roughly where the northward PV gradient is zero. Figure 3.18 plots PV at the surface averaged within the boundary currents in EXP0 and EXP1. Table 3.1 shows that the crossover latitudes in EXP0 and EXP1 are 1028 and $1351 \mathrm{~km}$, respectively. Thus south of the crossover latitudes, PV in the western boundary currents is plotted in Figure 3.18; while north of the crossover latitude, PV in the eastern boundary currents is plotted. In EXP0, PV stops increasing at about $920 \mathrm{~km}$ along western boundary. In EXP1, PV stops increasing at about 1250 $\mathrm{km}$. Western boundary currents start to separate from the western coast at these latitudes. North of the crossover latitudes, PV decreases with latitude along the eastern boundary in both EXP0 and EXP1. Results shown in Figure 3.18 supports the idea that the crossover latitude lies roughly where the northward PV gradient is zero, which is also the basic dynamics of the ad hoc analytical model when eddy flux is not considered. 


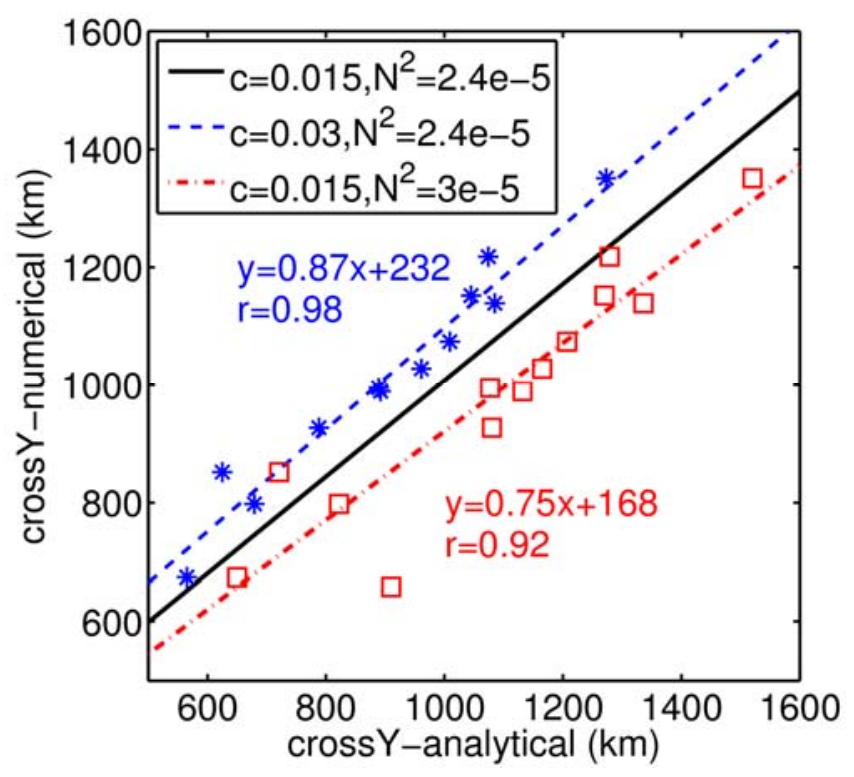

Figure 3.17: Test of sensitivity of crossover latitude to $c$ and $N^{2}$. The black line is the same as that in Figure 3.16, which represents ad hoc analytical model with $c=0.015$ and $N^{2}=2.4 \times 10^{-5} \mathrm{~s}^{-2}$. The red dash-dotted line and squares represent the ad hoc analytical model results with $c=0.015$ and $N^{2}=3 \times 10^{-5} \mathrm{~s}^{-2}$. The blue dashed line and stars represent ad hoc analytical model results with $c=0.03$ and $N^{2}=2.4 \times 10^{-5} \mathrm{~s}^{-2}$. 

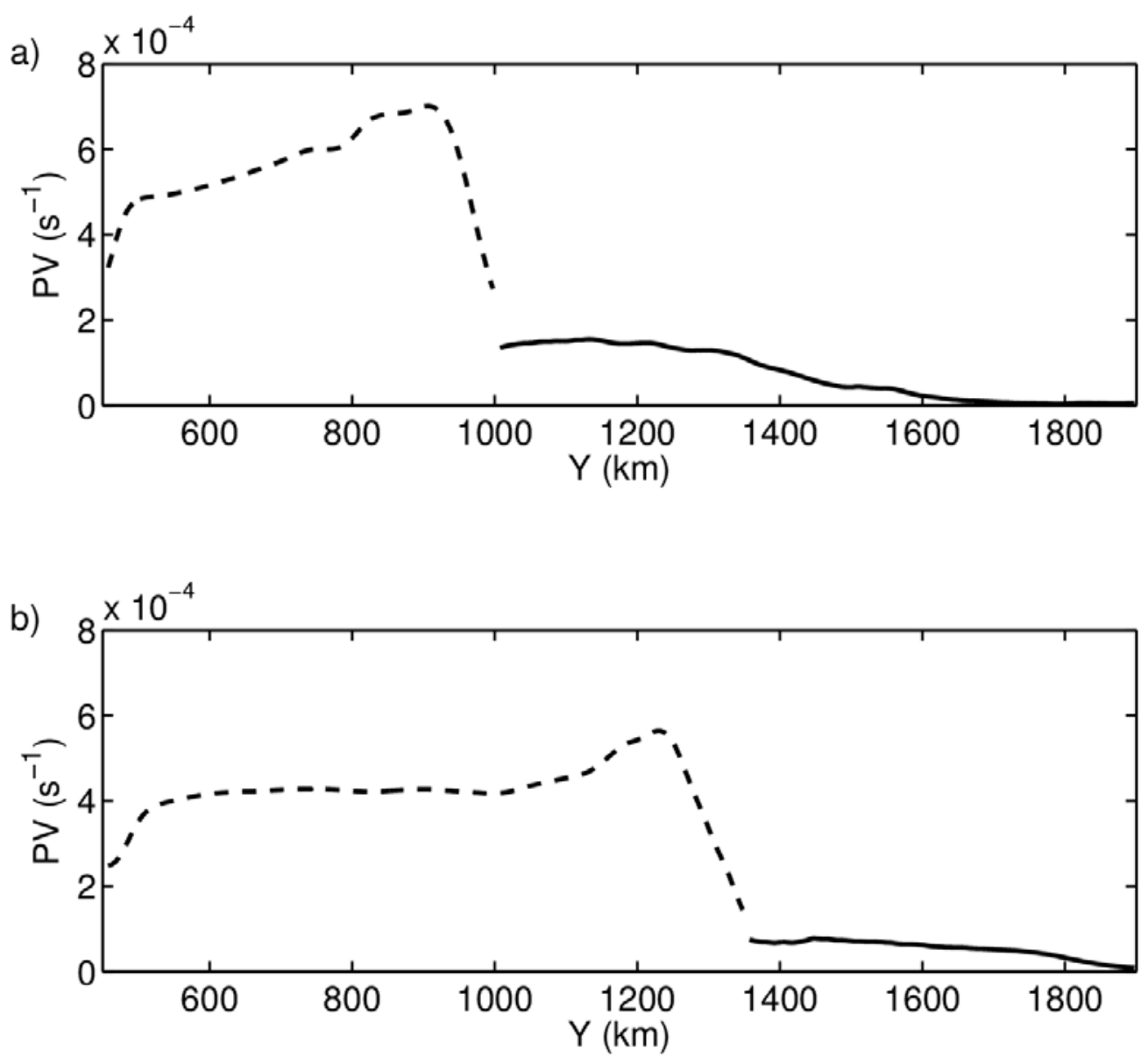

Figure 3.18: PV in boundary currents in (a) EXP0 and (b) EXP1. Dashed lines represent PV in western boundary currents and solid lines represent PV in eastern boundary current.

\subsection{Summary and Conclusions}

The buoyancy-driven circulation in the idealized Red Sea has been studied using a numerical and ad hoc analytical model on a $\beta$-plane. A specific configuration of the numerical model is that the surface buoyancy fluxes have a meridional gradient. Both freshwater and heat losses are stronger in the northern Red Sea than those in the southern Red Sea. The buoyancy losses in the idealized Red Sea are balanced by transports of freshwater and heat through the Strait of Bab el Mandeb. When the inflow enters the Red Sea, it turns left and moves northward on the western boundary 
until it reaches a certain latitude. The western boundary current then crosses the basin to the eastern boundary and continues its northward journey. The basic circulation consists of an anticyclonic gyre in the southern Red Sea and a cyclonic gyre in the northern Red Sea. This feature is different from the buoyancy-driven boundary circulation that arises in f-plane, semienclosed basin where the surface inflow from the open ocean flows cyclonically around the boundaries (e.g. Spall, 2004).

In order to understand what controls the crossover latitude of the western boundary current in the idealized Red Sea, a series of numerical experiments have been carried out, in which $f_{0}, \beta$ and the meridional gradient of the surface buoyancy fluxes are varied. The results of numerical experiments indicate that the crossover latitude of the western boundary current moves further north with smaller $f_{0}$, larger $\beta$ or larger meridional gradient of surface buoyancy fluxes. An $a d$ hoc analytical model based on thermal wind relation, density equation and PV dynamics agrees well with the numerical results. The advection of planetary PV tends to generate anticyclonic boundary currents, while the buoyancy-loss term tends to generate cyclonic boundary currents. Therefore, it is the competition between the advection of planetary PV and buoyancy-loss term that determines the crossover latitude of the northward western boundary current.

Both the numerical model and the ad hoc analytical model suggest that the crossover latitude varies with surface buoyancy forcing. If the mean surface buoyancy forcing increases, the contribution to the total PV advection from buoyancy forcing will increase, resulting in smaller crossover latitude. If the seasonal or interannula variation of surface buoyancy forcing is known, the corresponding variation of crossover latitude could be estimated by the ad hoc analytical 
model. For example, if the meridional gradient of the surface forcing increases, the crossover latitude will move northward.

Pedlosky and Spall (2005) studied the buoyancy-driven circulation in a $\beta$-plane using a quasigeostrophic two-layer model. They found that vertical velocity is enhanced in the narrow boundary currents. The vertical velocity in this chapter has a similar structure to the analytical model result in Pedlosky and Spall (2005). As shown in Figure 3.19, there is a pair of intense downwelling and upwelling along the western boundary, and the eastern boundary is dominated by downweling. The upwelling and downwelling near the western boundary in my model is much weaker than that in Pedlosky and Spall (2005). This could be a result of the sloping bottom in my model. In their study, there is a closed cyclonic gyre in the northern part of the model domain. In the southern part, the flow is constrained to be primarily zonal in the interior, with northward boundary currents along both eastern and western boundaries. Their circulation pattern in the northern part is very similar to what is simulated in the numerical experiments in this chapter. However, circulation in the southern basin is quite different since there is a closed anticyclonic gyre in this chapter. There are some numerical simulations in their paper that have something like a crossover, but it is much broader than what is found in the Red Sea circulation. There is no sharp crossover latitude. The discrepancy between Pedlosky and Spall (2005) and this chapter might be due to the model configuration. The inflow transport in their model is specified while the inflow transport in this thesis is part of the solution. In addition, the upperlayer thickness in their study is restored toward a specific value. Therefore, the buoyancy forcing in their study varies with time. However, the buoyancy forcing is steady in this chapter. The different model configuration might have caused the discrepancies. 


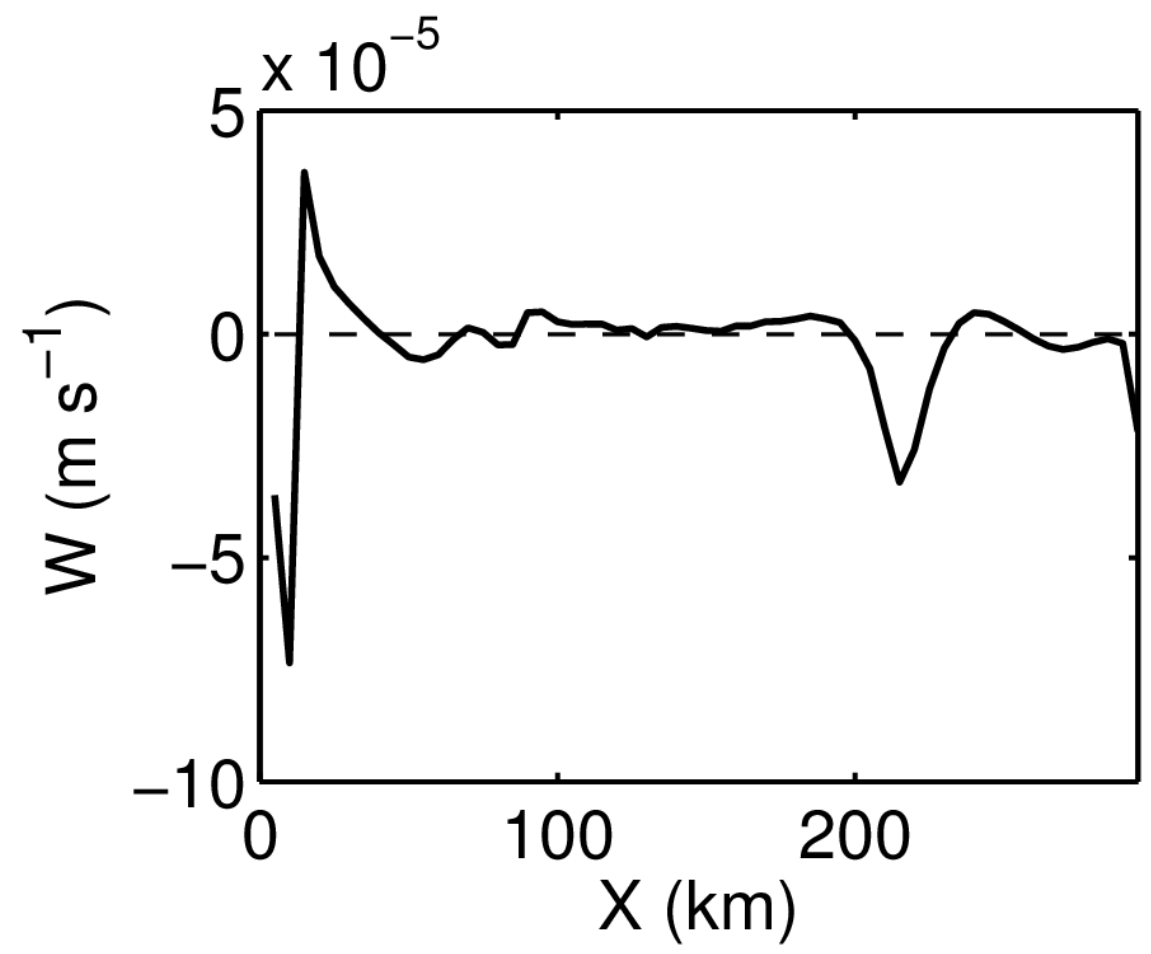

Figure 3.19: Mean vertical velocity $\left(\mathrm{m} \mathrm{s}^{-1}\right)$ in the northern gyre in EXP0.

Buoyancy-driven circulation in the idealized Red Sea consists of an anticyclonic boundary circulation in the southern Red Sea and a cyclonic boundary circulation in the northern Red Sea. This circulation pattern is very similar to that in the North Atlantic and North Pacific which includes an anticyclonic gyre in the subtropical region and a cyclonic gyre in the subpolar region. However, it is generally agreed that the two-gyre circulation in the North Atlantic and North Pacific is driven by wind forcing. On the contrary, the Red Sea circulation is primarily determined by buoyancy forcing.

It is natural to ask how the wind might influence the crossover latitude. In winter, wind in the northern Red Sea blows toward southeast and wind in the southern Red Sea blows toward northwest (Figure 3.20). Due to friction on both sides, wind near coast is weaker than that in the middle of the basin (Figure 3.20). In an idealized case (Figure 3.21), in the southern Red Sea 
wind stress curl is negative in the eastern half of the basin and is positive in the western half of the basin. In the northern Red Sea wind stress curl is positive in the eastern half and is negative in the western half. According to the Sverdrup relation, there should be a cyclonic gyre in the northern Red Sea and an anticyclinic gyre in the southern Red Sea. Therefore, winter wind in the Red Sea generates a circulation pattern that is similar to that generated by buoyancy forcing. There is a crossover latitude due to wind only, which would be south of the crossover latitude due to buoyancy forcing only found in Sofianos and Johns (2003) and Yao et al. (2014b).

The eddy flux originating from boundary currents, plays an important role in estimating the crossover latitude in the ad hoc analytical model. The eddy flux is related to the density difference between the boundary current and the interior region. Wind can also alter density in boundary current by driving upwelling or downwelling near coast. Thus wind can also influence the crossover latitude driven by buoyancy forcing by changing the density difference between the boundary currents and the interior. Therefore, wind has two impacts on the crossover latitude. One is that wind can generate crossover latitude by itself. The other one is that it can alter the crossover latitude by changing the stratification of boundary currents. 


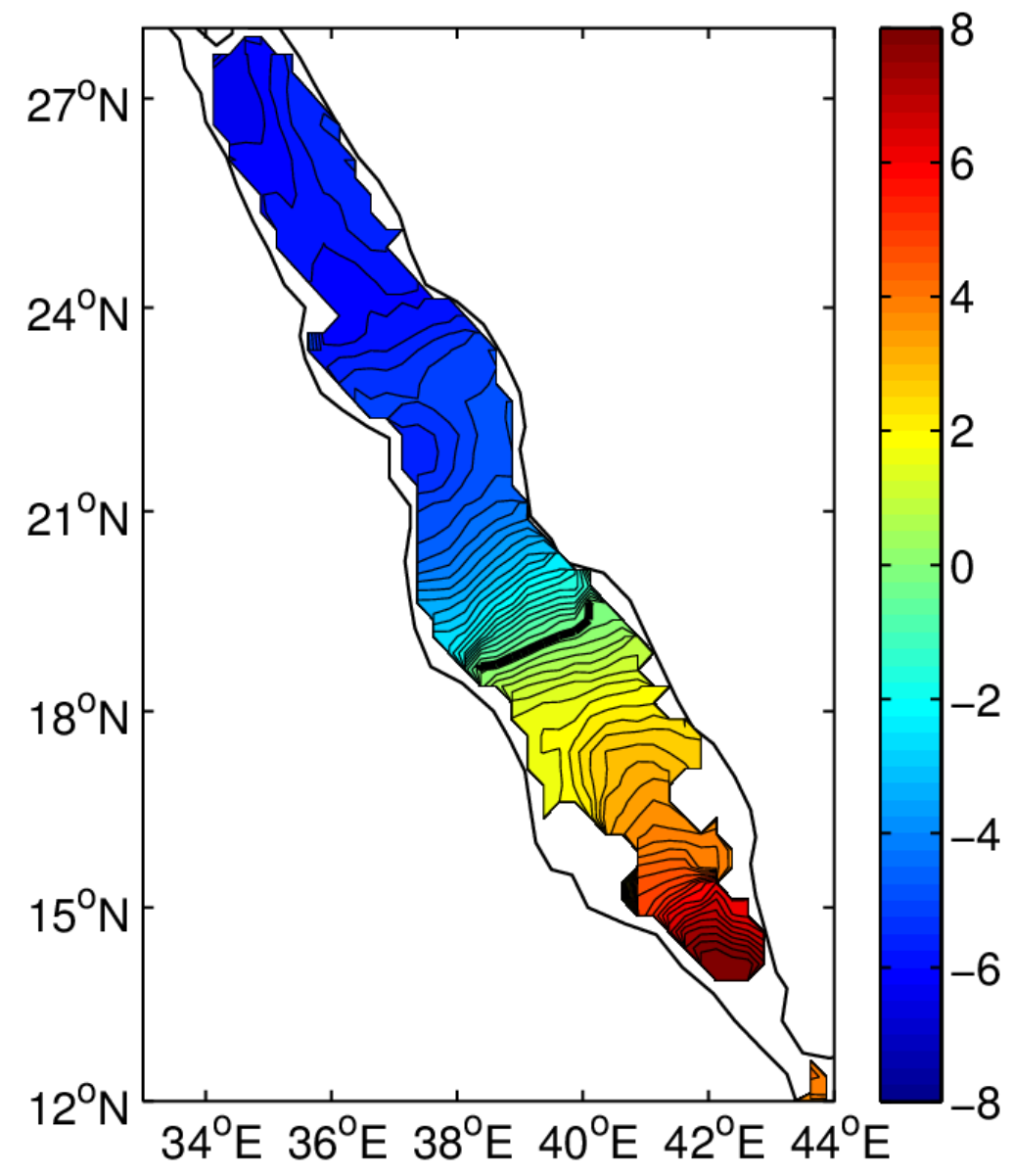

Figure 3.20: Wind component $\left(\mathrm{m} \mathrm{s}^{-1}\right)$ along the central axis of the Red Sea in December averaged from 1999 to 2009 QuikSCAT wind. 


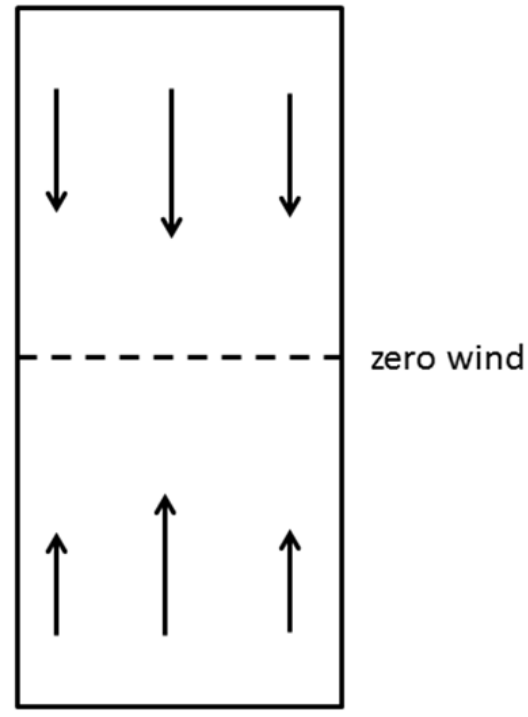

Figure 3.21: An idealized winter wind pattern in the Red Sea. 


\section{Chapter 4}

\section{Eddy Generation Mechanisms in the Red Sea}

\subsection{Introduction}

The focus of the preceding chapter was on mean buoyancy-driven circulation in the idealized Red Sea. Results indicate that the mean horizontal circulation in the idealized Red Sea is composed of several strong boundary currents. However, previous observational and modeling studies have shown that eddies play an important role in Red Sea circulation. Morcos (1970) described surface circulation in the Red Sea, inferred from temperature and salinity data collected in 1895-96 and 1897-98. That study showed a generally cyclonic circulation with a superimposed eddy field. Morcos and Soliman (1972) described a series of mainly cyclonic eddies and an anticyclone centered near $23^{\circ} \mathrm{N}$. Hydrographic surveys conducted from 1982 to 1987 revealed that the circulation of the Red Sea is composed of a series of gyres (Quadfasel and Baudner, 1993). Quadfasel and Baudner (1993) suggested that the cyclonic and anticyclonic gyres are not permanent, but tend to reappear at preferential locations, such as the anticyclone centered at $23^{\circ} \mathrm{N}$ and the cyclone near $26^{\circ} \mathrm{N}$. The distribution of chlorophyll-a from SeaWiFS indicated an anticyclone centered at $23^{\circ} \mathrm{N}$ in August 1998 and an anticyclone centered at $18.7^{\circ} \mathrm{N}$ in October 2002 (Acker et al., 2008). These results indicate that eddies in the Red Sea could influence distribution of chlorophyll-a and biological productivity. Sofianos and Johns (2007) analyzed shipboard ADCP data collected in August 2001 and concluded that a strong dipole was present near $19^{\circ} \mathrm{N}$, with a cyclonic eddy in the north and an anticyclonic eddy in the south. Mesoscale eddies can also be detected through analysis of satellite-derived sea level anomaly 
(SLA). Figure 4.1 is a snapshot of SLA, which is typical of anytime. It clearly shows the presence of anticyclonic and cyclonic eddies throughout the basin.

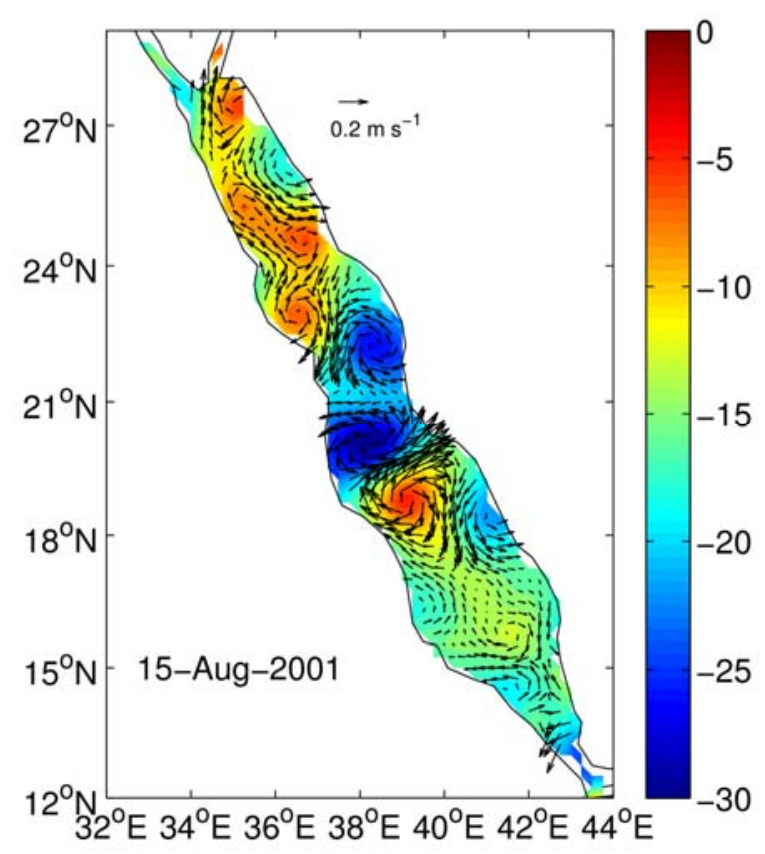

Figure 4.1: SLA (cm) and surface geostrophic current amomaly on August 15, 2001.

Previous observations and model work suggest that eddies in the Red Sea contribute to the main circulation pattern and the formation of water masses, such as the formation of Red Sea Overflow Water in the north, where there is apparently a persistent cyclonic gyre. The cyclonic gyre is usually associated with thermocline uplift, which might lead to the ventilation of the thermocline. Thermocline uplift in the center of the cyclonic eddy may bring cold water and nutrients from deep water to the surface layer, which is generally oligotrophic. This could increase regional productivity. In addition, eddies may transport nutrients from the coastal coral reefs into the interior of the Red Sea. Some eddies appear to extend across the width of the basin, 
which enhances the interaction between the two coasts. For example, with an eddy current speed of $1 \mathrm{~m} \mathrm{~s}^{-1}$, a particle could travel from the west coast to the east coast in 2 to 3 days.

The mechanisms that control eddy generation in the Red Sea are not well understood. Based on numerical modeling results, Clifford et al. (1997) pointed out that the formation of eddies in the Red Sea strongly depend on wind direction. They proposed that more eddies would be present when the wind had a cross-basin component because there would be more wind stress curl associated with cross-basin winds. Pedgley (1972) called attention to a gap in the high orography on the west coast of the Red Sea near $18^{\circ} \mathrm{N}$, which is called the Tokar Gap. Using the Weather Research and Forecasting (WRF) model, Jiang et al. (2009) pointed out that a series of mountain gaps along both sides of the Red Sea could funnel strong wind jets that blow across the basin. For example, in summer, there is a strong cross-basin wind jet blowing out of the Tokar Gap (the Tokar Wind Jet) onto the Red Sea (Hickey and Goudie, 2007). In winter, the wind jet near the Tokar Gap reverses its direction and blows from the Red Sea into the Tokar Gap (Pedgley, 1974). Zhai and Bower (2013) studied the response of the Red Sea to the Tokar Wind Jet in summer. By comparing scatterometer wind data with satellite SLA data, they found that an intense dipolar eddy spins up in response to the wind jet. The eddy pair has a typical horizontal scale of $140 \mathrm{~km}$, with a maximum speed of $1 \mathrm{~ms}^{-1}$.

Some numerical studies suggest that not all eddies in the Red Sea are generated by wind. For example, the cyclonic eddy in the northern Red Sea was reproduced by numerical simulations using the Miami Isopycnal Coordinate Ocean Model (MICOM), in an experiment forced only by surface buoyancy loss (Sofianos and Johns, 2003). Chen et al. (2014) reproduced the $23^{\circ} \mathrm{N}$ anticyclonic eddy using the unstructured-grid, Finite-Volume Community Ocean Model 
(FVCOM). They found that the eddy is formed by seasonally varying buoyancy forcing. These models indicate that eddies can be generated by surface buoyancy forcing in the Red Sea. However, they don't specify which mechanisms are responsible for eddy generation. This chapter discusses possible mechanisms for eddy generation in the Red Sea, using results from a series of idealized numerical experiments.

\subsection{Eddies Generated by Baroclinic Instability}

As described in detail in Chapter 3, an idealized configuration of the MITgem was run using a linear surface buoyancy forcing (EXP0). Snapshots of surface currents and density in EXP0 suggest that many eddies are generated from boundary currents. Figure 4.2 shows an eddy that is shed from the eastern boundary current and travels westward at a speed of about $3 \mathrm{~cm} \mathrm{~s}^{-1}$. This eddy disappears about 45 days after it is generated. The radius of the eddy is about $40 \mathrm{~km}$. Given its small scale and the resolution of satellite SLA, an eddy of this scale in the Red Sea might not be detected by satellite SLA. The eddy is confined in the upper $100 \mathrm{~m}$ and has a maximum current speed of $0.2 \mathrm{~m} \mathrm{~s}^{-1}$ (Figure 4.3). To begin the investigation of the formation process of this eddy, consider the characteristics of linear Rossby waves. The first baroclinic mode Rossby wave speed can be estimated using dynamical mode decomposition. The vertical structure of horizontal velocity is governed by the equation

$$
\frac{d}{d z}\left(\frac{1}{N^{2}(z)} \frac{d \psi}{d z}\right)+\frac{1}{c^{2}} \psi(z)=0
$$

where $\psi(z)$ is the vertical structure of horizontal velocity, and $N(z)$ is the Brunt-Vaisala frequency, subject to boundary conditions $\frac{d \psi}{d z}=0$ at both the surface and bottom. The solution 
of Eq. (4.1) is a series of barotropic and baroclinic modes $\psi_{n}(z), c_{n}{ }^{-1}, n=0,1,2, \cdots$, where $c_{n}{ }^{-1}$ is the eigenvalue and $\psi_{n}(z)$ is the corresponding eigenfunction; $c_{n}$ is the barotropic $(n=0)$ or the $n$th baroclinic $(n=1,2, \cdots)$ mode gravity wave speed. The Rossby radius of deformation can be calculated using $R_{n}=\frac{c_{n}}{f}$. The upper bound on the westward phase speed of Rossby waves can be estimated using $\beta R_{n}{ }^{2}$. The first baroclinic Rossby radius of deformation and upper bound on the first baroclinic Rossby phase speed calculated from the stratification in EXP0 are plotted in Figure 4.4. The phase speed of the first baroclinic Rossby waves is less than $0.1 \mathrm{~cm} \mathrm{~s}^{-1}$ in the region where the eddy appears, an order of magnitude less than the propagation speed of the model eddy. Therefore, the travel direction and speed of the eddy are not associated only with first baroclinic Rossby waves. Instead, eddy movement might be determined by the initial speed of the eddy when the eddy leaves the boundary current. Figure 4.5 shows another example in which the travel speed of the eddy, which locates at $\mathrm{X}=160 \mathrm{~km}, \mathrm{Y}=1800 \mathrm{~km}$ at day 60 , is much larger than the first baroclinic Rossby wave phase speed. This eddy travels northwestward at a 5 $\mathrm{cm} \mathrm{s}^{-1}$. 

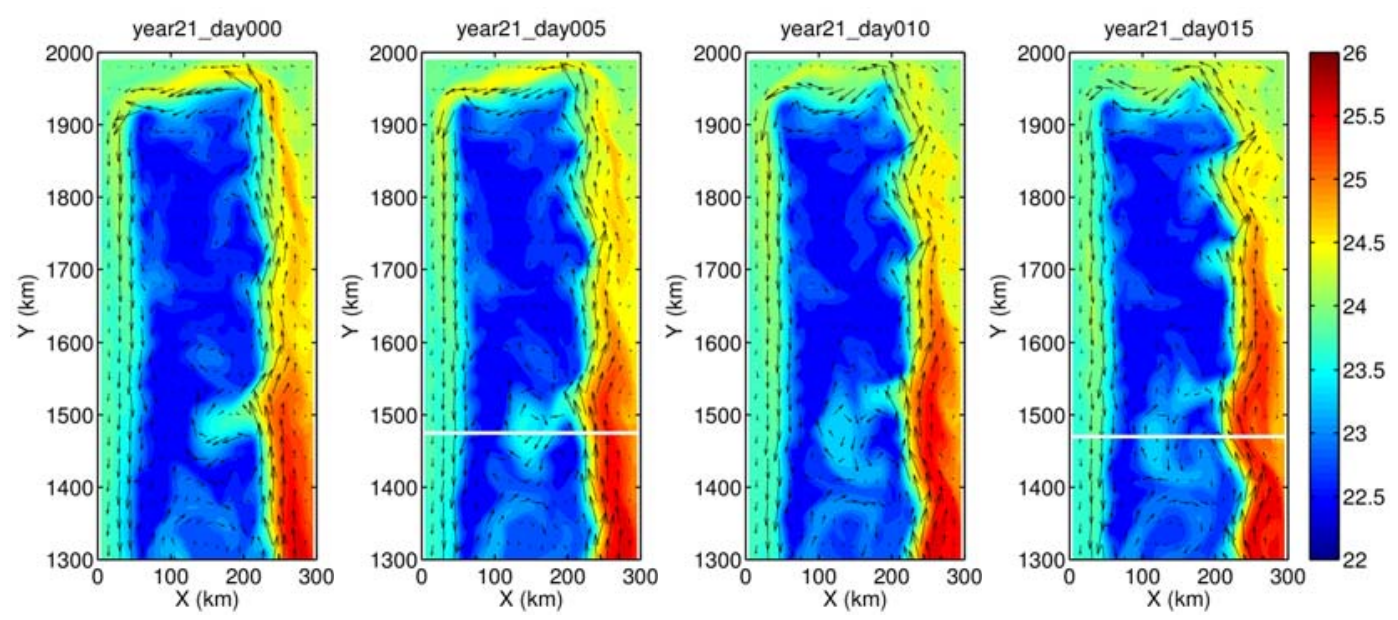

Figure 4.2: Surface temperature $\left({ }^{\circ} \mathrm{C}\right)$ and velocity $\left(\mathrm{m} \mathrm{s}^{-1}\right)$ for an eddy evolution in EXP0. Meridional velocities along the sections marked with white lines are plotted in Figure 4.3.
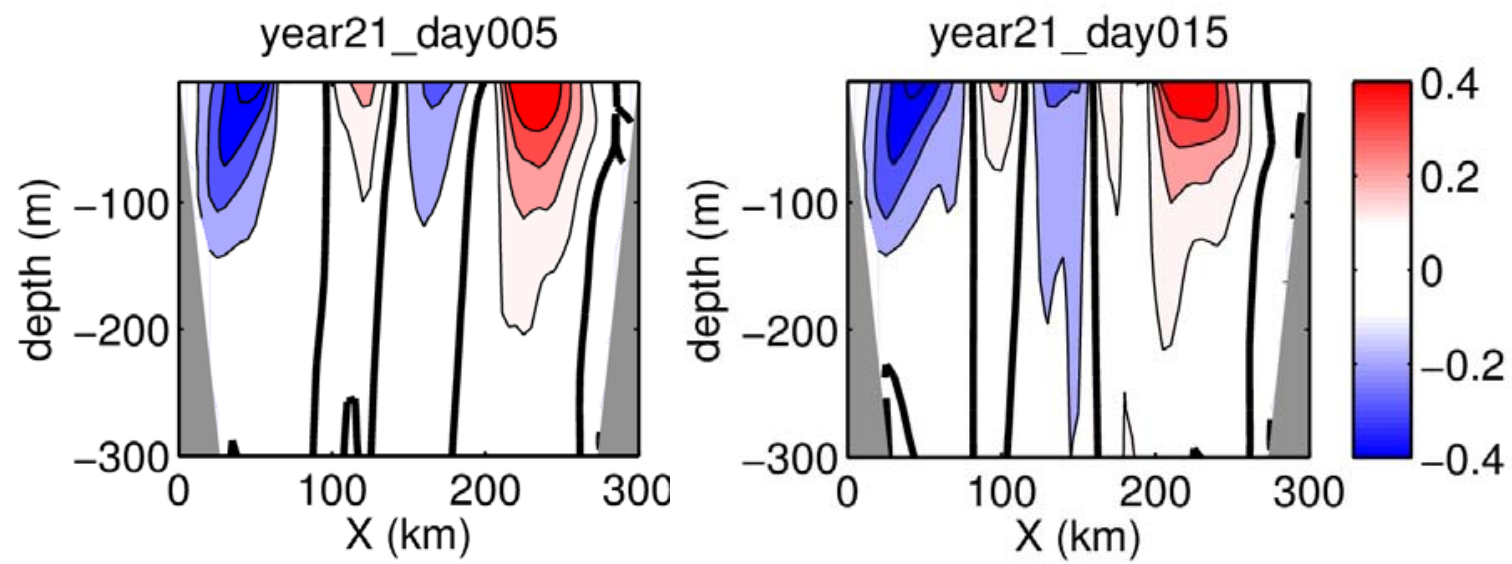

Figure 4.3: Meridional velocity $\left(\mathrm{m} \mathrm{s}^{-1}\right)$ at $\mathrm{Y}=1465 \mathrm{~km}$ in EXP0. The white lines in Figure 4.2 mark the location of the section. Thick black lines represent zero-contour. 
a)

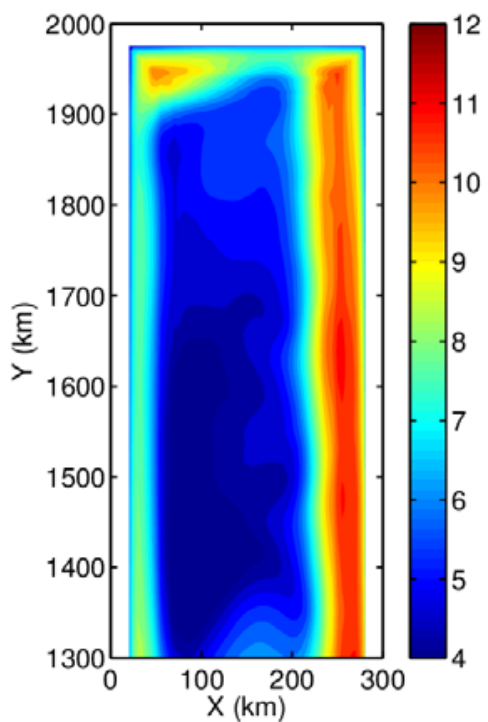

b)

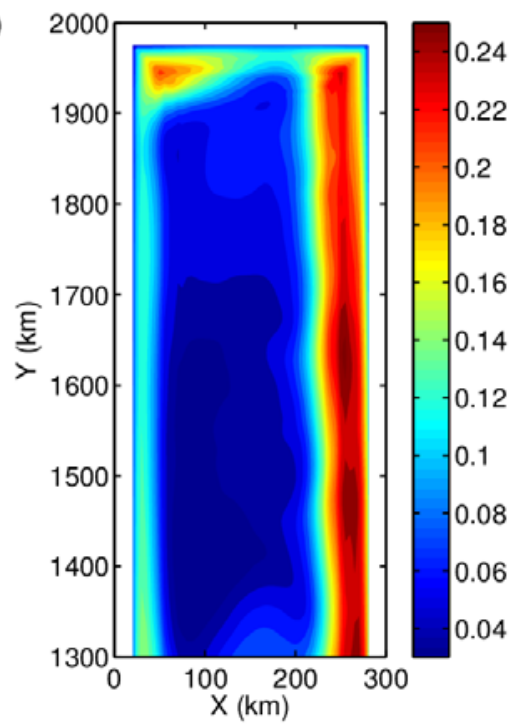

Figure 4.4: (a) The first baroclinic mode Rossby radius of deformation (km). (b) The phase speed $\left(\mathrm{cm} \mathrm{s}^{-1}\right)$ of the first baroclinic Rossby waves estimated through $\beta R_{1}^{2}$ in EXP0.
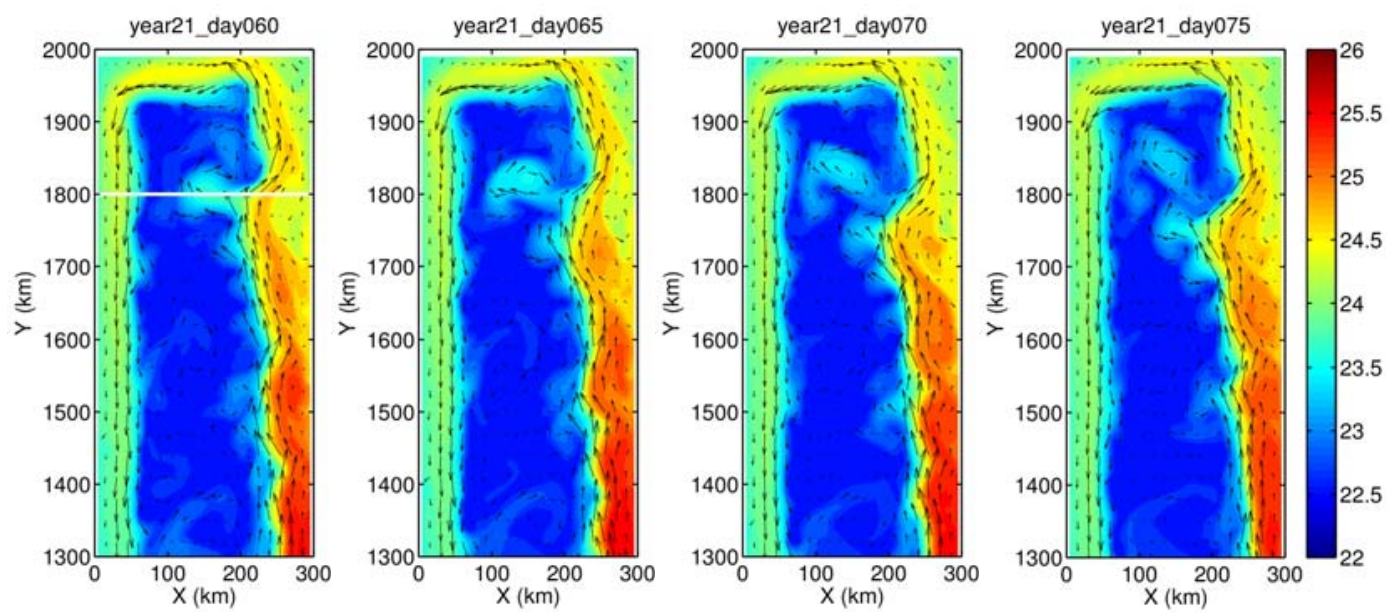

Figure 4.5: Sequence of surface temperature $\left({ }^{\circ} \mathrm{C}\right)$ and velocity for an eddy in EXP0. The whithe line indicates the location of the eddy.

In the following, it is argued that the eddies shown in Figure 4.2 and Figure 4.5 are primarily generated by instability along boundary currents. The change of the eddy kinetic energy in this numerical experiment can be written as 


$$
\frac{D}{D t}\left(\frac{\overline{u^{\prime} u^{\prime}}+\overline{v^{\prime} v^{\prime}}}{2}\right)=\frac{g}{\rho_{0}} \overline{u^{\prime} \rho^{\prime}} \frac{\overline{\rho_{x}}}{\overline{\rho_{z}}}+\frac{g}{\rho_{0}} \overline{v^{\prime}} \frac{\overline{\rho^{\prime}}}{\overline{\rho_{z}}}-\overline{v^{\prime} u^{\prime}} \frac{\partial V}{\partial x}+P
$$

where the overbars represent the time mean; primes represent the time-dependent deviations from the mean; $\rho_{x}, \rho_{y}$, and $\rho_{z}$ indicate the density derivative in the $x, y$, and $z$ directions; $A=\frac{g}{\rho_{0}} \overline{u^{\prime} \rho^{\prime}} \frac{\overline{\rho_{x}}}{\overline{\rho_{z}}}$ and $B=\frac{g}{\rho_{0}} \overline{v^{\prime} \rho^{\prime}} \frac{\overline{\rho_{y}}}{\overline{\rho_{z}}}$ represents mean to eddy energy conversion due to baroclinic instability; $C=-\overline{v^{\prime} u^{\prime}} \frac{\partial V}{\partial x}$ represents mean to eddy energy conversion due to barotropic instability; and $P$ represents other eddy energy sources or sinks, such as viscosity. The conversion term that involves $\frac{\partial U}{\partial y}$ is neglected because $U$ is much smaller than $V$ in meridional boundary currents. The integrated eddy kinetic energy and zonal eddy density flux in the upper $200 \mathrm{~m}$ in EXP0 are plotted in Figure 4.6. In the northern Red Sea, both the eddy kinetic energy and eddy density flux are larger along the eastern boundary current than they are along the western boundary current, implying that there are more eddy fluxes originating from eastern boundary current than those from the western one. The positive values of zonal eddy density flux along the eastern boundary current indicate that eddies are transporting buoyancy into the interior region, which balances the surface buoyancy loss there. 

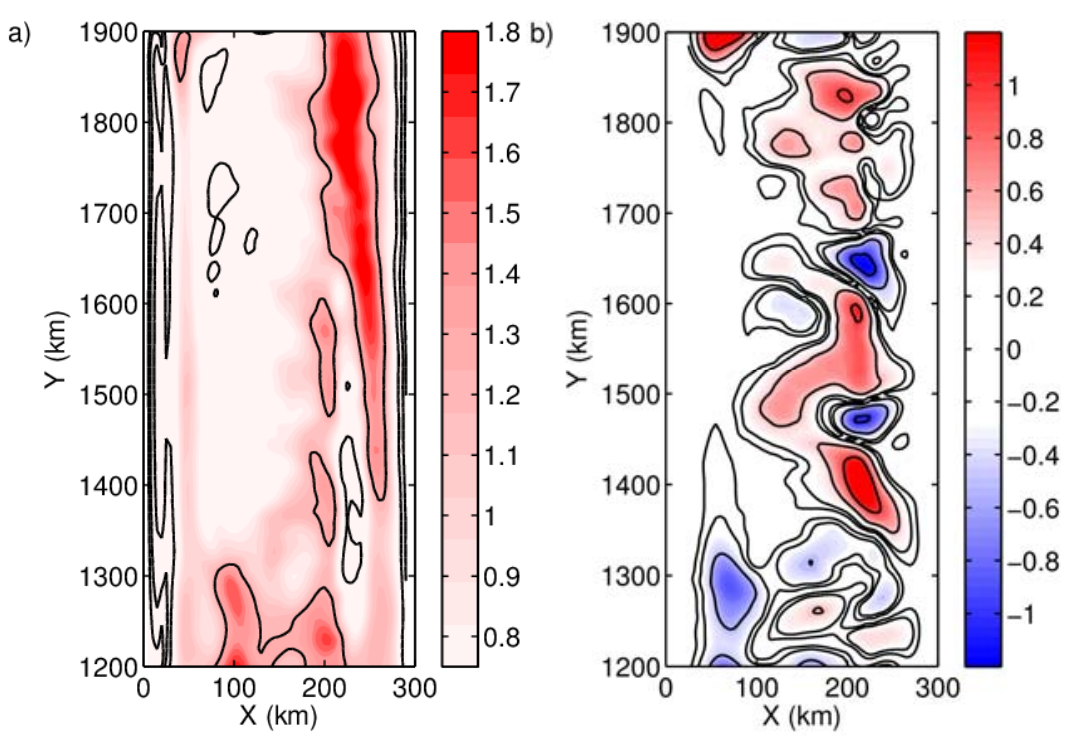

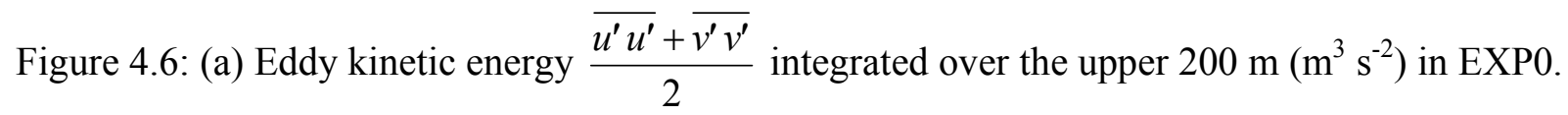
Contours of $0.25,0.5,1$ are plotted. (b) Zonal eddy density flux $\overline{u^{\prime} \rho^{\prime}}\left(\mathrm{kg} \mathrm{m}^{-1} \mathrm{~s}^{-1}\right)$ integrated in the upper $200 \mathrm{~m}$ in EXP0. Contours of $-1,-0.5,-0.2,-0.1,0,0.1,0.2,0.5,1$ are plotted.

The barotropic and baroclinic mean to eddy energy conversions are shown in Figure 4.7. Positive values indicate that eddies are extracting energy from the mean current. The primary regions of energy conversion due to barotropic and baroclinic instability are along the eastern boundary. However, the baroclinic energy conversion is about an order of magnitude larger than the barotropic energy conversion. Therefore, eddies shed from the boundary current are primarily generated by baroclinic instability. Figure 4.8 shows a zonal gradient section of $P V=-\frac{\mathrm{g}}{\rho_{0}}\left(f_{0}+\beta y+\frac{\partial v}{\partial x}-\frac{\partial u}{\partial y}\right) \frac{\partial \rho}{\partial z}$ in EXP0. The PV gradient changes sign vertically along both the eastern and western boundaries. A change in sign of the zonal PV gradient is a necessary condition for baroclinic instability, which leads to eddy generation from boundary currents. The baroclinic instability converts available potential energy to eddy kinetic energy. As suggested by 
Spall (2004), the eddy density flux is proportional to the density difference between the boundary and the interior. As the boundary current flows cyclonically, its density decreases due to surface buoyancy forcing and lateral eddy buoyancy flux. The density difference between the eastern boundary current and interior is about twice as large as the density difference between the western boundary current and interior. Therefore, the eastern boundary current is more efficient at generating eddies by baroclinic instability. This could explain why there are more eddies shed from the eastern boundary in the model.
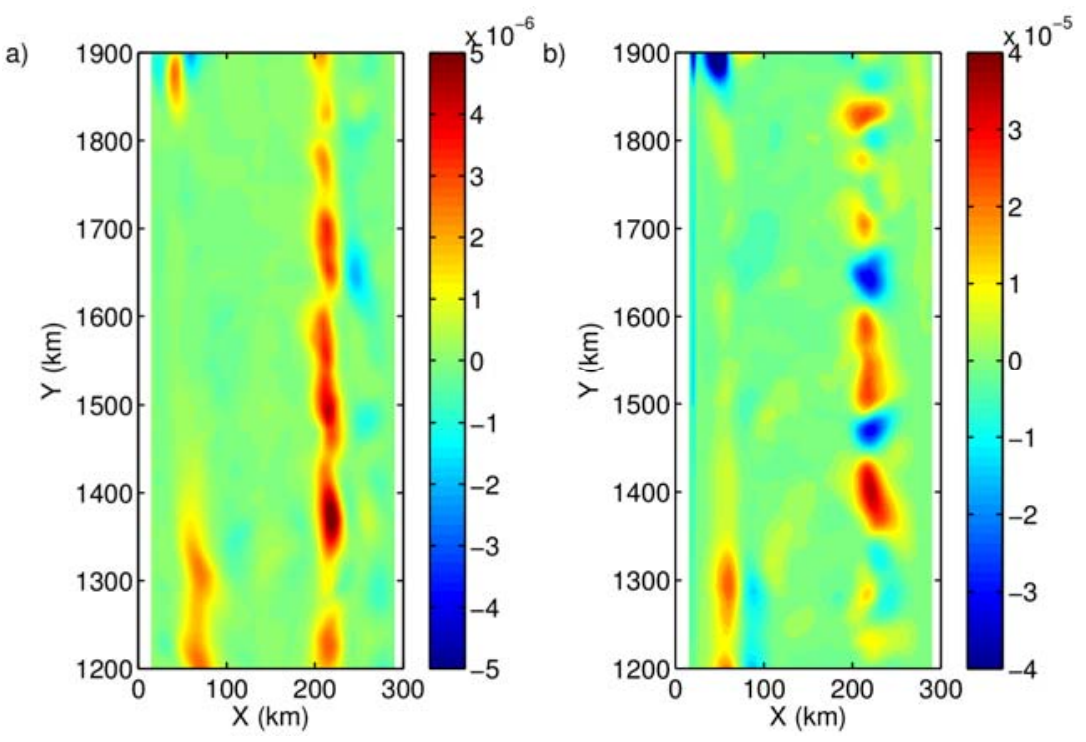

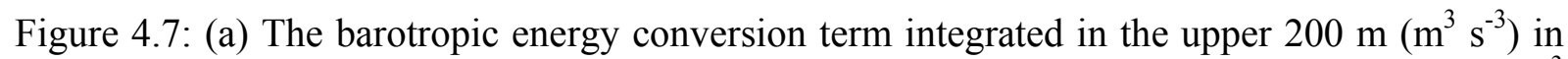
EXP0. (b) Sum of the two baroclinic energy conversion terms integrated in the upper $200 \mathrm{~m}\left(\mathrm{~m}^{3}\right.$ $\mathrm{s}^{-3}$ ) in EXP0. 


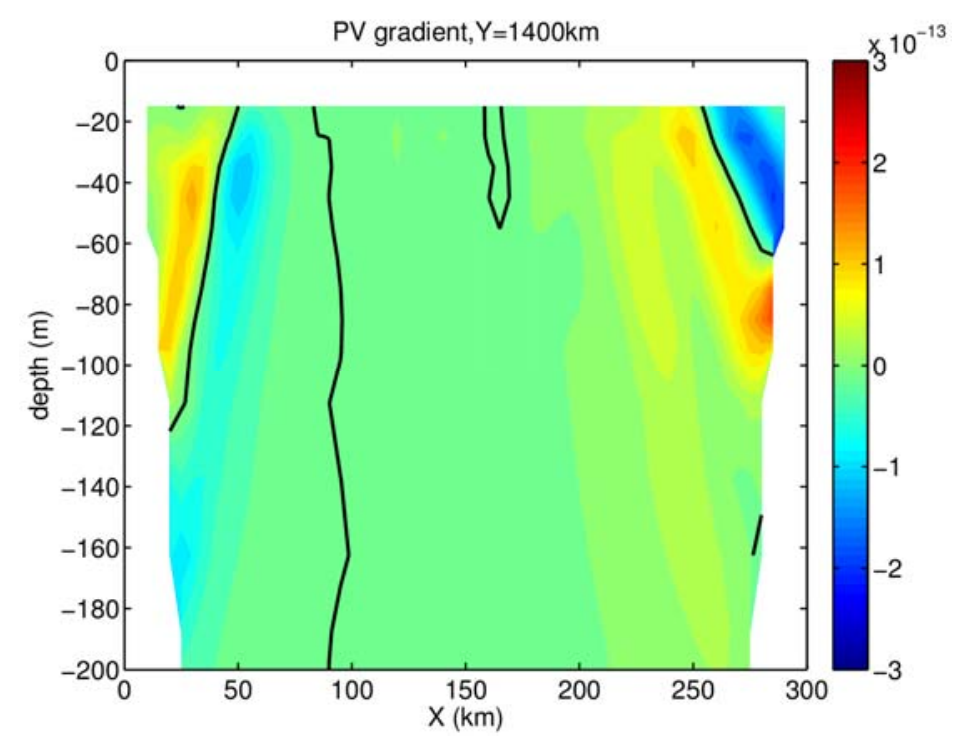

Figure 4.8: PV Zonal gradient $\left(\mathrm{s}^{-3}\right)$ at $\mathrm{Y}=1400 \mathrm{~km}$ in EXP0. Thick black lines represents zerocontour.

In March 2010, 29 GPS-tracked surface drifters were deployed in the northern Red Sea (Chen et al., 2014). Drifter locations were recorded every half hour. The trajectories of surface drifters show that there is a continuous southeastward boundary current near the western boundary (Figure 4.9). However, the current near the eastern boundary is much variable. This is consistent with our model results, which indicate the eastern boundary current is less stable due to baroclinic instability. 


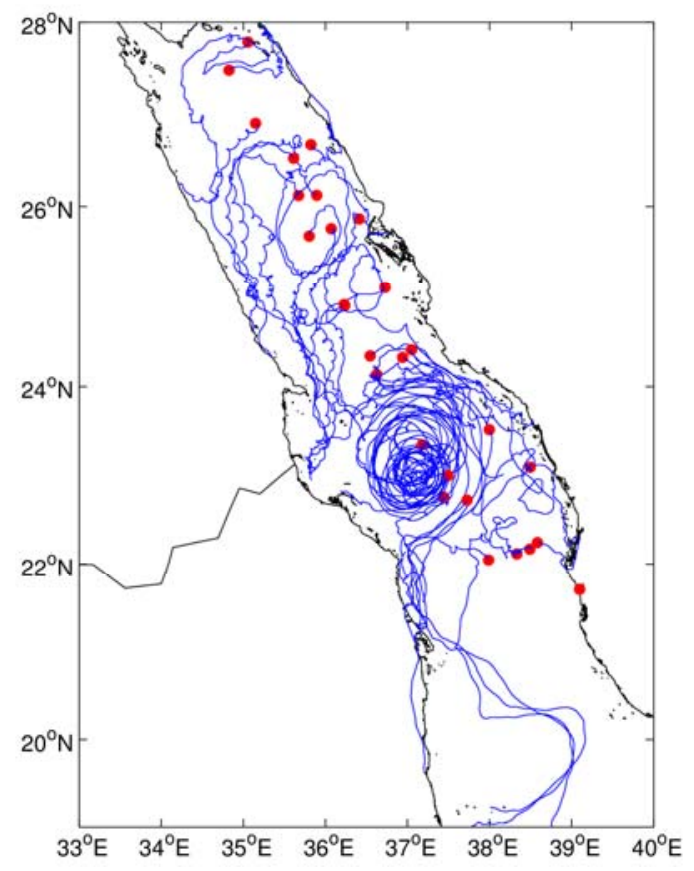

Figure 4.9: Trajectories of surface drifters from March 17 to May 14, 2010. The red dots represent starting locations of drifters. Drifter locations are plotted every half hour.

In addition to buoyancy forcing, there is also wind forcing in the Red Sea. Numerical simulation studies by Sofianos and Johns (2003) suggest that the Red Sea circulation is primarily determined by surface buoyancy forcing, with wind forcing playing a secondary role. Their study suggests that wind forcing in the Red Sea is less important for the general circulation than buoyancy forcing. However, wind forcing can modify the stratification and affect the strength of baroclinic instability in boundary currents. A numerical experiment (EXP0W) was conducted to test the influence of wind forcing on baroclinic instability in the Red Sea. The model configuration of EXP0W (Table 4.1) is same as for EXP0, except that a typical winter wind field is added (Figure 4.10). The magnitudes of the wind stress and wind stress curl are $0.06 \mathrm{~N} \mathrm{~m}^{-2}$ and $8 \times 10^{-8} \mathrm{~N} \mathrm{~m}^{-3}$, which are typical of the actual Red Sea. Results indicate that the eddy kinetic energy and zonal eddy density flux are still concentrated along the eastern boundary. However, 
their amplitudes are smaller than those in EXP0 (Figure 4.11). For example, the maximum values of eddy kinetic energy in EXP0 and EXP0W are 1.8 and $0.9 \mathrm{~m}^{3} \mathrm{~s}^{-2}$, respectively.

Wind forcing in the northern Red Sea is southward. It can drive westward Ekman currents (Figure 4.12) at the surface, resulting in upwelling along the eastern boundary. In EXP0, surface buoyancy loss in the interior region is primarily balanced by the eddy buoyancy flux from the boundary current. In EXP0W, in addition to the eddy buoyancy flux, the mean westward advection of buoyancy from the boundary current into the interior also contributes to balancing the surface buoyancy loss in the interior region. As a result, less eddy activity is needed in EXP0W than in EXP0. As already mentioned, eddy buoyancy flux is proportional to the density difference between the interior region and the boundary current. Wind-induced upwelling along the eastern boundary can increase density there. The westward advection of lighter water from the boundary into the interior can decrease the density in the interior region. Therefore, the density difference between the interior and boundary current is reduced when winter wind forcing is added in EXP0W. Thus, the eddy buoyancy flux is smaller in EXP0W than in EXP0. In another way, the wind-driven upwelling in EXP0W along the eastern boundary leads to less steeply sloped isopycnals, and therefore less available potential energy than the case in EXP0. 


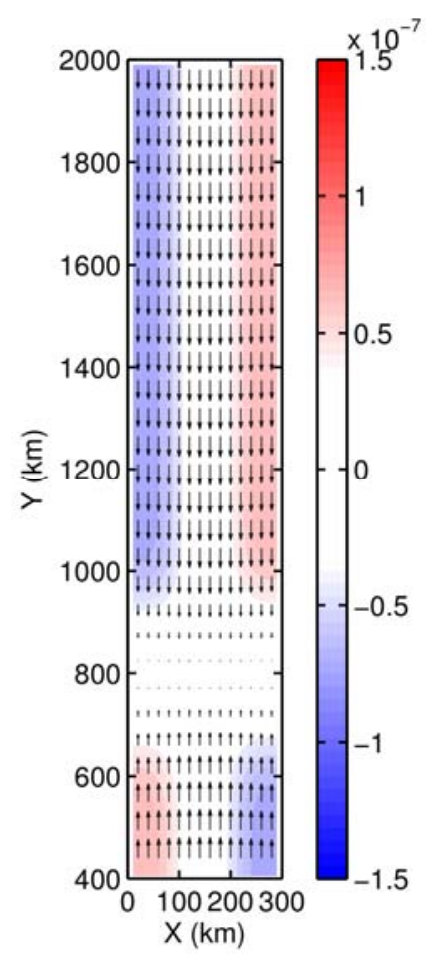

Figure 4.10: The wind stress (arrows) and wind stress curl $\left(\mathrm{N} \mathrm{m}^{-3}\right.$, color) used in EXP0W. 

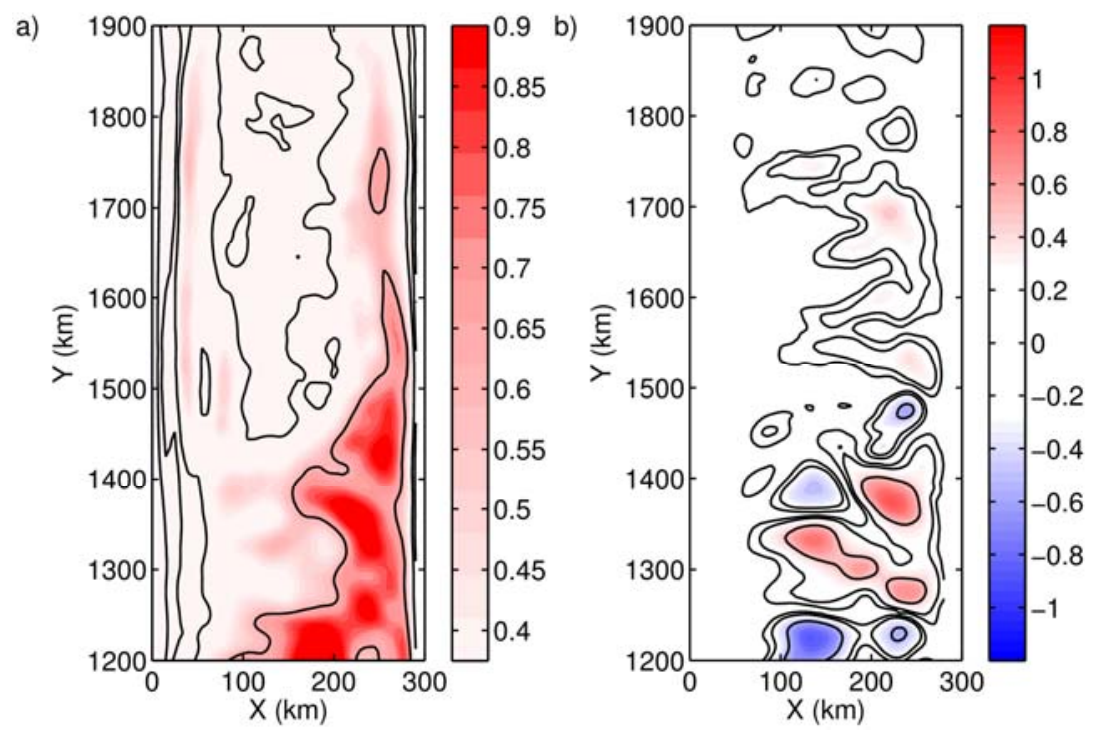

Figure 4.11: (a) Eddy kinetic energy $\frac{\overline{u^{\prime} u^{\prime}}+\overline{v^{\prime} v^{\prime}}}{2}$ integrated in the upper $200 \mathrm{~m}\left(\mathrm{~m}^{3} \mathrm{~s}^{-2}\right)$ in EXP0W. Contours of $0.125,0.25,0.5$ are plotted. (b) Zonal eddy density flux $\overline{u^{\prime} \rho^{\prime}}\left(\mathrm{kg} \mathrm{m}^{-1} \mathrm{~s}^{-1}\right)$ integrated in the upper $200 \mathrm{~m}$ in EXP0W. Contours of $-1,-0.5,-0.2,-0.1,0,0.1,0.2,0.5,1$ are plotted. 
Table 4.1: Model description

\begin{tabular}{ll}
\hline EXP \# & Difference from EXP0 \\
\hline EXP0W & Typical winter wind forcing is added. \\
EXPe1 & Modified surface buoyancy forcing from OAflux is used. \\
EXPjet1 & Model is forced by an idealized zonal wind jet; no buoyancy forcing. \\
EXPjet2 & Same as EXPjet1, but with weaker wind. \\
\hline
\end{tabular}

a)

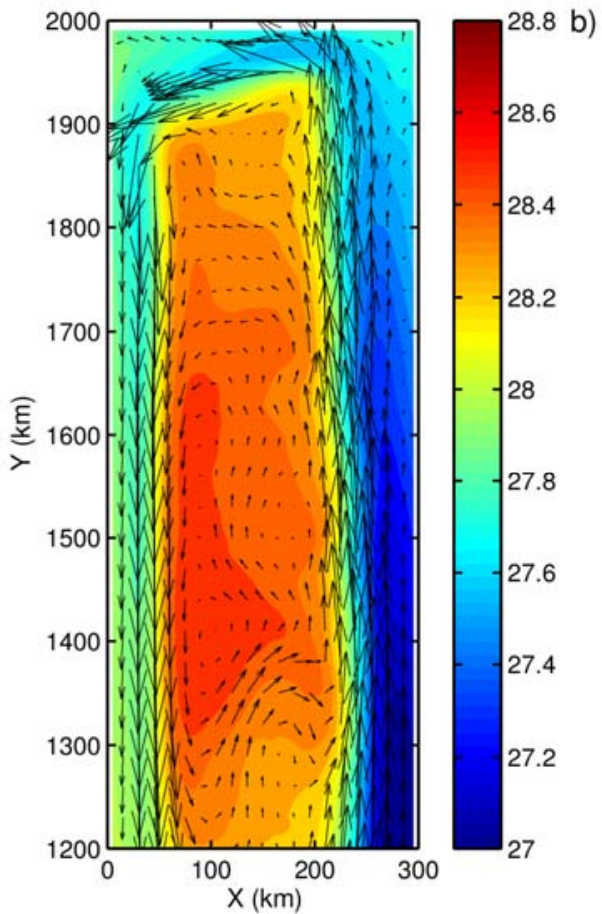

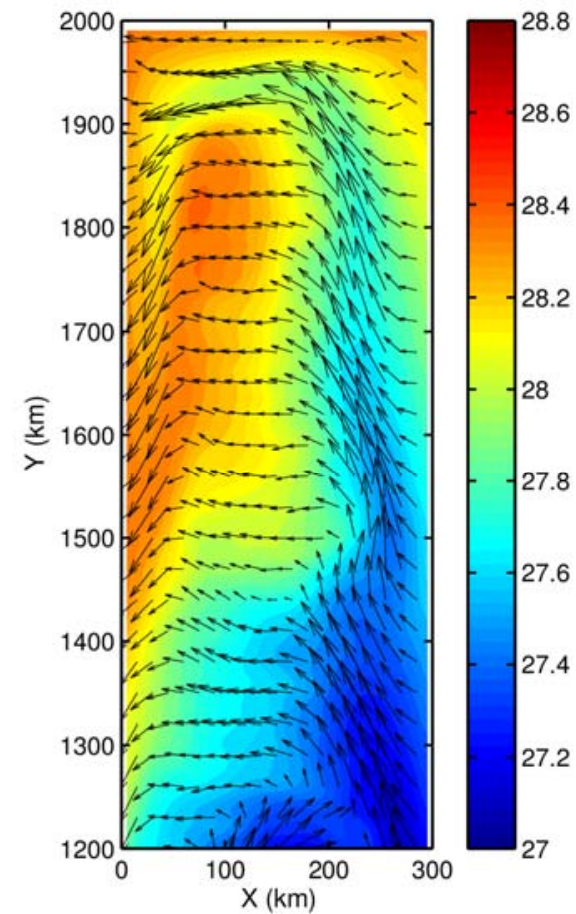

Figure 4.12: Mean density $\left(\mathrm{kg} \mathrm{m}^{-3}\right)$ and velocity at the surface for (a) EXP0 and (b) EXP0W. 


\subsection{Quasi-stationary Eddies Generated by Meridional Structure of Surface Buoyancy}

\section{Forcing}

The numerical simulation presented in this section (EXPe1, Table 4.1) uses a configuration similar to that of EXP0. The model is forced by climatological surface heat $(Q)$ and freshwater ( $E$ ) fluxes from OAflux product (Yu et al., 2008). Monthly mean OAflux data from 1984 to 2009 are used to generate the climatological sea surface buoyancy fluxes (Figure 4.13). The average heat flux and evaporation over the entire Red Sea calculated from OAflux data is $-20 \mathrm{~W}$ $\mathrm{m}^{-2}$ (negative heat flux indicates flux out of the ocean) and $1.7 \mathrm{~m} \mathrm{yr}^{-2}$, respectively. The data are adjusted so that the annual mean heat flux and evaporation rate are $-10 \mathrm{~W} \mathrm{~m}^{-2}$ and $2 \mathrm{~m} \mathrm{yr}^{-2}$, respectively, so as to be consistent with previous estimations (Sofianos et al., 2002). In the model, the zonally averaged 1-degree OAflux product is linearly interpolated into the meridional grids and the sea surface fluxes are zonally uniform. In EXPe1, buoyancy forcing in the northern Red Sea is larger than that in the southern Red Sea. However, instead of increasing linearly northward as in EXP0, buoyancy forcing in EXPe1 has some meridional structures, which is dominated by the meridional structure of heat flux. In the southern Red Sea, the buoyancy flux has a wavy structure, with a length scale of about $250 \mathrm{~km}$; in the northern Red Sea, the buoyancy flux has a maximum value at about $1780 \mathrm{~km}$. The model was run for 25 years with steady climatological surface heat flux and evaporation, and reached a quasi-steady state. 


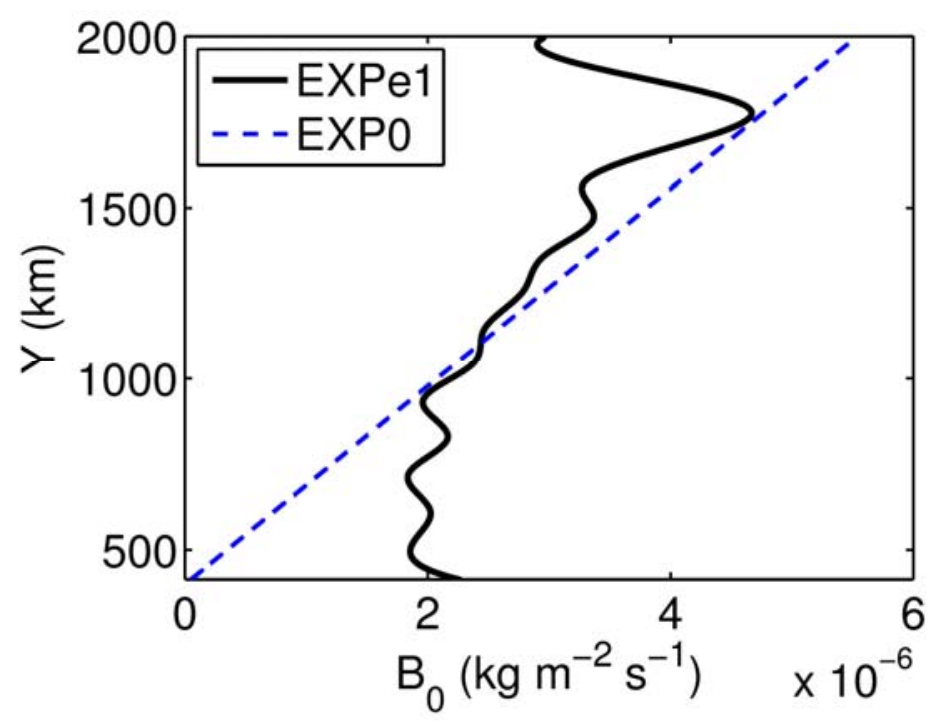

Figure 4.13: Climatological mean sea surface buoyancy flux used to drive the circulation in EXPe1 and EXP0.

The stream functions in the upper $200 \mathrm{~m}$ averaged over the final 5 years for EXPe1 and EXP0 are plotted in Figure 4.14. Stream functions in EXP0 are much simpler than those in EXPe1. In EXP0, the northward-flowing western boundary current crosses the basin at $1028 \mathrm{~km}$, and the circulation consists of a large anticyclonic gyre in the southern Red Sea and a large cyclonic gyre in the northern Red Sea. However, circulation in EXPe1 is much more complex. The northwardflowing western boundary current crosses the basin at about $1200 \mathrm{~km}$. Figure 4.14 shows three anticyclonic gyres centered at about $\mathrm{Y}=630,860$, and $1080 \mathrm{~km}$, with horizontal scales of about 200-250 km. North of the crossover latitude, there is a small anticyclonic gyre centered at $\mathrm{Y}=1340 \mathrm{~km}$, and north of that, a much larger cyclonic gyre occupies the entire northern Red Sea. Deformation of stream functions near the eastern boundary between $Y=1500$ and $1700 \mathrm{~km}$ indicates that a weak anticyclonic gyre tends to form in this region.

Figure 4.15 shows instantaneous horizontal velocity fields at the surface in EXPe1. This snapshot exhibits characteristics similar to those of the mean field. The southern Red Sea is 
dominated by three basin-scale anticyclonic gyres, and the northern Red Sea is dominated by a large cyclonic gyre and several much smaller gyres. The surface current speeds due to the eddy can reach $30 \mathrm{~cm} \mathrm{~s}^{-1}$ in the snapshot fields. The locations of gyres in EXPe1 vary with time, but they tend to remain near their mean locations, as indicated by the mean stream function.

Eddies in EXP0 are generated primarily by baroclinic instability in boundary currents and usually dissipate within one to two months. There is also baroclinic instability in EXPe1. Eddies generated by baroclinic instability are not shown in mean fields. Therefore, the smaller scale gyres shown in the mean fields in EXPe1 are not generated by baroclinic instability. The vertical structure of the southernmost anticyclonic gyre in EXPe1 is indicated in Figure 4.16 by zonal sections of temperature, salinity, and meridional velocity at $\mathrm{Y}=600 \mathrm{~km}$. The isotherms and isohalines are depressed in the center of the anticyclonic gyre. The anticyclonic gyre is confined in the upper $200 \mathrm{~m}$ and has maximum velocities of more than $30 \mathrm{~cm} \mathrm{~s}^{-1}$ at the surface. 

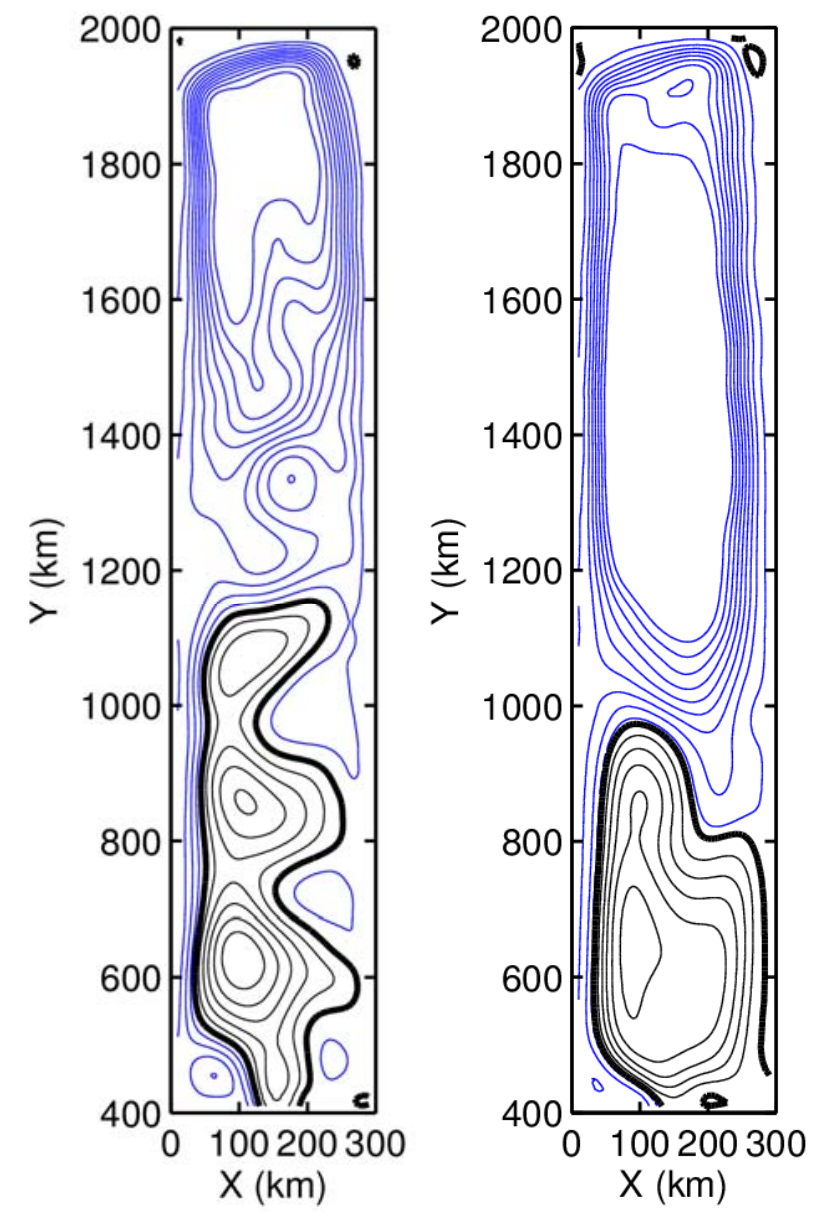

Figure 4.14: 5-year mean stream function (contour interval $=1000 \mathrm{~m}^{2} \mathrm{~s}^{-1}$ ) in the upper $200 \mathrm{~m}$ for EXPe1 (left) and EXP0 (right). The zero contour is marked with thick black lines. Thin blue lines represent negative values, and thin black lines represent positive values. The predicted latitudes of the predicted gyre centers are $680,900,1110,1400$ and $1650 \mathrm{~km}$ from the ad hoc analytical model. 


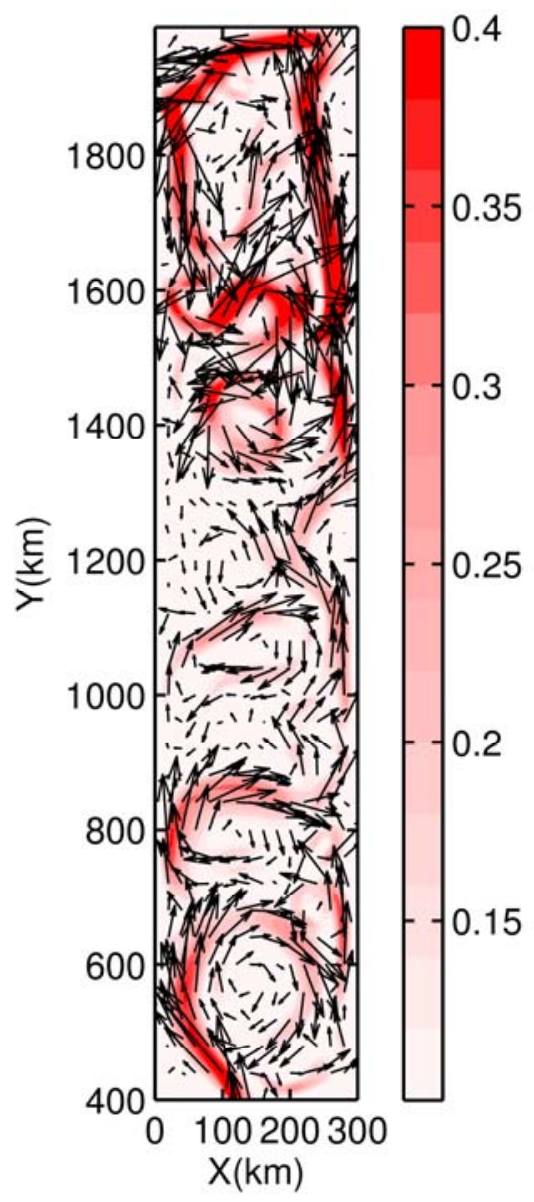

Figure 4.15: Snapshot of surface velocity vectors and speeds $\left(\mathrm{m} \mathrm{s}^{-1}\right)$ in EXPe1. 
a)

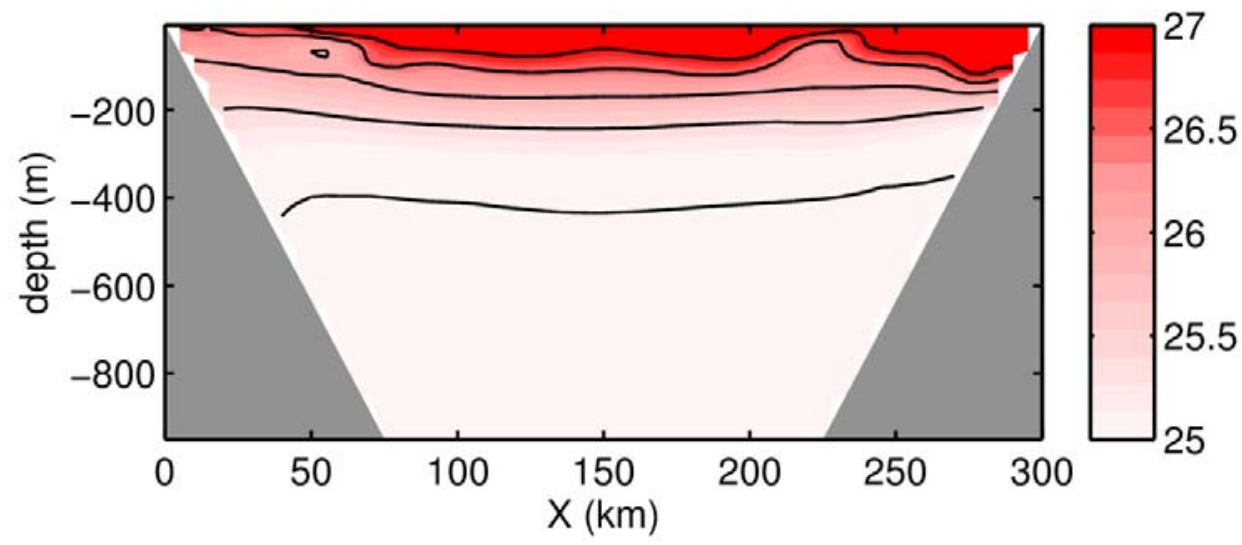

b)

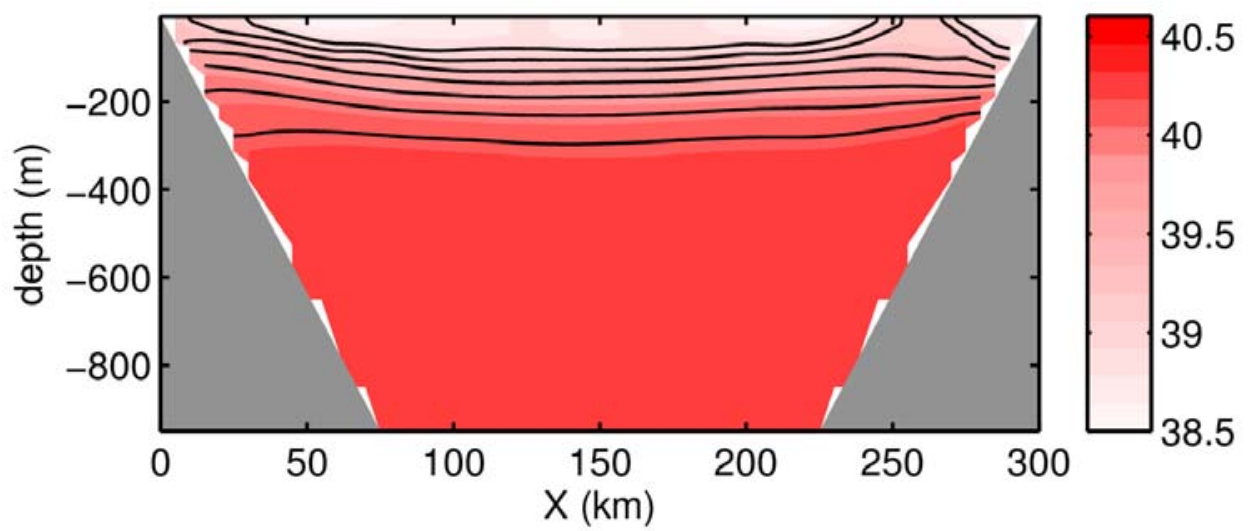

c)

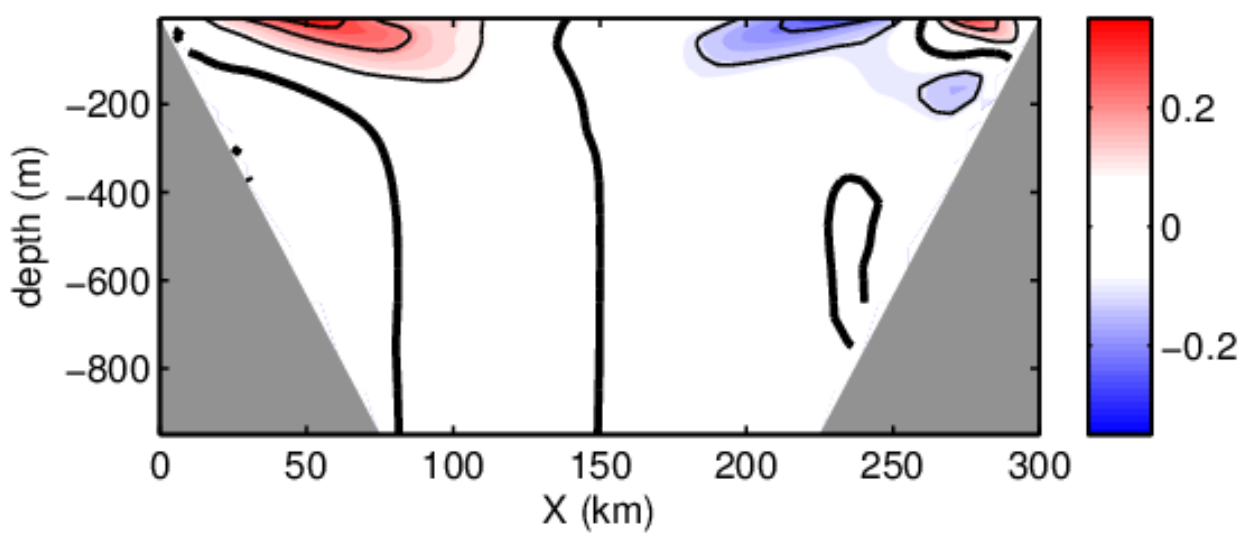

Figure 4.16: Zonal sections at $\mathrm{Y}=600 \mathrm{~km}$ : (a) Temperature (contour interval $=0.5{ }^{\circ} \mathrm{C}$ ). (b) Salinity (contour interval $=0.2$ ). (c) Meridional velocity (contour interval $=0.1 \mathrm{~m} \mathrm{~s}^{-1}$ ). Time is the same as in Figure 4.15.

Comparisons between EXPe1 and EXP0 in Figure 4.13 and Figure 4.14 suggest that the three anticyclonic gyres in EXPe1 might be generated by the meridional structure of the surface 
buoyancy forcing. In the preceding chapter, an ad hoc analytical model was developed to calculate velocity and density in boundary currents. The meridional velocity $(v)$ in the western boundary current can be calculated by substituting the buoyancy flux in EXPe1 into Eq. (3.6). To determine how the meridional structure of the surface buoyancy forcing influences the circulation pattern, $\frac{d v}{d y}$ is referenced to the result when a linear least square fit of buoyancy forcing is used in the analytical model. The $\frac{d v}{d y}$ anomaly is plotted in Figure 4.17. As depicted in Figure 4.18, positive $\frac{d v}{d y}$ anomaly implies divergence of meridional velocity, and westward velocity is required to compensate for the divergence. On the other hand, eastward velocity is required when the $\frac{d v}{d y}$ anomaly is negative. Therefore, the center of the anticyclonic gyre is at the latitude where the $\frac{d v}{d y}$ anomaly changes from positive to negative. The ad hoc analytical model result shown in Figure 4.17 indicates that the three anticyclonic gyres are centered at $\mathrm{Y}=680,900$, and $1110 \mathrm{~km}$. These locations are very close to the ones in the numerical simulation shown in Figure 4.14 for EXPe1.

The $\frac{d v}{d y}$ anomaly calculated by the ad hoc analytical model for the eastern boundary current in the northern Red Sea is plotted in Figure 4.19. It indicates that circulation in the northern Red Sea is dominated by a strong cyclonic gyre centered at about $\mathrm{Y}=1870 \mathrm{~km}$, where the $\frac{d v}{d y}$ anomaly changes from negative to positive. The ad hoc analytical model also implies that there 
might be two smaller and weaker anticyclonic gyres centered at about $\mathrm{Y}=1400$ and $1650 \mathrm{~km}$, which is in accordance with the numerical simulation shown in Figure 4.14.

In the ad hoc analytical model, the total buoyancy loss in the boundary current is balanced by the meridional advection of density. Total buoyancy loss is composed of surface buoyancy loss into the atmosphere and buoyancy loss into the interior region, which is represented by divergence of the zonal eddy fluxes. This divergence is assumed to be constant. Therefore, the meridional structure of the total buoyancy loss in the boundary current is determined by the surface buoyancy loss. The boundary current velocity is proportional to boundary current density in the form of the thermal wind relation. As a result, the meridional structure of the surface buoyancy forcing is reflected in $\frac{d v}{d y}$. Therefore, the meridional structure of the surface buoyancy flux may be one of the factors responsible for eddy generation in the actual Red Sea. 


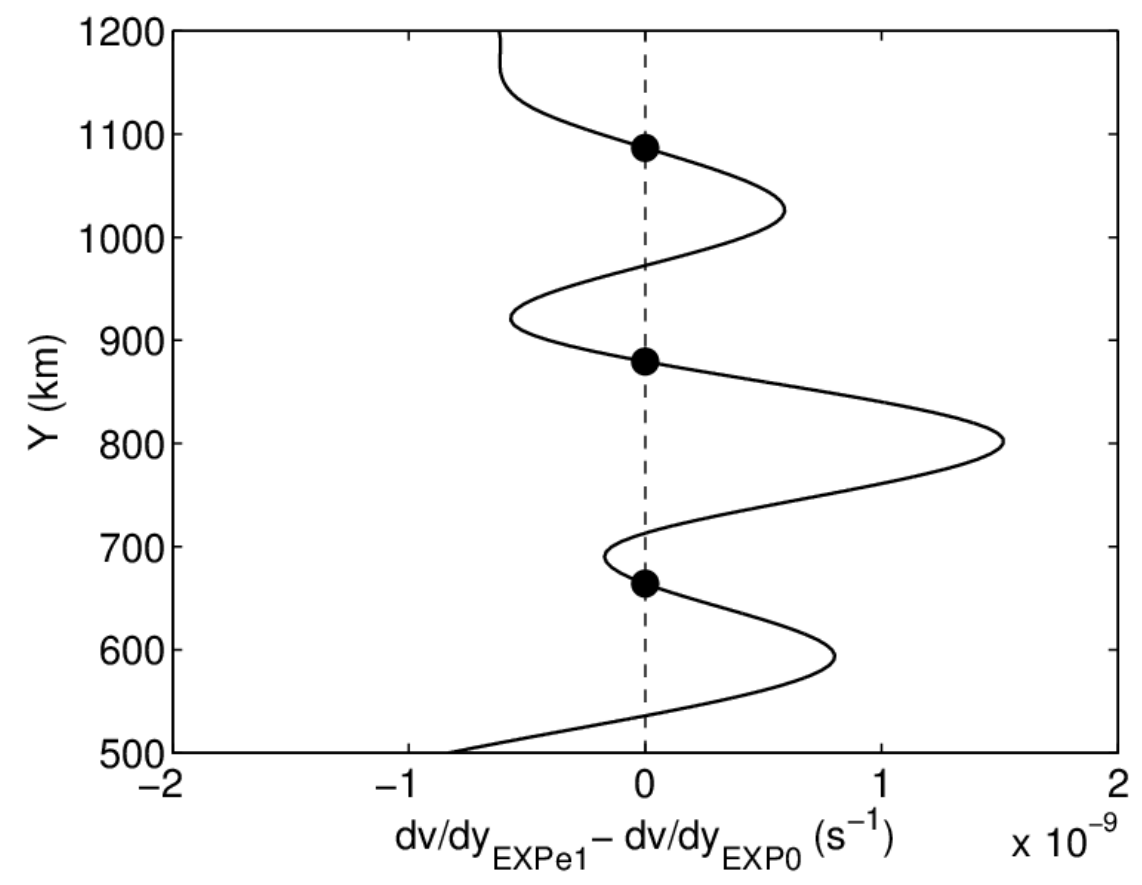

Figure 4.17: Meridional gradient of meridional velocity in the western boundary current in the southern Red Sea, as calculated from the analytical model. The black dots indicate locations of the centers of the predicted anticyclonic gyres.

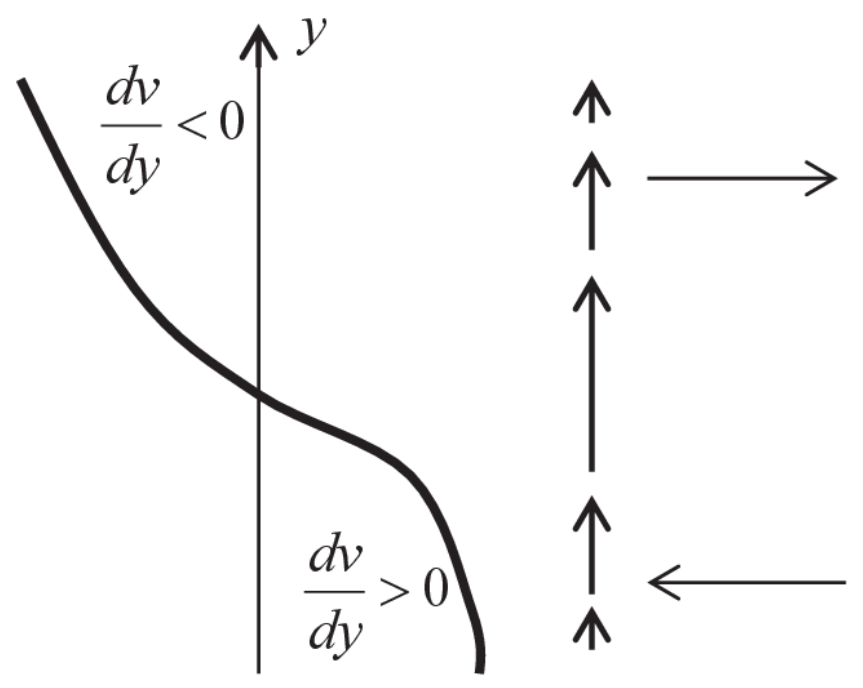

Figure 4.18: Schematic diagram showing how to determine the center of an anticyclonic gyre. 


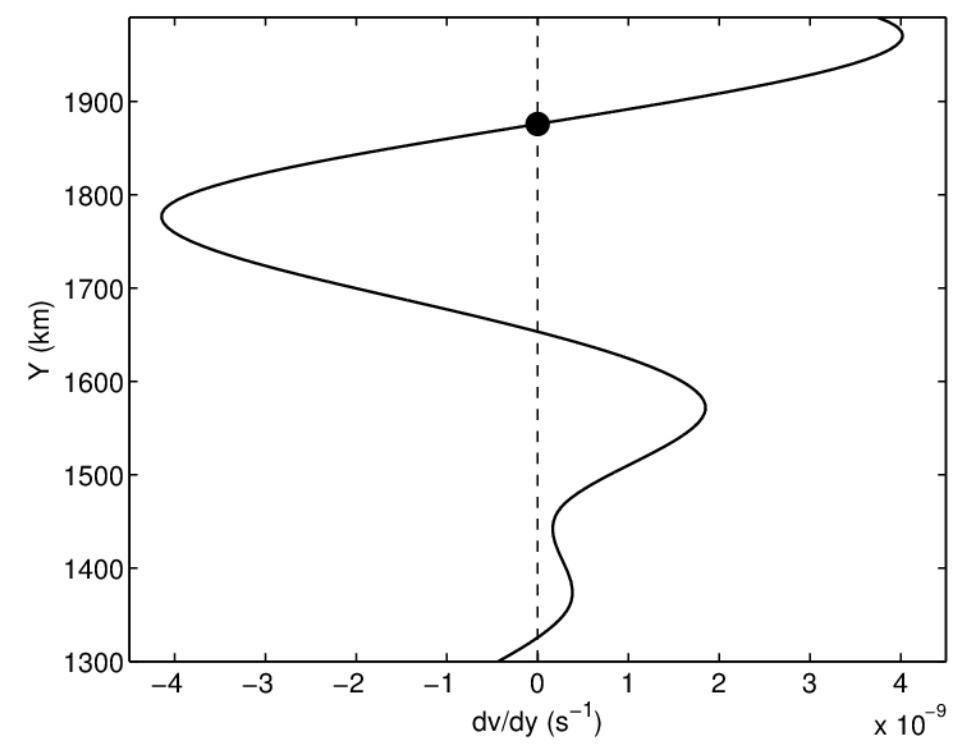

Figure 4.19: Meridional gradient of meridional velocity in the eastern boundary current in the northern Red Sea, as calculated from the analytical model.

\subsection{Eddies Generated by Cross-Basin Wind Jets}

Dipoles generated by wind jets blowing from mountain gaps have been observed in the Gulfs of Tehuantepec, Papagayo, Panama, Philippine Archipelago, and South China Sea (McCreary et al., 1989; Pullen et al., 2008; Rypina et al., 2010; Wang et al., 2006, 2008).

The mean wind field in the Red Sea is generally constrained to blow along the middle axis of the Red Sea due to high mountains on both sides of the basin. A series of mountain gaps exists along both sides. These gaps allow cross-basin component in the wind field. Clifford et al. (1997) conducted a series of high-resolution numerical experiments and suggested that the cross-basin component of the wind field could make the Red Sea circulation more eddy-like by conducting a series of high-resolution numerical experiments. Zhai and Bower (2013) studied the Red Sea response to one particular cross-basin wind jet, the Tokar Jet. This wind jet blows through the Tokar Gap on the Sudanese coast at about $18^{\circ} \mathrm{N}$ onto the Red Sea during the summer monsoon 
season. The speed of the Tokar Wind Jet can reach 20-25 m s${ }^{-1}$ (Pedgley, 1974; Jiang et al., 2009; Zhai and Bower, 2013).

By comparing QuikSCAT wind fields and satellite SLA data, Zhai and Bower (2013) found that the Tokar Wind Jet generates an intense dipole that includes an anticyclonic eddy to the south of the jet axis and a cyclonic eddy to the north. Shipboard ADCP data shows that the dipole had a maximum speed of about $1 \mathrm{~m} \mathrm{~s}^{-1}$ in August 2001 (Figure 4.20) (Sofianos and Johns, 2007). The dipole was confined to the upper $150 \mathrm{~m}$ (Figure 4.21). The wind stress that drives the strong dipole near the Tokar Gap has wind stress curl amplitude of $8 \times 10^{-7} \mathrm{~N} \mathrm{~m}^{-3}$ (Figure 4.22). However, over most of the Red Sea, the wind stress curl in the Red Sea is less than $2 \times 10^{-7} \mathrm{~N} \mathrm{~m}^{-3}$. Thus, eddies generated by wind stress curl are usually weaker than the dipole observed near the Tokar Gap.

The spatial scale and strength of the dipole are closely related to the strength of the Tokar Wind Jet, as shown by comparison of the EXPjet1 and EXPjet2 numerical experiments (Figure 4.24 and Figure 4.25). The initial and boundary conditions are same as for EXP0. The EXPjet1 and EXPjet2 experiments are driven by the wind stress shown in Figure 4.23 instead of the surface buoyancy forcing. The maximum values of wind stress and wind stress curl in EXPjet1 are 0.08 $\mathrm{N} \mathrm{m}^{-2}$ and $8 \times 10^{-7} \mathrm{~N} \mathrm{~m}^{-3}$, which are typical of the Tokar Wind Jet. The wind stress in EXPjet1 is about 6 times greater than the wind stress in EXPjet2. As a result, the maximum current speed in EXPjet1 is about 6 times stronger than the dipole in EXPjet2. By comparing the strength of the Tokar Wind Jet and strength of the dipole using QuikSCAT and satellite SLA, Zhai and Bower (2013) found that the dipole is stronger in years when the Tokar Wind Jet is stronger. Their result is in accordance with the model simulations in this study. In addition, eddies can penetrate to a 
deeper depth when the wind jet is stronger (Figure 4.25).

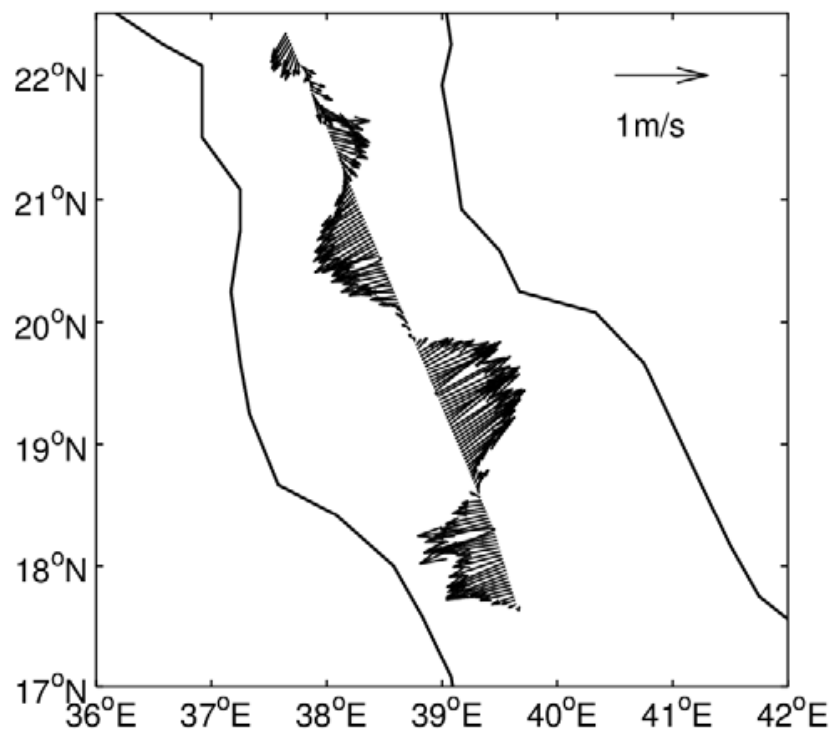

Figure 4.20: Shipboard ADCP-derived velocity vectors at $22 \mathrm{~m}$ along transect B on August 13, 2001. The Shipboard ADCP data were kindly provided by S. Sofianos.

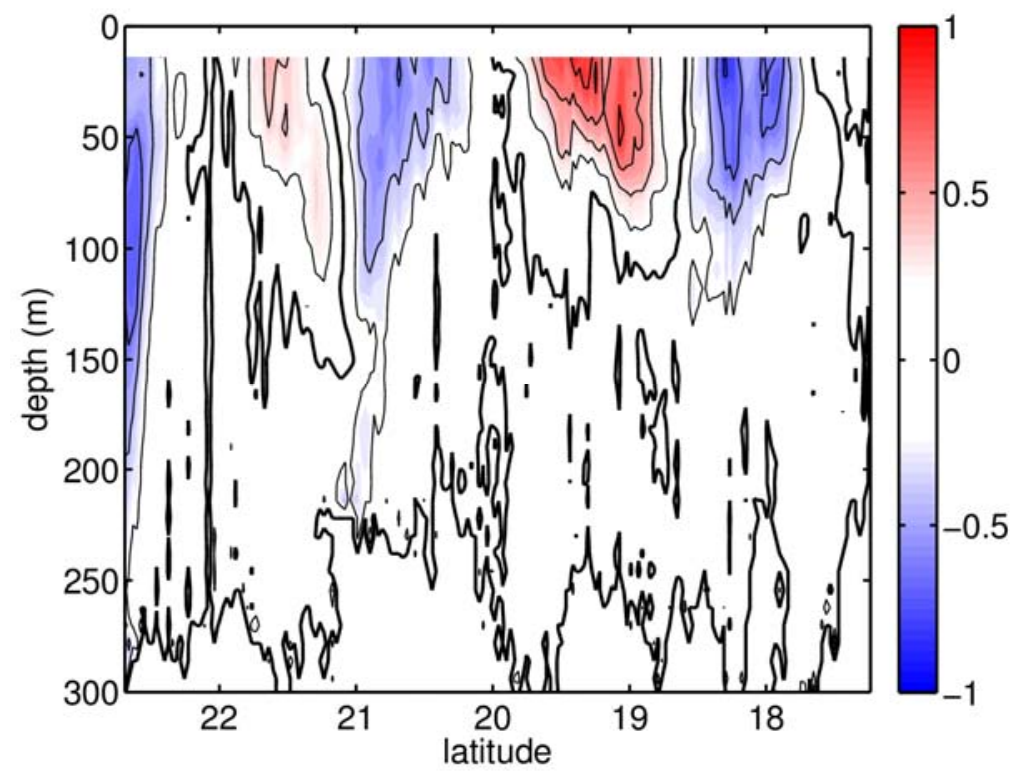

Figure 4.21: Shipboard ADCP-derived velocity $\left(\mathrm{m} \mathrm{s}^{-1}\right)$ in the direction that is perpendicular to transect B (Location shown in Figure 4.20). Positive values represent northeastward flow and negative values represent southwestward flow. The Shipboard ADCP data were kindly provided by S. Sofianos. 


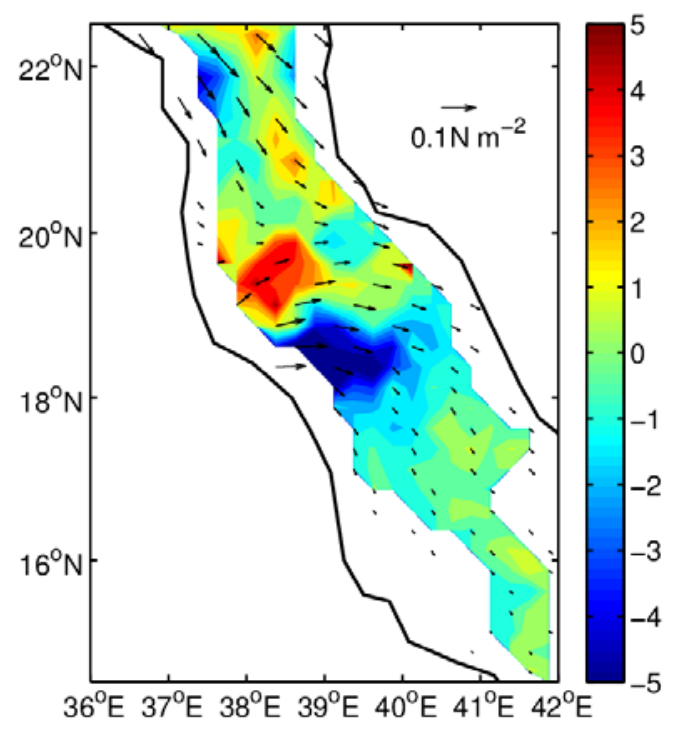

Figure 4.22: QuikSCAT wind stress $\left(\mathrm{N} \mathrm{m}^{-2}\right)$ and wind stress curl $\left(10^{-7} \mathrm{~N} \mathrm{~m}^{-3}\right)$ in August 2001.

a)

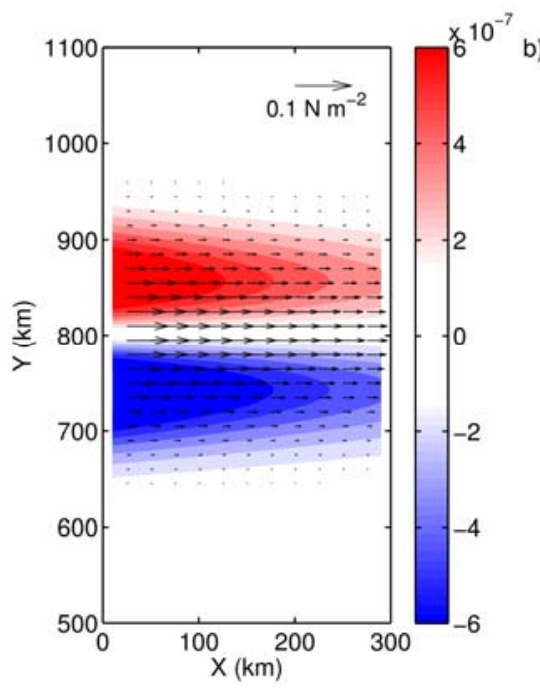

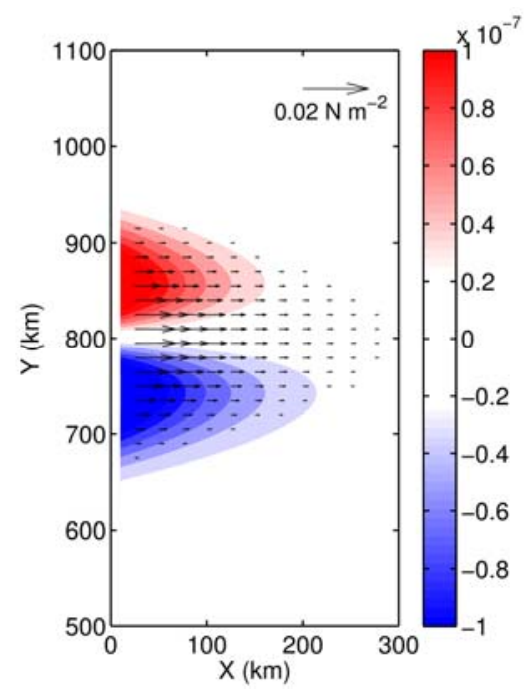

Figure 4.23: Wind stress and wind stress curl $\left(\mathrm{N} \mathrm{m}^{-3}\right)$ in (a) EXPjet1 and (b) EXPjet2. 

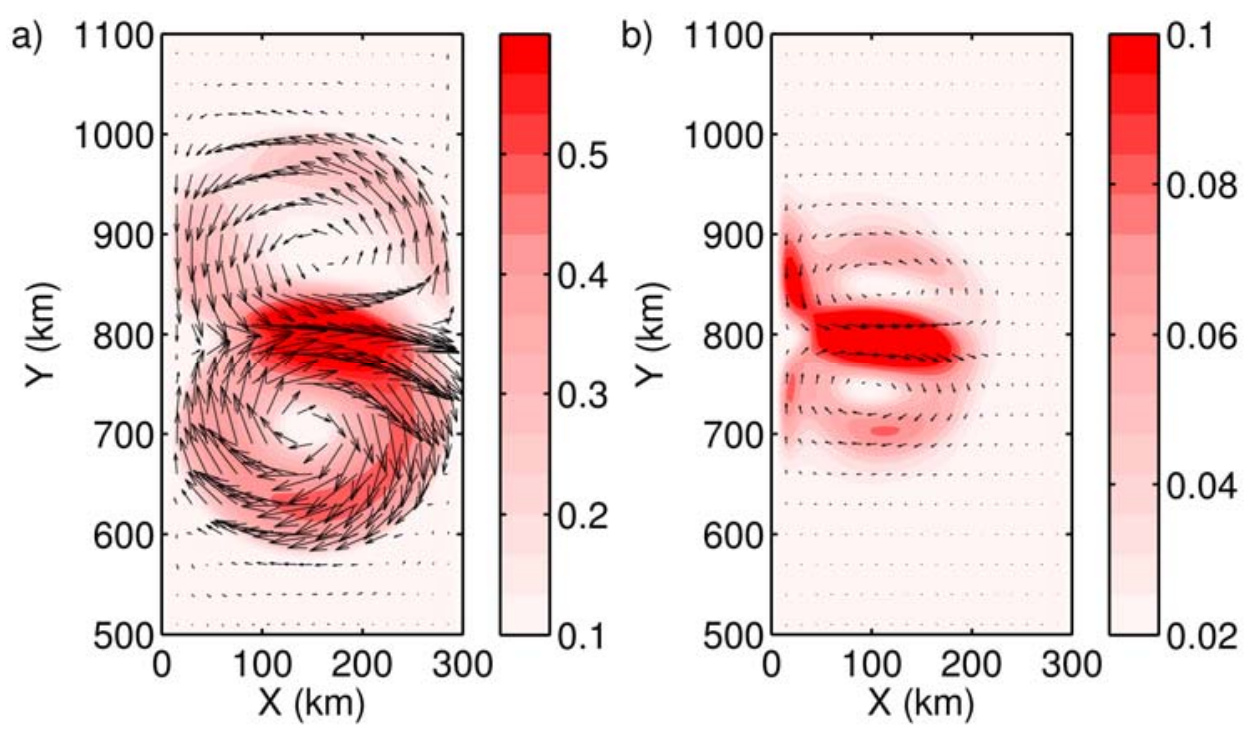

Figure 4.24: Surface current vector field overlapped with its magnitude (color contours, $\mathrm{m} \mathrm{s}^{-1}$ ) in (a) EXPjet1 and (b) EXPjet2 after the models were spun up for 1 month.
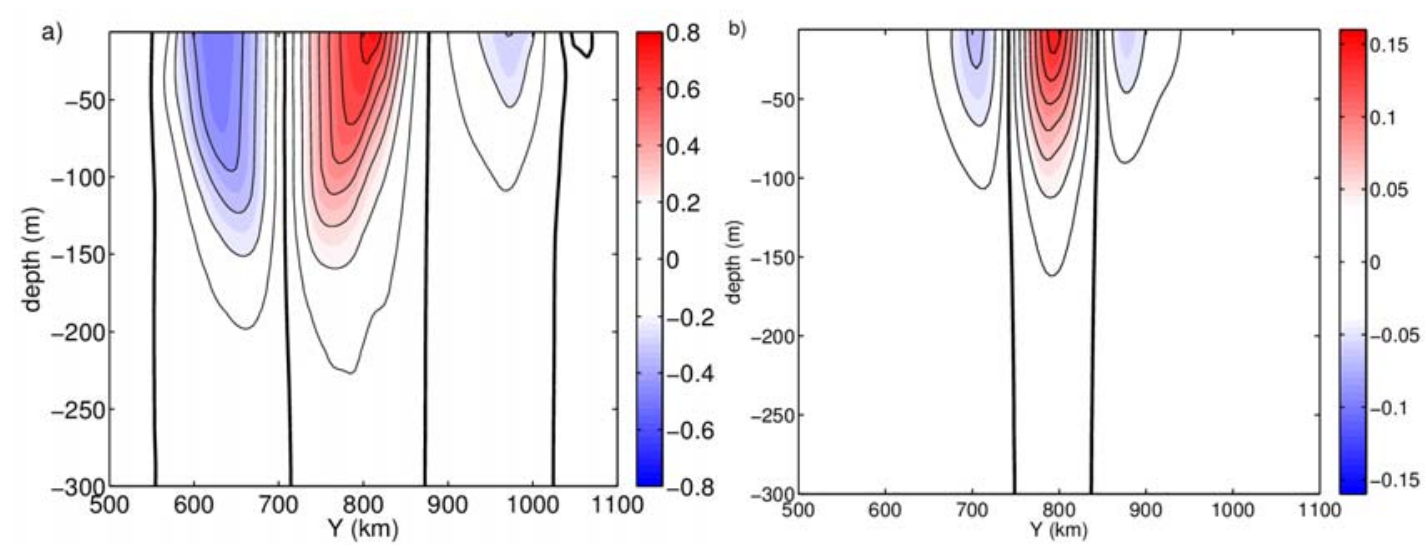

Figure 4.25: Meridional section of zonal velocity $\left(\mathrm{m} \mathrm{s}^{-1}\right)$ along $\mathrm{X}=150 \mathrm{~km}$ in (a) EXPjet1 and (b) EXPjet2.

\subsection{Conclusion}

This chapter investigates three mechanisms that might account for eddy generation in the Red Sea. Eddies generated by baroclinic instability play an important role in buoyancy-driven circulation in marginal seas because the eddy buoyancy flux originating from boundary currents 
can balance surface buoyancy loss over the interior region (Visbeck et al., 1996; Marshall and Schott, 1999; Spall, 2004, 2011 and 2013; Isachsen and Nost, 2012). Numerical experiments in this study shows that more eddies are generated from the eastern boundary current than the western boundary current in the northern Red Sea because the boundary current continues to lose buoyancy into the atmosphere as it moves cyclonically around the basin. Eddies generated by baroclinic instability usually have a diameter of about $80 \mathrm{~km}$ and can penetrate to a depth of 150 m. After they are shed from the boundary currents, they travel into the interior region at a speed of a few centimeters per second, which is much faster than the first baroclinic Rossby wave speed in that region. The maximum surface current speed of these eddies is about $0.2 \mathrm{~m} \mathrm{~s}^{-1}$. This study also shows that winds in the northern Red Sea tend to weaken the baroclinic instability by altering the stratification structure.

Eddies generated by baroclinic instability are not shown in the modeled mean circulation. However, quasi-stationary eddies are observed in the actual Red Sea. This study proposes that the meridional structure of the surface buoyancy forcing (MSSBF) can generate quasi-stationary eddies. The locations of these eddies vary with time, but they tend to remain near their mean locations. The maximum surface current speed of these eddies can reach $0.3 \mathrm{~m} \mathrm{~s}^{-1}$. Eddies generated by MSSBF can extend from the eastern coast to the western coast.

Cross-basin wind can also generate quasi-stationary eddies in the Red Sea. The wind stress curl of the Tokar Wind Jet can reach $8 \times 10^{-7} \mathrm{~N} \mathrm{~m}^{-3}$, which is able to generate a dipole with a maximum speed of up to $1 \mathrm{~m} \mathrm{~s}^{-1}$. In situ observations and satellite altimetry data suggest that this dipole can also extend from the eastern coast to the western coast. In addition to the Tokar Gap, a series of mountain gaps also exists on both sides of the Red Sea (Jiang et al., 2009). These 
mountain gaps can also funnel cross-basin wind jets over the Red Sea surface, which might generate dipoles in the Red Sea. The strength and horizontal scale of the dipoles are closely related to the strength of the wind jet. Further observations are needed to study the response of the Red Sea to these wind jets.

Eddies generated by MSSBF and cross-basin winds both can cover the width of the Red Sea, which provides a pathway for transport of nutritions and organisms from one coast to the other. These eddies can be detected by satellite altimetry data. Both the buoyancy forcing and the Tokar Wind Jet used in this chapter are steady. However, the buoyancy forcing and the Tokar Wind Jets have seasonal and interannual variability. How the seasonal and interannual variability can influence the eddy generation still remains to be answered in the future. In this Chapter, eddies generated by baroclinic instability are not shown in the 5-year circulation. This implies that baroclinic instability might generate eddies at random locations. However, Kohl (2007) pointed out that anticyclonic eddies are formed by baroclinic instability at a particular location in the Lofoten Basin. This location is associated with large-scale bottom depression. Eddies generated by baroclinic instability might be steered by bottom topography to generate larger energetic gyres. In this chapter, the bottom slope is uniform in the idealized Red Sea. However, the bathymetry in the actual Red Sea is very complex (Figure 1.1). For example, there is a bottome depression at about $25^{\circ} \mathrm{N}$ close to the eastern boundary. Therefore, eddies generated by baroclinic instability in the actural Red Sea might appear at a preferred location due to bottom topography. A lot of eddies are observed in the Red Sea. These eddies might be formed by baroclinic instability, bottom topography, cross-basin wind jets, or meridional structure of buoyancy forcing. However, without detailed analysis of each individual eddy, it is difficult to jump to a conclusion which mechanism is the most important in the Red Sea. 


\section{Chapter 5}

\section{Summary and Discussion}

This thesis addresses buoyancy-driven circulation in the Red Sea, using a combination of observations, as well as numerical modeling and an ad hoc analytical model. Chapter 2 is about the formation mechanism and spreading of RSOW. Chapter 3 examines the mechanism that controls the crossover of boundary currents in an idealized Red Sea. Chapter 4 investigates three mechanisms that might account for eddy generation. In this chapter, I summarize the main results of this thesis and discuss some of the limitations and future work.

\subsection{Summary of Major Findings}

Chapter 2 is motivated by the hypothesis that RSOW, a high-salinity water mass that enters the Indian Ocean through the Strait of Bab el Mandeb at the southern end of the Red Sea, is formed by open-ocean convection in the northern Red Sea. Analyses of in situ and satellite observations support the conclusion that the three preconditions required for open-ocean convection are satisfied in the northern Red Sea. After it is formed, RSOW, which can be identified as a layer with minimum PV and maximum CFC-12, spreads southward. To my knowledge, this study is the first to track the RSOW in the Red Sea using CFC-12 and PV. Numerical model results indicate that in the northern Red Sea, the RSOW flows southward along the western boundary; while in the southern Red Sea, the RSOW moves all over the basin instead of being confined to boundaries. Chapter 2 also suggests that the interannual variability of buoyancy forcing in the northern Red Sea might cause density variations in RSOW in different years. 
If diffusivity is not considered, the production rate of the RSOW is estimated to be $0.63 \mathrm{~Sv}$ using Walin's (1982) method. A comparison of this $0.63 \mathrm{~Sv}$ to the actual RSOW transport measured at the Strait of Bab el Mandeb suggests that the vertical diffusivity is about $3.4 \times 10^{-5} \mathrm{~m}^{2} \mathrm{~s}^{-1}$. This value is very close to estimations in other studies. The tracer release experiment in the Antarctic Circumpolar Current indicated that the diapycnal diffusivity was about $(1.3 \pm 0.2) \times 10^{-5} \mathrm{~m}^{2} \mathrm{~s}^{-1}$ near 1500-m depth (Ledwell et al., 2011). Based on fine-scale parameterization methods, Kunze et al., (2006) found that the vertical diffusivity ranged from $0.3 \times 10^{-5} \mathrm{~m}^{2} \mathrm{~s}^{-1}$ to $7 \times 10^{-5} \mathrm{~m}^{2} \mathrm{~s}^{-1}$, as functions of latitude and depth.

Chapter 3 investigates the buoyancy-driven circulation in an idealized Red Sea on a $\beta$-plane, using an eddy-resolving numerical model and an ad hoc analytical model. The surface buoyancy loss increases linearly northward in the idealized model. The resultant mean circulation consists of an anticyclonic gyre in the south and a cyclonic gyre in the north. In mid-basin, the northward surface flow crosses from the western boundary to the eastern boundary. SST images and geostrophic current anomaly calculated from SLA suggest that the crossover of boundary currents might exist in the Red Sea. Numerical studies in Chapter 3 indicate that the Red Sea circulation is a much more complex three-dimensional system compared to the two-dimensional circulation suggested by Phillips (1966), in which rotation is not included. Sofianos and Johns (2003) suggested that the reason for the existence of the crossover of boundary currents is that Rossby waves with the frequency of the forcing $\left(2 \pi \mathrm{yr}^{-1}\right)$ are no longer possible beyond the crossover latitude. This study found that the explanation of Sofianos and Johns (2003) is not applicable to the Red Sea because the crossover of boundary currents still exists when a steady forcing is used. An ad hoc analytical model based on PV dynamics, developed in Chapter 3, 
suggests that the competition between the advection of planetary PV and the term related to surface buoyancy loss determines the crossover latitude.

Based on the ad hoc analytical model, when the Coriolis parameter and surface buoyancy forcing are both constant in the model, the resultant circulation is dominated by cyclonic boundary currents, which agrees well with the numerical study of Spall (2004). The Labrador Sea, extending from about $55^{\circ} \mathrm{N}$ to $66^{\circ} \mathrm{N}$, is also a marginal sea subject to surface buoyancy loss. The Coriolis parameter increases about $8 \%$ from the southern end of the basin to the northern end, indicating that $\beta$-effect is not important in the Labrador Sea. Therefore, the ad hoc analytical model can also be used to explain why the observed circulation in Labrador Sea is dominated by cyclonic boundary currents (Cuny, 2002). On the contrary, the Coriolis parameter doubles from the southern Red Sea to the northern Red Sea. The large latitudinal extent of the Red Sea makes both the $\beta$-effect and the meridional increase of buoyancy loss important in determining the Red Sea circulation. As a result, the circulation in the Red Sea consists of an anticyclonic gyre in the southern basin and a cyclonic gyre in the northern basin. This circulation pattern with two counter-rotating gyres is very similar to the circulation pattern in the North Atlantic and North Pacific. However, it is generally agreed that the two-gyre circulation in the North Atlantic and North Pacific is driven by wind forcing. Chapter 3 suggests that a different mechanism might produce the same circulation pattern.

Many eddies are observed in the Red Sea. However, the mechanisms generating these eddies are still not clearly understood. Chapter 4 investigates three mechanisms that might be responsible for eddy generation in the Red Sea, based on results from a series of numerical experiments. First, eddies can be generated from buoyant boundary currents by baroclinic instability. The energy source for baroclinic instability is the available potential energy stored in steep isopycnal slopes. 
Baroclinic instability is an important mechanism for generating eddies in marginal seas. These eddies play an important role in balancing the surface buoyancy loss in the interior region, as suggested by previous work (Visbeck et al., 1996; Marshall and Schott, 1999; Spall, 2004, 2011 and 2013; Isachsen and Nost, 2012). A new phenomenon found in Chapter 4 is that as the boundary current flows around the basin, its ability to generate eddies reduces because the boundary current continuously loses buoyancy into the atmosphere and the interior region. This study also finds that there are fewer eddies if a typical winter wind is added in the numerical model because stratification is altered by winds. Second, Chapter 4 suggests a new mechanism for eddy generation in the Red Sea. It is found that eddies can be generated by the meridional structure of the surface buoyancy forcing. The spatial scale of these eddies is associated with the spatial scale of the surface buoyancy forcing. These eddies are quasi-stationary, tending to remain near their mean locations. Third, eddies can be generated by cross-basin wind fields. Cross-basin wind usually generates a dipole that includes two counter-rotating eddies. The strongest cross-basin wind jet, which is observed near the Tokar Gap, has a maximum wind stress curl of $8 \times 10^{-7} \mathrm{~N} \mathrm{~m}^{-3}$ and can generate eddies with a maximum current velocity of $1 \mathrm{~m} \mathrm{~s}^{-1}$. However, over most of the Red Sea, the wind stress curl is less than $2 \times 10^{-7} \mathrm{~N} \mathrm{~m}^{-3}$. Eddies generated by other cross-basin wind jets are much weaker than eddies generated by the Tokar Wind Jet. Eddies generated by wind jets are also observed in the eastern tropical Pacific Ocean using satellite SST images (Stumpf and Legeckis; 1977), with diameter around $300 \mathrm{~km}$. These eddies can propagate westward at the baroclinic Rossby wave speed. However, dipole generated by the Tokar Wind Jet cannot propagate due to the two boundaries of the Red Sea.

Another possible mechanism for eddy generation in the Red Sea which is not discussed in Chapter 4 is that the wavy coastline of the Red Sea can generate eddies. Marshall and Tansley 
(2001) suggested that boundary current tends to separate from boundary and form eddies when the radius of curvature of coastline is smaller than $\sqrt{U / \beta}$. All these mechanisms are possible in the Red Sea to generate eddies. However, without further observational investigation, it is difficult to distinguish which mechanism is dominant in the Red Sea.

\subsection{Limitations and Future Directions}

There are a number of limitations in the current approaches to studying the buoyancy-driven circulation in the Red Sea.

In situ observations are very sparse in the Red Sea. In Chapter 3, numerical simulations reveal that northward boundary currents cross the basin from the western boundary to the eastern boundary. SST and geostrophic current anomaly derived from satellite observations provide some sketchy evidences for the crossover of boundary currents. However, SST features don't necessarily indicate a flow direction. In addition, because dynamic height data are not available in the Red Sea, only geostrophic current anomaly can be estimated. Because evidence from SST and geostrophic current anomaly is insufficient to prove the existence of the crossover of boundary currents, direct observations of current speeds are necessary to explore whether crossover of boundary currents occurs in the Red Sea. I hope this study will inspire some field observations. In the future, long-term mooring arrays can be deployed along the western boundary in the southern Red Sea to investigate the existence of a western boundary current in the southern Red Sea and how such a boundary current might change under different conditions.

As suggested by Sofianos and Johns (2003), the Red Sea circulation is primarily determined by buoyancy forcing. In Chapter 4, I demonstrate that a typical winter wind field can weaken baroclinic instability and modify the buoyancy-driven circulation. Therefore, wind in the Red 
Sea plays a secondary, but not negligible role in determining the circulation. One of the future areas of research is to further investigate the wind's influence on the crossover latitude. The typical winter wind field, as shown in Figure 4.10, generates a northward current along the eastern boundary and a southward current along the western boundary in the northern Red Sea, according to the Sverdrup relation. In the southern Red Sea, the wind generates a northward current along the western boundary and a southward current along the eastern boundary. The typical winter wind generates a cyclonic gyre in the northern Red Sea and an anticyclonic gyre in the southern Red Sea, which has the same direction as the circulation due solely to buoyancy forcing. Therefore, further exploration of the wind's influence is crucial to understanding Red Sea circulation. 


\section{Appendix A}

\section{Relation between Boundary Current and Interior Densities}

This derivation generally follows Spall (2004), though he used temperature instead of density.

Firstly, we will derive the relation between the boundary current density and the interior density in the southern gyre (south of $Y_{C}$ ). The density equation is $\bar{u} \frac{\partial \bar{\rho}}{\partial x}+\bar{v} \frac{\partial \bar{\rho}}{\partial y}+\frac{\partial \overline{u^{\prime} \rho^{\prime}}}{\partial x}+\frac{\partial \overline{v^{\prime} \rho^{\prime}}}{\partial y}=B_{0}$. In the interior region, the mean circulation is neglected. As shown in Figure 3.11, the sea surface buoyancy loss in the interior region in the southern gyre is assumed to be balanced by lateral eddy fluxes originating from boundary current I. If we integrate the density equation over the interior region (shaded in blue in Figure 3.11) in the southern gyre, the buoyancy budget for the interior region in the southern gyre can be written as

$$
-L_{i n S} H \overline{u^{\prime} \rho^{\prime}}=\int_{A_{S}} B_{0} d A=W_{i n S} B_{T S},
$$

where $L_{i n S}$ and $W_{i n S}$ are length and width of the interior region in the southern gyre, $A_{S}$ is the area of interior region, $H$ is the vertical scale of the boundary current, $B_{T S}=\int_{Y_{S}}^{Y_{C}} B_{0} d y$ and $B_{0}(y)$ is the surface buoyancy loss as defined in (1). The eddy buoyancy flux from boundary current I is represented by $\overline{u^{\prime} \rho^{\prime}}, u^{\prime}$ and $\rho^{\prime}$ are the deviations of $u$ and density from their time means, and the overbar indicates a temporal average. For simplicity, the eddy buoyancy flux along the eastern boundary of area $A_{S}$ is neglected. 
We assume that the eddy buoyancy flux is proportional to the mean boundary current velocity $V_{b S}$ (Stone, 1972; Visbeck et al., 1996; Spall and Chapman, 1998; Spall, 2004) and density difference between the boundary current and the interior, i.e.

$$
-\overline{u^{\prime} \rho^{\prime}}=c V_{b S}\left(\rho_{b S}-\rho_{i n S}\right)
$$

where $c$ is a nondimensional correlation coefficient, $\left(\rho_{b S}-\rho_{i n S}\right)$ is density difference between the boundary current and the interior, $\rho_{b S}$ is mean density of boundary current I as labeled in Figure $3.11, \rho_{i n S}$ is the density of the interior region in the southern gyre. The mean velocity of boundary current I $V_{b S}$ is related to the density difference between boundary current and interior through the thermal wind relation

$$
V_{b S}=\frac{H g}{2 \rho_{0} \overline{f_{S}}} \frac{\rho_{b S}-\rho_{i n S}}{L},
$$

where $L$ is the width of the boundary current, and $\overline{f_{S}}$ is the mean Coriolis parameter in the southern gyre. Combining (A1), (A2) and (A3), an estimate of the density difference between the boundary current and the interior is given by

$$
\rho_{b S}-\rho_{i n S}=\sqrt{\frac{2 W_{i n S} B_{T S} \rho_{0} \overline{f_{S}} L}{c H^{2} g L_{i n S}}} .
$$

In the northern gyre, the sea surface buoyancy losses in the interior region are assumed to be balanced by lateral eddy fluxes originating from boundary currents III. The buoyancy budget for the interior region can be written as 


$$
L_{i n N} H \overline{u^{\prime} \rho^{\prime}}=\int_{A_{N}} B_{0} d A=W_{i n N} B_{T N}
$$

where $L_{i n N}$ and $W_{i n N}$ are length and width of the interior region in the northern gyre, $A_{N}$ is the area of interior region, $B_{T N}=\int_{Y_{C}}^{Y_{N}} B_{0} d y$. Using similar relations expressed in (A2) and (A3), the density difference between the boundary and interior in the northern gyre is given by

$$
\rho_{b N}-\rho_{i n N}=-\sqrt{\frac{2 W_{i n N} B_{T N} \rho_{0} \overline{f_{N}} L}{c H^{2} g L_{i n N}}},
$$

where $\rho_{i n N}$ is mean density of boundary current III. 


\section{Bibiliography}

Acker, J., Leptoukh, G., Shen, S., Zhu, T., Kempler, S., 2008: Remotely-sensed chlorophyll a observations of the northern Red Sea indicate seasonal variability and influence of coastal reefs. Journal of marine systems, 69, 191-204.

Beal, L. M., A. Ffield, and A. L. Gordon (2000): Spreading of Red Sea overflow waters in the Indian Ocean, J. Geophys. Res., 105(C4), 8549-8564.

Bentamy, A., Croize-Fillon, D., and Perigaud, C., 2008: Characterization of ASCAT measurements based on buoy and QuikSCAT wind vector observations, Ocean Sci., 4, 265-274.

Biton, E., H. Gildor, and W. R. Peltier, 2008: Red Sea during the Last Glacial Maximum: Implications for sea level reconstruction, Paleoceanography, 23, PA1214.

Biton, E., and H. Gildor, 2011: The general circulation of the Gulf of Aqaba (Gulf of Eilat) revisited: The interplay between the exchange flow through the Straits of Tiran and surface fluxes, J. Geophys. Res., 116, C08020, doi:10.1029/2010JC006860.

Bower, A., 2010: Cruise Report-R/V Aegaeo KAUST Leg1 northeastern Red Sea, 16-29 March 2010, 28 pp.

Bower, A., and Y. Abualnaja, 2011: Cruise Report-R/V Aegaeo KAUST Leg1 eastern Red Sea, 15 September-10 October 2011, 25 pp.

Bower, A. S., H. D. Hunt, and J. F. Price, 2000: Character and dynamics of the Red Sea and Persian Gulf outflows, J. Geophys. Res., 105(C3), 6387-6414.

Bower, A. S., W. E. Johns, D. M. Fratantoni, and H. Peters, 2005: Equilibration and circulation of Red Sea Outflow Water in the Western Gulf of Aden. J. Phys. Oceanogr., 35, 1963-1985.

Cember, R. P., 1988: On the sources, formation, and circulation of Red-Sea deep-water. Journal of Geophysical Research-Oceans, 93 (C7), 8175-8191.

Chen, C., L. Ruixiang, L. Pratt, R. Limeburner, R. Beardsley, A. S. Bower, H. Jiang, Y. Abualnaja, X. Liu, Q. Xu, H. Lin, J. Lan, T.-W. Kim, 2014: Process modeling studies of physical mechanisms of the formation of an anticyclonic eddy in the central Red Sea, J. Geophys. Res. Oceans, 119, 1445-1464.

Churchill, J., A. S. Bower, D. C. McCorkle, and Y. Abualnaja: The transport of nutrient-rich Indian Ocean water through the Red Sea and into coastal reef systems. Journal of Marine Research, submitted.

Clifford, M., C. Horton, J. Schmitz, and L. H. Kantha, 1997: An oceanographic nowcast/forecast system for the Red Sea, J. Geophys. Res., 102(C11), 25101-25122 
Cuny, J., P. B. Rhines, P. P. Niiler, S. Bacon, 2002: Labrador Sea Boundary Currents and the Fate of the Irminger Sea Water. J. Phys. Oceanogr., 32, 627-647.

Eshel, G., and N. H. Naik, 1997: Climatological coastal jet collision, intermediate water formation, and the general circulation of the Red Sea, J. Phys. Oceanogr., 27, 1233-1257.

Griffies, S., M., and W. Hallberg, R., 2000: Biharmonic friction with a Smagorinsky-like viscosity for use in large-scale eddy-permitting ocean models, Mon. Wea. Rev., 128(8), 29352946.

Gordon, A. L., J. R. E. Lutjeharms and M. L. Grundlingh, 1987: Stratification and circulation at the Agulhas Retroflection, Deep-Sea Res., 34, 565-599.

Hickey, B., and A. S. Goudie, 2007: The use of TOMS and MODIS to identify dust storm source areas: The Tokar delta (Sudan) and the Seistan basin (south west Asia), in Geomorphological Variations, edited by A. S. Goudie and J. Kalvoda, pp. 37- 57, P3K, Prague.

Isachsen, P. E., and O. A. Nost, 2012: The air sea transformation and residual overturning circulation within the Nordic Seas. J. Mar. Res., 70, 31-68.

Jiang, H., J. T. Farrar, R. C. Beardsley, R. Chen, and C. Chen (2009): Zonal surface wind jets across the Red Sea due to mountain gap forcing along both sides of the Red Sea, Geophys. Res. Lett., 36, L19605, doi:10.1029/2009GL040008.

Kohl, A., 2007: Generation and stability of a quasi-permanent vortex in the Lofoten Basin. $J$. Phys. Oceanogr., 37, 2637-2651.

Kunze, Eric, Eric Firing, Julia M. Hummon, Teresa K. Chereskin, Andreas M. Thurnherr, 2006: Global Abyssal Mixing Inferred from Lowered ADCP Shear and CTD Strain Profiles. J. Phys. Oceanogr., 36, 1553-1576.

Ledwell, J. R., L. C. St. Laurent, J. B. Girton, J. M. Toole, 2011: Diapycnal Mixing in the Antarctic Circumpolar Current. J. Phys. Oceanogr., 41, 241-246.

Maillard, C., 1974: Eaux intermediaires et formation d'eau profonde en Mer Rouge, L'oceanographie physique de la Mer Rouge, CNEXO, Paris, 105-133.

Maillard, C., Soliman, G., 1986: Hydrography of the Red Sea and exchanges with the Indian Ocean in summer. Oceanology Acta, 9, 249-269.

Manasrah, R., M. Badran, H. U. Lass, and W. Fennel, 2004: Circulation and winter deep-water formation in the northern Red Sea, Oceanologia, 46 (1), 5-23.

Marshall, J., C. Hill, L. Perelman, and A. Adcroft, 1997: Hydrostatic, quasi-hydrostatic, and nonhydrostatic ocean modeling, J. Geophys. Res., 102(C3), 5733-5752.

Marshall, J., and F. Schott, 1999: Open-ocean convection: Observations, theory, and models, Rev. Geophys., 37(1), 1-64. 
Marshall, D. P., and C. E. Tansley, 2001: An implicit formula for boundary current separation. J. Phys. Oceanogr., 31, 1633-1638.

McCreary, J. P., H. S. Lee, and D. B. Enfield, 1989: Response of the coastal ocean to strong offshore winds: With application to circulations in the Gulf of Tehuantepec and Papagayo, J. Mar. Res., 47, 81-109.

Morcos, S., 1970: Physical and chemical oceanography of the Red Sea. Oceanogr. Mar. Biol., 8, 73-202.

Morcos, S., and G. F. Soliman, 1972: Circulation and deep water formation in the Northern Red Sea in winter, L'oceanographic physique de la Mer Rouge, CNEXO, Paris , 91-103.

Murray, S., A. Hecht, and A. Babcock, 1984: On the mean flow in the Tiran Strait in winter, $J$. Mar. Res., 42, 265-287.

Murray, S.P., Johns, W., 1997: Direct observations of seasonal exchange through the Bab el Mandeb strait. Geophysical Research Letters, 24, 2557-2560.

Neumann, A.C., McGill, D.A., 1962: Circulation of the Red Sea in early summer. Deep-Sea Research, 8, 223-235.

Papadopoulos, Vassilis P., Yasser Abualnaja, Simon A. Josey, Amy Bower, Dionysios E. Raitsos, Harilaos Kontoyiannis, Ibrahim Hoteit, 2013: Atmospheric Forcing of the Winter Air-Sea Heat Fluxes over the Northern Red Sea. J. Climate, 26, 1685-1701.

Patzert, W.C., 1974: Volume and heat transports between the Red Sea and Gulf of Aden, notes on the Red Sea heat budget. In: L'oceanographie physique de la Mer Rouge, CNEXO, Paris, pp. 191-201.

Pedgley, D., 1972: Desert depression over north-east Africa. Met. Mag. 101, 228-243.

Pedgley, D.E., 1974: An outline of the weather and climate of the Red Sea. In: L'oceanographie physique de la Mer Rouge, CNEXO, Paris, pp. 9-27.

Pedlosky, J., 1996: Ocean Circulation Theory. Springer, 453 pp.

Pedlosky, J., and M. A. Spall, 2005: Boundary intensification of vertical velocity in a $\beta$-plane basin. J. Phys. Oceanogr., 35, 2487-2500.

Phillips, O.M., 1966: On turbulent convection currents and the circulation of the Red Sea. DeepSea Res., 13, 1149-1160.

Pickart, Robert S., Daniel J. Torres, R. Allyn Clarke, 2002: Hydrography of the Labrador Sea during active convection. J. Phys. Oceanogr., 32, 428-457. 
Plähn, O., B. Baschek, T. H. Badewien, M. Walter, and M. Rhein, 2002: Importance of the Gulf of Aqaba for the formation of bottom water in the Red Sea, J. Geophys. Res., 107(C8), doi:10.1029/2000JC000342.

Price, J. F., and M. O. Baringer, 1994: Outflows and deep water production by marginal seas. Prog. Oceanogr. 33, 161-200.

Pullen, J., J. D. Doyle, P. May, C. Chavanne, P . Flament, and R. A. Arnone, 2008: Monsoon surges trigger oceanic eddy formation and propagation in the lee of the Philippine Islands, Geophys. Res. Lett., 35, L07604, doi:10.1029/2007GL033109.

Quadfasel, D., Baudner, H., 1993: Gyre-scale circulation cells in the Red-Sea. Oceanologica Acta, $16(3), 221-229$.

Rhein, M., J. Fischer, W. M. Smethie, D. Smythe-Wright, R. F. Weiss, C. Mertens, D. H. Min, U. Fleischmann, and A. Putzka, 2002: Labrador Sea Water: Pathways, CFC Inventory, and Formation Rates. J. Phys. Oceanogr., 32, 648-665.

Rypina, I.I., L.J. Pratt, J. Pullen, J. Levin, and A. Gordon, 2010: Chaotic advection in an archipelago. J. Phys. Oceanogr., 40(9), 1988-2006

Schlosser, P., Bullister, J.L. and Bayer, R., 1991: Studies of deep water formation and circulation in the Weddell Sea using natural and anthropogenic tracers. Marine Chemistry, 35, 97-122.

Send, U., J. Font, G. Krahmann, C. Millot, M. Rhein, J. Tintore, 1999: Recent advances in observing the physical oceanography of the western Mediterranean Sea. Progress in Oceanogr., 44,37-64.

Smeed, D.A., 2004: Exchange through the Bab el Mandab. Deep-Sea Research, II 51, 455-474.

Smethie, W., 1993: Tracing the thermohaline circulation in the western North Atlantic using chlorofluorocarbons. Progress in Oceanography, Vol. 31, Pergamon, 51-99.

Smethie, W. M., Jr., and R. A. Fine, 2001: Rates of North Atlantic deep water formation calculated from chlorofluorocarbon inventories, Deep Sea Res. I, 48(1), 189-215.

Smethie, W., R. A. Fine, and E. P. Jones, 2000: Tracing the flow of North Atlantic Deep Water using chlorofluorocarbons. J. Geophys. Res., 105, 14297-14323.

Sofianos, S. S., and W. E. Johns, 2002: An Oceanic General Circulation Model (OGCM) investigation of the Red Sea circulation, 1, Exchange between the Red Sea and the Indian Ocean, J. Geophys. Res.,107(C11), 3196, doi:10.1029/2001JC001184.

Sofianos, S. S., W. E. Johns, and S. P. Murray, 2002: Heat and freshwater budgets in the Red Sea from direct observations at Bab el Mandeb, Deep Sea Res., Part II, 49, 1323- 1340. 
Sofianos, S. S., and W. E. Johns, 2003: An Oceanic General Circulation Model (OGCM) investigation of the Red Sea circulation: 2. Three-dimensional circulation in the Red Sea, $J$. Geophys. Res., 108, 3066, doi:10.1029/2001JC001185, C3.

Sofianos, S. S., and W. E. Johns 2007: Observations of the summer Red Sea circulation, J. Geophys. Res., 112, C06025, doi:10.1029/2006JC003886.

Spall, M. A., 2004: Boundary currents and water mass transformation in marginal seas. J. Phys. Oceanogr., 34, 1197-1213.

Spall, M. A., 2011: On the role of eddies and surface forcing in the heat transport and overturning circulation in marginal sea. J. Clim., 24, 4844-4858.

Spall, M. A., 2013: On the circulation of Atlantic Water in the Arctic Ocean.J. Phys. Oceanogr., 43, 2352-2371.

Spall, M. A., David C. Chapman, 1998: On the efficiency of baroclinic eddy heat transport across narrow fronts. J. Phys. Oceanogr., 28, 2275-2287.

Stone, P. H., 1972: A simplified radiative-dynamical model for the static stability of rotating atmospheres. J. Atmos. Sci., 29, 405-418.

Stumpf, H. G., R. V. Legeckis, 1977: Satellite observations of mesoscale eddy dynamics in the eastern tropical Pacific Ocean. J. Phys. Oceanogr., 7, 648-658.

Tragou, E., and C. Garrett, 1997: The shallow thermohaline circulation of the Red Sea, Deep Sea Res., Part I, 44, 1355 - 1376.

Tziperman, E., 1986: On the role of interior mixing and air-sea fluxes in determining the stratification and circulation of the cceans. J. Phys. Oceanogr., 16, 680-693.

Valentine, H. R., J. R. E. Lutjeharms, G. B. Brundrit, 1993: The water masses and volumetry of the southern Agulhas Current region, Deep Sea Res., Part I, 40, 1285-1305.

van Sebille, E., P. Spence, M. R. Mazloff, M. H. England, S. R. Rintoul, and O. A. Saenko, 2013: Abyssal connections of Antarctic Bottom Water in a Southern Ocean State Estimate, Geophys. Res. Lett., 40, 2177-2182.

Visbeck, M., J. Marshall, and H. Jones, 1996: Dynamics of isolated convective regions in the ocean. J. Phys. Oceanogr., 26, 1721- 1734.

Walin, G., 1982: On the relation between sea-surface heat flow and thermal circulation in the ocean. Tellus, 34: 187-195.

Wang, G., D. Chen, and J. Su, 2006: Generation and life cycle of the dipole in the South China Sea summer circulation, J. Geophys. Res., 111, C06002, doi:10.1029/2005JC003314. 
Wang, G., D. Chen, and J. Su, 2008: Winter eddy genesis in the eastern South China Sea due to orographic wind jets, Journal of Physical Oceanography, 38, 726-732.

Werner, F. and K. Lange., 1975: A Bathymetric Survey of the Sill Area between the Red Sea and the Gulf of Aden. Geol. Jahrb. D, 13: 125-130.

Willey, D. A., R. A. Fine, R. E. Sonnerup, J. L. Bullister, W. M. Smethie Jr., and M. J. Warner (2004): Global oceanic chlorofluorocarbon inventory, Geophys. Res. Lett., 31, L01303.

Wyrtki, K., 1971: Oceanographic Atlas of the international Indian Ocean Expedition, 531 pp., Nat. Sci. Found., Washington, D.C..

Wyrtki, K. 1973: Physical oceanography of the Indian Ocean. In: Ecological studies. Analysis and synthesis, Vol. 3, Springer-Verlag, 18-36.

Yao, F., I. Hoteit, L. J. Pratt, A. S. Bower, P. Zhai, A. Köhl, and G. Gopalakrishnan, 2014a: Seasonal overturning circulation in the Red Sea: 1. Model validation and summer circulation, J. Geophys. Res. Oceans, 119, doi:10.1002/2013JC009004.

Yao, F., I. Hoteit, L. J. Pratt, A. S. Bower, A. Köhl, G. Gopalakrishnan, and D. Rivas, 2014b: Seasonal overturning circulation in the Red Sea: 2. Winter circulation, J. Geophys. Res. Oceans, 119, doi:10.1002/2013JC009331.

Yu, L., X. Jin, and R. A. Weller (2008): "Multidecade Global Flux Datasets from the Objectively Analyzed Air-sea Fluxes (OAFlux) Project: Latent and sensible heat fluxes, ocean evaporation, and related surface meteorological variables." Woods Hole Oceanographic Institution, OAFlux Project Technical Report. OA- 2008-01, 64pp.

Zhai, P., and A. S. Bower (2013), The response of the Red Sea to a strong wind jet near the Tokar Gap in summer, J. Geophys. Res. Oceans, 118, 422-434 